\title{
ESTIMACIÓN Y CONTROL DE PROCESOS BIOTECNOLÓGICOS MULTIVARIABLES
}

\author{
TESIS DE DOCTORADO
}

\section{SEBASTIÁN NUÑEZ}

Presentada ante la Facultad de Ingeniería de la

Universidad Nacional de La Plata

como requisito para la obtención del grado académico de

\section{DOCTOR EN INGENIERÍA}

Dirección de Tesis:

Dr. Hernán DE BATTISTA

Dr. Fabricio GARELLI

Jurado de Tesis:

Dr. Hernán D. ALVAREZ ZAPATA

Dra. Marta BASUALDO

Dr. José L. FIGUEROA

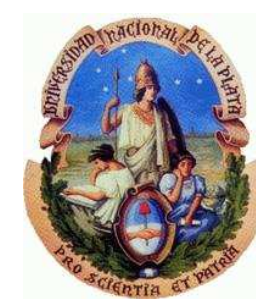

Fecha de la defensa oral y pública: 5 de diciembre de 2014 

A Nadia y a mis padres 


\section{Índice general}

Agradecimientos VII

Resumen

$\begin{array}{ll}\text { Abstract } & \text { XI }\end{array}$

Lista de símbolos $\quad$ XIII

1. Introducción $\quad 1$

1.1. Motivaciones y Objetivos . . . . . . . . . . . . . . . . 2

1.2. Organización de la Tesis . . . . . . . . . . . . . 3

1.3. Principales aportes . . . . . . . . . . . . . 5

2. Estado del arte $\quad 9$

2.1. Modelizado de bioprocesos . . . . . . . . . . . . . . . . . 9

2.1.1. Modelo de caja negra y balances elementales . . . . . 11

2.1.2. Cinética del crecimiento microbiano . . . . . . . . . 13

2.1.3. Balance de masas en la fase líquida . . . . . . . . 16

2.1.4. Sistemas de cultivo . . . . . . . . . . . . . 19

Cultivo por lotes . . . . . . . . . . . . . . 19

Cultivo semi-continuo . . . . . . . . . . 21

Cultivo continuo . . . . . . . . . . . 22

2.1.5. Formación de producto . . . . . . . . . . . . 23

2.1.6. Procesos multi-sustrato . . . . . . . . . . . . 25

2.1.7. Modelo de estados generalizado . . . . . . . . . . 27

2.2. Importancia de la regulación del crecimiento . . . . . . . . . 27

2.3. Estrategias de alimentación para cultivos semi-continuos . . 29

2.3.1. Descripción de las estrategias . . . . . . . . . . 29

2.3.2. Leyes exponenciales para regulación del crecimiento . 31

Alimentación exponencial de lazo abierto . . . . . . . 31

Alimentación exponencial con correción PI . . . . . . 32

Alimentación proporcional a la biomasa . . . . . . . . 32

2.4. Observación y Estimación de variables . . . . . . . . . . . . . . 34

2.4.1. Observadores por modo deslizante . . . . . . . . . 35

Derivadores de primer y segundo orden . . . . . . 36 
2.4.2. Observadores por modo deslizante aplicados en bioprocesos ...................... 39

2.5. Resumen del capítulo . . . . . . . . . . . . . . . . . . . 40

3. Estimación de tasa de crecimiento basada en medición de producto 43

3.1. Descripción del proceso . . . . . . . . . . . . . . . . . 43

3.2. Estimación de biomasa y tasa de crecimiento . . . . . . . . . 44

3.2.1. Algoritmo por Modo Deslizante de primer orden . . . 44

3.2.2. Algoritmo por Modo Deslizante de segundo orden . . 47

3.2.3. Extensión al caso de proceso alimentado . . . . . . . 49

3.2.4. Cotas de error ante incertidumbre en los parámetros 50

3.3. Aplicación en un proceso de producción de hidrógeno biológico 51

3.3.1. Descripción del proceso . . . . . . . . . . . . 51

3.3.2. Modelo del proceso de fotofermentación . . . . . . . . 52

Análisis de observabilidad aplicado al proceso de fotofermentación ........... 53

3.3.3. Diseño del observador de segundo orden . . . . . . . 54

Resultados . . . . . . . . . . . . . . . 54

3.4. Resumen del capítulo . . . . . . . . . . . . . . . . . . 59

4. Estimación de múltiples tasas de reacción basada en medición de concentraciones de sustancias $\quad 61$

4.1. Descripción del problema . . . . . . . . . . . . . . . 62

4.2. Algoritmo por Modo Deslizante de segundo orden . . . . . . 65

4.3. Resultados experimentales . . . . . . . . . . . . 69

4.4. Comparación con observadores de alta ganancia en caso de

fallas típicas . . . . . . . . . . . . . . . . 74

4.5. Resumen del capítulo . . . . . . . . . . . . . . . 77

5. Regulación de tasa de crecimiento preservando otros sustratos en exceso $\quad 79$

5.1. Regulación descentralizada en procesos aeróbicos . . . . . . . 80

5.1.1. Modelo del cultivo aeróbico . . . . . . . . . . . . 80

5.1.2. Problema bajo estudio . . . . . . . . . . . 82

5.2. Control descentralizado con adaptación de la ley de alimen-

tación ..................... 84

5.2.1. Algoritmo de adaptación de la alimentación por modo deslizante . . . . . . . . . . . 86

5.2.2. Análisis de las condiciones de modo deslizante . . . . 87

5.3. Resultados y discusión . . . . . . . . . . . . . . . 89

5.3.1. Aplicación a leyes de alimentación de lazo abierto . . 90

5.3.2. Aplicación a una ley de control de lazo cerrado . . . . 93

5.4. Resumen del capítulo . . . . . . . . . . . . . . . . . 96 
6. Regulación de múltiples tasas de crecimiento en cultivos multi-sustrato

6.1. Descripción del problema . . . . . . . . . . . . . . . . . 100

6.2. Regulación de tasa de crecimiento utilizando medición de biomasa . . . . . . . . . . . . . . . . . 102

6.2.1. Resultados . . . . . . . . . . . . . . . . 108

6.2.2. Extensión a un modelo con inhibición competitiva entre los sustratos . . . . . . . . . . . . . . 109 Análisis . . . . . . . . . . . . . . . . 112

Resultados . . . . . . . . . . . . . 115

6.3. Resumen del capítulo . . . . . . . . . . . . . . . . . . 118

$\begin{array}{ll}\text { 7. Conclusiones } & 119\end{array}$

A. Análisis de una condición de observabilidad no lineal 123

A.1. Definiciones . . . . . . . . . . . . . . . . . 123

A.2. Análisis aplicado al proceso con producción asociada . . . . 125

A.3. Condiciones de observabilidad de cultivos semi-continuos multisustrato . . . . . . . . . . . . 126

B. Regulación de tasa de crecimiento utilizando medición de biomasa y un sustrato

Bibliografía 


\section{Agradecimientos}

En orden cronológico, quisiera agradecer en primer lugar a mis padres, ya que fueron ellos quienes realizaron el esfuerzo necesario para que yo pueda venir desde mi pueblo -Las Flores, Pcia. de Buenos Aires- a estudiar ingeniería en la Universidad Nacional de La Plata. También quiero agradecerle a Nadia, mi compañera en la vida, por hacerme feliz y soportarme durante estos años de estudio.

En el ámbito laboral, aprovecho la oportunidad para agradecer profundamente a mis directores de tesis, Hernán y Fabricio, quienes me marcaron el camino a seguir y me guiaron con tanta claridad y buenos consejos durante estos cinco años. Quién también merece una mención especial es Fernando Inthamoussou, alias el griego, ya que fue él quién me llamó una vez por teléfono para avisarme sobre la posibilidad de postularme a una beca de doctorado. El lugar donde se realiza la labor diaria es muy importante para el desarrollo de cualquier trabajo. Por eso también le agradezco, en particular, al resto de los compañeros de oficina (José, Pablo, Paul y Ricardo), y de forma extensiva le agradezco también a los demás miembros del Leici. Mi estancia en España fue una gran experiencia, no sólo por el trabajo de investigación realizado sino también por las personas con las que tuve el placer de convivir. Por eso quiero agradecerles a Alejandro y Yadira por haberme hecho sentir como en casa durante los seis meses que estuve compartiendo piso con ellos. También le agradezco al Dr. Jesús Picó por el apoyo que me brindó durante mi estadía y también por la colaboración que realiza con mi grupo de trabajo. 


\section{Resumen}

La presente tesis doctoral aborda problemas de estimación y control de variables en procesos biotecnológicos. Se aportan soluciones novedosas a dos cuestiones relevantes para el control de estos procesos: i) el diseño de observadores (sensores virtuales) de variables no medibles a partir de las mediciones disponibles, y ii) el diseño de lazos de regulación del crecimiento en cultivos de microorganismos que utilizan múltiples sustratos.

Con el objetivo de disponer de estimaciones de variables importantes del proceso que no son accesibles en línea, se diseñan observadores que utilizan información de la dinámica de las variables medidas. En primer lugar se proponen observadores por modo deslizante para procesos en los que sólo es medible la concentración de producto. En este caso se estiman, con dinámica de error reducida, la tasa de crecimiento y la concentración de biomasa, dos variables que son muy importantes para el monitoreo de los cultivos. Luego se presenta un observador por modo deslizante de segundo orden capaz de estimar múltiples tasas de formación y consumo de sustancias a partir de medir la concentración de estas sustancias. En este caso se obtiene convergencia en tiempo finito. Esto permite considerar las estimaciones obtenidas para la implementación de lazos de realimentación, donde la ventaja es que no se agrega dinámica adicional del observador.

La segunda parte de la tesis trata problemas de regulación en el contexto de procesos alimentados con múltiples sustratos. Se diseña un algoritmo supervisor basado en modo deslizante cuyo objetivo es evitar que un sustrato necesario para el crecimiento alcance concentraciones que comprometan la operación deseada del proceso. En particular se considera un proceso aeróbico con regulación de la tasa de crecimiento, donde el oxígeno disuelto es un sustrato necesario para el crecimiento microbiano y cuya disminución puede llevar a respuestas indeseadas, tanto en el lazo de control de alimentación como en el comportamiento del microorganismo. Finalmente, se realiza el diseño de leyes de flujo proporcionales a la biomasa para cultivos semi-continuos alimentados con dos sustratos, donde el objetivo de control es la regulación de la tasa de crecimiento total. La incorporación del error de regulación en la tasa de crecimiento permite mejorar el desempeño del proceso. Se realiza además la extensión de las leyes de alimentación a modelos que incorporan el efecto de inhibición competitiva entre los sustratos. 
Estos modelos tienen particular relevancia, entre otras aplicaciones, en los procesos de biorremediación de sustancias tóxicas. 


\section{Abstract}

This thesis addresses problems of estimation and control in biotechnological processes. Innovative solutions to two important issues for the control of these processes are provided: i) the design of observers (software sensors) for estimating non measurable variables from the available measures, and ii) the design of control loops for microbial growth rate regulation using multiple substrates.

With the aim of providing estimates of important process variables that are not available online, observers are designed using the dynamics information of the measured variables. First, sliding mode observers are proposed for processes in which the only measurable variable is the product concentration. In this case, estimates of the microbial growth rate and biomass concentration are obtained with reduced error dynamics. Next, a second order sliding mode observer is presented for estimating multiple rates of substance formation and consumption from measures of these substance concentrations. In this case, finite-time convergence is achieved. This allows considering the estimates for the implementation of feedback control loops where the key advantage is that no additional dynamics of the observer is added.

The second part of the thesis deals with problems of growth rate regulation in the context of multi-substrate processes. A supervisor algorithm based on sliding mode is designed in order to avoid that a necessary nutrient for growth reach concentrations that may affect the desired operating condition. In particular a fed-batch aerobic process with growth rate regulation is considered, where dissolved oxygen is a necessary substrate for microbial growth and its shortage may lead to undesired responses, both in the control loop and the behavior of the micro-organism. Finally, feeding laws proportional to biomass are designed for fed-batch processes in which the control objective is to regulate the overall growth rate. The incorporation of an estimation of the growth rate improves the process performance. Also, the extension of the feeding laws to growth models with competitive inhibition between substrates is presented. These models have particular relevance, among other applications, in the treatment of toxic compounds. 


\section{Lista de símbolos}

$\alpha \quad$ Coeficiente de formación de producto asociado a crecimiento

$\beta \quad$ Coeficiente de formación de producto no asociado a crecimiento

$\lambda_{i} \quad$ Parámetro de la ley de alimentación exponencial $(\mathrm{L} / \mathrm{g} / \mathrm{h})$

$\mu \quad$ Tasa específica de crecimiento $\left(\mathrm{h}^{-1}\right)$

$\mu_{\max }$ Tasa específica de crecimiento máxima $\left(\mathrm{h}^{-1}\right)$

$k_{\text {str } 1}$ Parámetro del agitador $1\left(\mathrm{rpm}^{-k_{s t r} / \mathrm{h}}\right)$

$k_{s t r 2}$ Parámetro del agitador $2(-)$

OTR Tasa de transferencia de oxígeno al medio líquido $(\mathrm{g} / \mathrm{L} / \mathrm{h})$

$c_{D O}$ Concentración de oxígeno disuelto $(\mathrm{g} / \mathrm{L})$

$c_{D O}^{*}$ Concentración de oxígeno en saturación $(\mathrm{g} / \mathrm{L})$

F Caudal de alimentación $(\mathrm{L} / \mathrm{h})$

$K_{L} a$ Coeficiente de transferencia volumétrica de $O_{2}\left(\mathrm{~h}^{-1}\right)$

$k_{o} \quad$ Constante de saturación para oxígeno $(\mathrm{g} / \mathrm{L})$

$k_{s} \quad$ Constante de saturación $(\mathrm{g} / \mathrm{L})$

$m_{o} \quad$ Tasa de consumo de oxígeno para mantenimiento $(\mathrm{g} / \mathrm{g} / \mathrm{h})$

$m_{s}$ Tasa de consumo de sustrato para mantenimiento $(\mathrm{g} / \mathrm{g} / \mathrm{h})$

$N \quad$ Velocidad de agitación $(r p m)$

$p \quad$ Concentración de producto $(\mathrm{g} / \mathrm{L})$

$q_{p} \quad$ Tasa específica de formación de producto $(\mathrm{g} / \mathrm{g} / \mathrm{h})$

$q_{s} \quad$ Tasa específica de consumo de sustrato $(\mathrm{g} / \mathrm{g} / \mathrm{h})$

$q_{\mathrm{O}_{2}}$ Tasa específica de consumo de oxígeno $(\mathrm{g} / \mathrm{g} / \mathrm{h})$ 
$s \quad$ Concentración de sustrato (g/L)

$S_{i(i n)}$ Concentración de sustrato $i$ en la entrada (g/L)

$v \quad$ Volumen de cultivo (L)

$x \quad$ Concentración de biomasa (g/L)

$Y_{a / b}$ Rendimiento del compuesto b en a (unidades C-mol)

$y_{a / b}$ Rendimiento del compuesto b en a (unidades gramos) 


\section{Capítulo 1}

\section{Introducción}

Los procesos biotecnológicos son de gran importancia en diferentes industrias. Son procesos de interés en la industria alimenticia por la posibilidad de obtener productos tales como: aminoácidos [1] y ácidos acético, cítrico, fumárico, láctico, entre otros $[2,3$, 4]. En la industria farmacéutica se utilizan en la producción de ácido clavulánico [5], proteínas recombinantes [6] y diversos precursores requeridos en la producción de antibióticos y antivirales [7]. Algunos metabolitos como los carotenoides, las lipasas y la biomasa de microalgas tienen una gran variedad de aplicaciones industriales $[8,9,10]$. También se los considera para el tratamiento de desechos orgánicos, la biodegradación de sustancias peligrosas $[11,12]$ y la producción de combustibles alternativos (hidrógeno, metano, butano, entre otros) [13, 14]. Existe a su vez una variedad de microorganismos capaces de generar biopolímeros los cuales, además de ser biodegradables, exhiben interesantes propiedades físicas [15].

Básicamente, el crecimiento de biomasa (microorganismos) procede del consumo de nutrientes (fuente de carbono y energía, nitrógeno, oxígeno, minerales, etc.) en la medida que las condiciones del medio ( $\mathrm{pH}$, temperatura, etc.) sean adecuadas. Con el objetivo de proveer las mejores condiciones para el crecimiento microbiano se utilizan dispositivos en los cuales las condiciones de cultivo se encuentran controladas. Según la escala del proceso, dichos dispositivos pueden ser tubos agitados, biorreactores de pequeño volumen (del orden de algunos litros de capacidad) hasta sistemas de cultivo de escala industrial (con volúmenes útiles que van desde decenas a miles de litros). Asociado al crecimiento de la biomasa, ocurren reacciones que transforman los reactivos en productos. La mayoría de los productos que forman los microorganismos lo hacen en respuesta a las condiciones ambientales a los que están sometidos. Debido a esto, los medios de cultivo se optimizan para mejorar el rendimiento del producto deseado. Además de establecer un valor de referencia para las variables fisicoquímicas y una composición para el medio de cultivo, se requieren lazos de control avanzados capaces de mantener las condiciones metabólicas deseadas durante el 
proceso productivo, a fin de optimizar la producción de metabolitos, evitar la formación de productos indeseados, minimizar tiempo de producción, entre otros objetivos.

\subsection{Motivaciones y Objetivos}

La capacidad para controlar los procesos biotecnológicos de manera automática tiene un gran interés por cuanto permite reducción de costos, incremento de producción y mejora de la calidad de los metabolitos. Permite además el desarrollo de nuevos productos obtenibles a partir de biorreacciones más complicadas que pueden incluir la utilización de más de un sustrato principal en forma simultánea. El control y monitoreo también ayuda a la reproducibilidad del proceso, es decir, a mantener la calidad uniforme de los metabolitos producidos en las sucesivas ejecuciones del proceso productivo. Esto es muy recomendado por las organizaciones que establecen los estándares de calidad para las diferentes industrias. Dentro de esas recomendaciones se destaca la iniciativa PAT (Process Analytical Technology) para la industria biofarmacéutica, la cual fue lanzada por la Food and Drugs Administration (FDA) en 2004 [16]. Esta iniciativa tiene como objetivo alentar a las compañías a que adopten herramientas modernas que permitan mejorar y controlar los procesos de producción asegurando la calidad del producto final. En las herramientas mencionadas en la iniciativa, se encuentran "el diseño de un sistema de medición que permita el seguimiento en tiempo real (o casi en tiempo real) de todos los atributos críticos" y además "el diseño del control del proceso tal que permita realizar ajustes que aseguren el control de todos los atributos críticos". De esta manera, los elementos de monitoreo y control son considerados relevantes para asegurar la calidad de los metabolitos.

Desde el punto de vista del control, los procesos biotecnológicos representan un desafío complejo e interesante. Por tratarse de procesos que utilizan agentes biológicos, es muy difícil - sino imposible - representar con exactitud la gran cantidad de reacciones y procesos químicos que se producen en los organismos celulares. Los modelos más sencillos que se pueden obtener son modelos macroscópicos obtenidos a partir de balances de materia y energía. Esos modelos resultan ser no lineales e incluso variantes en el tiempo. Además, están sujetos a incertidumbre en los parámetros, los cuales dependen de variables fisicoquímicas y del estado metabólico del microorganismo. A esto se suma el problema de la poca cantidad de variables disponibles en línea. En muchos casos, las mediciones más exactas son obtenidas a partir de muestras tomadas manualmente por un operador y analizadas en el laboratorio (mediciones "off-line") y por tanto no son aplicables para la implementación de algoritmos de control de lazo cerrado. En este contexto, los procesos biotecnológicos presentan al menos dos grandes desafíos: 
- Estimación de variables: se requieren algoritmos robustos capaces de estimar aquellas variables de interés que no se pueden medir directamente ya sea por el elevado costo de los sensores o por la inexistencia de los mismos.

- Desarrollo de algoritmos de control: además de regular variables físicas tales como temperatura, $\mathrm{pH}$, presión y aireación, existe interés en controlar el estado del microorganismo, maximizar la producción de un metabolito, evitar la producción de metabolitos secundarios indeseados, entre otros objetivos. Esto ha generado un campo de investigación, muy activo en las últimas décadas, en lo que respecta al diseño de las leyes de alimentación. Dichas leyes son los perfiles temporales con los cuales se provee al biorreactor de medio de cultivo con nutrientes. La ley de alimentación puede ser obtenida a partir de la optimización de funciones de costo (productividad, duración del proceso, etc.), o partir de lazos cerrados que regulan variables de interés tales como la concentración de sustancias, la velocidad de crecimiento, entre otras [17].

A partir de los desafíos mencionados, los objetivos principales de esta Tesis son:

- Desarrollar algoritmos para la estimación en línea de variables fundamentales de biorreacciones multivariables a partir de medidas accesibles aun en presencia de incertidumbres y perturbaciones típicas.

- Desarrollar algoritmos de control de la tasa de crecimiento de biomasa en biorreacciones multi-sustrato que garanticen la estabilidad del sistema dinámico aun en presencia de incertidumbres y perturbaciones.

\subsection{Organización de la Tesis}

El resto del documento se organiza de la siguiente manera. El Capítulo 2 comienza con una descripción de conceptos empleados en el modelizado de procesos biotecnológicos desde un punto de vista macroscópico ingenieril. Los conceptos allí explicados se utilizan en los capítulos siguientes para desarrollar los aportes de la Tesis. Luego se describen leyes de alimentación para cultivos semi-continuos, con especial atención a leyes exponenciales ampliamente utilizadas en la regulación del crecimiento microbiano. Dado que la implementación de esas leyes a lazo cerrado requiere de variables no medibles, el capítulo culmina con una descripción del estado del arte en lo referente a algoritmos de estimación (observadores) utilizados en bioprocesos, donde se pone especial énfasis en la estimación de tasas de reacción.

El Capítulo 3 trata el problema de estimación de variables en procesos con producción asociada al crecimiento y a la cantidad de biomasa. En 
particular se desarrollan observadores para la estimación de dos variables fundamentales del proceso como son la concentración de biomasa y la tasa de crecimiento microbiana a partir de medir la concentración de producto. Como ejemplo de aplicación se presenta el proceso de fotofermentación con bacterias productoras de hidrógeno biológico.

Al igual que la tasa de crecimiento microbiana, las tasas de formación y consumo de otras sustancias relevantes en el medio de cultivo son de especial interés y su estimación ha sido tema de investigación durante los últimos 30 años. En el Capítulo 4 se presenta un observador de múltiples tasas de reacción a partir de la medición de variables relacionadas. Las estimaciones obtenidas son de utilidad tanto para monitoreo del transcurso del cultivo como para la implementación de estrategias de control a lazo cerrado. En ese capítulo se presentan además resultados experimentales obtenidos en un cultivo de la levadura Saccharomyces cerevisiae.

La segunda parte de la Tesis abarca aplicaciones de control en procesos multi-sustrato. En los procesos de formación de biomasa por crecimiento aeróbico, la tasa de crecimiento depende no sólo del sustrato principal - su fuente de carbono y en muchos casos de energía - sino también del oxígeno, el cual es requerido para poder metabolizar la fuente de carbono. Cuando el oxígeno no se encuentra en exceso puede tener lugar un fenómeno de limitación por oxígeno, el cual trae diferentes problemas asociados. En el Capítulo 5, se desarrolla un algoritmo por modo deslizante que modifica el perfil de alimentación con el objetivo de evitar que, debido al alto consumo de oxígeno, la concentración de oxígeno disuelto caiga por debajo de un determinado valor. La propuesta se enmarca dentro del consumo multisustrato, ya que la fuente de carbono y el oxígeno son dos sustratos esenciales para el crecimiento.

En el Capítulo 6 se estudia la regulación de la tasa de crecimiento en presencia de dos sustratos que cumplen la misma función (en particular dos fuentes de carbono). Se presenta una ley de alimentación no lineal para procesos con cinética de crecimiento aditiva, donde las estimaciones requeridas pueden obtenerse con el observador propuesto en el Capítulo 4. Además, la ley propuesta se basa sólo en la medición en línea de la concentración de biomasa. En particular se extienden resultados previos aplicados a cultivos monosustrato para acelerar la convergencia al punto de operación. También se evalúa la posiblidad de utilizar flujos proporcionales a la cantidad de biomasa en procesos donde existe inhibición de un sustrato en el camino metabólico del otro sustrato.

Finalmente, en el Capítulo 7 se detallan las conclusiones obtenidas y se describen posibles trabajos futuros. 


\subsection{Principales aportes}

Los principales aportes realizados en esta Tesis se resumen en los siguientes puntos:

- Se propusieron observadores por modo deslizante para la estimación de la concentración de microorganismo y la tasa de crecimiento en un cultivo por lote a partir de la medición de la concentración de producto. La estrategia es aplicable en sistemas donde la dinámica de formación de producto siga un modelo de la forma propuesta por LuedekingPiret. La aplicación presentada es la estimación de concentración de bacteria y su tasa de crecimiento en un proceso de producción de hidrógeno por fotofermentación.

- Se propuso un observador por modo deslizante de segundo orden para la estimación de múltiples tasas de crecimiento, consumo de sustancias y formación de producto a partir de la medición en línea de variables relacionadas del proceso. Las estimaciones logradas presentan convergencia en tiempo finito y sólo requieren cotas en las tasas de cambio máximas de las variables a estimar. También se realizó la validación experimental del observador propuesto con datos obtenidos en una fermentación, en modo de cultivo continuo, del microorganismo $S$. cerevisiae.

- Se realizó un aporte a las estructuras de control descentralizadas que se utilizan en los cultivos semi-continuos aeróbicos. En particular se desarrolló un lazo auxiliar por modo deslizante que modifica el valor de referencia del lazo principal de alimentación de sustrato con el fin de evitar que el otro sustrato esencial (oxígeno) caiga por debajo de un valor preestablecido por el usuario. Este valor puede ser, por ejemplo, la concentración de oxígeno disuelto crítica del cultivo. Esta propuesta es aplicable a esquemas de alimentación tanto en lazo abierto como en lazo cerrado y no requiere la medición de variables adicionales del proceso.

- Se desarrolló una ley de control para cultivos semi-continuos alimentados con dos sustratos con el objetivo de regular las tasas de crecimiento individuales. Se propusieron estrategias que se basan en la sola medición de la concentración de biomasa, incluyendo un término de correción no lineal para mejorar la convergencia y reducir los errores ante variaciones en los parámetros.

Los aportes mencionados dieron lugar a una serie de publicaciones en revistas científicas y congresos nacionales e internacionales: 
- Publicaciones en Revistas:

S. Nuñez, F. Garelli, and H. De Battista, "Sliding mode observer for biomass estimation in a biohydrogen production process," International Journal of Hydrogen Energy, vol. 37, no. 13, pp. 10089 - 10094, 2012

S. Nuñez, H. De Battista, F. Garelli, A. Vignoni, and J. Picó, "Secondorder sliding mode observer for multiple kinetic rates estimation in bioprocesses," Control Engineering Practice, vol. 21, no. 9, pp. 1259 $-1265,2013$

S. Nuñez, F. Garelli, and H. De Battista, "Decentralized control with minimum dissolved oxygen guaranties in aerobic fed-batch cultivations," Industrial \& Engineering Chemistry Research, vol. 52, no. 50, pp. 18014-18021, 2013

S. Nuñez, F. Garelli, and H. De Battista, "Second-order sliding mode observer for biomass concentration and growth rate estimation in batch photo-bioreactors," International Journal of Hydrogen Energy, vol. 39 , no. 16 , pp. $8772-8779,2014$

S. Nuñez, H. De Battista, F. Garelli, and J. Picó, "Sufficient conditions for state observability in multi-substrate bioprocesses with additive growth dynamics," Latin America Transactions, IEEE, vol. 12, no. 5, pp. $928-934,2014$

- Publicaciones en Congresos:

S. Nuñez, H. De Battista, and F. Garelli, "Control y acondicionamiento de la tasa de crecimiento específico en bioprocesos aeróbicos," in Anales de la XIV Reunión de Trabajo en Procesamiento de la Información y Control (RPIC 2011), 2011

S. Nuñez, H. De Battista, A. Vignoni, and F. Garelli, "Observador de segundo orden para velocidades específicas en bioprocesos," in Anales del $23^{\circ}$ Congreso Argentino de Control Automático (AADECA 2012), 2012

A. Vignoni, S. Nuñez, H. De Battista, J. Picó, E. Picó-Marco, and F. Garelli, "Specific kinetic rates regulation in multi-substrate fermentation processes," in Proceedings of the 12th IFAC Symposium on Computer Applications in Biotechnology, pp. 42 - 47, 2013 
S. Nuñez, H. De Battista, F. Garelli, and J. Picó, "Sufficient conditions for state observability in multi-substrate bioprocesses with additive growth dynamics," in Anales del Congreso Bienal de IEEE Argentina (ARGENCON 2014), 2014

S. Nuñez, F. Garelli, H. De Battista, and J. Picó, "Diseño de control no lineal para regulación de tasa de crecimiento en cultivos multisustrato," in Actas de las XXXV Jornadas de Automática, España, 2014

Además, al momento de la presentación de esta Tesis, se tienen los siguientes trabajos en preparación:

S. Nuñez, F. Garelli, H. De Battista "Product-based sliding mode observers for biomass growth rate estimation in fed-batch processes".

S. Nuñez, H. De Battista, F. Garelli, "Growth rate regulation in multisubstrate fed-batch processes with substrate inhibition". 


\section{Capítulo 2}

\section{Estado del arte}

En este capítulo se describen aspectos relacionados con el modelizado de los procesos biotecnológicos, la importancia de la regulación de variables, las leyes de alimentación disponibles y observadores que se han propuesto para resolver la falta de mediciones requeridas por los algoritmos de control. Más detalladamente, la primera sección se dedica a describir conceptos básicos para modelizado de un proceso biotecnológico desde el punto de vista de la ingeniería de control. El objetivo general de esta primera parte es introducir aquellos conceptos, expresiones matemáticas, modelos y modos de operación de biorreactores que se consideran en los capítulos siguientes. La segunda sección hace foco en la importancia de la regulación de variables críticas del proceso, en especial aquellas relacionadas con el estado metabólico del microorganismo. A continuación, en la tercera sección se describen leyes de alimentación típicas y se estudian aquellas que permiten alcanzar la regulación de las variables de interés, en particular del crecimiento exponencial. Finalmente, dado que muchas de las variables requeridas no pueden medirse en línea, se describen observadores (también llamados sensores de software) diseñados para estimar aquellas variables requeridas para monitoreo y control.

\subsection{Modelizado de bioprocesos}

Tipos de modelos Los modelos utilizados para describir los procesos biotecnológicos pueden clasificarse en cuatro grupos según el nivel de detalle y complejidad [28]. La descripción más sencilla está dada por los modelos no estructurados y no segregados donde la biomasa se representa con una sola variable (usualmente, la concentración total) y no se considera segregación en la población de células (es decir se supone células 'promedio'). En estos modelos, las reacciones dependen solamente de condiciones macroscópicas en la fase líquida del biorreactor. Por otro lado, un modelo segregado considera a la población de células como una colección de conjuntos de células, donde cada conjunto tiene a su vez diferentes propiedades (por ejemplo: di- 


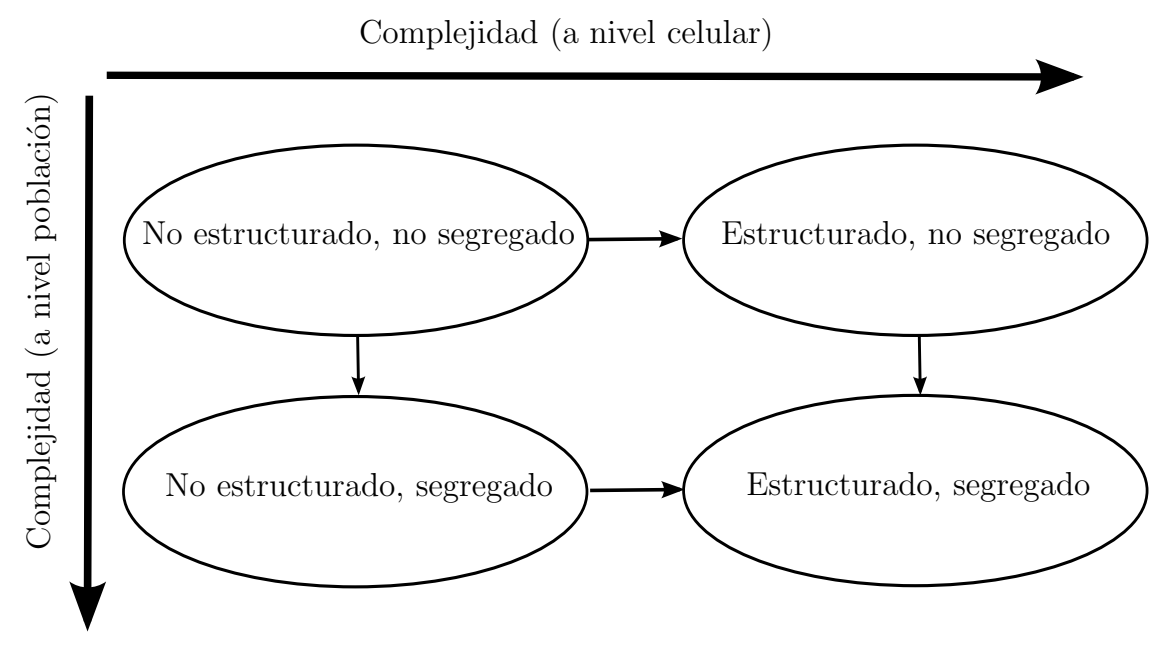

Figura 2.1: Diferentes tipos de complejidad en modelos de bioprocesos.

ferente edad y/o productividad). En los modelos estructurados se considera más de una variable para representar a la biomasa. Por ejemplo se puede considerar diferentes compartimientos con el objetivo de modelizar las concentraciones de metabolitos internos de interés. La Figura 2.1 representa la ubicación de las cuatro combinaciones de modelos posibles, en función de la complejidad matemática y el nivel de detalle del proceso.

En esta Tesis se consideran modelos del primer tipo (no estructurados, no segregados). Si bien son los modelos más sencillos, en muchas ocasiones representan una buena aproximación del cultivo para el diseño de estrategias de monitoreo y control.

Requerimientos esenciales de los microorganismos Para el crecimiento, mantenimiento y demás actividades celulares los microorganismos toman del medio de cultivo diferentes sustancias. Los nutrientes requeridos por las células se pueden categorizar en macronutrientes, los cuales son requeridos en el orden de los gramos, y micronutrientes los cuales se requieren en cantidades mucho menores. Los ocho macronutrientes principales son: carbono, nitrógeno, hidrógeno, oxígeno, azufre, fósforo, potasio y magnesio. Dentro de los micronutrientes pueden mencionarse algunos minerales requeridos en pequeña cantidad, por ejemplo calcio, cinc, hierro, manganeso, entre otros. En algunos casos, se requiere también de algunos compuestos orgánicos que no pueden ser sintetizados a partir de la fuente de carbono. Estos compuestos, denominados factores de crecimiento, deben ser suministrados como nutrientes e incluyen sustancias como aminoácidos, vitaminas, y demás factores que estimulan la síntesis del metabolito de interés.

El crecimiento de la biomasa a partir de un conjunto de nutrientes disueltos en el medio líquido es el resultado de una gran cantidad de reacciones químicas que ocurren dentro de la células. Como se mencionó previamente, los modelos no estructurados no ofrecen detalle alguno de lo que ocurre in- 


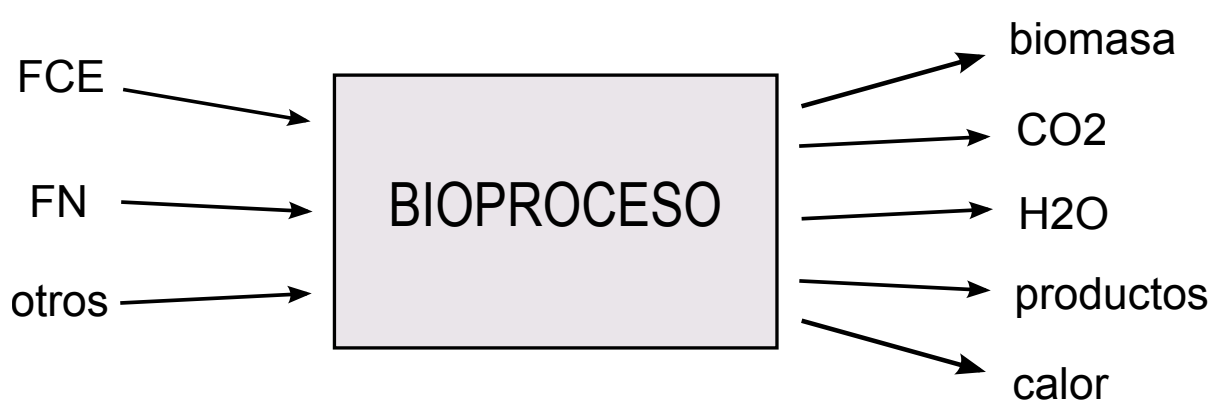

Figura 2.2: Modelo macroscópico de caja negra con el que se representa el crecimiento celular.

ternamente en las células sino que representan los fenómenos observados a nivel macroscópico.

\subsubsection{Modelo de caja negra y balances elementales}

En la representación no estructurada se considera el balance macroscópico de las sustancias involucradas en el crecimiento microbiano. Un diagrama conceptual del enfoque aplicado se presenta en la Figura 2.2. Básicamente, el crecimiento celular se modeliza como una única reacción. En forma general, la formación de biomasa a partir de una fuente de carbono y energía (FCE), una fuente de nitrógeno $(\mathrm{FN})$ y oxígeno $\mathrm{O}_{2}$ puede representarse de la forma

$\mathrm{FCE}+a \mathrm{FN}+b \mathrm{O}_{2} \rightarrow Y_{x / s}$ Biomasa $+Y_{p / s}$ Prod. $+Y_{\mathrm{CO}_{2} / s} \mathrm{CO}_{2}+w \mathrm{H}_{2} \mathrm{O}+q$ Calor

En esta expresión todos los coeficientes están referidos a lo que se denomina 1 carbono-mol (C-mol) de FCE. ${ }^{1}$ De esta manera, $Y_{x / s}$ representa los C-moles de biomasa formados por cada C-mol de FCE consumido, $Y_{p / s}$ e $Y_{\mathrm{CO} / \mathrm{s}}$ los C-moles de producto y $\mathrm{CO}_{2}$ formados por cada $\mathrm{C}$-mol de FCE, respectivamente. Además, $a$ y $b$ son los moles de $\mathrm{FN}$ y oxígeno consumidos por cada C-mol de FCE, respectivamente. Nótese que también se forma cierta cantidad de agua y además se genera calor. Luego, puede realizarse un balance de cada compuesto involucrado. En particular, el balance de carbono resulta en

$$
Y_{x / s}+Y_{\mathrm{CO}_{2} / s}+Y_{p / s}=1,
$$

donde $Y_{1 / 2}$ tiene unidades de C-mol compuesto 1 / C-mol compuesto 2. Este balance describe la distribución del carbono en los diferentes compuestos del lado derecho de la expresión (2.1) e impone restricciones a los posibles valores que pueden tomar los rendimientos involucrados. Los coeficientes $Y_{1 / 2}$ se denominan rendimientos y son importantes pues miden la eficiencia

\footnotetext{
${ }^{1}$ Un carbono-mol de una sustancia es la cantidad de esa sustancia que contiene un 1 mol (12 gr.) de carbono
} 
del proceso de producción. Por ejemplo, si el objetivo del proceso productivo es maximizar la biomasa, entonces los objetivos serán maximizar $Y_{x / s} \mathrm{y}$ minimizar $Y_{p / s}$. El balance de otros compuestos puede realizarse de forma análoga. Además del carbono, los compuestos más importantes para los cuales se realiza el balance son el hidrógeno, oxígeno y nitrógeno por tratarse de los constituyentes mayoritarios de la biomasa [28]. Los rendimientos $Y_{1 / 2}$ definidos en esta sección pueden expresarse en gramos (es decir gr. sustancia 1 / gr. sustancia 2) utilizando la relación

$$
y_{1 / 2}=Y_{1 / 2} \frac{\sigma_{1}}{\sigma_{2}}
$$

donde $\sigma_{1}$ y $\sigma_{2}$ son los factores de conversión de C-mol a gramos de las sustancias 1 y 2 , respectivamente.

El análisis del balance de energía correspondiente se puede simplificar introduciendo el concepto de grado de reducción de un compuesto [29]. Como su nombre indica, el grado de reducción de un compuesto $(\gamma)$ es una medida de cuán reducido se encuentra el compuesto. Su valor numérico coincide con la cantidad de electrones transferidos desde el compuesto al oxígeno cuando se oxida $1 \mathrm{C}$-mol de la sustancia. Es decir que es una medida de la cantidad de electrones disponibles por cada C-mol de sustancia. Dado que el valor de $\gamma$ surge de un balance, el resultado depende del nivel de referencia al que se oxida el compuesto. Como nivel de referencia se entiende a cuáles compuestos les corresponde $\gamma=0$. Usualmente, se considera como niveles de referencia a $\mathrm{CO}_{2}, \mathrm{H}_{2} \mathrm{O}$ y un compuesto nitrogenado, por ejemplo $\mathrm{NH}_{3}$. Con estos niveles de referencia, cada molécula de $\mathrm{O}_{2}$ recibe cuatro electrones (dos por cada átomo). Luego, en la oxidación de un compuesto genérico de la forma $\mathrm{CH}_{a} \mathrm{O}_{b} \mathrm{~N}_{c}$ donde se tiene la siguiente reacción

$$
\mathrm{CH}_{a} \mathrm{O}_{b} \mathrm{~N}_{c}+n \mathrm{O}_{2} \rightarrow g \mathrm{CO}_{2}+w \mathrm{H}_{2} \mathrm{O}+\mathrm{kNH}_{3}
$$

el grado de reducción del compuesto es la cantidad $\gamma=4 n$. A partir del balance elemental de $C, H, O$ y $N$ aplicado a la expresión anterior se obtiene que $n=1+(a-3 c) / 4-b / 2$. De esta manera el grado de reducción del compuesto resulta

$$
\gamma=4 n=4+a-2 b-3 c .
$$

La importancia de esta expresión radica en que permite calcular $\gamma$ a partir de los coeficientes $a, b, c$ que definen al compuesto sin realizar el balance de cada elemento en (2.4).

Ahora, retomando la expresión (2.1), la cantidad de electrones a ambos lados de la reacción debe ser la misma. Esto se traduce en que debe cumplirse

$$
\gamma_{s}-4 b=Y_{x / s} \gamma_{x}+Y_{p / s} \gamma_{p},
$$

donde $\gamma_{s}, \gamma_{x}$ y $\gamma_{p}$ son los grados de reducción correspondientes a la FCE, biomasa y producto, respectivamente. Estos valores se obtienen a partir de 
la fórmula química correspondiente de cada sustancia expresada en C-mol y haciendo uso de (2.5) [29]. Nótese que en la expresión anterior no aparecen aquellos compuestos para los cuales se consideró que su valor de $\gamma$ es cero (en este caso $\mathrm{FN}, \mathrm{H}_{2} \mathrm{O}$ y $\mathrm{CO}_{2}$ ). La expresión (2.6) puede reordenarse de la forma

$$
\frac{Y_{x / s} \gamma_{x}}{\gamma_{s}}+\frac{Y_{x / p} \gamma_{p}}{\gamma_{s}}+\frac{4 b}{\gamma_{s}}=1
$$

donde cada sumando representa una medida de cómo se distribuyen los electrones disponibles de la FCE.

Las expresiones (2.2) y (2.7) resumen dos balances elementales que debe cumplir la reacción (2.1). Pueden aplicarse por ejemplo para cuantificar la máxima cantidad de biomasa obtenible a partir de un determinado sustrato o para verificar la consistencia de un conjunto de observaciones experimentales. Cabe destacar que la expresión (2.1) describe el crecimiento del microorganismo a partir de nutrientes y oxígeno. En caso de que el crecimiento microbiano sea anaeróbico pueden desarrollarse expresiones similares.

\subsubsection{Cinética del crecimiento microbiano}

Desde el punto de vista cinético, puede considerarse una expresión análoga a (2.1)

$r_{s} \mathrm{FCE}+r_{n} \mathrm{FN}+r_{\mathrm{O}_{2}} \mathrm{O}_{2} \rightarrow r_{x}$ Biomasa $+r_{p}$ Prod. $+r_{\mathrm{CO} 2} \mathrm{CO}_{2}+r_{w} \mathrm{H}_{2} \mathrm{O}+$ Calor

donde $r_{j}$ es la tasa volumétrica de formación o consumo de la sustancia $j$. Nuevamente, debido a que debe cumplirse el balance de carbono, se tiene que

$$
r_{s}=r_{x}+r_{C O 2}+r_{p}
$$

En el análisis de los bioprocesos suele emplearse la definición de tasas de consumo y formación de compuestos por unidad de biomasa, la cual se describe a continuación.

Definición 2.1 (Tasas específicas de reacción) La tasa específica de formación o consumo de la sustancia $j$ se define como

$$
q_{j}=\frac{r_{j}}{x} .
$$

Luego, utilizando la expresión (2.10) pueden definirse

$$
\begin{array}{lr}
\frac{r_{x}}{x}=q_{x}=\mu & \text { tasa específica de crecimiento, } \\
\frac{r_{s}}{x}=q_{s} & \text { tasa específica de consumo de sustrato, } \\
\frac{r_{O_{2}}}{x}=q_{O_{2}} & \text { tasa específica de consumo de } O_{2}, \\
\frac{r_{p}}{x}=q_{p} & \text { tasa específica de formación de producto. }
\end{array}
$$




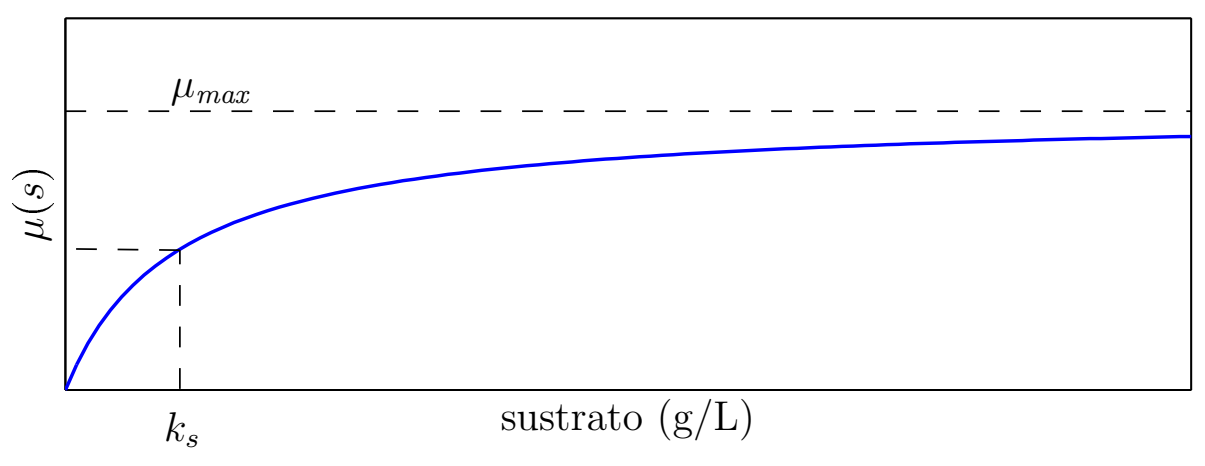

Figura 2.3: Modelo de Monod (ec. (2.11)).

La tasa específica de crecimiento $\mu$ es uno de los parámetros más importantes del proceso. Desde el punto de vista macroscópico, se han propuesto diferentes relaciones empíricas para describir la relación entre $\mu$ y diferentes factores del medio de cultivo como son la concentración de nutrientes, $\mathrm{pH}$, temperatura, etc. El estudio de la dependencia de $\mu$ con el sustrato que actúa como fuente de carbono revela importantes aspectos del bioproceso.

Modelo de Monod Uno de los modelos más importantes para describir la relación entre la tasa de crecimiento y el sustrato es el modelo de Monod [30]:

$$
\mu(s)=\mu_{\max } \frac{s}{s+k_{s}} .
$$

En este modelo $\mu_{\max }$ es la tasa de crecimiento máxima y $k_{s}$ es la denominada constante de saturación (o constante de afinidad). Como función del sustrato, la expresión (2.11) es una función monótonamente creciente, la cual tiende a $\mu_{\max }$ cuando $s$ tiende a infinito (Figura 2.3). De hecho, cuando $s \gg k_{s}$ el valor de la tasa de crecimiento se hace independiente de la concentración de sustrato. En este caso se dice que el sustrato se encuentra en exceso. Por el contrario, cuando $s$ se encuentra en concentraciones bajas, por ejemplo en valores cercanos a $k_{s}$, la tasa de crecimiento cambia con $s$ y se dice que el sustrato es limitante del crecimiento. Esta limitación cinética es la idea básica para la regulación de $\mu$ utilizando como acción de control el flujo de alimentación del sustrato [31]. Si bien el modelo de Monod es muy sencillo, es capaz de describir relativamente bien los resultados experimentales obtenidos con muchos microorganismos. De ahí que sea un modelo muy popular para representar la dependencia de $\mu$ con el sustrato principal.

Modelos con Inhibición De acuerdo al modelo de Monod, cuando el sustrato se encuentra en exceso la tasa de crecimiento satura en el valor $\mu_{\max }$. En algunos microorganismos, una concentración elevada de sustrato puede 


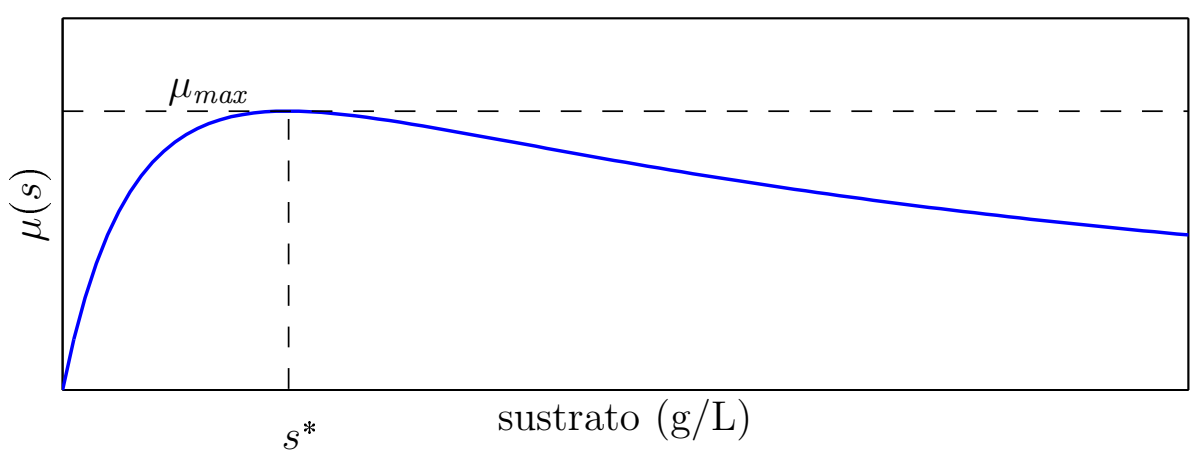

Figura 2.4: Modelo de Haldane (ec. (2.12)).

tener un efecto inhibitorio en la tasa de crecimiento. Muchos de los modelos que describen este efecto se basan en expresiones obtenidas originalmente para la cinética de inhibición de enzimas. Un modelo muy utilizado para representar la inhibición de $\mu$ con $s$ es el denominado modelo de Haldane

$$
\mu(s)=\mu_{o} \frac{s}{s^{2} / k_{i}+s+k_{s}},
$$

donde $k_{i}$ se denomina constante de inhibición y $\mu_{o}=\mu_{\max }\left(1+2 \sqrt{k_{s} / k_{i}}\right)$. En este modelo la tasa de crecimiento presenta un máximo en $s^{*}=\sqrt{k_{s} k_{i}}$ y a partir de $s^{*}$ la función (2.12) decrece (Figura 2.4). Otras sustancias pueden producir efecto inhibitorio, por ejemplo para el caso de inhibición por producto se han propuesto extensiones al modelo (2.11) de la forma

$$
\mu(\cdot)=\mu_{\max } \frac{s}{s+k_{s}} f(p),
$$

donde $f(p)$ es una función decreciente de la concentración de producto [32].

Otros modelos de $\mu$ Si bien los modelos de Monod y Haldane han sido muy difundidos, existen cultivos biológicos en los cuales estos modelos no se ajustan satisfactoriamente a los valores experimentales. Otras expresiones empíricas que se han propuesto para describir la dependencia de $\mu$ con el sustrato son las siguientes:

$$
\begin{aligned}
\text { Blackman: } \mu(s) & =\left\{\begin{array}{ll}
\mu_{\max } \frac{s}{2 k} & \text { si } s<2 k \\
\mu_{\max } & \text { si } s \geqslant 2 k
\end{array},\right. \\
\text { Tessier: } \mu(s) & =\mu_{\max }\left(1-e^{-k s}\right), \\
\text { Moser: } \mu(s) & =\mu_{\max } \frac{s^{n}}{s^{n}+k_{m}}, \\
\text { Contois: } \mu(\cdot) & =\mu_{\max } \frac{s}{s+k x} .
\end{aligned}
$$


El modelo de Blackman puede proveer un mejor ajuste de $\mu$ a bajas concentraciones de $s$ pero es un modelo con un cambio de pendiente discontinuo. El modelo de Moser puede verse como una generalización de la expresión de Monod. El modelo de Contois predice reducción de la tasa de crecimiento cuando se incrementa la concentración de biomasa. Este último modelo es muy utilizado para representar la dinámica del crecimiento en procesos de tratamiento de residuos [33].

Efecto de las condiciones de operación sobre $\mu$. La fuente de carbono no es la única variable que causa efectos sobre la tasa de crecimiento. Las condiciones de operación del biorreactor (por ejemplo temperatura y $\mathrm{pH}$ ) ejercen efectos que pueden ser muy diferentes entre un proceso y otro. Por consiguiente, los fenómenos involucrados suelen ser complejos de modelizar. Se ha observado que el efecto de la temperatura sobre $\mu_{\max }$ es similar al efecto que produce la temperatura en la actividad de una enzima: la actividad se incrementa con la temperatura hasta un cierto valor y luego, para valores de temperatura superiores, la actividad decrece [28]. A partir de esta observación es razonable suponer que exista una temperatura óptima de cultivo para cada microorganismo. El efecto del $\mathrm{pH}$ en la actividad celular se debe a la sensibilidad de las enzimas individuales, las cuales son afectadas por el cambio de $\mathrm{pH}$. Además, los microorganismos tienen la capacidad de mantener el $\mathrm{pH}$ interno relativamente constante ante cambios del pH externo. Sin embargo, esto ocurre a expensas de un incremento de la energía utilizada para mantenimiento. De esta manera, es esperable que si el pH no está en su valor óptimo haya una reducción sustancial de la tasa de crecimiento. En forma general, los efectos de la temperatura, el pH y otros factores pueden ser incluidos en el modelo de $\mu$ agregando términos multiplicativos [34]

$$
\mu(\cdot)=\mu_{\max } f_{1}(s) f_{2}(T) f_{3}(p H) f_{4}\left(O_{2}\right) \ldots,
$$

donde cada una de las funciones $f_{i}(\cdot) \in[0,1]$ modeliza el efecto de un nutriente o parámetro particular. Cuando se asume que la tasa de crecimiento es función de un único sustrato, se considera que las condiciones de operación (ej: temperatura y $\mathrm{pH}$ ) se encuentran reguladas por lazos de control independientes.

\subsubsection{Balance de masas en la fase líquida}

La Figura 2.5 presenta un esquema simplificado de un biorreactor de tanque agitado donde $F_{\text {in }}$ y $F_{\text {out }}$ representan a la entrada y salida de flujos, respectivamente. En forma general, una cantidad de sustancia $C$ diluida en una fase liquída (de volumen $v$ ) se encuentra con una concentración $c=C / v$. La tasa de cambio de la cantidad total de la sustancia está gobernada por 


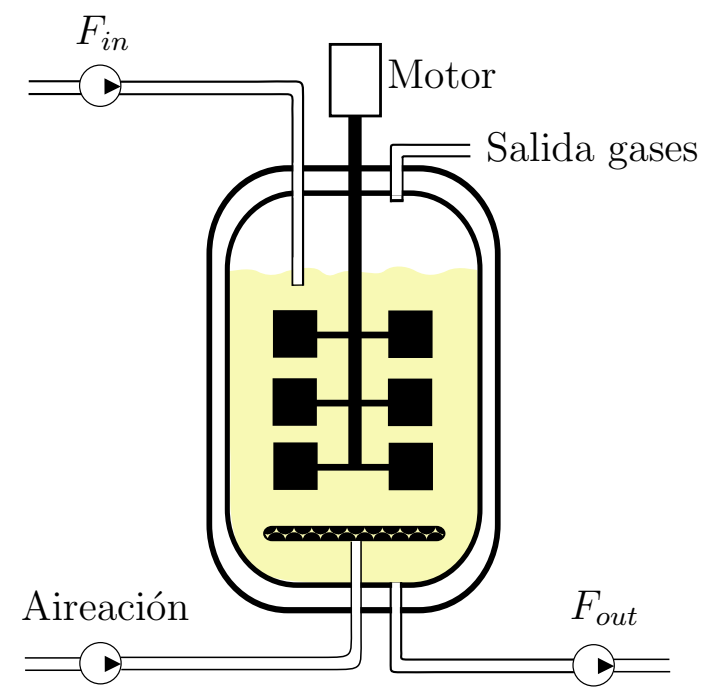

Figura 2.5: Esquema simplificado de un biorreactor de tanque agitado.

el balance de masas correspondiente

$$
\dot{C}=(\dot{c v})=F_{\text {in }} c_{\text {in }}-F_{\text {out }} c_{\text {out }} \pm r_{c} v \pm \text { intercambio. }
$$

En la expresión anterior, $F_{\text {in }} c_{\text {in }}$ (respectivamente $F_{\text {out }} c_{\text {out }}$ ) es la cantidad de sustancia que ingresa (sale) con concentración $c_{\text {in }}\left(c_{\text {out }}\right)$ por unidad de tiempo, $r_{c} v$ es la tasa de producción o consumo de la sustancia debido a la actividad biológica y el último término se refiere al intercambio con otra fase (en este caso la fase gaseosa del biorreactor). El modelizado del proceso utilizando ecuaciones diferenciales independientes de las coordenadas espaciales requiere de algunas hipótesis, las cuales se describen a continuación.

Suposición 2.1 Las condiciones de operación del biorreactor son tales que el mezclado es perfecto.

La suposición 2.1 asume que no existen gradientes de concentración en todo el volumen del biorreactor y entonces las concentraciones de las sustancias de interés son uniformes. En el balance de masa (2.19), esto implica que $c_{\text {out }}=c$. De esta manera, el balance de la cantidad de biomasa $(X)$ y sustrato $(S)$ resulta en:

$$
\begin{aligned}
& (\dot{x v})=-F_{\text {out }} x+\mu x v, \\
& \dot{(\dot{s v})}=F_{\text {in }} S_{\text {in }}-F_{\text {out }} s-\frac{\mu x v}{y_{x / s}}
\end{aligned}
$$

donde se utilizó la igualdad $r_{x}=\mu x$ y el hecho de que no ingresa biomasa al biorreactor. En las expresiones anteriores, $x$ y $s$ denotan la concentración 
de biomasa y sustrato respectivamente. Nótese en la expresión (2.21) que el consumo de sustrato se representa asociado al crecimiento, es decir

$$
r_{s}=\frac{\mu x}{y_{x / s}}
$$

Puede suceder que exista un consumo paralelo de sustrato para mantenimiento (esto significa energía requerida para funciones celulares no asociadas a la producción de nuevas células). En caso de que ese consumo no sea despreciable frente al consumo de sustrato para crecimiento, se puede reemplazar la expresión de $r_{s}$ anterior por la propuesta de Pirt [35]

$$
r_{s}=\left(\frac{\mu}{y_{x / s}^{\prime}}+m_{s}\right) x,
$$

donde $m_{s}$ se denomina coeficiente de mantenimiento y el parámetro $y_{x / s}^{\prime}$ es el rendimiento que se obtendría en caso de $m_{s}=0$ (rendimiento teórico). Cabe destacar que en los casos en que $m_{s}>0$, el rendimiento neto $y_{x / s}$ no es constante sino que es dependiente de $\mu$ (comparar con ec. (2.22)).

Suposición 2.2 Las densidades del cultivo y del volumen que ingresa/egresa son iguales y constantes.

La suposición 2.2 permite relacionar el cambio de volumen del cultivo con los caudales de entrada y salida a través de la expresión

$$
\dot{v}=F_{\text {in }}-F_{\text {out }} .
$$

Cabe destacar que las hipótesis consideradas tienen validez en biorreactores agitados de volumen pequeño a mediano y en cultivos donde las concentraciones de las sustancias involucradas no sean muy elevadas.

En los cultivos aeróbicos, el oxígeno requerido por las células se transfiere desde la fase gaseosa usualmente por aireación y agitación. La tasa de transferencia volumétrica de oxígeno desde la fase gaseosa (burbujas) hacia el seno de la fase líquida puede representarse por

$$
O T R=K_{L} a\left(c_{D O}^{*}-c_{D O}\right),
$$

donde $c_{D O}$ y $c_{D O}^{*}$ son las concentraciones de oxígeno disuelto en la fase líquida y de saturación, respectivamente, y $K_{L} a$ es la tasa de transferencia de masa volumétrica. Cabe destacar que la solubilidad del oxígeno en el medio de cultivo es muy baja, del orden de $8 \mathrm{mg} / \mathrm{L}$, y que además cambia con la concentración de sales y con la temperatura [36]. El consumo de oxígeno que realiza la biomasa (también denominado en inglés oxygen uptake rate $(O U R))$ se describe por

$$
r_{O_{2}}=\left(\frac{\mu}{y_{x / o}}+m_{o}\right) x
$$


Esta expresión es análoga a la de consumo de sustrato (2.23), donde $y_{x / o}$ es la cantidad de biomasa producida por unidad de oxígeno consumido cuando el mantenimiento es nulo. Luego, el balance (2.19) para oxígeno disuelto resulta en

$$
\left(\dot{c_{D O}} v\right)=-F_{\text {out }} c_{D O}-r_{O_{2}} v+O T R v,
$$

donde se consideró el hecho de que no ingresa oxígeno por las entradas de flujos sino desde la fase gaseosa.

A partir del balance de masas de las principales sustancias puede verse que la dinámica depende de las entradas de flujo. En función de los caudales aplicados al biorreactor se tienen tres modos básicos de operación, los cuales se describen en la próxima sección.

\subsubsection{Sistemas de cultivo}

\section{Cultivo por lotes}

En los denominados cultivos por lotes (del inglés batch) no se aplican entradas, es decir que $F_{\text {in }}=F_{\text {out }}=0$. En consecuencia se tiene un sistema con volumen constante $\left(v=v_{0}\right)$. A partir del balance de masas (2.20)-(2.21), la dinámica de las concentraciones de biomasa y sustrato resulta

$$
\begin{aligned}
\dot{x} & =\mu x, \\
\dot{s} & =-\frac{\mu x}{y_{x / s}} .
\end{aligned}
$$

En estos procesos, las concentraciones iniciales de biomasa y nutrientes, junto con los parámetros fisicoquímicos de operación, definen el curso del cultivo. En un experimento por lotes existen hasta cinco fases claramente identificables (ver Figura 2.6): (1) fase de latencia (o retardo), (2) fase exponencial, (3) fase de desaceleración, (4) fase estacionaria y (5) fase de decrecimiento (o de muerte). La fase de latencia ocurre debido a la adaptación del microorganismo a las nuevas condiciones ambientales a las que se encuentra sometido. Esto incluye la síntesis de las enzimas necesarias para la actividad metabólica que deben realizar en el nuevo entorno. La duración de esta etapa, que depende del microorganismo y de las condiciones del biorreactor, puede acortarse si la biomasa es transferida desde un medio de cultivo similar. Una vez adaptado a las nuevas condiciones, el microorganismo comienza a crecer. En la etapa de crecimiento exponencial el sustrato principal se encuentra en exceso. Si la tasa de crecimiento es de la forma (2.11) y los factores ambientales son adecuados, entonces se alcanza la velocidad máxima de crecimiento $\mu_{\max }$. Luego, al reducirse las concentraciones de los sustratos, la tasa de crecimiento disminuye hasta que, eventualmente, la etapa de crecimiento culmina. Usualmente, el medio de cultivo se prepara de manera tal de que el sustrato limitante sea la fuente de carbono. No obstante, el crecimiento también puede detenerse debido a inhibición generada por sustancias acumuladas durante la fase de crecimiento exponencial. 


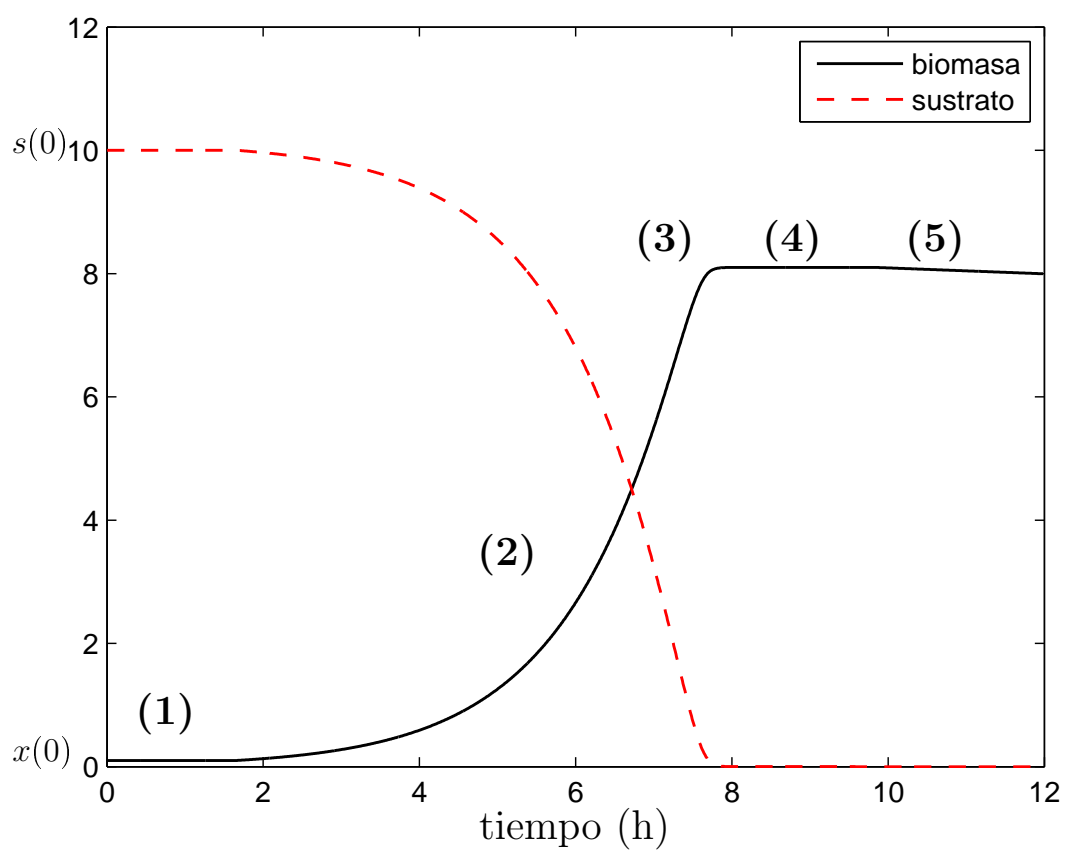

Figura 2.6: Curva típica de un cultivo por lotes (valores utilizados: $x(0)=$ $\left.0,1 \mathrm{~g} / \mathrm{L}, s(0)=10 \mathrm{~g} / \mathrm{L}, \mu_{\max }=0,8 \mathrm{~h}^{-1}, y_{x / s}=0,8 \mathrm{~g} / \mathrm{g}\right)$.

En la fase estacionaria la tasa de crecimiento neta es nula. Finalmente, la concentración de biomasa puede reducirse debido a muerte de las células o a metabolismo endógeno (esto último se refiere a reacciones en las células que consumen sustancia de las células mismas). En la Figura 2.6 se ilustra un ejemplo donde una concentración inicial de sustrato $(s(0)=10 \mathrm{~g} / \mathrm{L})$ fue consumida completamente para dar un incremento de biomasa igual a $\Delta x=y_{x / s} s(0)=8 \mathrm{~g} / \mathrm{L}$.

Es conveniente destacar en este punto que los modelos de $\mu$ descriptos en las expresiones (2.11)-(2.17) no modelizan la fase de latencia. Esta fase se observa cuando las condiciones ambientales cambian lo suficiente como para que el microorganismo requiera adaptar su metabolismo. En caso de requerirse modelizar este efecto puede considerarse el modelo de Baranyi and Roberts [37], el cual incorpora una función de ajuste para representar el ajuste gradual de las células a las nuevas condiciones ambientales.

Sin dudas, la principal ventaja de los cultivos por lotes es su simplicidad y facilidad de operación. Otra característica es que permiten determinar parámetros como $\mu_{\max }$ e $y_{x / s}$ con relativa facilidad. Por otro lado, durante la fase exponencial el microorganismo crece con sustrato en exceso y por consiguiente la tasa de crecimiento no puede ser regulada con ese nutriente. Además puede aparecer inhibición debido a la acumulación de algún subproducto del crecimiento. También puede suceder que, debido a la alta demanda de oxígeno, se genere limitación al alcanzarse la tasa máxima de transferencia de oxígeno del biorreactor. Finalmente, ciertos productos de 
interés no se generan durante la fase de crecimiento exponencial sino que lo hacen hacia el final del cultivo, es decir cuando las concentraciones de los sustratos son menores y por consiguiente la tasa de crecimiento es menor a $\mu_{\max }$. Muchos de los problemas del cultivo por lotes se pueden resolver con el denominado cultivo semi-continuo (en inglés fed-batch).

\section{Cultivo semi-continuo}

En este modo de operación del biorreactor se tiene $F_{\text {in }}>0, F_{\text {out }}=0$. Es decir que se introduce progresivamente medio de cultivo fresco al biorreactor pero no se extrae nada hasta que el proceso haya finalizado. En este caso, la dinámica de las principales variables resulta en

$$
\begin{aligned}
& \dot{x}=\mu x-\frac{F_{i n}}{v} x, \\
& \dot{s}=-\frac{\mu x}{y_{x / s}}+\left(S_{i n}-s\right) \frac{F_{i n}}{v}, \\
& \dot{v}=F_{i n},
\end{aligned}
$$

donde el cociente $F_{\text {in }} / v$ se denomina dilución $(D)$. A menudo se considera a $D$ como la entrada de control del proceso. El significado físico de esta variable es que su valor numérico es igual al número de volúmenes de biorreactor que ingresan al mismo por unidad de tiempo. Nótese que se considera un flujo de entrada que no contiene biomasa y por esta razón sólo aparece en la dinámica de $x$ un término negativo asociado a la dilución.

La principal ventaja del modo de operación semi-continuo es que permite evitar la sobrealimentación de sustrato y de esta manera evitar también la inhibición de la tasa de crecimiento. Además, con una ley de alimentación adecuada, es posible regular $\mu$ en valores menores a $\mu_{\max }$. Esto permite alcanzar objetivos tales como obtener condiciones óptimas para la generación de un determinado producto, evitar los problemas asociados a la limitación por oxígeno, mejorar la reproducibilidad del proceso, maximizar el crecimiento celular, obtener altas concentraciones de biomasa evitando el efecto tóxico de nutrientes, entre otros. Por estas razones, este modo de cultivo es a menudo preferido por sobre los otros modos de operación [38].

Debido a la importancia de este tipo de proceso, en la sección 2.3 se describen diferentes estrategias de alimentación aplicadas para satisfacer diferentes objetivos. En particular se presta especial atención a leyes exponenciales de la forma

$$
F_{i n}(t)=F_{o} e^{\mu t}
$$

las cuales son utilizadas para regular la tasa de crecimiento en un valor predefinido. Algunas de estas estrategias utilizan realimentación de variables como la biomasa y el volumen. Leyes de alimentación tanto de lazo abierto como de lazo cerrado serán consideradas en el Capítulo 5, donde se presenta un algoritmo que actúa como lazo auxiliar de la alimentación para resolver 
problemas asociados con la limitación por oxígeno disuelto. También se consideran leyes que realimentan la cantidad de biomasa en el Capítulo 6, donde se diseña una ley de alimentación para un cultivo alimentado con dos sustratos.

\section{Cultivo continuo}

En este modo de operación se tiene tanto flujo de entrada como de salida. En los casos en los que se opera a volumen constante se tiene $F_{\text {in }}=F_{\text {out }}>0$. Luego, el balance correspondiente para las concentraciones de biomasa y sustrato resulta:

$$
\begin{aligned}
& \dot{x}=\left(\mu-\frac{F_{i n}}{v}\right) x, \\
& \dot{s}=-\frac{\mu x}{y_{x / s}}+\left(S_{i n}-s\right) \frac{F_{i n}}{v} .
\end{aligned}
$$

Estas expresiones corresponden a procesos sin recirculación de biomasa. Cuando parte de la biomasa que fluye fuera del biorreactor es reciclada, utilizando por ejemplo un tanque sedimentador, debe incorporarse una variable que describa la dinámica de la biomasa que reingresa al biorreactor como también términos de dilución adicionales en cada variable de estado [34]. Una característica importante del modo de operación continuo es la posibilidad de alcanzar concentraciones de estado estacionario $(\bar{x}, \bar{s})$. A partir de las expresiones (2.31), las concentraciones $(\bar{x}, \bar{s})$ obedecen a las expresiones:

$$
\begin{aligned}
\mu(\bar{s}) & =D, \\
\bar{x} & =y_{x / s}\left(S_{i n}-\bar{s}\right) .
\end{aligned}
$$

Luego, utilizando la expresión de $\mu(s)$ pueden obtenerse los valores de estado estacionario como función de $D$. Por ejemplo, en caso de que la tasa de crecimiento responda a la expresión de Monod (ec. (2.11)) la solución de la expresión (2.32a) resulta

$$
\bar{s}=\frac{D k_{s}}{\mu_{\max }-D} .
$$

El coeficiente de mantenimiento $m_{s}$, descripto en la expresión (2.23), genera una reducción de $\bar{x}$ de acuerdo a

$$
\bar{x}=\frac{y_{x / s}^{\prime} D\left(S_{i n}-\bar{s}\right)}{D+m_{s} y_{x / s}^{\prime}} .
$$

La Figura 2.7 presenta un ejemplo de los valores de estado estacionario de biomasa y sustrato (expresiones (2.32b)-(2.34)) obtenidos como función de $D$ para una cinética tipo Monod. De acuerdo al modelo de Monod, si se intenta operar con diluciones cercanas a $\mu_{\max }$ la concentración de sustrato 


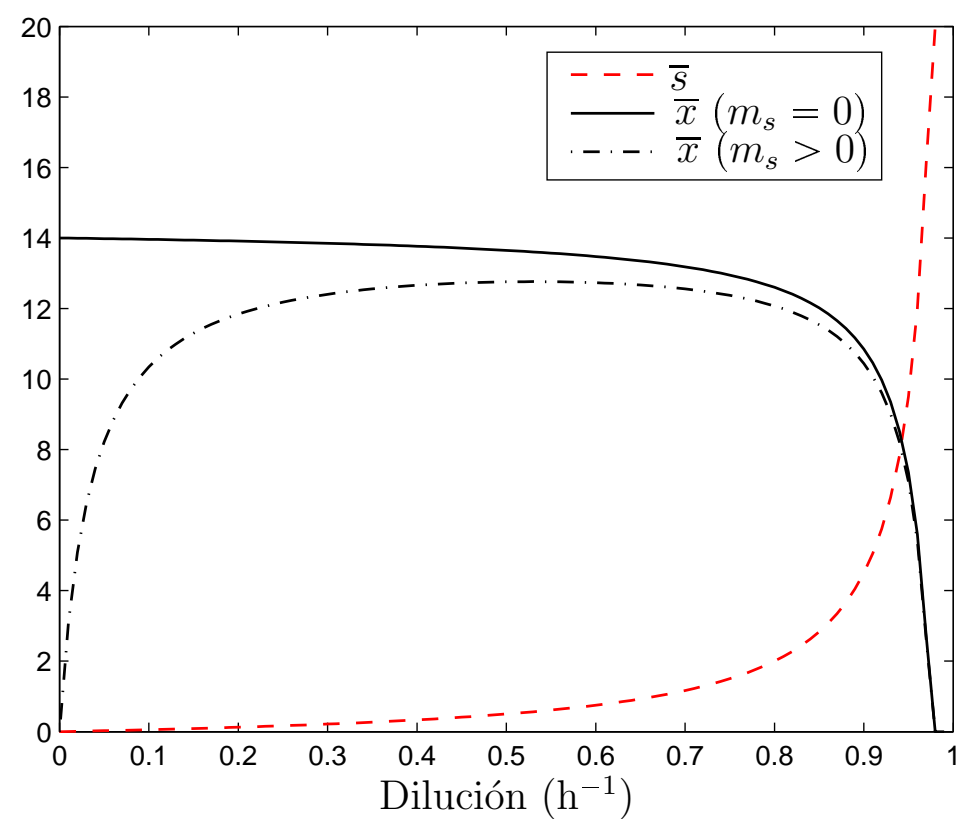

Figura 2.7: Ejemplo de concentraciones de estado estacionario en un cultivo continuo como función de la dilución para el caso de cinética Monod (valores utilizados: $\mu_{\max }=1 \mathrm{~h}^{-1}, k_{s}=0,5 \mathrm{~g} / \mathrm{L}, y_{x / s}^{\prime}=0,8 \mathrm{~g} / \mathrm{g}, S_{i n}=20 \mathrm{~g} / \mathrm{L}$, $\left.m_{s}=0,05 \mathrm{~g} / \mathrm{g} / \mathrm{h}\right)$.

requerida crece en forma no acotada (ver (2.33)). En la práctica se tiene una cota superior dada por la concentración de sustrato en la entrada, es decir $\bar{s} \leqslant S_{i n}$. Intentar operar a diluciones mayores a un valor de dilución crítico produce el lavado del biorreactor, es decir $x(t) \rightarrow 0$, dado que egresa mayor cantidad de biomasa que la que crece por unidad de tiempo.

El modo de operación continuo es muy utilizado para estudios fisiológicos ya que en estado estacionario es posible regular la tasa de crecimiento con la dilución. De esta manera pueden realizarse diferentes pruebas manteniendo el resto de los parámetros bajo estricto control. Por otro lado, dado que se trata de un sistema abierto existe mayor riesgo de contaminación del cultivo. Además, la etapa previa de estabilización del biorreactor puede ser dificultosa e insumir una cantidad valiosa de tiempo y recursos [39].

\subsubsection{Formación de producto}

La formación de producto es una característica de los cultivos con microorganismos. Si el objetivo es maximizar la producción de biomasa, este fenómeno resulta claramente indeseado, no sólo por la reducción de la productividad del cultivo sino porque además existen productos que, a partir de cierto valor de concentración, pueden resultar inhibitorios del crecimiento. Por otro lado, si el objetivo es obtener una enzima, una proteína recom- 
binante o incluso el bio-tratamiento de residuos, entonces la generación de productos es una cuestión primordial para el desarrollo rentable del bioproceso y en estos casos un claro objetivo de control es la maximización del bioproducto generado. Dado que los productos pueden ser acumulados dentro de las células o secretados, las estrategias para maximizar la producción del bioproceso dependerán del tipo de producto.

Desde un punto de vista dinámico, la formación de los productos puede clasificarse de la siguiente manera:

- Productos asociados al crecimiento. En este caso se tiene $r_{p}=\mu x / y_{x / p}$, donde $y_{x / p}$ es el rendimiento correspondiente. Un ejemplo de este tipo es la fermentación anaeróbica de azúcares (por ejemplo con formación de etanol) usando $S$. cerevisiae. Dado que la formación del producto depende de $\mu$, es de interés alimentar el biorreactor de tal manera que la tasa de crecimiento específica se mantenga constante. Tal es el caso de la producción del antígeno de superficie de la hepatitis B utilizando S. cerevisiae [40].

- Productos no asociados al crecimiento. En este caso $r_{p}=k_{p} x$. Como el nombre lo indica, la formación de producto no se relaciona con la tasa de crecimiento sino con la concentración de biomasa. En estos casos, maximizar el producto es equivalente a maximizar la concentración final de biomasa. El cultivo semi-continuo brinda la posibilidad de extender la fase estacionaria y aumentar así la producción de productos. Como ejemplo de este caso se tiene la producción de algunos anticuerpos con cultivos de hibridomas [41] y la fermentación de diversos antibióticos [42, 43].

- Modelo mixto. En algunos casos la formación de productos se relaciona no sólo con el crecimiento sino también con la cantidad de biomasa. Este es el caso del modelo de Luedeking y Piret, el cual se describe a continuación.

Modelo de Luedeking y Piret Este modelo establece que la tasa de formación de un producto $p$ está relacionada con la tasa de crecimiento y con la concentración del microorganismo. De esta manera, en un cultivo por lote se tiene

$$
\dot{p}=\alpha \dot{x}+\beta x,
$$

donde $\dot{x}=\mu x$. De este modo resulta $r_{p}=(\alpha \mu+\beta) x$. Los parámetros empíricos $\alpha$ y $\beta$ se denominan coeficiente de formación de producto asociado y no asociado al crecimiento, respectivamente. Su determinación se realiza a partir de valores experimentales realizando un gráfico de $\dot{p} / x$ vs $\mu$ [44].

Originalmente, la expresión (2.35) fue desarrollada para describir la formación de ácido láctico en un cultivo de Lactobacillus debruickii. Actualmente, este modelo ha sido modificado para describir la formación de otras 
sustancias incluyendo ácido glucónico, succínico, lipasas, etc. [45, 46, 47]. También se han propuesto versiones modificadas para describir la formación de hidrógeno a partir de distintos tipos de microorganismos tales como los cultivos mixtos anaeróbicos y las bacterias fotosintéticas [48, 49]. En el Capítulo 3 se aprovecha la estructura de la expresión (2.35) y se presentan observadores que estiman la concentración de biomasa y la tasa de crecimiento. Como aplicación de los observadores, se presenta la estimación de las variables mencionadas en un cultivo por lote de una bacteria fotosintética productora de hidrógeno.

\subsubsection{Procesos multi-sustrato}

Existen biorreaciones de creciente interés industrial en las que el microorganismo crece consumiendo más de un sustrato en forma simultánea. En estos casos pueden distinguirse (al menos) dos sustratos los cuales pueden limitar el crecimiento simultáneamente. A este tipo de procesos se los llama en general cultivos multi-sustrato. Una forma de introducir la influencia de más de un sustrato en el modelo no estructurado (2.41) es a través de la tasa de crecimiento $\mu$. De esta manera, y en función de cómo sean consumidos los sustratos, pueden distinguirse diferentes expresiones para $\mu$. En particular, en el caso de dos sustratos limitantes del crecimiento, pueden distinguirse los siguientes modelos cinéticos [50]:

- Modelo aditivo

$$
\mu=\mu_{1}+\mu_{2}
$$

- Modelo multiplicativo

$$
\mu=\mu_{1}\left(s_{1}\right) \mu_{2}\left(s_{2}\right)
$$

- Modelo no interactivo

$$
\mu=\mu_{1} \text { or } \mu_{2}
$$

- Modelo combinado

$$
\mu=\mu_{1}\left(s_{1}\right)+\mu_{2}\left(s_{1}, s_{2}\right)
$$

En el modelo aditivo se asume que el crecimiento microbiano proviene del consumo de dos sustratos los cuales son utilizados en dos caminos metabólicos paralelos. En este caso, ambos sustratos pueden considerarse homólogos en el sentido de que proveen una función similar para el crecimiento celular (por ejemplo: dos fuentes de carbono y energía) [51]. Los términos $\mu_{i}$ de la expresión (2.36) pueden ser función del $s_{i}$ correspondiente o bien presentar términos cruzados para considerar el efecto de un sustrato en el camino metabólico del otro [52]. En el modelo multiplicativo, se asume que el crecimiento celular puede darse sólo en presencia de dos sustratos 
Tabla 2.1: Cultivos multi-sustrato modelizados con diferentes modelos de $\mu$.

\begin{tabular}{lccc}
\hline Microorganismo & Modelo & Sustratos & Ref. \\
\hline P. pastoris & $(2.36)$ & glicerol, metanol & {$[53]$} \\
P. putida CSV86 & $(2.36)$ & glucosa, alcohol bencílico & {$[54]$} \\
H. polymorpha DL-1 & $(2.36)$ & glicerol, metanol & {$[55]$} \\
Bacterias prod. de $H_{2}$ & $(2.36)$ & glucosa, peptona & {$[56]$} \\
P. aeruginosa & $(2.37)$ & glucosa, oxígeno & {$[57]$} \\
& $(2.37)$ & nitrógeno, oxígeno & {$[58]$} \\
P. putida & $(2.37)$ & fenol, oxígeno & {$[59]$} \\
C. necator DSM 545 & $(2.37)$ & glucosa, nitrógeno & {$[60]$} \\
Cyanothece 51142 & $(2.37)$ & glicerol, nitrato & {$[61]$} \\
S. cerevisiae & $(2.38)$ & glucosa, oxígeno & {$[62]$} \\
C. taiwanensis R186 & $(2.39)$ & fenol, glicerol & {$[63]$} \\
C. lusitaniae & $(2.39)$ & glucosa, celobiosa, xilosa & {$[64]$} \\
B. Pertussis & $(2.39)$ & glutamato, lactato & {$[65]$} \\
\hline
\end{tabular}

esenciales, es decir nutrientes que no cumplen la misma función fisiológica (sustratos heterólogos, también llamados nutrientes complementarios). Algunos ejemplos de este tipo de sustratos son glucosa (o cualquier otra fuente de carbono) y una fuente de nitrógeno o bien una fuente de carbono y una de oxígeno, etc. En el modelo no interactivo, la tasa de crecimiento es limitada por uno de los sustratos mientras el otro no tiene efecto en la tasa neta de crecimiento. Un caso particular del crecimiento no interactivo es el crecimiento diáuxico, que ocurre cuando el microorganismo consume uno de los sustratos y luego de agotada la fuente primaria de carbono y energía utiliza el segundo sustrato (en general entre las dos etapas de crecimiento aparece una fase de latencia). El modelo (2.39) puede verse como una combinación de los modelos aditivo y multiplicativo. Se han reportado situaciones en las cuales la presencia de un segundo sustrato incrementa el valor de $\mu$ con la condición de que la actividad de un segundo camino metabólico está sujeto a la presencia de los dos nutrientes. Esto se puede modelizar asumiendo que uno de los sustratos es consumido en dos caminos metabólicos mientras que el segundo sustrato es esencial para la segunda ruta metabólica.

La Tabla 2.1 presenta ejemplos de procesos biotecnológicos multi-sustrato con diferente comportamiento respecto de la tasa de crecimiento. Como puede verse, se han reportado modelos con diversos sustratos combinando fuentes de carbono, nitrógeno y oxígeno. En algunos casos se considera estos procesos para biorremediación de sustancias tóxicas como fenol y tolueno.

Nuevamente, a partir del balance de masas, puede encontrarse el modelo de estados que describe la dinámica de la biomasa y los dos sustratos en cuestión. En particular, para el caso de dos sustratos alimentados mediante dos entradas individuales (por ejemplo dos fuentes de carbono) en modo 
semi-continuo se tiene

$$
\begin{aligned}
\dot{x} & =\mu x-\frac{x}{v} F_{1}-\frac{x}{v} F_{2}, \\
\dot{s}_{1} & =-\sigma_{1} x+\frac{\left(S_{1 i n}-s_{1}\right)}{v} F_{1}-\frac{s_{1}}{v} F_{2}, \\
\dot{s}_{2} & =-\sigma_{2} x-\frac{s_{2}}{v} F_{1}+\frac{\left(S_{2 i n}-s_{2}\right)}{v} F_{2}, \\
\dot{v} & =F_{1}+F_{2},
\end{aligned}
$$

donde $\mu$ corresponde a una de las expresiones descriptas en (2.36)-(2.39) y $F_{i}$ es el flujo de entrada del sustrato $i$. Nótese que la expresión de la tasa de consumo del sustrato $\left(\sigma_{i}\right)$ dependerá de cómo se consuma ese nutriente, es decir del modelo de $\mu$.

En esta Tesis se tratan algunos problemas relevantes que pueden encuadrarse dentro de los cultivos multi-sustrato. En el Capítulo 5 se aborda el problema que resulta en los cultivos aeróbicos cuando uno de los sustratos esenciales para el crecimiento (oxígeno) alcanza valores extremadamente bajos. De acuerdo a la clasificación anterior, el caso en estudio corresponde a dos sustratos esenciales con cinética descripta por la ec. (2.37). En el Capítulo 6 se describen leyes de alimentación de dos sustratos homólogos para el caso de cinética aditiva (ec. (2.36)).

\subsubsection{Modelo de estados generalizado}

En forma general, a partir del balance de $n$ componentes, se obtiene el siguiente modelo de estados [34]

$$
\dot{\boldsymbol{\xi}}=\boldsymbol{K} \boldsymbol{r}(\boldsymbol{\xi}, t)-D(t) \boldsymbol{\xi}(t)+\boldsymbol{F}(t)-\boldsymbol{Q}(\boldsymbol{\xi}),
$$

donde $\boldsymbol{\xi}(t) \in \mathbb{R}_{+}^{n}$ es el vector de estados, $\boldsymbol{K}$ es una matriz de coeficientes de dimensión $(n \times m)$ y $\boldsymbol{r}(\cdot) \in \mathbb{R}^{m}$ el vector de las tasas volumétricas $\left(r_{x}, r_{s}, r_{p}, \ldots\right)$. El vector $\boldsymbol{F}(t) \in \mathbb{R}_{+}^{n}$ contiene el aporte de las $j$ entradas para cada estado, $D(t) \in \mathbb{R}_{+}$la tasa de dilución total y $\boldsymbol{Q}(\boldsymbol{\xi}) \in \mathbb{R}_{+}^{n}$ la tasa de intercambio con la fase gaseosa. Este modelo, que describe en forma compacta la evolución de $n$ sustancias en un proceso de $m$ reacciones, suele tomarse como modelo para el diseño de observadores y algoritmos de control [66, 67]. La expresión (2.41) será considerada en el Capítulo 4 para el desarrollo de un observador de $l$ tasas de reacción a partir de la medición de $l$ componentes del vector $\boldsymbol{\xi}(t)$.

\subsection{Importancia de la regulación del creci- miento}

Un objetivo de especial interés en el desarrollo de los procesos biotecnológicos es lograr que el microorganismo alcance la condición metabólica 
deseada [68]. Entre los parámetros involucrados en la definición del estado metabólico, la tasa de crecimiento juega un papel muy importante. De hecho, se ha reportado que diversos atributos fisiológicos de las células varían como una función de la tasa específica de crecimiento. Por ejemplo, el contenido de lípidos o la fracción de carbohidratos almacenados en las células de $S$. cerevisiae pueden vincularse con el valor de $\mu$. También se ha relacionado la tasa de crecimiento con la capacidad de las células para sintetizar proteínas, propiedad muy importante en la producción de proteínas recombinantes. Usualmente el rendimiento de producción de proteínas aumenta al decrecer el valor de $\mu$ [69]. Además, ciertos problemas industriales como la regulación de la cantidad de lipopolisacárido en vacunas y la optimización de la tasa específica de producción de proteínas recombinantes con Pichia pastoris han sido relacionados con el problema de regulación de $\mu$ $[70,71]$. De esta manera, la tasa de crecimiento tiene relación directa no sólo con el crecimiento y el rendimiento del proceso sino también con la síntesis de metabolitos, al tiempo que aparece involucrada en muchas reacciones intracelulares. Desde el punto de vista extracelular y al nivel de procesos productivos, la tasa de crecimiento tiene relevancia en [69]:

I. La maximización de la productividad: en procesos de producción de proteínas asociadas al crecimiento, o en cualquier situación donde la biomasa es el producto final, es de esperar que la operación más eficiente sea la de crecimiento exponencial a una tasa óptima.

II. La regulación del estado metabólico: tal como se describió previamente, varios atributos fisiológicos de las células varían como una función de la tasa de crecimiento.

III. La formación y calidad del producto: la capacidad de mantener las células en un estado metabólico particular relacionado con $\mu$, promoviendo un metabolismo particular para la producción de metabolitos secundarios, es de particular importancia para diferentes industrias. Además, se ha reportado que la regulación de $\mu$ es relevante para garantizar la reproducibilidad del proceso [72].

De los modos de operación típicos, los cultivos semi-continuos son a menudo seleccionados para la producción de metabolitos. En la próxima sección se describen estrategias de alimentación, incluyendo aquellas que permiten regular la tasa de crecimiento a un valor constante, es decir estrategias adecuadas para alcanzar el crecimiento exponencial a una tasa deseada. 


\subsection{Estrategias de alimentación para culti- vos semi-continuos}

\subsubsection{Descripción de las estrategias}

Con el objetivo de alimentar a la biomasa con los nutrientes necesarios, debe definirse el perfil temporal para el flujo de alimentación. Se han propuesto diferentes esquemas en función de las variables disponibles para realimentación y del objetivo de control planteado. Una posible clasificación de las leyes de alimentación para cultivos semi-continuos comprende (adaptado de [17]):

- Estrategias de alimentación precalculadas: incluye leyes de alimentación constantes, lineales o exponenciales calculadas a partir del modelo del proceso. Cuando la alimentación es constante se tiene como desventaja que la tasa de crecimiento decrece de manera continua. Una ley lineal permite reducir este efecto pero es la ley de alimentación exponencial la que permite regular la tasa de crecimiento en un valor constante $\mu=\mu_{r}$, siendo éste el objetivo de control en algunas aplicaciones.

- Leyes de alimentación basadas en regular una variable fisicoquímica: comprende estrategias que vinculan la alimentación de nutrientes con la medición de $\mathrm{pH}$ (técnica pH-stat) u oxígeno disuelto (técnica DOstat). En muchas de estas estrategias se aprovechan los cambios rápidos de la variable medida que ocurren al agotarse el sustrato principal. De esta manera, cuando el pH (o DO) se incrementa por encima del valor de referencia un controlador tipo ON/OFF actúa sobre la bomba de alimentación correspondiente [73, 74].

- Estrategias de alimentación basadas en monitoreo del sustrato o tasa de consumo del mismo: comprende leyes implementadas midiendo la concentración de nutriente o calculando en línea el consumo de nutrientes. Uno de los primeros aportes en esta línea fue el de Konstantinov et al. [75], donde se estimó el consumo de glucosa a partir de la medición de gases. La técnica denominada DO-stat balanceado agrega además un lazo de control para regular el oxígeno disuelto. En [76] se utilizó un analizador de glucosa en línea para regular la concentración de glucosa y mejorar la producción de una proteína.

- Leyes de alimentación con términos feedforward-feedback: comprende estrategias que combinan una parte precalculada, es decir un término obtenido del balance de masas y de los parámetros del modelo, y otra de corrección a partir de una variable medida o una estimación del parámetro a regular. Para el caso de regulación de tasa de crecimiento 


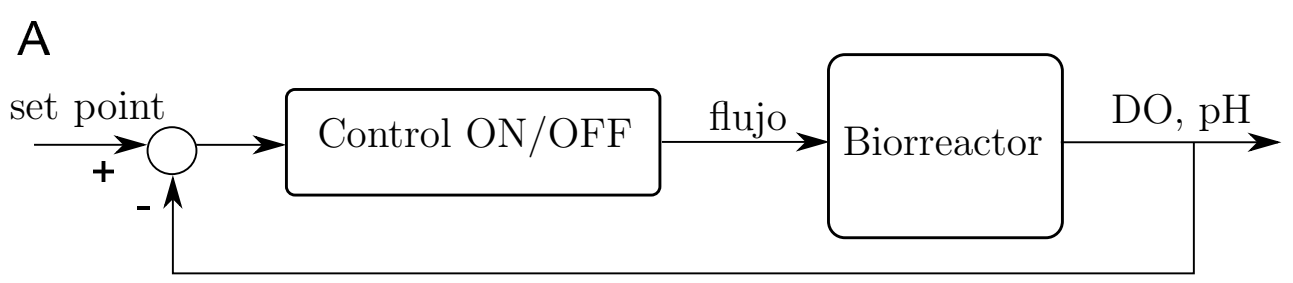

B

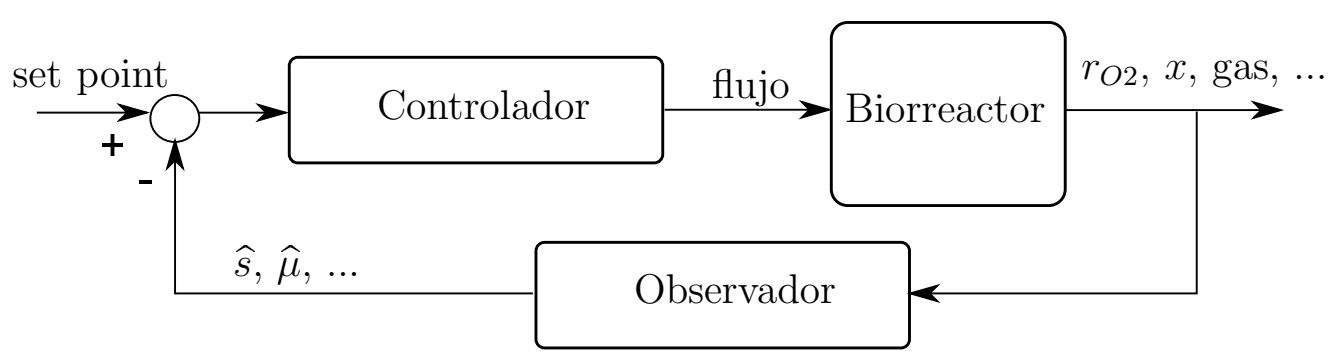

Figura 2.8: A) esquema basado en realimentación de variables fisicoquímicas. B) esquema basado en realimentación de variables estimadas [17].

se han propuesto algoritmos que realimentan una estimación de $\mu$ $[77,78]$.

- Leyes de alimentación basadas en el valor actual de biomasa: en caso de disponer de medición de biomasa puede implementarse una familia de controladores que utilizan este valor para determinar el flujo de alimentación. Cuando el objetivo es regular la tasa de crecimiento, puede aplicarse alimentación proporcional a la cantidad medida de biomasa [79]. Otra posibilidad es realimentar una estimación obtenida mediante un algoritmo adecuado. En este último caso, si existe dinámica adicional introducida por el observador, puede incrementar fuertemente la complejidad del análisis de estabilidad. Una posible solución a este problema es la combinación de leyes de alimentación proporcionales a la biomasa con observadores de convergencia en tiempo finito.

- Aplicación de lógica difusa: una ventaja de este enfoque es que permite incorporar un conjunto de reglas definidas en función de la experiencia obtenida en la operación del proceso. Por ejemplo, en [80] se utilizó para regular la producción de penicilina manipulando el flujo de alimentación. También se han diseñado leyes basadas en lógica difusa para otros procesos y para diagnóstico de fallas [17].

Con excepción de las leyes de alimentación precalculadas, las estrategias descriptas en la clasificación anterior emplean algún tipo de realimentación. Luego, pueden ser clasificadas en aquellas que realimentan variables medidas y aquellas que requieren observadores (Figura 2.8). En cualquier caso, el objetivo es alimentar de forma adecuada al biorreactor y evitar así la 
subalimentación y la sobrealimentación de nutrientes. Es importante destacar que si el cultivo es subalimentado se reduce el crecimiento, afectando la productividad, mientras que la sobrealimentación de nutrientes puede llevar a efectos inhibitorios y a la formación de subproductos indeseados. Como se explicó en la sección 2.1.2, el control del crecimiento microbiano mediante el flujo de alimentación se realiza a través de un sustrato en concentración limitante. Si bien en muchos casos se utiliza como sustrato limitante a la fuente de carbono y energía, se han reportado estudios donde se utiliza como limitante a la fuente de nitrógeno u otro compuesto (por ejemplo fosfato) ya sea para estudios fisiológicos o porque se obtienen mejoras en la producción específica de un metabolito [81].

\subsubsection{Leyes exponenciales para regulación del creci- miento}

La ley de alimentación con perfil exponencial es apropiada para regular el crecimiento a tasa constante. Esto se debe a que se necesita alimentación proporcional a la cantidad de biomasa la cual, con tasa de crecimiento constante, evoluciona en forma exponencial. En esta sección se describe con mayor detalle este tipo de flujos de alimentación, desde la ley precalculada de lazo abierto a aquellas que consideran realimentar la biomasa e incluso inyectar el error en la tasa de crecimiento.

\section{Alimentación exponencial de lazo abierto}

Esta estrategia de alimentación no utiliza ninguna variable medida para la manipulación del flujo de alimentación de nutrientes. En lugar de ello, el controlador manipula la entrada sólo por referencia a las ecuaciones del modelo, es decir se trata de una ley de alimentación precalculada. El flujo requerido se calcula a partir de las expresiones (2.20) y (2.29b)

$$
\begin{aligned}
(\dot{x v}) & =\mu x v \\
\dot{s} & =-\left(\frac{\mu}{y_{x / s}}+m_{s}\right) x+\left(S_{i n}-s\right) \frac{F_{i n}}{v},
\end{aligned}
$$

considerando que $F_{\text {out }}=0$. Luego, regular la tasa de crecimiento en $\mu(t)=$ $\mu_{r}$ implica

a. crecimiento exponencial de la biomasa, esto es $X(t)=x v=x_{0} v_{0} e^{\mu_{r} t}$.

b. nulidad de la derivada temporal, es decir $\dot{\mu}=\frac{\partial \mu}{\partial s} \frac{\partial s}{\partial t}=0$, con lo cual se requiere $\dot{s}=0$. En particular, la concentración de sustrato limitante debe alcanzar el valor $s(t)=s_{r}$ tal que $\mu\left(s_{r}\right)=\mu_{r}$. 
De esta manera, resolviendo $(2.42)$ con $\mu=\mu_{r}$ y reemplazando $\dot{s}=0$ en (2.43) se obtiene

$$
F_{\text {exp }}(t)=\frac{\frac{\mu_{r}}{y_{x / s}}+m_{s}}{S_{i n}-s_{r}} x_{0} v_{0} e^{\mu_{r} t} .
$$

En esta expresión se asume un crecimiento celular exponencial. Si el crecimiento real resulta menor al valor asumido por el perfil predeterminado puede ocurrir el fenómeno de sobrealimentación de nutrientes. Por otro lado, la expresión (2.44) es muy simple y por consiguiente extensamente aplicada, incluso en cultivos de alta densidad celular $[82,83]$.

\section{Alimentación exponencial con correción PI}

La estrategia exponencial precalculada (2.44) no considera diversas fuentes de incertidumbre que pueden causar que la regulación no sea lo suficientemente precisa. Se han realizado aportes en los que se consideran términos adicionales con efecto proporcional e integral. En [77], el término correctivo se agrega en forma aditiva a la expresión (2.44), es decir que el flujo total aplicado es

$$
F(t)=F_{e x p}(t)+k_{c}\left(e+\frac{1}{T_{c}} \int e\right),
$$

donde $e$ es el error de regulación de $\mu$. Una desventaja de esta estrategia es que, debido a la evolución exponencial de la parte precalculada, los parámetros del término de realimentación deben ser reajustados cada cierta cantidad de tiempo. Una variante en la que el término de corrección es aplicado en el argumento de la parte exponencial

$$
F(t)=F_{o} \exp \left(\left(\mu_{r}+k_{p} e+k_{i} \int e\right) t\right)
$$

se presenta en [78]. Como ya se mencionó, a estas expresiones se las llama leyes de alimentación feedforward-feedback por la combinación de un término precalculado con uno realimentado.

\section{Alimentación proporcional a la biomasa}

Otro tipo de leyes de alimentación son aquellas que proveen medio de cultivo en forma proporcional a la cantidad de biomasa actual. Esto tiene la ventaja de requerir una acción de control menor cuando el crecimiento de la biomasa no sigue el perfil deseado, ya que no hay un término precalculado con variación exponencial fija, y así es factible evitar la sobrealimentación de sustrato. En caso de disponer de medición de biomasa y volumen, pueden aplicarse expresiones de la forma

$$
F(t)=\lambda x v
$$


donde $\lambda$ es un coeficiente de proporcionalidad que puede ser constante, variante en el tiempo e incluso contener un término correctivo para aumentar la robustez respecto de los parámetros del modelo. Esta ley de alimentación aparece por primera vez en [84] en el crecimiento exponencial de $E$. coli utilizando mediciones de volumen y de turbiedad en línea. En [79] se demostró la estabilidad del proceso semi-continuo alimentado con el flujo (2.47) utilizando conceptos de estabilidad parcial [85] y también se extendieron los resultados a casos donde existe formación de producto no asociada al crecimiento. Nuevamente, para obtener $\dot{s}=0$ con $\mu=\mu_{r}$ la ganancia que corresponde en la expresión (2.47) es

$$
\lambda_{r}=\frac{\frac{\mu_{r}}{y_{x / s}}+m_{s}}{S_{i n}-s_{r}} .
$$

Para tasas de crecimiento monótonas, esta ley de alimentación provee convergencia desde cualquier condición inicial de sustrato. En caso de cinéticas tipo Haldane, puede ocurrir convergencia a valores de sustrato indeseados. Una posible solución a este problema consiste en acotar el valor de flujo máximo, de manera que el único punto de equilibrio alcanzable sea el deseado. Si bien la estrategia (2.47)-(2.48) provee una alimentación proporcional a la biomasa, es una ley de lazo abierto respecto a $\mu$. Luego, pueden incorporarse términos de realimentación con el objetivo de mejorar la performance (velocidad de convergencia, robustez ante los parámetros, etc.). Una ley de alimentación basada en (2.47), con realimentación en $\lambda$ fue propuesta en [86]

$$
\lambda(\cdot)=f\left(\lambda_{r}(1+k e), \lambda^{*}\right),
$$

donde $f(\cdot, \cdot)$ es una función utilizada para acotar el valor de $\lambda, k$ es una ganancia de proporcionalidad y $\lambda^{*}$ la cota requerida. Esta estrategia permite tratar cinéticas no monótonas como el modelo de Haldane, evitando la evolución de la concentración de sustrato a la zona indeseada. Posteriormente, se desarrollaron algoritmos con acciones proporcional e integral explotando conceptos de invariancia, los cuales son capaces de eliminar errores de estado estacionario en la regulación de $\mu$ ante errores en los parámetros de (2.48) [87].

En el Capítulo 5, se considera un problema que involucra las leyes de alimentación (2.44) y (2.47) cuando la regulación se aplica a cultivos aeróbicos. También se realizan propuestas en el diseño de estrategias de alimentación para cultivos multi-sustrato, en particular se trata el problema de alimentar dos fuentes de carbono. En [88] se presenta una extensión de la expresión (2.47)-(2.48) para procesos multi-sustrato con cinética aditiva (sección 2.1.6). En el Capítulo 6, ese resultado se extiende en dos direcciones: i) agregando un término de realimentación proporcional no-lineal y de esta forma mejorando la convergencia y robustez y ii) considerando el caso en el que la cinética es aditiva pero que además existe un efecto de inhibición competitiva entre los sustratos. 
Si bien las leyes de alimentación exponenciales con un término de correción proveen un mejor desempeño en cuanto al objetivo de regulación, su implementación requiere conocer la tasa de crecimiento, la cual es una variable no medible que debe ser estimada a partir de las mediciones disponibles. La siguiente sección describe brevemente el estado del arte en la estimación de tasas de formación y consumo de sustancias, entre ellas la tasa de crecimiento. Se presta especial atención a los algoritmos por modo deslizante por ser una técnica atractiva para el diseño de algoritmos con interesantes propiedades de robustez.

\subsection{Observación y Estimación de variables}

La estimación en línea de variables es una cuestión relevante para el control y monitoreo de procesos biotecnológicos. Básicamente, las variables de interés son de dos tipos: concentraciones de sustancias (biomasa, sustratos, metabolitos, etc.) o tasas de reacción (formación o consumo de sustancias) [89]. En función de las salidas disponibles se pueden diseñar observadores capaces de obtener una estimación de aquellas variables no medibles, donde la robustez a incertidumbres típicas en el modelo del proceso es una característica deseada. En particular, las tasas de reacción, ya sean de formación o consumo de las diferentes sustancias $\left(q_{s}, q_{p}\right.$, etc.), brindan información valiosa acerca de lo que está sucediendo en el medio de cultivo. El conocimiento de todas estas señales tiene dos aplicaciones relevantes. En primer lugar, las velocidades de reacción pueden ser utilizadas en lazos cerrados de control para mejorar la productividad y reproducibilidad del proceso. En segundo lugar, la disponibilidad de información en línea es muy útil para el control de calidad, seguimiento del proceso y detección de problemas [90]. De todas ellas, la tasa de crecimiento microbiana es de las más importantes ya que, como se describió en la sección 2.2, no sólo se relaciona con el crecimiento de la biomasa y el consumo de los sustratos sino que también tiene influencia en la formación de productos y en la calidad de los metabolitos producidos.

Desafortunadamente, las tasas (específicas) de reacción no están disponibles fácilmente, ya que son funciones no lineales sujetas a incertidumbre y que dependen no sólo de los estados (concentraciones de sustancias) sino también de las condiciones de operación (temperatura, pH, etc.) En este contexto, el uso de observadores (también llamados sensores de software cuando se integran junto con los sensores de hardware [91]) para obtener una estimación en línea de las tasas específicas evita el problema de la identificación del modelo, al tiempo que agrega mayor cantidad de información para los esquemas de control de lazo cerrado y para realizar estudios de los cultivos [66].

Debido a la importancia de la tasa de crecimiento como variable indicadora de la actividad microbiana, su estimación ha sido investigada extensi- 
vamente. Uno de los primeros aportes fue la propuesta de Bastin [92], donde se presentaron observadores que no dependen del modelo analítico de $\mu \mathrm{y}$ son de esta manera robustos respecto a una fuente de incertidumbre típica del modelo. Se tiene así una familia de observadores asintóticos con cierta robustez que pueden ser aplicados para estimar otras tasas de reacción [34]. Para la estimación se requiere la medición de al menos tantas variables de estado como el número de tasas de reacción y por lo general la velocidad de convergencia del observador no se puede asignar (esto último resulta dependiente de la tasa de dilución). Por ejemplo, en [93] se presentó la estimación de múltiples tasas de reacción aplicada a un proceso de producción de levadura de panadería, donde se estima la tasa de crecimiento en cada una de las vías metabólicas utilizando un observador asintótico de la concentración de biomasa. Los algoritmos basados en el filtro de Kalman extendido [94] pueden considerar cierta incertidumbre en los parámetros del modelo y cierto nivel de ruido en la medición. Sin embargo, su aplicación depende fuertemente de la versión linealizada del modelo. Otra familia de observadores, los denominados de alta ganancia [95, 66, 96], pueden ser aplicados en las estimación de múltiples tasas. Un problema de estos observadores, y de otros algoritmos continuos, es que no pueden determinar si no hay error en la estimación. Si bien ese efecto puede reducirse aumentando las ganancias, se aumenta también la sensibilidad al ruido de medición. Dentro de los observadores que incluyen términos discontinuos se destacan los basados en modo deslizante $[97,98,99,100,101]$, los cuales serán descriptos en la próxima sección. Otro enfoque de estimación de tasa de crecimiento, que no se basa en el modelo del proceso pero requiere conjuntos de datos de entrenamiento, se basa en redes neuronales artificiales [102].

\subsubsection{Observadores por modo deslizante}

Entre los diferentes enfoques para el diseño de observadores, tanto de concentraciones como de tasas de reacción, los algoritmos basados en modo deslizante (MD) presentan características distintivas. En estos algoritmos se utiliza una acción discontinua para lograr que las trayectorias del estado alcancen la denominada superficie deslizante y se "deslicen" sobre ella a partir de un determinado instante de tiempo. Esa superficie se define como función de las variables y parámetros accesibles, de manera que el error de estimación converge a cero con una dinámica deseada llamada dinámica de deslizamiento. En los algoritmos de MD de primer orden, la primera derivada temporal de la función de deslizamiento es discontinua, lo que conduce al fenómeno de chattering en alguna de las estimaciones. Este efecto puede degradar el rendimiento del observador [103]. En los algoritmos de MD de segundo orden, la señal discontinua aparece en la segunda derivada con respecto al tiempo de la función de deslizamiento, brindando así estimaciones más suaves mientras que preservan las propiedades de convergencia. 
En forma general se construye una función de los estados $S(\boldsymbol{x})$ y la superficie deslizante se define como

$$
S(\boldsymbol{x})=0,
$$

donde $\boldsymbol{x} \in \mathbb{R}^{n}$ es el estado del sistema. Para el diseño de observadores, $S(\boldsymbol{x})$ suele definirse como combinación lineal de los estados, es decir que las superficies de conmutación suelen ser hiper-planos dentro del espacio de estados.

El objetivo de aplicar la acción discontinua es alcanzar en tiempo finito la superficie definida en (2.50) y mantener las trayectorias del sistema evolucionando sobre la misma. Luego, en función de cómo se relacionen las variables a estimar con la evolución del sistema restringido a (2.50) podrán obtenerse estimaciones de las variables de interés con diferentes características. En todos los casos se obtienen observadores con dinámica reducida, lo cual es una característica deseada. En general, la dinámica del error de estimación puede exhibir diferentes tipos de convergencia, por ejemplo convergencia asintótica, o de tiempo finito. En el último caso, el observador no agrega dinámica y las estimaciones son exactas (al margen del ruido de medición). Esto presenta una gran ventaja sobre otras estrategias como los observadores de alta ganancia, los cuales no pueden estimar en forma exacta las tasas de reacción.

A continuación se describen algoritmos de primer y segundo orden con el objetivo de ilustrar la aplicación de estos observadores a la estimación de variables. Para esto se considera el siguiente problema: dada una señal $x(t)$, estimar su derivada

$$
\dot{x}(t)=r(t) .
$$

Este problema se resume en la construcción de un algoritmo capaz de estimar la derivada temporal de la señal $x(t)$, es decir un algoritmo derivador. Para este problema, una hipótesis razonable es requerir que la señal $r(t)$ o sus derivadas temporales sean acotadas. Este tipo de hipótesis no impone una fuerte restricción para el desarrollo de observadores aplicados en procesos biotecnológicos ya que, teniendo en cuenta restricciones fisicas, las variables de interés pueden ser acotadas. En general, sea $\hat{x}(t)$ la variable del observador que estima a $x(t)$, el error de estimación puede definirse como

$$
\widetilde{x}(t) \triangleq x(t)-\widehat{x}(t)
$$

Luego, para el diseño de los derivadores puede definirse la función de conmutación $S(\boldsymbol{x})=\tilde{x}$.

\section{Derivadores de primer y segundo orden}

Suponiéndose que la señal $r(t)$ es acotada y que se conoce una cota $\bar{r}$ tal que $|r(t)|<\bar{r}$, un algoritmo derivador por MD de primer orden está des- 
cripto por las expresiones

$$
\begin{aligned}
& \dot{\hat{x}}(t)=\widehat{r}(t), \\
& \widehat{r}(t)=a \operatorname{sign}(\widetilde{x})+b \widetilde{x}
\end{aligned}
$$

donde los parámetros $a, b$ se eligen tal que $a>\bar{r}$ y $b>0$ [103]. Nótese que el algoritmo (2.53) consiste de una copia del sistema (ec. (2.51)) y que $\widehat{r}$ posee un término de corrección discontinuo dado por la función signo $\operatorname{sign}(\cdot)$. El objetivo de la discontinuidad es aportar el signo correcto a la derivada de $\widehat{x}$. Este algoritmo converge en tiempo finito, es decir que existe un $T_{S M}<\infty$ tal que, a partir de una condición inicial $\widehat{x}(0) \neq x(0)$, se alcanza $\widetilde{x}(t) \equiv 0$ en $t=T_{S M}$. Luego si la acción de control aplicada es adecuada, el sistema evoluciona sobre esa superficie para todo tiempo futuro. Una cota conservativa para el tiempo de convergencia del algoritmo (2.53) está dada por

$$
T_{S M}<\frac{1}{b} \log \left(1+\frac{b|\widetilde{x}(0)|}{a-\bar{r}}\right) .
$$

Entre las ventajas de este algoritmo puede destacarse que

a) la convergencia de $\hat{r}$ ocurre en tiempo finito con lo que se obtiene diferenciación exacta de la señal $x(t)$.

b) se tiene robustez respecto de $r(t)$, ya que sólo se requiere conocer una cota superior.

Por otro lado, la estimación obtenida es una función discontinua. De hecho, la señal $\hat{r}(t)$ puede interpretarse como la suma de dos señales: una señal continua de baja frecuencia que equivale a $r(t)$ y otra de conmutación a alta frecuencia (idealmente frecuencia infinita). Una forma de obtener una estimación continua (pero no exacta) consiste en aplicar un filtro a $\widehat{r}(t)$. Luego, la señal filtrada es una estimación continua de $r(t)$.

Una mejora respecto del algoritmo anterior se logra con algoritmos de modo deslizante de segundo orden. Nuevamente se considera la expresión (2.51) y el problema de estimar $r(t)$ a partir de la medición de $x(t)$. El siguiente algoritmo, presentado por A. Levant en [104], permite resolver el problema para señales que satisfagan $|\dot{r}(t)| \leqslant L$, con $L$ una constante conocida:

$$
\begin{aligned}
\dot{\widehat{x}}(t) & =\widehat{r}+a_{1}|\widetilde{x}|^{\frac{1}{2}} \operatorname{sign}(\widetilde{x}), \\
\dot{\widehat{r}}(t) & =a_{2} \operatorname{sign}(\widetilde{x}) .
\end{aligned}
$$

Este algoritmo converge a $x-\hat{x}=r-\hat{r}=0$ en tiempo finito para parámetros adecuados $a_{1}, a_{2}$. Inicialmente, la demostración de convergencia se realizaba analizando las trayectorias obtenidas para el peor caso en el plano $(\widetilde{x}, \dot{\widetilde{x}})$. En los últimos años se lograron demostraciones de convergencia utilizando funciones de Lyapunov [99, 105, 106], lo cual le dió más versatilidad y la 

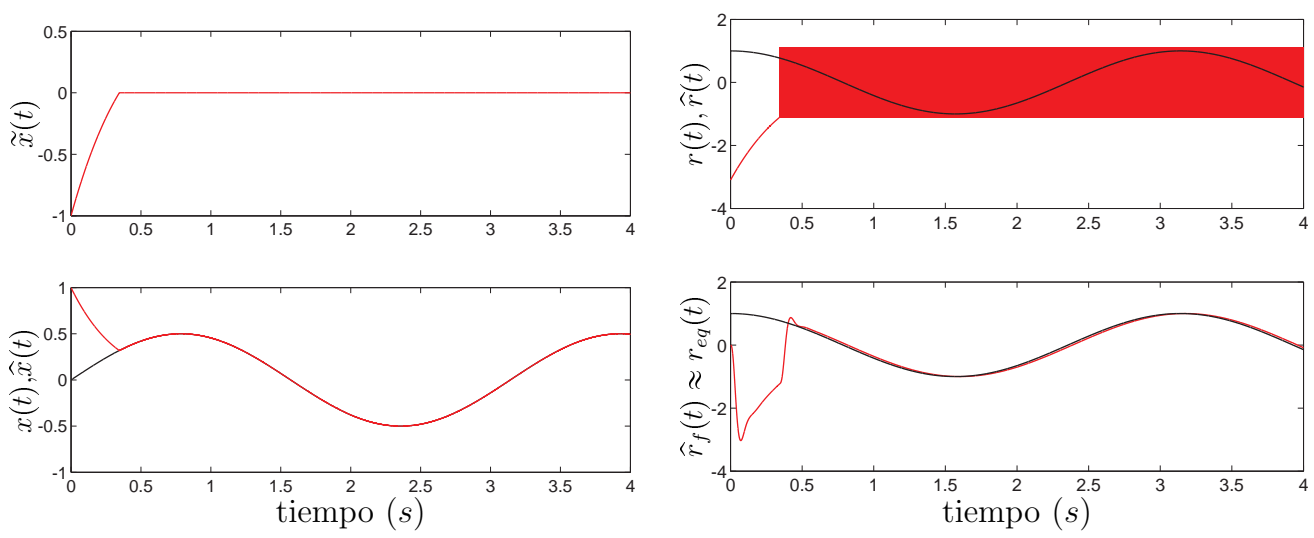

Figura 2.9: Resultados obtenidos con el algoritmo (2.53): señales a estimar (línea negra), señales del observador (línea roja). En el gráfico superior derecho se observa la señal discontinua (2.53b) y debajo la señal filtrada.

posibilidad de realizar extensiones para rechazar diferentes tipos de perturbaciones. En el Capítulo 3 se utilizarán estos métodos para seleccionar las ganancias de un observador basado en la medición de producto. Las principales ventajas del algoritmo de segundo orden incluyen estimación continua de la señal de interés y robustez, dado que sólo se requiere conocer la cota superior de la segunda derivada de la señal a diferenciar. Además, la estimación obtenida de $r(t)$ es la mejor que se puede obtener ante niveles de ruido acotados y bajo discretización del algoritmo cuando sólo se dispone de $L$ [104].

Ejemplo numérico Las Figuras 2.9 y 2.10 presentan los resultados obtenidos al aplicar los observadores (2.53) y (2.55) para estimar la derivada de la señal $x(t)=\sin (t)$. Dado que el objetivo de este ejemplo es ilustrar el concepto de ambos observadores, los parámetros de los algoritmos se seleccionaron de manera de tener tiempos de convergencia similares. En la parte izquierda de las figuras puede apreciarse la distancia a la superficie de modo deslizante $\widetilde{x}=0$ y la comparación entre la señal de entrada y la variable correspondiente en el derivador. Puede apreciarse que se alcanza convergencia en $T_{S M} \approx 0,4 \mathrm{seg}$. En la parte derecha de la Figura 2.9 se observa la señal discontinua generada por el algoritmo de primer orden, y una aproximación continua de $r(t)$ obtenida mediante filtrado. Por otro lado, el observador de segundo provee una estimación continua, tal como se aprecia en la parte derecha de la Figura 2.10.

Estos derivadores son la idea básica sobre la cual se basan los observadores desarrollados para diversas aplicaciones, entre las que se encuentra la estimación de tasas de reacción en procesos biotecnológicos. 

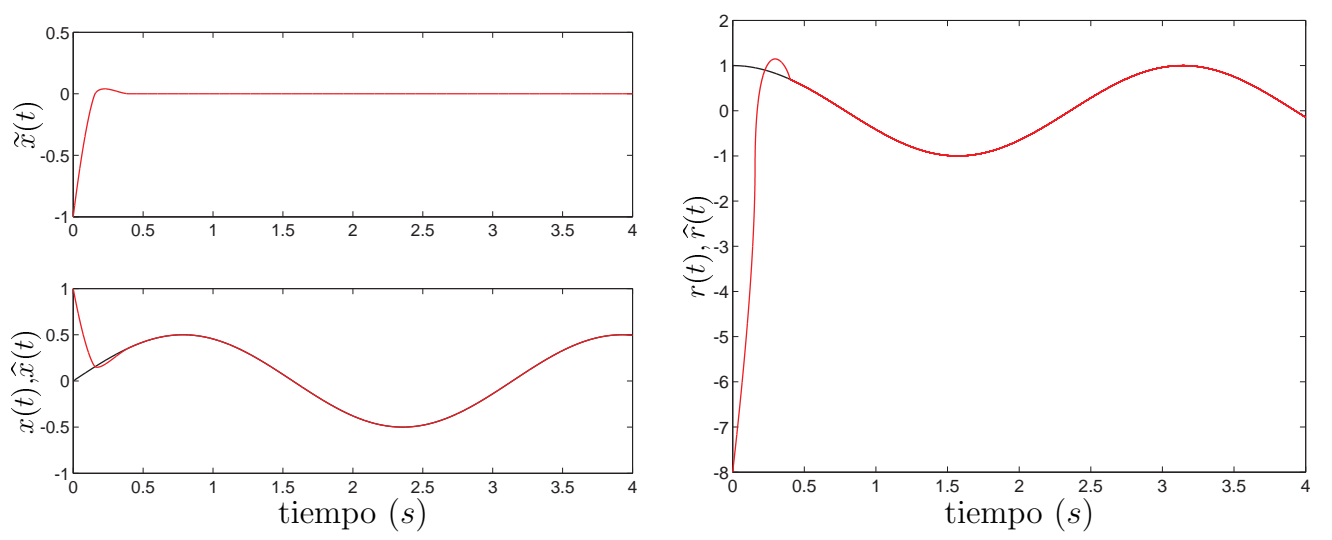

Figura 2.10: Resultados obtenidos con el algoritmo (2.55): señales a estimar (línea negra), señales del observador (línea roja). A la derecha se observa la señal continua definida en (2.55b).

\subsubsection{Observadores por modo deslizante aplicados en bioprocesos}

En el problema de interés, las señales desconocidas aparecen en la derivada temporal de los estados. En [97] se presentaron observadores por modo deslizante de primer orden para estimar la tasa de crecimiento específica y la concentración de sustrato, a partir de la medición de la biomasa. Si bien la estimación exacta de $\mu$ era una señal discontinua de alta frecuencia, esta señal fue útil para construir un observador de sustrato. Las estimaciones resultantes fueron robustas bajo incertidumbres típicas del modelo con una dinámica de convergencia de primer orden. En [98], se utilizaron mediciones de sustrato para estimar la tasa de consumo del mismo. La dinámica del error resultó exponencialmente estable, mientras que ciertas incertidumbres del modelo y perturbaciones son rechazadas. En [107], se utilizó un algoritmo de primer orden para estimar biomasa a partir de la medición de sustrato en un proceso de tratamiento de residuos. También se han presentado implementaciones de observadores por MD en tiempo discreto [108]. Dentro de los algoritmos de segundo orden, en [100] se presentó una estimación de $\mu$ con convergencia en tiempo finito a partir de la medición de biomasa. Más precisamente, la propuesta es una versión modificada del algoritmo (2.55), donde se incorpora la función multiplicativa dada por la concentración de biomasa en la estructura del observador. Luego, en [109], se desarrollaron nuevos algoritmos de segundo orden, con una demostración de estabilidad diferente, los cuales fueron aplicados en cultivos por lotes, semi-continuo y continuo. Otras generalizaciones al algoritmo (2.55) pueden encontrarse en $[99,106]$, donde las modificaciones apuntan a rechazar diferentes tipos de perturbaciones. Recientemente, se han propuesto estrategias que admiten, entre varias generalizaciones, ganancias y cotas de las perturbaciones ambas 
variantes en el tiempo, lo que permite una mayor robustez del observador [101]. En otros casos, es de utilidad estimar una combinación de las tasas de reacción. En [110], se presenta la utilización de un banco de observadores por MD de segundo orden para estimar la diferencia de dos tasas de reacción. Esa estimación es útil en la implementación de estrategias de seguimiento de un punto óptimo de crecimiento en un cultivo de $E$. coli.

Los aportes de esta Tesis en la estimación de variables para monitoreo y control se centran en dos partes. En el Capítulo 3 se obtienen estimaciones de la concentración de biomasa y $\mu$ en un proceso con cinética dada por la expresión (2.35), a partir de la medición de la concentración de producto. La dinámica reducida del observador logra que el error de estimación presente convergencia exponencial de primer orden. En el Capítulo 4 se presenta un algoritmo capaz de estimar múltiples tasas de formación / consumo de sustancias con convergencia en tiempo finito, donde la mayor dificultad la introducen las funciones variantes en el tiempo que multiplican a las tasas de reacción a estimar.

\subsection{Resumen del capítulo}

En la descripción macroscópica de los procesos biotecnológicos, la biorreacción que representa el crecimiento celular y la formación de subproductos se modeliza como una sola reacción. A partir de los balances correspondientes de masa y energía pueden encontrarse los rendimientos $Y_{a / b}$ y las tasas volumétricas de consumo y producción de cada sustancia. Esto a su vez permite definir las correspondientes tasas específicas. Una vez definidas las tasas de reacción es posible realizar un balance de masas para describir la evolución de las principales variables como son la concentración de biomasa, sustratos, productos, oxígeno, entre otras. El modelo hallado puede aplicarse a los tres modos básicos de operación de un biorreactor agitado para encontrar el modelo no lineal que describe la dinámica del proceso. Los productos se generan como respuesta del microorganismo al medio al que se encuentra sometido. La tasa específica de formación de productos puede exhibir tres modelos matemáticos siendo el más general el modelo de Luedeking y Piret. El balance de masas realizado en cultivos con un sustrato limitante puede extenderse a cultivos multi-sustrato, donde la mayor complejidad se produce por la interacción que ejercen los sustratos a través de la tasa de crecimiento.

Dentro de los parámetros que definen el estado metabólico del microorganismo, la tasa de crecimiento es uno de los más importantes. En los cultivos semi-continuos, puede lograrse regulación del crecimiento a una tasa constante mediante el diseño de la ley de alimentación. Con el objetivo de alcanzar la tasa de crecimiento deseada se tienen diferentes versiones de la estrategia de alimentación exponencial: desde la ley precalculada hasta propuestas más robustas que realimentan el error de regulación, incluyen- 
do términos proporcionales e integrales. Desde el punto de vista práctico, la implementación de estas últimas requiere estimaciones de $\mu$, las cuales deben obtenerse a partir de las mediciones disponibles. Para esto, se dispone de diferentes estrategias de estimación de variables, entre las que se destacan los observadores continuos como los asintóticos y de alta ganancia, y observadores con términos discontinuos como los de modo deslizante. En la última sección se puso especial atención a estos últimos algoritmos, los cuales encuentran aplicación en los procesos biotecnológicos debido a las interesantes características de robustez y convergencia que se pueden alcanzar. Prueba de ello es la gran variedad de contribuciones publicadas, en las que se trata de obtener estimaciones cada vez más robustas a diferentes incertidumbres y perturbaciones del proceso. 


\section{Capítulo 3}

\section{Estimación de tasa de crecimiento basada en medición de producto}

En el capítulo anterior fueron descriptos modelos en los cuales la formación de productos puede resultar asociada al crecimiento microbiano, no asociada al crecimiento o, en un caso más general, resultar una combinación de ambos tipos. Si bien muchos productos son acumulados intracelularmente, otros son excretados al medio de cultivo. En este capítulo se presenta la estimación de variables a partir de la sola medición del producto generado. La hipótesis de trabajo es que el proceso obedece a una cinética tipo Luedeking-Piret, es decir que la tasa de formación del metabolito se relaciona no sólo con la concentración de biomasa sino también con su tasa de crecimiento. En particular, se presentan observadores de la concentración de biomasa y de la tasa de crecimiento microbiana basados en medición del producto. Como aplicación de los resultados se presenta un proceso de producción de hidrógeno biológico (biohidrógeno) el cual tiene creciente interés por representar una fuente alternativa de producción de este combustible.

\subsection{Descripción del proceso}

A partir del análisis realizado en la sección 2.1, un proceso por lote con cinética de formación de producto dada por el modelo de Luedeking-Piret (ec. (2.35)) puede describirse por las siguientes expresiones

$$
\begin{aligned}
& \dot{x}=r_{x}=\mu(s) x, \\
& \dot{s}=-\frac{1}{y_{x / s}} \mu(s) x, \\
& \dot{p}=\alpha \mu(s) x+\beta x .
\end{aligned}
$$

Nótese que en caso de un cultivo semi-continuo, deben considerarse los términos de dilución correspondientes. La ley de formación de producto 
asociada tanto al crecimiento como a la concentración de biomasa es muy útil para describir la formación de diferentes metabolitos y ha sido extensamente aplicada en el modelizado de diferentes procesos.

\subsection{Estimación de biomasa y tasa de creci- miento}

Se definen $(\hat{p}, \hat{x}, \hat{\mu})$ a las estimaciones de $(p, x, \mu)$, respectivamente, $\mathrm{y}$ como

$$
\begin{aligned}
& \tilde{p}=p-\hat{p}, \\
& \widetilde{x}=x-\widehat{x}, \\
& \tilde{\mu}=\mu-\widehat{\mu},
\end{aligned}
$$

a los respectivos errores de estimación. Dado que sólo se mide $p(t)$, la única señal de error disponible para la construcción del observador es $\widetilde{p}$. Por esta razón se considera

$$
S(\cdot)=\tilde{p}
$$

como función de conmutación. Nótese además que si se obtiene $\widetilde{p}(t)=0$, entonces $\hat{p}(t)$ copiará la evolución temporal de la variable $p(t)$. A continuación se presenta el diseño de observadores por modo deslizante que utilizan la expresión (3.7) para obtener estimaciones de $x$ y $\mu$.

\subsubsection{Algoritmo por Modo Deslizante de primer or- den}

Dado el sistema descripto por las expresiones (3.1)-(3.3), se propone el siguiente algoritmo por modo deslizante de primer orden:

$$
\begin{aligned}
\dot{\hat{x}} & =\widehat{\mu} \widehat{x}, \\
\dot{\hat{p}} & =\alpha \hat{\mu} \widehat{x}+\beta \widehat{x}, \\
\widehat{\mu} & =\frac{M}{\widehat{x}} \operatorname{sign}(\widetilde{p}),
\end{aligned}
$$

con condiciones iniciales $\widehat{x}(0)=\widehat{x}_{0}>0, \hat{p}(0)=p(0)$. Nótese que las expresiones (3.8a)-(3.8b) son una copia de las expresiones del modelo (3.1) y (3.3), respectivamente, mientras que el término discontinuo se propone en la estimación de $r_{x}$.

Análisis Tomando la derivada temporal de $\tilde{p}$ se obtiene la siguiente expresión

$$
\dot{\widetilde{p}}=\alpha \mu x+\beta \widetilde{x}-\alpha M \operatorname{sign}(\widetilde{p}) \text {. }
$$


La denominada condición de alcanzabilidad (reachability condition) [111] es:

$$
\tilde{p} \dot{\tilde{p}}<0
$$

En este caso resulta

$$
\begin{aligned}
\tilde{p} \tilde{\tilde{p}} & =\widetilde{p}(\alpha \mu x+\beta \widetilde{x})-\alpha M|\widetilde{p}| \\
& =\alpha|\widetilde{p}|\left[\left(\mu x+\frac{\beta}{\alpha} \tilde{x}\right) \operatorname{sign}(\tilde{p})-M\right],
\end{aligned}
$$

donde se utilizó la identidad

$$
\tilde{p}=|\widetilde{p}| \operatorname{sign}(\tilde{p})
$$

Luego puede verse fácilmente que la condición (3.10) se cumple si

$$
\left|\mu x+\frac{\beta}{\alpha} \widetilde{x}\right|<M
$$

La expresión del lado izquierdo puede acotarse utilizando la desigualdad triangular

$$
\left|\mu x+\frac{\beta}{\alpha} \tilde{x}\right| \leqslant|\mu x|+\frac{\beta}{\alpha}|\widetilde{x}|<\overline{r_{x}}+\frac{\beta}{\alpha}|\overline{\widetilde{x}}|
$$

donde $\overline{r_{x}}$ y $|\overline{\widetilde{x}}|$ son cotas para la derivada de la concentración de biomasa y para el error de estimación, respectivamente. Luego si se satisface

$$
M>\overline{r_{x}}+\frac{\beta}{\alpha}|\overline{\widetilde{x}}|,
$$

se cumple la condición (3.10). Cuando (3.10) es válida en el entorno de la superficie de conmutación, se garantiza la existencia de modo deslizante. Sin embargo, no es suficiente para probar la convergencia a la superficie en tiempo finito desde una condición inicial alejada. De hecho, la expresión (3.10) implica que la derivada temporal de la función definida positiva $V(\widetilde{p})=\widetilde{p}^{2} / 2$ es negativa lo que prueba la convergencia asintótica a la superficie de modo deslizante.

La denominada condición de alcanzabilidad $\eta$ ( $\eta$-reachability condition) [111] es

$$
\tilde{p} \dot{\widetilde{p}}<-\eta|\widetilde{p}|,
$$

con $\eta>0$ una constante de diseño. Utilizando nuevamente la identidad (3.12), la expresión anterior puede escribirse en la forma

$$
\begin{array}{ll}
\dot{\tilde{p}}<-\eta & \text { si } \tilde{p}>0, \\
\dot{\tilde{p}}>\eta & \text { si } \tilde{p}<0 .
\end{array}
$$


Luego, por integración de la expresión anterior se tiene que el tiempo requerido para alcanzar la superficie desde una condición inicial de módulo $|\widetilde{p}(0)|$ resulta acotado por

$$
T_{S M}<\frac{|\widetilde{p}(0)|}{\eta}
$$

A partir de (3.16) y las cotas definidas previamente se tiene

$$
\tilde{p} \dot{\tilde{p}}+\eta|\widetilde{p}|<\alpha|\widetilde{p}|\left[\overline{r_{x}}+\frac{\beta}{\alpha} \overline{\widetilde{x}}+\frac{\eta}{\alpha}-M\right] .
$$

Nuevamente, utilizando cotas razonables en $\overline{r_{x}}$ y en el error de estimación de biomasa puede obtenerse un valor de $M$. En particular, se satisface (3.16) si

$$
M>\overline{r_{x}}+\frac{\beta}{\alpha} \overline{\widetilde{x}}+\frac{\eta}{\alpha} .
$$

El análisis realizado pone en evidencia que es posible obtener valores finitos en el parámetro del observador tal que se cumpla una condición de convergencia en tiempo finito. Al igual que en el análisis realizado para el derivador de primer orden (2.53), se requiere una cota sobre la tasa de cambio de la variable a estimar (en este caso la concentración de biomasa) y una cota sobre el error de estimación. Este tipo de hipótesis sobre la señal a estimar o alguna de sus derivadas es común en el diseño de observadores. Una cota para el crecimiento de la biomasa al inicio del proceso puede obtenerse a partir de información previa, o estimarse como $\bar{r}_{x}=\mu_{\max } x_{m}$ con $x_{m}$ un valor de biomasa superior al esperado para las primeras horas de cultivo.

Una vez alcanzada la superficie, se establece un régimen deslizante donde se cumple la denominada condición de invariancia [103]

$$
\begin{aligned}
& \tilde{p}=0, \\
& \dot{\widetilde{p}}=0 .
\end{aligned}
$$

Por otro lado, a partir de las expresiones (3.1), (3.3), (3.8a) y (3.8b), se obtiene que la dinámica del error está descripta por

$$
\begin{aligned}
& \dot{\tilde{p}}=\alpha \dot{\tilde{x}}+\beta \tilde{x}, \\
& \dot{\widetilde{x}}=\mu \tilde{x}+(\mu-M \operatorname{sign}(\widetilde{p})) \hat{x} .
\end{aligned}
$$

Las expresiones anteriores combinadas con (3.21) implican que

$$
\begin{aligned}
& \widehat{p}(t)=p(t), \\
& \alpha \dot{\widetilde{x}}+\beta \widetilde{x}=0 .
\end{aligned}
$$

Es decir que la variable del observador copia la dinámica de la variable medida (concentración de producto) y de (3.25) se tiene la siguiente dinámica reducida

$$
\dot{\tilde{x}}=-\frac{\beta}{\alpha} \widetilde{x}
$$


Esto significa que la dinámica del error de estimación de biomasa converge a cero con una constante de tiempo $\tau=\alpha / \beta$. A partir de la condición de invariancia (3.21), puede interpretarse que la señal discontinua $\widehat{\mu}(t)$ se comporta como una señal ficticia continua $\mu_{e q}(t)$ la cual logra que el sistema evolucione sobre $\tilde{p}=0$. Esa señal ficticia $\mu_{e q}(t)$ puede obtenerse combinando (3.23) y (3.26):

$$
\mu_{e q}(t)=\left(\mu(t)+\frac{\beta}{\alpha}\right) \frac{\widetilde{x}}{\widehat{x}}+\mu(t) .
$$

Luego, a medida que $\widetilde{x} \rightarrow 0$, de la expresión anterior se tiene que $\mu_{e q}(t) \rightarrow$ $\mu(t)$. Dado que $\widehat{\mu}(t)$ es discontinua, una estimación continua (pero no exacta) $\widehat{\mu}_{e q}(t)$ de $\mu_{e q}(t)$ puede obtenerse mediante un filtro pasabajos.

Con el objetivo de mejorar la estimación de $\mu$, la próxima sección presenta un observador por modo deslizante de segundo orden, el cual tiene algunas características superiores respecto al algoritmo de primer orden.

\subsubsection{Algoritmo por Modo Deslizante de segundo or- den}

Dado el sistema descripto en (3.1)-(3.3), se propone el siguiente algoritmo por modo deslizante de segundo orden:

$$
\begin{aligned}
\dot{\hat{x}} & =\widehat{r_{x}}, \\
\dot{\hat{p}} & =\alpha\left(\widehat{r_{x}}+u_{2}\right)+\beta \widehat{x}, \\
\dot{\hat{r_{x}}} & =M_{1} \operatorname{sign}(\widetilde{p}), \\
u_{2} & =M_{2}|\widetilde{p}|^{1 / 2} \operatorname{sign}(\widetilde{p}), \\
\widehat{\mu} & =\frac{\widehat{r_{x}}}{\widehat{x}},
\end{aligned}
$$

con condiciones iniciales $\widehat{x}(0)>0$ y $\widehat{p}(0)=p(0)$. Nuevamente, la expresión (3.28b) es una copia del modelo (3.3) donde se trata de utilizar la información de la dinámica de $p$. Esta expresión contiene términos de corrección en $u_{2}$ y también en la derivada de $\widehat{r_{x}}$. A diferencia del observador de primer orden, la tasa volumétrica de formación de biomasa $\left(r_{x}\right)$ se estima con el estado continuo $\widehat{r_{x}}$. Luego la estimación de $\widehat{\mu}$ resulta ser una función continua.

Análisis Con el objetivo de analizar las propiedades del algoritmo (3.28), se toma la derivada temporal de las expresiones (3.4), (3.5) y (3.6). La dinámica del error queda descripta por:

$$
\begin{aligned}
\dot{\tilde{p}} & =\alpha \tilde{r_{x}}+\beta \tilde{x}-\alpha M_{2}|\widetilde{p}|^{1 / 2} \operatorname{sign}(\tilde{p}), \\
\dot{\widetilde{x}} & =\widetilde{r_{x}}, \\
\dot{\widetilde{r_{x}}} & =d\left(r_{x}\right) / d t-M_{1} \operatorname{sign}(\widetilde{p}),
\end{aligned}
$$


con $\widetilde{r_{x}} \triangleq r_{x}-\widehat{r_{x}}$.

Para analizar la convergencia en tiempo finito de la variable $\widetilde{p}$, un método consiste en analizar el peor caso de las trayectorias en el plano $(\widetilde{p}, \dot{\widetilde{p}})$ $[104,112]$. Otro enfoque más flexible, basado en funciones de Lyapunov, consiste en considerar el sistema (3.29)-(3.31) como la dinámica de error en un algoritmo derivador de segundo orden sujeto a perturbaciones. Con el cambio de variable $e_{1}=\tilde{p} / \alpha$ y $e_{2}=\widetilde{r_{x}}$ se tiene la forma estándar

$$
\begin{aligned}
& \dot{e}_{1}=\rho_{1}(t)+e_{2}-k_{2}\left|e_{1}\right|^{1 / 2} \operatorname{sign}\left(e_{1}\right), \\
& \dot{e}_{2}=\rho_{2}(t)-k_{1} \operatorname{sign}\left(e_{1}\right)
\end{aligned}
$$

con $\left(k_{1}, k_{2}\right)=\left(M_{1}, \alpha^{1 / 2} M_{2}\right)$ y donde las perturbaciones que afectan al sistema son

$$
\begin{aligned}
& \rho_{1}(t)=\frac{\beta}{\alpha} \tilde{x}, \\
& \rho_{2}(t)=\frac{d}{d t}\left(r_{x}\right) .
\end{aligned}
$$

Una función de Lyapunov cuadrática estricta para la expresión (3.32) fue presentada por primera vez en [99]. A partir de ese desarrollo se introdujeron generalizaciones del algoritmo para rechazar diferentes tipos de perturbaciones en la dinámica de las variables $e_{1}$ y $e_{2}$. Para el caso en que las perturbaciones tienen cotas absolutas de la forma $\left|\rho_{1}(t)\right|<\bar{\rho}_{1}$ y $\left|\rho_{2}(t)\right|<\bar{\rho}_{2}$, pueden encontrarse parámetros $k_{1}$ y $k_{2}$ que garanticen la convergencia uniforme de trayectorias acotadas al entorno de $e_{1}=\dot{e}_{1}=0$ en tiempo finito. Una condición suficiente para este tipo de estabilidad fue presentada en [113] (Teo. 4.3, pág. 123)). Sea $\boldsymbol{P}$ una matriz simétrica definida positiva tal que $V=\boldsymbol{\xi}^{T} \boldsymbol{P} \boldsymbol{\xi}$ es función de Lyapunov para el sistema (3.32) sin perturbaciones (donde $\boldsymbol{\xi}^{T}=\left(\left|e_{1}\right|^{1 / 2} \operatorname{sign}\left(e_{1}\right) \quad e_{2}\right)$ es el cambio de variable aplicado). Una condición suficiente para que las trayectorias converjan al entorno del origen, válida para un valor arbitrario $\bar{\rho}_{1}>0$, es que $\bar{\rho}_{2}$ sea lo suficientemente pequeño. Más precisamente las trayectorias convergen si $\bar{\rho}_{2}<\frac{\lambda_{\min }(\boldsymbol{Q})}{4 \lambda_{\max }(\boldsymbol{P})}$. En este resultado $\boldsymbol{P}$ y $\boldsymbol{Q}$ son matrices simétricas definidas positivas que satisfacen la ecuación de Lyapunov

$$
\boldsymbol{A}^{T} \boldsymbol{P}+\boldsymbol{P} \boldsymbol{A}=-\boldsymbol{Q}
$$

con $\boldsymbol{A}=\left[\begin{array}{ll}-k_{2} & 1 \\ -k_{1} & 0\end{array}\right]$. Dado que $\boldsymbol{A}$ puede reescribirse como $\boldsymbol{A}=\boldsymbol{A}_{0}-\boldsymbol{K} \boldsymbol{C}$ con $\boldsymbol{A}_{0}=\left(\begin{array}{ll}0 & 1 \\ 0 & 0\end{array}\right), \boldsymbol{K}^{T}=\left[\begin{array}{ll}k_{2} & k_{1}\end{array}\right]$ y $\boldsymbol{C}=\left[\begin{array}{ll}1 & 0\end{array}\right]$, la ecuación (3.34) puede
expresarse como

$$
\boldsymbol{A}_{0}^{T} \boldsymbol{P}+\boldsymbol{P} \boldsymbol{A}_{0}-\boldsymbol{C}^{T} \boldsymbol{K}^{T} \boldsymbol{P}-\boldsymbol{P} \boldsymbol{K} \boldsymbol{C}+\boldsymbol{Q}=\mathbf{0} .
$$


La ventaja de la expresión (3.35) es que es lineal en las variables de decisión $\boldsymbol{P}, \boldsymbol{P K}$. Luego el problema consiste en encontrar matrices simétricas definidas positivas $\boldsymbol{P}$ y $\boldsymbol{Q}$ y un vector de ganancias $\boldsymbol{K}$ sujeto a la restricción anterior. Este problema puede resolverse analíticamente o pueden aplicarse algoritmos numéricos muy eficientes que brindan la posibilidad de añadir restricciones adicionales sobre las matrices a encontrar.

Una particularidad del sistema (3.32) es que si bien la perturbación $\rho_{1}$ no puede acotarse con $\left|e_{1}\right|$, esta converge a cero al alcanzarse la superficie de modo deslizante. Para ver esto nótese que una vez alcanzada la superficie $\widetilde{p}=0$, combinando (3.29) y (3.30) con la condición de invariancia (3.21), se tiene

$$
0=\alpha \dot{\widetilde{x}}+\beta \widetilde{x}
$$

y de este modo

$$
\dot{\widetilde{x}}=-\frac{\beta}{\alpha} \widetilde{x}
$$

Luego, el error de estimación en biomasa converge con dinámica de primer orden. Además, $\widetilde{r_{x}}$ converge con la misma dinámica.

\subsubsection{Extensión al caso de proceso alimentado}

En el caso de que el cultivo sea semi-continuo o continuo, el modelo del proceso resulta

$$
\begin{aligned}
& \dot{x}=\mu(s) x-D x, \\
& \dot{s}=-\frac{1}{y_{x / s}} \mu(s) x+D\left(S_{i n}-s\right), \\
& \dot{p}=\alpha \mu(s) x+\beta x-D p,
\end{aligned}
$$

con $D=F_{\text {in }} / v \geqslant 0$.

Bajo la hipótesis de que la entrada aplicada (dilución) es conocida, el observador (3.28) puede modificarse para incluir el término de dilución

$$
\begin{aligned}
\dot{\hat{x}} & =\widehat{r_{x}}-D \widehat{x}, \\
\dot{\hat{p}} & =\alpha\left(\widehat{r_{x}}+u_{2}\right)+\beta \widehat{x}-D p, \\
\dot{\hat{r_{x}}} & =M_{1} \operatorname{sign}(\widetilde{p}), \\
u_{2} & =M_{2}|\widetilde{p}|^{1 / 2} \operatorname{sign}(\widetilde{p}) .
\end{aligned}
$$

Analizando la dinámica de las variables de error se encuentra que

$$
\begin{aligned}
\dot{\widetilde{p}} & =\alpha \widetilde{r_{x}}+\beta \widetilde{x}-\alpha M_{2}|\widetilde{p}|^{1 / 2} \operatorname{sign}(\widetilde{p}), \\
\dot{\widetilde{x}} & =\widetilde{r_{x}}-D \widetilde{x} \\
\dot{r_{x}} & =\rho(t)-M_{1} \operatorname{sign}(\widetilde{p}) .
\end{aligned}
$$


Dado que la dilución es no negativa, en los casos semi-continuo y continuo existe una mejora de la convergencia del error de estimación en biomasa (véase expresión (3.30)). De hecho, combinando (3.42) y (3.43) con la restricción de modo deslizante (3.21), la dinámica del error en la estimación de biomasa resulta

$$
\dot{\tilde{x}}=-\left(\frac{\beta}{\alpha}+D\right) \tilde{x}
$$

\subsubsection{Cotas de error ante incertidumbre en los paráme- tros}

Los resultados anteriores se obtuvieron para el caso nominal, es decir, cuando los parámetros $\alpha$ y $\beta$ son conocidos. En esta sección se analiza el efecto de errores constantes en estos parámetros, los cuales se definen de la siguiente manera

$$
\begin{aligned}
\alpha_{o b s} & =a_{1} \alpha, \\
\beta_{o b s} & =a_{2} \beta,
\end{aligned}
$$

donde $\alpha_{o b s}, \beta_{o b s}$ son los parámetros del observador y $a_{1}, a_{2}$ son coeficientes que miden el desajuste. Para el observador de segundo orden, que provee estimaciones continuas de $\mu$, la dinámica de $\tilde{x}$ resulta en

$$
\alpha \dot{\tilde{x}}+\beta \tilde{x}+\alpha\left(1-a_{1}\right) \dot{\widehat{x}}+\beta\left(1-a_{2}\right) \hat{x}=0,
$$

de la cual resulta

$$
\dot{\widetilde{x}}=-\frac{\beta}{\alpha} a_{2} \widetilde{x}+\frac{\beta}{\alpha}\left(a_{2}-1\right) x+\left(a_{1}-1\right) \widehat{r_{x}} .
$$

Claramente en el caso nominal (es decir cuando $a_{1}=a_{2}=1$ ), la expresión (3.48) se reduce a la expresión (3.37). A partir de (3.48) y tal como se esperaba, el error de estimación en la biomasa ingresa en tiempo finito a una bola centrada en el origen, la cual puede definirse como

$$
\widetilde{x} \in \mathcal{B}\left(\frac{\frac{\beta}{\alpha}\left(a_{2}-1\right) \bar{x}+\left(a_{1}-1\right) \overline{r_{x}}}{\frac{\beta}{\alpha} a_{2}}\right) .
$$

En un cultivo por lote con $m_{s} \approx 0$, el valor $\bar{x}$ puede determinarse fácilmente con la expresión de balance estequiométrico

$$
\bar{x}=x_{0}+y_{x / s} S_{0}
$$

donde $S_{0}$ es la concentración de sustrato inicial. Esta última expresión proviene del balance estequiométrico $\Delta x=Y_{x / s} \Delta s$. El caso alimentado, donde $D(t)>0$, puede tratarse de forma análoga considerando cotas sobre el valor de dilución.

En la siguiente sección se evalúa el observador propuesto en un proceso por lote de fotofermentación. 


\subsection{Aplicación en un proceso de producción de hidrógeno biológico}

\subsubsection{Descripción del proceso}

La fotofermentación del hidrógeno es un proceso de producción llevado a cabo por un tipo de bacterias fotosintéticas denominado bacterias púrpuras no del azufre. ${ }^{1}$ En condiciones anaerobias estas bacterias son capaces de utilizar ácidos orgánicos simples como donante de electrones. Entre esos sustratos se encuentran productos de fermentación común tales como lactato y acetato. Luego, si existe limitación de nitrógeno en el medio, los electrones disponibles pueden ser utilizados por la enzima nitrogenasa para generar hidrógeno [114].

Una de las principales ventajas de la fotofermentación es el alto rendimiento de conversión de los ácidos orgánicos y el hecho de que la conversión del sustrato es completa. La utilización de la enzima nitrogenasa tiene la ventaja de una menor inhibición con el oxígeno. Además estas bacterias tienen habilidad de fotofermentar con un amplio espectro de luz y, dado que consumen ácidos orgánicos, brindan la posibilidad de utilizarlas para el tratamiento de residuos.

Si bien la fotofermentación es un método de producción muy prometedor, estos procesos se ven afectados por muchos factores, entre ellos: la concentración y el tipo de sustrato, la relación carbono-nitrógeno, intensidad de la luz, las condiciones fisiológicas, el pH, la temperatura [115]. Las variables ambientales pueden ser controlados para asegurar condiciones de cultivo óptimas. Sin embargo, las variables bioquímicas son mucho más difíciles de controlar, ya que rara vez son accesibles en línea.

Con el objetivo de hacer una contribución hacia un proceso de producción de biohidrógeno rentable, es esencial aplicar estrategias de control avanzadas que puedan optimizar el proceso y mejorar las tasas de producción. Dado que las estrategias de lazo cerrado requieren información en línea, la implementación de observadores para la estimación de las variables no accesibles resulta crucial. Las posibles aplicaciones de un observador de biomasa y tasa de crecimiento para este proceso incluyen conocer el estado de crecimiento de las bacterias (es decir, determinar si ocurre el crecimiento exponencial o no) y monitorear el valor de biomasa alcanzado con el objetivo de determinar en línea el rendimiento del proceso. En [116], se presentó un observador asintótico basado en la medición de biogás con aplicación en un digestor anaeróbico continuo. Las estimaciones se utilizaron para la implementación de un controlador predictivo basado en modelo. Un estimador de

\footnotetext{
${ }^{1}$ La denominación púrpura se debe al color púrpura, rojo o incluso anaranjado, que poseen estas bacterias debido a los pigmentos que contienen. Esos pigmentos son los que le permiten realizar fotosíntesis para obtener energía. Las bacterias denominadas "no del azufre" no pueden utilizar este compuesto como donante de electrones.
} 
estados de horizonte móvil para un cultivo por lote de Rhodobacter capsulatus fue desarrollado en [117]. En ese trabajo se estiman concentraciones de biomasa y sustrato a partir de la medición de biohidrógeno pero no se proporciona ninguna estimación robusta de la tasa de crecimiento.

\subsubsection{Modelo del proceso de fotofermentación}

El siguiente modelo representa el proceso de fotofermentación por lotes con la bacteria $R$. capsulatus, en condiciones anaeróbicas [118]. A partir del balance de masas (descripto en la sección 2.1.3), la variación de biomasa, sustrato e hidrógeno puede describirse con las expresiones

$$
\begin{aligned}
\dot{x} & =\mu(s) x \\
\dot{s} & =-\frac{1}{y_{x / s}} \mu(s) x, \\
\dot{p} & =\alpha \mu(s) x+\beta x, \\
\mu(s) & =\mu_{\max } \frac{s}{s+k_{s}}
\end{aligned}
$$

donde $x$ es la concentración de bacterias, $s$ la concentración de ácidos orgáni$\cos (\mathrm{g} / \mathrm{L})$ y $p$ el biohidrógeno producido $(\mathrm{mL}) . y_{x / s}$ es el rendimiento sustrato a biomasa y $\alpha, \beta$ los coeficientes del modelo de Luedeking-Piret (sección 2.1.5). El hidrógeno se produce en presencia de luz y el efecto de la intensidad de luz aplicada $\left(I_{o}\right)$ se considera en el término de formación de hidrógeno asociado al crecimiento

$$
\alpha=\frac{1}{y_{p}} \phi\left(I_{o}\right)
$$

donde $y_{p}$ es el rendimiento correspondiente y $\phi(\cdot)$ es una función determinada experimentalmente [118].

El objetivo es obtener estimaciones de $\mu(t)$ y $x(t)$ utilizando únicamente mediciones de biohidrógeno y sin asumir un modelo explícito para $\mu(\cdot)$. Si se logra este objetivo, se eliminará una fuente de incertidumbre. El problema a tratar se restringe con las siguientes suposiciones:

Suposición 3.1 Se dispone de medición del biohidrógeno producido.

Suposición 3.2 Se conocen los parámetros $\alpha$ y $\beta$.

Para la medición del producto se aprovecha el hecho de que el hidrógeno gaseoso escapa de la fase líquida y puede ser recuperado de la fase gaseosa. Se han reportado dispositivos que permiten la medición del hidrógeno producido en procesos de fotofermentación [117]. La suposición 3.2 asume la disponibilidad de los parámetros $\alpha$ y $\beta$ para una dada intensidad de luz $I_{o}$. En la sección 2.1.5 se comentó brevemente que existe un procedimiento 
Tabla 3.1: Valores utilizados en (3.51a)-(3.51d) para fotofermentación por lotes de $R$. capsulatus [117].

\begin{tabular}{cc}
\hline Parámetro & Valor \\
\hline$\mu_{\max }$ & $0,4 \mathrm{~h}^{-1}$ \\
$k_{s}$ & $10 \mathrm{~g} / \mathrm{L}$ \\
$y_{x / s}$ & $0,7 \mathrm{~g} / \mathrm{g}$ \\
$y_{p}$ & $1 \mathrm{~g} / \mathrm{L}$ \\
$\alpha$ & 5 \\
$\beta$ & 16 \\
\hline
\end{tabular}

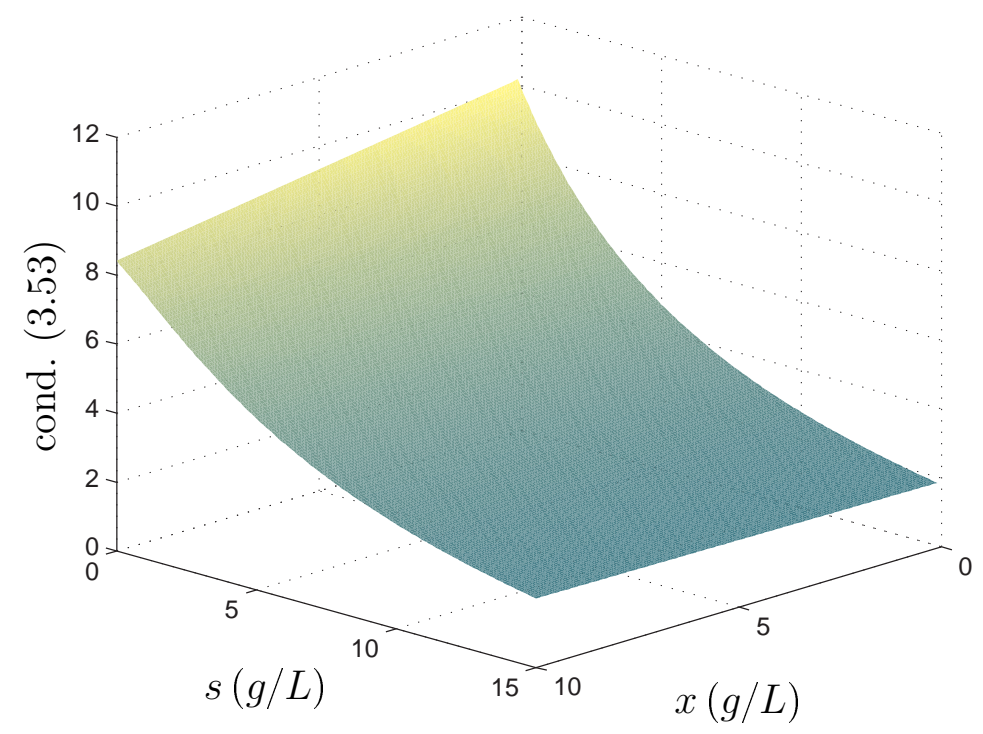

Figura 3.1: Evaluación de la condición (3.53) para el proceso con cinética Monod.

para determinar los coeficientes de la expresión (3.51c) basado en graficar $r_{p} / x$ en función de $\mu$. De todas maneras, como la incertidumbre en estos parámetros es una fuente de error en la estimación, se analizará la robustez del observador a estas incertidumbres.

La Tabla 3.1 presenta los valores utilizados en el modelo (3.51a)-(3.51d), los cuales fueron tomados de [117, 118].

\section{Análisis de observabilidad aplicado al proceso de fotofermentación}

La Figura 3.1 muestra la evaluación de la siguiente condición algebraica

$$
\left(\alpha^{2} \mu^{2}+2 \alpha \beta \mu+\beta^{2}\right) \frac{\partial \mu}{\partial s}+(\alpha \mu-\beta) \frac{\alpha x}{y_{x / s}}\left(\frac{\partial \mu}{\partial s}\right)^{2}-(\alpha \mu+\beta) \frac{\alpha \mu x}{y_{x / s}} \frac{\partial^{2} \mu}{\partial s^{2}} \neq 0 .
$$


la cual fue obtenida evaluando el rango de la denominada codistribución de observabilidad [119]. Esta expresión fue determinada evaluando la independencia lineal de los covectores formados por el diferencial de la concentración de producto y sus sucesivas derivadas temporales (ver detalles en el Apéndice A.2). En la Figura 3.1 se presenta la evaluación numérica en la región $\left[0, S_{0}\right] \times\left[x_{i}, x_{f}\right]$, con $S_{0}=15 \mathrm{~g} / \mathrm{L}, x_{i}=0,1 \mathrm{~g} / \mathrm{L}, x_{f}=10 \mathrm{~g} / \mathrm{L}$ y los parámetros del proceso presentados en la Tabla 3.1. Puede apreciarse que para el caso en estudio la expresión (3.53) no se anula en la región considerada. En particular, en la evolución temporal típica de un cultivo por lotes la condición inicial es de una concentración de biomasa pequeña con una concentración grande de sustrato. El final del proceso ocurre cuando el sustrato se agota y donde se espera obtener una concentración de biomasa mayor. El resultado obtenido en la Figura 3.1 permite concluir que es factible distinguir la biomasa y el sustrato a partir de la salida (biohidrógeno) y sus dos primeras derivadas temporales. Nótese que estamos enfocados en observar la biomasa y una función del sustrato $(\mu)$ en lugar de la concentración de sustrato en sí. La observabilidad local de $\mu$ es equivalente a la observabilidad del sustrato dado que, por ser la tasa de crecimiento una función monótona, existe una relación algebraica uno a uno entre estas variables.

\subsubsection{Diseño del observador de segundo orden}

El observador de segundo orden fue configurado resolviendo la expresión (3.35). Para la matriz $\boldsymbol{Q}=\left(\begin{array}{ll}2 & 0 \\ 0 & 2\end{array}\right)$, una solución es $\boldsymbol{P}=\left(\begin{array}{cc}1,5 & -1 \\ -1 & 1,5\end{array}\right)$ y $k_{1}=2,6, k_{2}=2,4$. Con estas matrices $\boldsymbol{P}$ y $\boldsymbol{Q}$ se garantiza convergencia, en el sentido de trayectorias acotadas que convergen a un entorno en tiempo finito, ante perturbaciones que satisfagan $\left|\rho_{2}\right|=\left|\dot{r}_{x}\right|<0,2$. Cabe destacar que, de acuerdo a las curvas típicas de un cultivo por lote, se espera que $r_{x}$ se incremente lentamente en las primeras horas del proceso.

\section{Resultados}

El desempeño del observador de segundo orden se evalúa en tres escenarios. En primer lugar, el algoritmo se prueba con el modelo nominal es decir, cuando se conocen los parámetros de la cinética de biohidrógeno. A continuación, se realiza una evaluación ante ruido en la medición. Finalmente, el observador es evaluado ante errores de $\pm 10 \%$ en los coeficientes de formación de biohidrógeno asociado y no asociado al crecimiento.

Las condiciones iniciales tanto del cultivo por lote como las utilizadas en el observador se presentan en la Tabla 3.2. La duración de la fermentación se consideró 25 horas. Cabe destacar que en el observador es razonable utilizar la primer muestra adquirida como condición inicial del estado $\hat{p}$, es decir $\widehat{p}_{0}=p_{0}$. 
Tabla 3.2: Condiciones iniciales utilizadas.

\begin{tabular}{ll}
\hline Proceso & Observador \\
\hline$x_{0}=0,13 \mathrm{~g} / \mathrm{L}$ & $\hat{x}_{0}=1 \mathrm{~g} / \mathrm{L}$ \\
$s_{0}=12,57 \mathrm{~g} / \mathrm{L}$ & $\widehat{r_{x 0}}=0 \mathrm{~h}^{-1}$ \\
$p_{0}=0 \mathrm{~mL}$ & $\hat{p}_{0}=p_{0} \mathrm{~mL}$ \\
\hline
\end{tabular}

Resultados obtenidos en condición nominal La Figura 3.2 presenta las estimaciones obtenidas y los estados propios del observador de segundo orden. Puede apreciarse la rápida convergencia a la superficie de conmutación y que se establece el régimen deslizante en $T_{S M}=1,2 \mathrm{~h}$. En este observador se estiman $r_{x}$ y $x$ con funciones continuas. En el gráfico superior se observa que, una vez alcanzada la superficie de conmutación, el error en la estimación de biomasa evoluciona con la dinámica impuesta por (3.37) donde la constante de tiempo involucrada resulta $\tau=\alpha / \beta \approx 0,3 \mathrm{~h}$. Cabe destacar que este valor es mucho menor a la duración de una fermentación típica. También se aprecia la convergencia de la tasa de crecimiento, donde la reducción del valor de $\mu$ hacia el final del cultivo puede atribuirse al agotamiento del sustrato.

Resultados obtenidos con ruido en la medición La Figura 3.3 presenta los resultados ante ruido gaussiano aditivo y multiplicativo $(0,1 \%)$ con media nula y $\sigma=2,5 \mathrm{~mL}$ en la señal de biohidrógeno. Puede apreciarse que en las estimaciones de $x(t)$ se obtuvo una respuesta aceptable mientras que la estimación de $\mu$ resultó más afectada. Nótese que el efecto del ruido sobre el estado $\widehat{r}_{x}$ resultó apróximadamente de la misma amplitud durante todo el proceso. Luego, la gran variación obtenida en $\widehat{\mu}$ durante la primera mitad de la fermentación puede atribuirse a la baja concentración de biomasa que hubo durante las primeras horas. De hecho, el efecto del ruido sobre $\widehat{\mu}=\widehat{r_{x}} / \widehat{x}$ se redujo sustancialmente con el aumento de la concentración de biomasa.

Desempeño ante incertidumbre en el modelo A partir del desarrollo presentado en la sección 3.2.4, se consideran errores de $\pm 10 \%$ en los coeficientes $\alpha$ y $\beta$.

En primer lugar se analiza el efecto de un error $\alpha_{o b s}=\alpha \pm 10 \%$ con $\beta_{o b s}=\beta$. En este caso, las cotas de error en $\widetilde{x}$ calculadas con la expresión (3.49), para $\overline{r_{x}}=1 \mathrm{~g} / \mathrm{L} / \mathrm{h}$ y $\beta / \alpha=16 / 5$, resultan $\pm 0,03 \mathrm{~g} / \mathrm{L}$. La respuesta temporal de las señales de error pueden verse en la Figura 3.4. Se aprecia que los errores en ambas estimaciones son pequeños. De hecho, el error en estimación de biomasa resultó dentro de la cota calculada mientras que el error en $\mu$ resulta, a los fines prácticos, despreciable (por debajo de 0,01 $\left.\mathrm{h}^{-1}\right)$. 

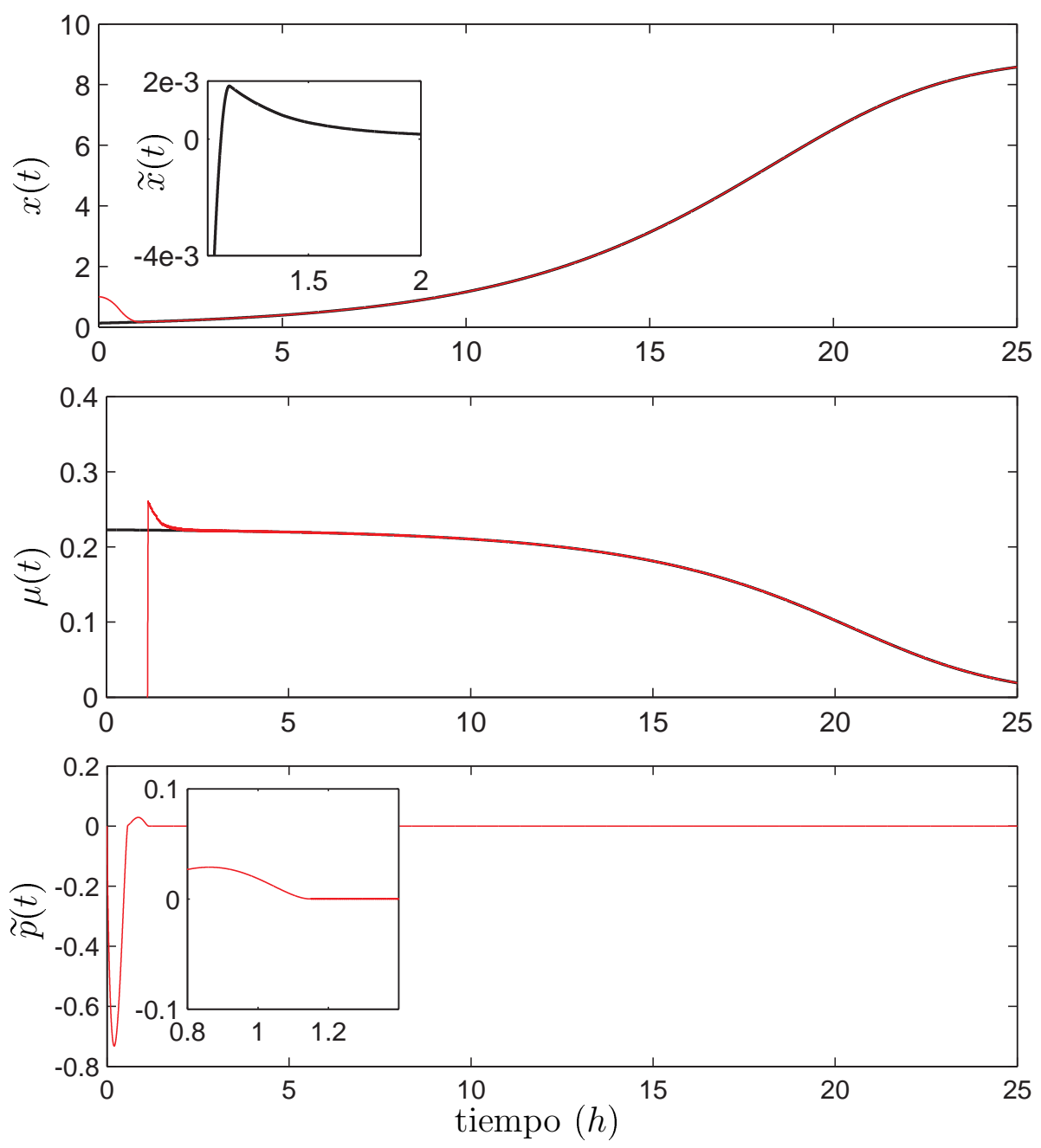

Figura 3.2: Resultados obtenidos con el observador de segundo orden (3.28). Arriba: biomasa (línea negra), y biomasa estimada (línea roja). Centro: tasa de crecimiento $\hat{\mu}$ (línea negra) y señal estimada $\hat{\mu}$ (línea roja). Abajo: distancia a la superficie de conmutación $\widetilde{p}=0$.

Ahora se considera el error en $\beta_{\text {obs }}=\beta \pm 10 \%$ mientras que $\alpha_{o b s}=\alpha$. Recuérdese que el error en $\beta$ afecta al término proporcional de la biomasa en la tasa de formación de producto (ec. (3.51c)). Por lo tanto, su influencia aumenta con la concentración de biomasa. Utilizando la expresión (3.49), los límites de error de concentración de biomasa son $[-1 ; 0,81] \mathrm{g} / \mathrm{L}$. Teniendo en cuenta que la concentración de biomasa final en la Figura 3.2 es de aproximadamente $9 \mathrm{~g} / \mathrm{L}$, se tiene que el error obtenido al final del cultivo es de aproximadamente $10 \%$. Es decir, del mismo orden de error en $\beta$. La Figura 3.5 muestra los errores de estimación obtenidos en este caso. Se aprecia que la estimación de la biomasa permanece dentro de los límites calculados mientras que el error en la estimación de $\mu$ es despreciable como en el caso anterior. 

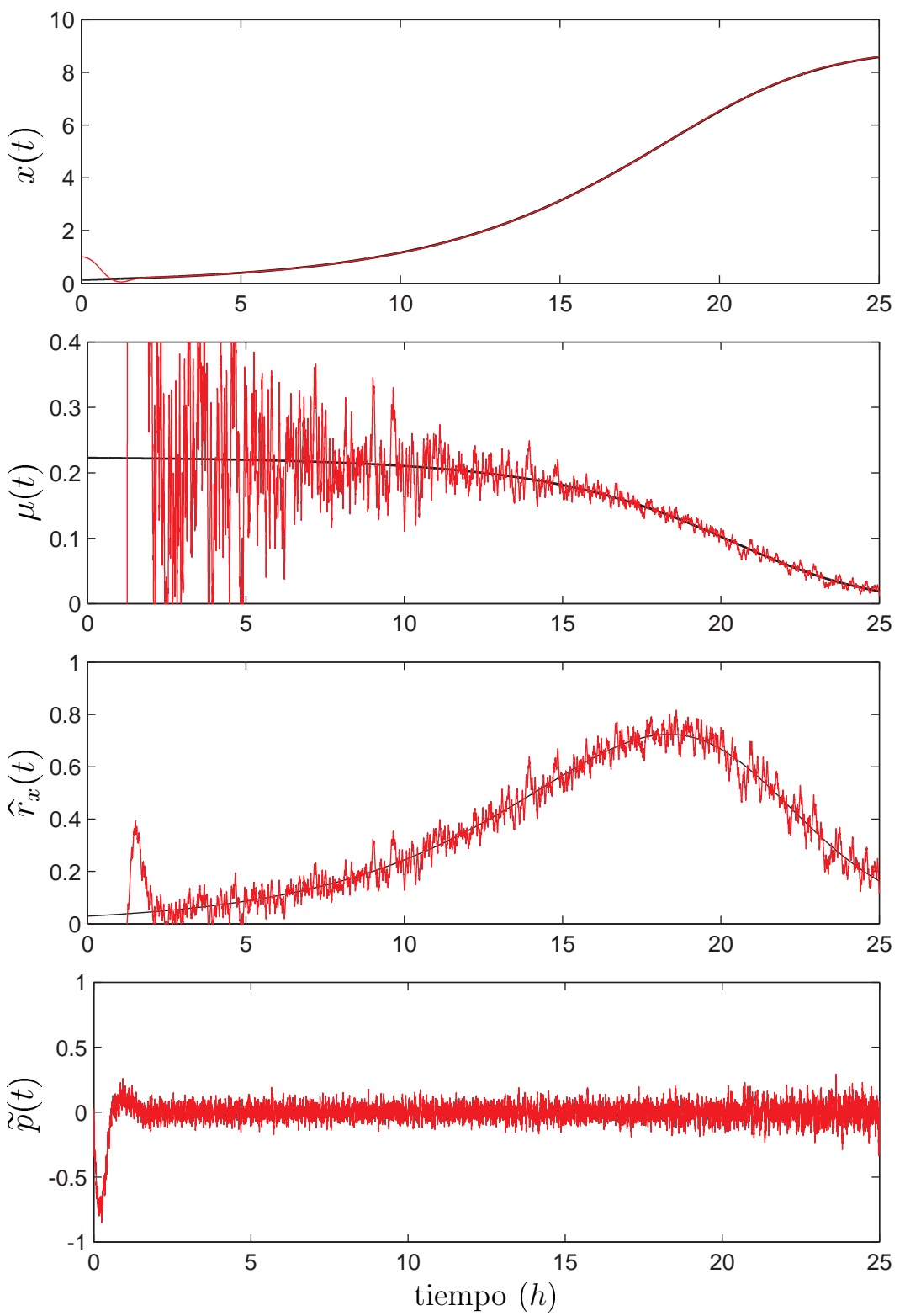

Figura 3.3: Resultados obtenidos con el observador de segundo orden (3.28) ante ruido en la medición de biohidrógeno: valores reales (línea negra) y valores estimados (línea roja). 

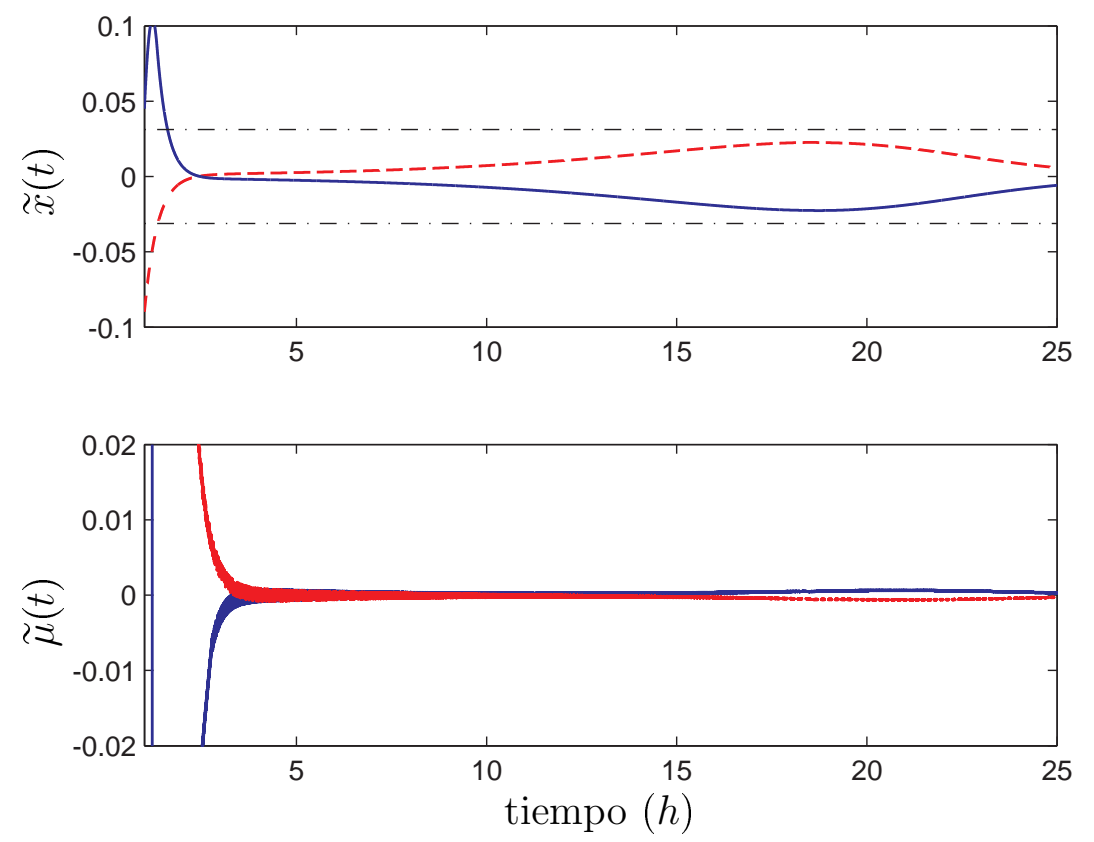

Figura 3.4: Errores obtenidos en caso de incertidumbre en $\alpha:+10 \%$ (línea a trazos roja) y $-10 \%$ (línea azul).
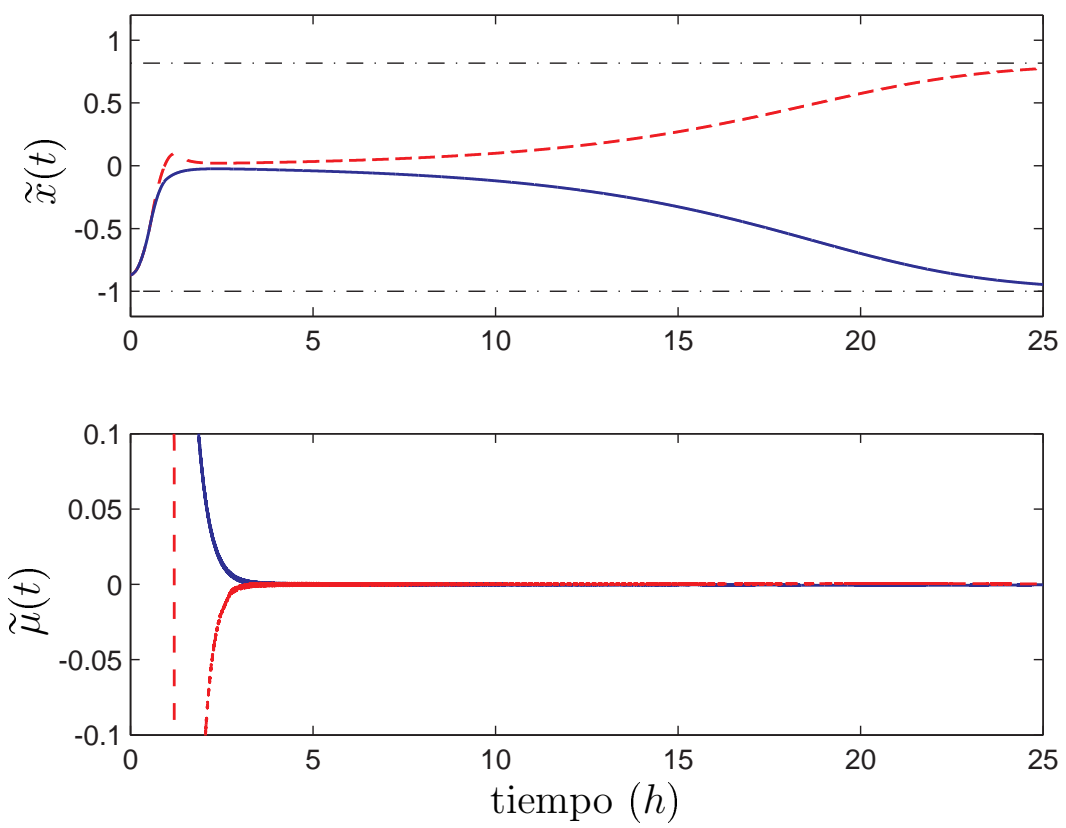

Figura 3.5: Errores obtenidos en caso de incertidumbre en $\beta$ : $+10 \%$ (línea a trazos roja) y $-10 \%$ (línea azul). 


\subsection{Resumen del capítulo}

En este capítulo se diseñaron observadores para procesos con cinética de formación de producto tipo Luedeking-Piret. Se presentaron dos algoritmos para estimación de biomasa y su tasa de crecimiento basados en técnicas de modo deslizante de primer y segundo orden. Las principales ventajas de estos algoritmos incluyen robustez respecto del modelo de $\mu$, y el hecho de que exhiben dinámica reducida en el error de estimación. En particular, la convergencia de la estimación de biomasa presenta dinámica de primer orden. Como ejemplo de aplicación se presentó la generación de hidrógeno con bacterias fotosintéticas a partir de ácidos órganicos. Estos sustratos pueden provenir de una etapa de fermentación anterior lo que brinda la posibilidad de realizar tratamiento de residuos. Si bien la dinámica de convergencia en modo deslizante resulta dependiente de parámetros del proceso, en el caso de estudio la constante de tiempo resultó mucho menor respecto de la duración de una fermentación típica. La incertidumbre en las constantes del modelo de Luedeking-Piret da lugar a errores acotados en la estimación de biomasa y a errores despreciables en la estimación de $\mu$. 


\section{Capítulo 4}

\section{Estimación de múltiples tasas de reacción basada en medición de concentraciones de sustancias}

En este capítulo se pretende diseñar un observador de múltiples tasas específicas de reacción utilizando técnicas de modo deslizante de segundo orden. Desde el punto de vista de control de bioprocesos, el objetivo es el mismo que en el capítulo anterior: añadir información sobre la actividad de los microorganismos con el fin de aumentar las señales disponibles en línea para control de lazo cerrado y monitoreo del proceso productivo. Por lo tanto, el observador propuesto aquí se aplica para estimar un conjunto de $l$ tasas específicas tanto sean de producción como de consumo sobre la base de $l$ mediciones en línea de variables relacionadas.

Dado que el objetivo es estimar variables que se encuentran en la derivada temporal de los estados (concentraciones), no sólo se requiere un algoritmo derivador robusto sino que se requiere un algoritmo capaz de tratar con funciones variantes en el tiempo, las cuales aparecen multiplicando a la señal que se desea estimar. Por ejemplo, supongamos que se desea estimar $\mu$ en un proceso por lotes a partir de la medición de biomasa. En este caso se requiere un derivador capaz de obtener $\mu$ de la expresión $\dot{x}=r_{x}=\mu x$. Los algoritmos clásicos, como los derivadores descriptos en la sección 2.4.1 y los observadores presentados en el capítulo anterior, no incorporan esas funciones dentro de la estructura del algoritmo. De este modo, las cotas requeridas sobre las funciones involucradas podrían resultar elevadas y en algunos casos difíciles de acotar. Por estas razones es conveniente intentar incorporar esas funciones que multiplican a la variable a estimar en la estructura del observador. En un caso más general, las tasas de formación y consumo de las diferentes sustancias aparecen multiplicadas por la biomasa y otras funciones que pueden ser concentraciones de especies en la 
dinámica de las variables medidas. Obtener un algoritmo de estimación que incorpore esas funciones en su estructura requiere modificaciones, tanto en la estructura del observador como en la proposición de las condiciones de estabilidad.

El problema de incorporar la concentración de biomasa en la estructura del observador ya ha sido tratado en trabajos donde se estima la tasa de crecimiento (ver por ejemplo [109]). Sin embargo, en un caso más general, la biomasa y otras sustancias multiplican a las funciones a estimar. El objetivo de este capítulo es incorporar esas variables en el diseño del observador, lo cual requiere también su incorporación en el análisis de estabilidad. En particular se considera el rango de variación de esas señales para el diseño del algoritmo de estimación. La principal diferencia con otras propuestas de tiempo continuo es que las estimaciones se obtienen en tiempo finito. Así, a partir de un cierto instante de tiempo, el observador no añade dinámica adicional. Además, a diferencia de las propuestas por modo deslizante de primer orden, las estimaciones resultantes son suaves. En consecuencia, no se requerirían elementos de filtrado adicionales en posibles lazos cerrados. También es de esperar robustez en las estimaciones dado que no se requiere un modelo de las variables a estimar. De esta manera, el aporte principal de este capítulo es el algoritmo por modo deslizante de segundo orden descripto en la Proposición 4.1, el cual posee propiedades de convergencia en tiempo finito y robustez respecto del modelo de las tasas a estimar.

\subsection{Descripción del problema}

De acuerdo a lo descripto en la expresión (2.41), el modelo general de un cultivo en biorreactor agitado puede describirse con la siguiente expresión general

$$
\dot{\boldsymbol{\xi}}=\boldsymbol{K} \boldsymbol{r}(\boldsymbol{\xi}, t)-D(t) \boldsymbol{\xi}(t)+\boldsymbol{F}(t)-\boldsymbol{Q}(\boldsymbol{\xi}),
$$

donde $\boldsymbol{\xi}(t) \in \mathbb{R}_{+}^{n}$ es el vector de estados, $\boldsymbol{K}$ es una matriz de coeficientes de dimensión $(n \times m), \boldsymbol{r}(\cdot) \in \mathbb{R}^{m}$ el vector de tasas de reacción, $D(t) \in \mathbb{R}_{+}$ la dilución, $\boldsymbol{F}(t) \in \mathbb{R}_{+}^{n}$ contiene el flujo de entrada para cada estado y $\boldsymbol{Q}(\boldsymbol{\xi}) \in \mathbb{R}_{+}^{n}$ el término que describe el intercambio con la fase gaseosa.

La expresión (4.1) describe la dinámica de las sustancias (bio)químicas en el cultivo, las cuales evolucionan con $m$ tasas de reacción $\boldsymbol{r}(\boldsymbol{\xi}, t)$. Dado que las reacciones sólo pueden ocurrir en presencia de un conjunto de reactantes, $r_{i}(\cdot)$ es cero siempre que la concentración de uno de los reactantes requeridos sea cero. De este modo, las reacciones involucradas pueden ser factorizadas de la forma $r_{i}(\boldsymbol{\xi}, t)=\alpha_{i}(\boldsymbol{\xi}, t) \prod_{j \in \mathcal{J}_{i}} \xi_{j}$ donde $\alpha_{i}(\cdot)$ resulta en general una función no lineal de los estados y $\mathcal{J}_{i}$ es el conjunto que indica los reactantes requeridos para la reacción $i$ [34]. En forma matricial, esta factorización resulta

$$
\boldsymbol{r}(\boldsymbol{\xi}, t)=\boldsymbol{G}(\boldsymbol{\xi}, t) \boldsymbol{\alpha}(\boldsymbol{\xi}, t)
$$


donde $\boldsymbol{G}(\boldsymbol{\xi}, t)$ es una matriz diagonal dependiente de los estados de dimensión $(m \times m)$.

Los $\alpha_{i}(\cdot)$ definidos en (4.2) se denominan tasas de reacción específicas por unidad de cada reactivo. También pueden considerarse por unidad de biomasa y en ese caso se obtiene la definición (2.10). Estas funciones no lineales y variantes en el tiempo proporcionan información importante sobre el proceso (por ejemplo, tasa de crecimiento microbiana, tasa específica de consumo de oxígeno, la tasa específica de producción de metabolitos), pero el modelizado y la correspondiente identificación de los parámetros involucrados puede ser una tarea extremadamente difícil. Con el objetivo de añadir información sobre el proceso (posiblemente para aplicarlo en control de lazo cerrado), se presenta un observador para las tasas específicas de reacción. En particular, el objetivo es obtener un observador robusto de un conjunto formado por $l$ tasas específicas $\boldsymbol{\alpha}_{l}(t)=\left[\begin{array}{lll}\alpha_{1}(t), \ldots, & \alpha_{l}(t)\end{array}\right]^{T}$. Para esto se considera que se tienen disponibles $l$ mediciones de $\boldsymbol{\xi}(t)$, las cuales son representadas en un vector $\boldsymbol{z}$, es decir $\boldsymbol{z}(t)=\left[\begin{array}{llll}\xi_{1}(t), \ldots, & \xi_{l}(t)\end{array}\right]^{T}$. Sean $\boldsymbol{K}_{l}$ y $\boldsymbol{G}_{l}(\cdot)$ las submatrices de $\boldsymbol{K}$ y $\boldsymbol{G}(\cdot)$ correspondientes a la dinámica de $\boldsymbol{z}$ mientras que $\boldsymbol{F}_{l}$ y $\boldsymbol{Q}_{l}$ denotan los vectores correspondientes de $\boldsymbol{F}$ y $\boldsymbol{Q}$ respectivamente.

Para el desarrollo del observador, se asumen las siguientes condiciones:

Suposición 4.1 Las variables de estado son positivas y acotadas.

Suposición 4.2 La matriz $\boldsymbol{G}_{l}$ y los vectores $\boldsymbol{F}_{l}$ y $\boldsymbol{Q}_{l}$ están disponibles.

Suposición 4.3 Se conoce una cota $\bar{\rho}_{i}>0$ para la derivada temporal de cada $\alpha_{i}$.

Suposición 4.4 La matriz $\boldsymbol{K}_{l}$ es invertible.

Suposición 4.5 Se conocen dos matrices diagonales $\boldsymbol{G}_{1}, \boldsymbol{G}_{2}$ tal que

$$
\mathbf{0}<\boldsymbol{G}_{1} \leqslant \boldsymbol{G}_{l}(\cdot) \leqslant \boldsymbol{G}_{2}
$$

En primer lugar, la suposición 4.1 se cumple ya que las variables de estado son concentraciones de sustancias o cantidades con sentido físico. La suposición 4.2 es común en el diseño de observadores y se refiere a la disponibilidad de mediciones en línea [67]. Cabe destacar que en muchos procesos puede asumirse $\boldsymbol{Q}_{l}=\mathbf{0}$. La suposición 4.3 requiere disponer de una cota para la derivada temporal de cada variable a estimar. Estas cotas pueden determinarse a partir de conocimiento práctico del cultivo a monitorear o analizando las expresiones involucradas según el modo de operación [109]. La suposición 4.4 asegura que $l$ tasas específicas pueden ser estimadas de las $l$ variables disponibles en línea. De otro modo, el vector de datos medidos podría ser explicado con una cantidad menor de reacciones [120]. A partir 
de la expresión (4.2) se tiene que los elementos que conforman la matriz diagonal $\boldsymbol{G}_{l}$ son productos de variables de estado, los cuales resultan positivos y acotados debido a la suposición 4.1. En el caso que uno de los reactantes requeridos para una reacción se agote, al menos una de las reacciones no ocurrirá. En ese caso, la estimación de $l$ tasas no tiene sentido y el problema a considerar es la estimación de una cantidad menor a $l$. En la suposición 4.5, los elementos que conforman las matrices $\boldsymbol{G}_{1}$ y $\boldsymbol{G}_{2}$ deben ser seleccionados por el diseñador, basándose en conocimiento acerca del cultivo a ser monitoreado. En particular, deben seleccionarse cotas superiores e inferiores para los productos de estados que aparecen en la matriz $\boldsymbol{G}_{l}$. Con el objetivo de ilustrar las diferentes descomposiciones que pueden resultar en $\boldsymbol{\alpha}(\cdot)$ y $\boldsymbol{G}_{l}$ se presenta un ejemplo con las tasas volumétricas de formación de biomasa y consumo de sustrato. Suponiendo que se tiene las reacciones

$$
\boldsymbol{r}(\cdot)=\left(\begin{array}{c}
\mu x \\
q_{s} x
\end{array}\right)
$$

Cuando la factorización (4.2) se considera por unidad de biomasa se obtiene

$$
\boldsymbol{G} \boldsymbol{\alpha}(\cdot)=\left(\begin{array}{cc}
x & 0 \\
0 & x
\end{array}\right)\left(\begin{array}{l}
\mu \\
q_{s}
\end{array}\right)
$$

En este caso, las matrices $\boldsymbol{G}_{1}$ y $\boldsymbol{G}_{2}$ de la Suposición 4.5 son cotas en la excursión de la concentración de biomasa. Si en cambio se desea estimar las tasas $\alpha_{i}$ por unidad de biomasa y de sustrato podría considerarse [67]

$$
\boldsymbol{G} \boldsymbol{\alpha}(\cdot)=\left(\begin{array}{cc}
x s & 0 \\
0 & x s
\end{array}\right)\left(\begin{array}{l}
\alpha_{1} \\
\alpha_{2}
\end{array}\right)
$$

donde ahora las matrices $\boldsymbol{G}_{1}$ y $\boldsymbol{G}_{2}$ acotan al producto $x s$.

A partir de la discusión previa se considera el siguiente subsistema

$$
\begin{aligned}
\dot{\boldsymbol{z}} & =\boldsymbol{K}_{l} \boldsymbol{G}_{l}(\cdot) \boldsymbol{\alpha}_{l}(\boldsymbol{\xi}, t)-D \boldsymbol{z}+\boldsymbol{F}_{l}-\boldsymbol{Q}_{l} \\
\dot{\boldsymbol{\alpha}}_{l} & =\boldsymbol{R} \boldsymbol{\rho}(t)
\end{aligned}
$$

donde $\boldsymbol{\alpha}_{l}(t)$ es el vector de las $l$ tasas específicas a estimar y $\boldsymbol{R}=\operatorname{diag}\left\{\bar{\rho}_{i}\right\}$ la matriz que contiene las cotas de las derivadas temporales. Nótese que $\boldsymbol{\rho}(t)$ es un vector de $l$ funciones desconocidas para las cuales se tiene $\|\boldsymbol{\rho}(t)\|_{\infty} \leqslant 1$. 


\subsection{Algoritmo por Modo Deslizante de se- gundo orden}

Con el objetivo de introducir un observador por modo deslizante de segundo orden, se considera la siguiente notación

$$
\begin{aligned}
\boldsymbol{G}_{o} & =\left(\boldsymbol{G}_{1}+\boldsymbol{G}_{2}\right) / 2, \\
\Delta \boldsymbol{G} & =\left(\boldsymbol{G}_{2}-\boldsymbol{G}_{1}\right) / 2, \\
\delta & =\left\|\boldsymbol{G}_{o}^{-1} \Delta \boldsymbol{G}\right\|_{\infty}, \\
\check{\boldsymbol{G}}_{l}(\cdot) & =\boldsymbol{G}_{o}^{-1} \boldsymbol{G}_{l}(\cdot),
\end{aligned}
$$

donde $\|\cdot\|_{\infty}$ es la norma matricial inducida correspondiente. A partir de las definiciones y con las suposiciones introducidas para $\boldsymbol{K}_{l}, \boldsymbol{G}_{\boldsymbol{o}}$ y $\boldsymbol{R}$, puede verse fácilmente que la matriz $\boldsymbol{K}_{l} \boldsymbol{G}_{o} \boldsymbol{R}$ es no singular. Para definir la superficie de modo deslizante, se considera el vector auxiliar $\boldsymbol{\sigma}$ definido por

$$
\boldsymbol{\sigma}=\left(\boldsymbol{K}_{l} \boldsymbol{G}_{o} \boldsymbol{R}\right)^{-1}(\boldsymbol{z}-\widehat{\boldsymbol{z}}),
$$

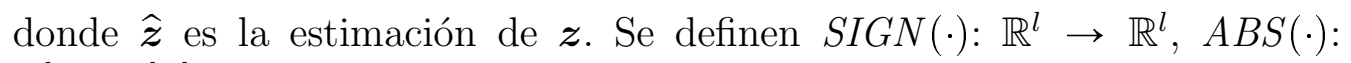
$\mathbb{R}^{l} \rightarrow \mathbb{R}^{l \times l}$, como extensiones de las funciones escalares $\operatorname{sign}(\cdot)$ y $|\cdot|$, respectivamente:

$$
\begin{aligned}
\operatorname{SIGN}(\boldsymbol{\sigma}) & =\operatorname{col}\left(\operatorname{sign}\left(\sigma_{i}\right)\right), \\
A B S(\boldsymbol{\sigma}) & =\operatorname{diag}\left\{\left|\sigma_{i}\right|\right\} .
\end{aligned}
$$

A partir de la expresión (4.9), se tiene que si existe un $T^{*}>0$ tal que $\boldsymbol{\sigma} \equiv \mathbf{0}$ para todo $t>T^{*}$, es decir si se logra que el sistema evolucione sobre la superficie de modo deslizante definida por $\boldsymbol{\sigma}(\boldsymbol{z})=\mathbf{0}$, entonces se obtiene $\hat{\boldsymbol{z}}(t) \equiv \boldsymbol{z}(t)$. Cuando esto ocurre, el estado estimado copia al estado medido. Como consecuencia de esta observación, es de interés obtener un sistema dinámico que logre que la variable definida en (4.9) se anule en tiempo finito.

Proposición 4.1 (Resultado principal) El sistema definido por

$$
\begin{aligned}
\dot{\hat{\boldsymbol{z}}} & =\boldsymbol{K}_{l}\left(\boldsymbol{G}_{l}(\cdot) \boldsymbol{R} \boldsymbol{u}_{1}+2 k_{2} \boldsymbol{G}_{o} \boldsymbol{R} \boldsymbol{u}_{2}\right)-D \boldsymbol{z}+\boldsymbol{F}_{l}-\boldsymbol{Q}_{l}, \\
\dot{\boldsymbol{u}}_{1} & =k_{1} S I G N(\boldsymbol{\sigma}) \\
\boldsymbol{u}_{2} & =(A B S(\boldsymbol{\sigma}))^{1 / 2} S I G N(\boldsymbol{\sigma}), \\
\hat{\boldsymbol{\alpha}} & =\boldsymbol{R} \boldsymbol{u}_{1}
\end{aligned}
$$

es un observador por modo deslizante de segundo orden de (4.6)-(4.7). Existen parámetros $k_{1}>1$ y $k_{2}>0$ para los cuales se obtiene convergencia en tiempo finito de las tasas específicas, es decir la condición $\widehat{\boldsymbol{\alpha}}(t) \equiv \boldsymbol{\alpha}_{l}(t)$ $\forall t>T^{*}$ se alcanza para cierto $T^{*}>0$. 
Para demostrar la propuesta anterior, a partir de $\widetilde{\boldsymbol{\alpha}}=\boldsymbol{\alpha}_{l}-\widehat{\boldsymbol{\alpha}}$, la dinámica del error está dada por $(\boldsymbol{\sigma}, \widetilde{\boldsymbol{\alpha}})$ :

$$
\begin{aligned}
& \dot{\boldsymbol{\sigma}}=\boldsymbol{R}^{-1}\left(\breve{\boldsymbol{G}}_{l}(\cdot) \widetilde{\boldsymbol{\alpha}}-2 k_{2} \boldsymbol{R} \boldsymbol{u}_{2}\right), \\
& \dot{\tilde{\boldsymbol{\alpha}}}=\boldsymbol{R}\left(\boldsymbol{\rho}(t)-k_{1} S I G N(\boldsymbol{\sigma})\right) .
\end{aligned}
$$

Aplicando el cambio de coordenadas $\left(\boldsymbol{x}_{1}, \boldsymbol{x}_{2}\right)=\left(\boldsymbol{R} \boldsymbol{u}_{2}, \widetilde{\boldsymbol{\alpha}}\right)$ al sistema (4.12) resulta

$$
\begin{aligned}
& \dot{\boldsymbol{x}}_{1}=\boldsymbol{R}\left(A B S\left(\boldsymbol{x}_{1}\right)\right)^{-1}\left(-k_{2} \boldsymbol{x}_{1}+\frac{\breve{\boldsymbol{G}}_{l}(\cdot)}{2} \boldsymbol{x}_{2}\right) \\
& \dot{\boldsymbol{x}}_{2}=\boldsymbol{R}\left(A B S\left(\boldsymbol{x}_{1}\right)\right)^{-1}\left(A B S\left(\boldsymbol{x}_{1}\right) \boldsymbol{\rho}(t)-k_{1} \boldsymbol{x}_{1}\right),
\end{aligned}
$$

donde se utilizaron las expresiones (ver ec. (4.12c))

$$
\begin{aligned}
S I G N\left(\boldsymbol{x}_{1}\right) & =S I G N(\boldsymbol{\sigma}), \\
A B S\left(\boldsymbol{x}_{1}\right) & =\boldsymbol{R}(A B S(\boldsymbol{\sigma}))^{1 / 2} .
\end{aligned}
$$

Ahora, dada la $i$-ésima tasa específica se puede armar un vector $\boldsymbol{\zeta}_{i}$ con la $i$-ésima componente de $\boldsymbol{x}_{1}$ y $\boldsymbol{x}_{2}$ (es decir $\boldsymbol{\zeta}_{i}=\left[\begin{array}{ll}x_{1 i} & x_{2 i}\end{array}\right]^{T}$ ). La ecuación diferencial correspondiente es

$$
\dot{\boldsymbol{\zeta}}_{i}=\frac{\bar{\rho}_{i}}{\left|x_{1 i}\right|}\left(\begin{array}{cc}
-k_{2} & \check{\boldsymbol{G}}_{l(i, i)} / 2 \\
-\left(k_{1}-\rho_{i}(t) \operatorname{sign}\left(x_{1 i}\right)\right) & 0
\end{array}\right) \boldsymbol{\zeta}_{i}=\frac{\bar{\rho}_{i}}{\left|x_{1 i}\right|} \boldsymbol{A}(t) \boldsymbol{\zeta}_{i}
$$

donde $\breve{\boldsymbol{G}}_{l(i, i)}$ es la componente $(i, i)$ de la matriz $\breve{\boldsymbol{G}}_{l}$. Además, considerando que

$$
\boldsymbol{G}_{l}(\cdot) \in\left\{\boldsymbol{G}_{o}+\Delta \boldsymbol{G} \boldsymbol{U}_{l}\right\}
$$

se tiene

$$
\check{\boldsymbol{G}}_{l}(\cdot)=\boldsymbol{G}_{o}^{-1} \boldsymbol{G}_{l} \in\left\{\boldsymbol{I}_{l}+\boldsymbol{G}_{o}^{-1} \Delta \boldsymbol{G} \boldsymbol{U}_{l}\right\},
$$

donde $\boldsymbol{I}_{l}$ es la matriz identidad de dimensión $l$ y $\boldsymbol{U}_{l}$ es un matriz diagonal de $(l \times l)$ con $\left\|\boldsymbol{U}_{l}\right\|_{\infty} \leqslant 1$. Considerando la expresión anterior puede mostrarse que las matrices $\boldsymbol{A}(t)$ definidas en (4.17) pertenecen al conjunto $\mathcal{A}$ definido por

$$
\begin{aligned}
\mathcal{A} & =c o \bigcup_{\mathrm{i}} \boldsymbol{A}_{\mathrm{i}}, \quad \mathrm{i}=1, \ldots, 4 \\
\boldsymbol{A}_{\mathrm{i}} & =\left[\begin{array}{cc}
-k_{2} & \frac{1}{2}\left(1+\delta v_{\mathrm{i}}\right) \\
-\left(k_{1}-u_{\mathrm{i}}\right) & 0
\end{array}\right], \\
u & =\{-1,-1,1,1\}, \quad v=\{-1,1,-1,1\} .
\end{aligned}
$$

Con el objetivo de demostrar la convergencia en tiempo finito de las coordenadas $\boldsymbol{\zeta}_{i}$ se propone la función de Lyapunov común $V\left(\boldsymbol{\zeta}_{i}\right)=\sum_{i} \boldsymbol{\zeta}_{i}^{T} \boldsymbol{P} \boldsymbol{\zeta}_{i}$. Utilizando (4.17), la derivada temporal de $V(t)$ resulta en

$$
\dot{V}(t)=\sum_{i} \frac{\bar{\rho}_{i}}{\left|x_{1 i}\right|} \boldsymbol{\zeta}_{i}^{T}\left(\boldsymbol{A}^{T}(t) \boldsymbol{P}+\boldsymbol{P} \boldsymbol{A}(t)\right) \boldsymbol{\zeta}_{i} .
$$


El requerimiento es encontrar una matriz $\boldsymbol{P}>0$ tal que $\dot{V}(t)<0$ sobre todas las soluciones de (4.17). Para esto se considera la siguiente proposición.

Proposición 4.2 Dada la inclusión diferencial politópica

$$
\dot{\boldsymbol{\zeta}}=\boldsymbol{A}(t) \boldsymbol{\zeta}, \quad \boldsymbol{A}(t) \in \mathcal{A}
$$

con $\mathcal{A}$ definido en (4.20). Para cada $k_{1}>1$ y $0<\delta<1$ pueden encontrarse valores positivos de $k_{2}$ tal que la expresión (4.22) es cuadráticamente estable para toda $\boldsymbol{A}(t) \in \mathcal{A}$.

La estabilidad del sistema (4.22) fue probada en [100] para el caso en que $\delta=0$ con la función de Lyapunov $V(\boldsymbol{\zeta})=\boldsymbol{\zeta}^{T} \boldsymbol{P} \boldsymbol{\zeta}$. La Proposición 4.2 es una extensión para considerar el caso $\delta>0$. La diferencial principal a la hora de obtener la solución numérica consiste en el requerimiento de una grilla que cubra los valores de $\left(k_{1}, \delta\right)$ en lugar de sólo $k_{1}$. Esto es requerido para incluir a todos los sistemas descriptos con la expresión (4.22).

La inclusión diferencial politópica se dice cuadráticamente estable si existe una función $V(\boldsymbol{z})=\boldsymbol{z}^{T} \boldsymbol{P} \boldsymbol{z}, \boldsymbol{P}>0$ tal que su valor decrece sobre cualquier trayectoria no nula de (4.22).

Dado que $\dot{V}(\boldsymbol{z})=\boldsymbol{z}^{T}\left(\boldsymbol{A}^{T}(t) \boldsymbol{P}+\boldsymbol{P} \boldsymbol{A}(t)\right) \boldsymbol{z}$, una condición necesaria y suficiente para estabilidad cuadrática es

$$
\begin{aligned}
\boldsymbol{P} & >0, \\
\boldsymbol{A}^{T}(t) \boldsymbol{P}+\boldsymbol{P} \boldsymbol{A}(t) & <0 \quad \forall \boldsymbol{A}(t) \in \mathcal{A} .
\end{aligned}
$$

Esta condición es equivalente a determinar si existe una matriz de Lyapunov $\boldsymbol{P}$ común a todos los vértices del politopo $\mathcal{A}$, es decir tal que verifique las siguientes restricciones

$$
\mathcal{F}=\left\{\begin{array}{l}
\boldsymbol{P}>0 \\
\boldsymbol{Q}_{i} \triangleq-\left(\boldsymbol{A}_{i}^{T} \boldsymbol{P}+\boldsymbol{P} \boldsymbol{A}_{i}\right)>0
\end{array}\right\},
$$

para $i=1 \ldots 4$.

Ahora las matrices $\boldsymbol{A}_{1}, \boldsymbol{A}_{2}, \boldsymbol{A}_{3}$ y $\boldsymbol{A}_{4}$ se reescriben en una forma más conveniente:

$$
\boldsymbol{A}_{i}=k_{2} \boldsymbol{A}_{0}+\boldsymbol{A}_{i}^{*}
$$

donde

$$
\begin{aligned}
& \boldsymbol{A}_{0}=\left[\begin{array}{cc}
-1 & 0 \\
0 & 0
\end{array}\right], \\
& \boldsymbol{A}_{1}^{*}=\left[\begin{array}{cc}
0 & \frac{1}{2}(1+\delta) \\
-\left(k_{1}-1\right) & 0
\end{array}\right], \\
& \boldsymbol{A}_{2}^{*}=\left[\begin{array}{cc}
0 & \frac{1}{2}(1+\delta) \\
-\left(k_{1}+1\right) & 0
\end{array}\right], \\
& \boldsymbol{A}_{3}^{*}=\left[\begin{array}{cc}
0 & \frac{1}{2}(1-\delta) \\
-\left(k_{1}-1\right) & 0
\end{array}\right], \\
& \boldsymbol{A}_{4}^{*}=\left[\begin{array}{cc}
0 & \frac{1}{2}(1-\delta) \\
-\left(k_{1}+1\right) & 0
\end{array}\right] .
\end{aligned}
$$




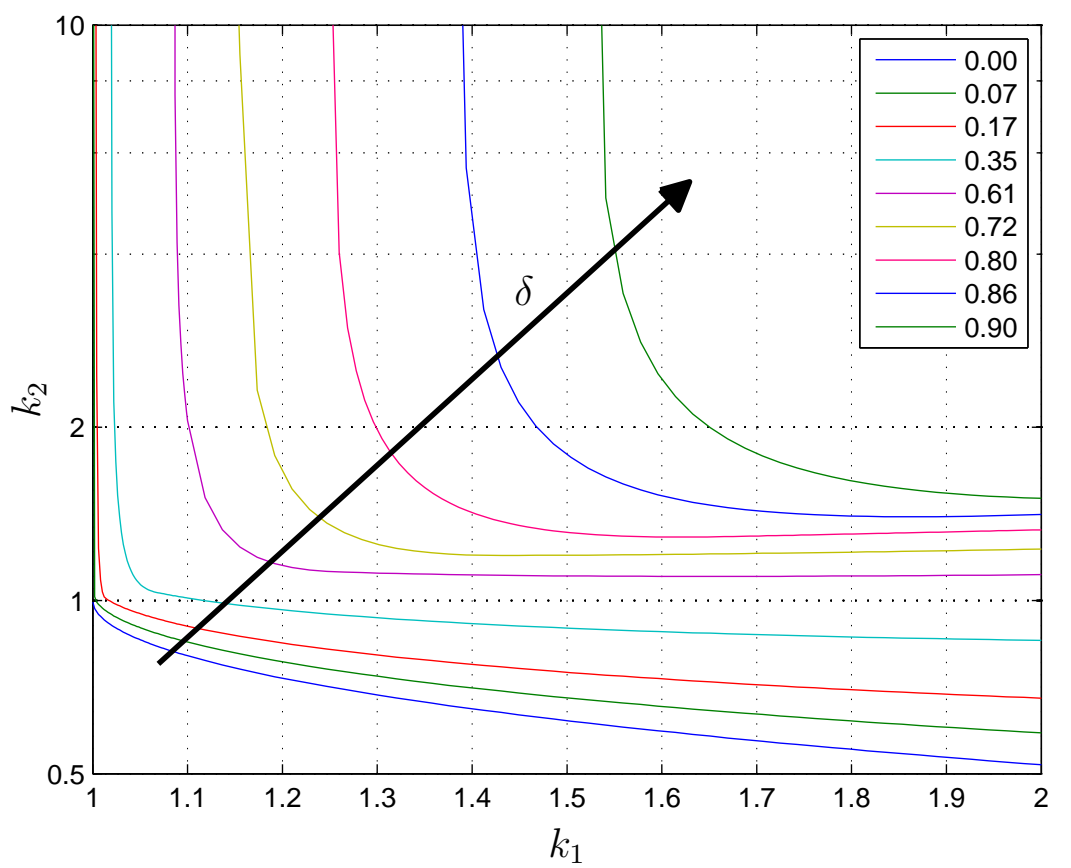

Figura 4.1: Valores mínimos de $k_{2}$ vs. $k_{1}$ para los cuales el sistema (4.22) es estable.

La existencia de una matriz $\boldsymbol{P}$ para cualquier $k_{1}>1$ y $0<\delta<1$ puede determinarse analizando la factibilidad del siguiente problema de autovalores generalizado (GEVP) en $\boldsymbol{P}$ y $k_{2}$ [121]:

$$
\begin{array}{cc}
\text { mín } & k_{2} \\
\text { s.t. } & k_{2}>0, \quad \boldsymbol{P}>0, \quad \mathcal{F}^{*},
\end{array}
$$

con

$$
\mathcal{F}^{*}=\left\{\left(\boldsymbol{A}_{i}^{*^{T}} \boldsymbol{P}+\boldsymbol{P} \boldsymbol{A}_{i}^{*}\right)+k_{2}\left(\boldsymbol{A}_{0}^{T} \boldsymbol{P}+\boldsymbol{P} \boldsymbol{A}_{0}\right) \prec 0 ;\right\},
$$

para $i=1 \ldots 4$.

El problema de autovalores generalizados es un problema cuasi-convexo. En este caso, se puede resolver aplicando un algoritmo de bisección en $k_{2}$ y determinando si es factible la desigualdad matricial lineal (LMI) resultante. Para esto, se hace una grilla que cubra los valores de $k_{1}$ y $\delta$ deseados y se resuelven las LMI. En este caso se utilizó el software YALMIP [122]. La Figura 4.1 muestra el conjunto de valores de $k_{1}$ y $k_{2}$ para los cuales el problema LMI es factible parametrizado con los valores de $\delta$. Es decir, dado un valor $\delta$, para todos los puntos por encima de la curva correspondiente, la expresión (4.22) es cuadráticamente estable.

Luego, los valores para $k_{1}$ y $k_{2}$ para la Proposición 4.1 se obtienen de la aplicación de la Proposición 4.2. Esto se realiza de la siguiente manera: dado un $k_{1}>1$ y cierto valor de $\delta$, se selecciona el valor de $k_{2}$ tal que la expresión (4.22) sea estable. Dado que $\delta$ es el máximo elemento de la matriz 
$\left\|\boldsymbol{G}_{o}^{-1} \Delta \boldsymbol{G}\right\|$, este valor es de utilidad para obtener $\dot{V}(t)<0$ para todas las tasas de reacción.

Finalmente, para dos valores factibles $k_{1}$ y $k_{2}$, el sistema alcanza un entorno de la superficie de deslizamiento y de este modo se establece el régimen deslizante. A partir de ese momento, debido a la condición de invariancia se tiene $(\boldsymbol{\sigma} \equiv \mathbf{0})$ [103]. Como resultado, para cierto tiempo finito $T^{*}$, $\widehat{\boldsymbol{z}}(t) \equiv \boldsymbol{z}(t) \forall t>T^{*}$. Igualando las expresiones (4.6) y (4.12a), se obtiene $\widehat{\boldsymbol{\alpha}}(t)=\boldsymbol{\alpha}_{l}(\boldsymbol{\xi}, t)$. Nótese en la expresión (4.12c) que cuando el sistema se encuentra restringido a la dinámica impuesta por $\boldsymbol{\sigma}=\mathbf{0}$, la matriz $A B S(\boldsymbol{\sigma})$ es la matriz nula, y de este modo $\boldsymbol{u}_{2}=\mathbf{0}$.

\subsection{Resultados experimentales}

Como ejemplo de aplicación del observador, se estiman la tasa específica de crecimiento y la tasa neta de producción de etanol de una cepa de $S$. cerevisiae cultivada en modo continuo. La propuesta fue evaluada bajo dos escenarios diferentes. En primer lugar, el observador fue probado en condición de funcionamiento normal y en el segundo caso fue evaluado ante dos fallas típicas del sensor, las cuales fueron generadas digitalmente.

Se dispone de mediciones en línea de la concentración de biomasa $(x)$ y la concentración de etanol $(e)$. La biomasa se midió con un sensor basado en medición de densidad óptica [123]. Las muestras del sensor obtenidas cada 12 seg. se filtraron en una ventana temporal de 120 seg. Por otro lado, la concentración de etanol se midió con un sensor comercial (Raven Biotech) con tiempo de muestreo de $120 \mathrm{seg}$. Cabe destacar que estos tiempos de muestreo son mucho menores a la dinámica del proceso. El volumen de operación del biorreactor es de 3 litros y la fermentación se extendió por casi 94 horas. Durante las primeras 23 horas, se operó en modo por lote. Luego se aplicó el perfil de dilución que se muestra en línea a trazos en la Figura 4.3b. Puede apreciarse que la tasa de dilución cambió del valor 0,18 a $0,22 \mathrm{~h}^{-1}$ en $t \approx 50 \mathrm{~h}$.

De acuerdo con el balance de masas presentado en la sección 2.1.4, la dinámica de las variables en el cultivo continuo resultan

$$
\begin{aligned}
& \dot{x}=\mu x-D x, \\
& \dot{s}=-q_{s} x+D\left(S_{i n}-s\right), \\
& \dot{e}=q_{e} x-D e,
\end{aligned}
$$

con $D=F_{\text {in }} / v$ la tasa de dilución, $s$ la concentración de sustrato, $S_{\text {in }}$ la concentración de sustrato en la entrada y $v$ el volumen del biorreactor.

Dado que $x$ y $e$ son variables medidas, el subsistema a considerar es de dimensión $l=2$. Nótese en las expresiones (4.29) que $\mu$ y $q_{e}$ representan tasas específicas por unidad de biomasa. Luego el subsistema en la forma 
(4.6) es

$$
\dot{z}=\left(\begin{array}{ll}
1 & 0 \\
0 & 1
\end{array}\right)\left(\begin{array}{ll}
x & 0 \\
0 & x
\end{array}\right)\left(\begin{array}{c}
\mu \\
q_{e}
\end{array}\right)-D \boldsymbol{z},
$$

con $\boldsymbol{z}=\left[\begin{array}{ll}x & e\end{array}\right]^{T}, \boldsymbol{\alpha}_{l}=\left[\begin{array}{ll}\mu & q_{e}\end{array}\right]^{T}$ y $\boldsymbol{F}_{l}=\boldsymbol{Q}_{l}=\mathbf{0}$. En esta factorización se tiene $\boldsymbol{K}_{l}=\boldsymbol{I}_{2}$ y $\boldsymbol{G}_{l}=x \boldsymbol{I}_{2}$.

Dado que la matriz $\boldsymbol{G}_{l}$ contiene en su diagonal a la concentración de biomasa, las matrices $\boldsymbol{G}_{1}$ y $\boldsymbol{G}_{2}$ (definidas en (4.8)) contienen en la diagonal una cota superior $(\bar{x})$ y una inferior $(\underline{x})$ para la concentración de microorganismo. En este caso se seleccionaron los valores $\underline{x}=2 \mathrm{~g} / \mathrm{L}$ y $\bar{x}=18 \mathrm{~g} / \mathrm{L}$, los cuales resultan suficientemente conservativos para la excursión esperada de $x(t)$. De esta manera, las matrices $\boldsymbol{G}_{1}$ y $\boldsymbol{G}_{2}$ resultan

$$
\begin{aligned}
& \boldsymbol{G}_{1}=2 \boldsymbol{I}_{2}, \\
& \boldsymbol{G}_{2}=18 \boldsymbol{I}_{2},
\end{aligned}
$$

y luego se obtiene $\boldsymbol{G}_{o}=10 \boldsymbol{I}_{2}, \Delta \boldsymbol{G}=8 \boldsymbol{I}_{2}$ y $\delta=0,80$.

Para las cotas $\bar{\rho}_{i}$ se seleccionaron los valores 0,1 y 0,25 , respectivamente y se obtuvo $\boldsymbol{R}=\operatorname{diag}\{0,1 \quad 0,25\}$. Estas cotas pueden ajustarse en la práctica de acuerdo a experiencia previa que se tenga del proceso a monitorear, tomando información de simulaciones del proceso o analizando la estequiometría del proceso [67, 109].

Los valores obtenidos para la ganancia $k_{2}$, en función de valores elegidos para $k_{1}$, fueron hallados resolviendo el problema (4.27)-(4.28). Los resultados se presentan en la Figura 4.1. Puede apreciarse para cualquier $\delta$ que, mientras menor sea $k_{1}$, mayor resulta el valor mínimo de $k_{2}$. Para obtener un problema de minimización factible para $\delta=0,8$ con un valor de $k_{2}$ no muy grande, se seleccionó $k_{1}=1,35$. A partir de resolver (4.27)-(4.28), el mínimo $k_{2}$ resulta 1,5715 , eligiéndose $k_{2}=1,75$. Cabe destacar que ésta no es la única metodología para diseñar las ganancias $k_{1}$ y $k_{2}$. Otra posibilidad que puede explorarse es la de ganancias adaptivas [124, 125]. Recientemente se ha publicado un enfoque para el diseño de ganancias variables que permite considerar cotas variantes en el tiempo para las perturbaciones a rechazar [101].

El observador fue iniciado con la primera muestra obtenida, es decir $\hat{\boldsymbol{z}}\left(t_{0}\right)=\left(x\left(t_{0}\right), e\left(t_{0}\right)\right)$, mientras que para los estados que representan a las tasas específicas se seleccionó $\left(\widehat{\mu}\left(t_{0}\right), \widehat{q}_{e}\left(t_{0}\right)\right)=(0,0)$. La Figura 4.2 muestra los valores medidos de biomasa y etanol y los correspondientes estados del observador $\hat{z}_{1}$ y $\hat{z}_{2}$. Como puede apreciarse, los estados del observador se mantienen prácticamente solapados con las variables que estiman. De esta manera, los estados $\widehat{z}_{1} \mathrm{y} \widehat{z}_{2}$ copian la dinámica de $x$ y $e$, respectivamente.

La Figura 4.3 presenta $\hat{\mu}(t)$ y la coordenada $\sigma_{1}$. En este proceso, el perfil de dilución fue aplicado en operación a lazo abierto, es decir que $\mu$ no fue regulada mediante lazo cerrado. Como se explicó en la sección 


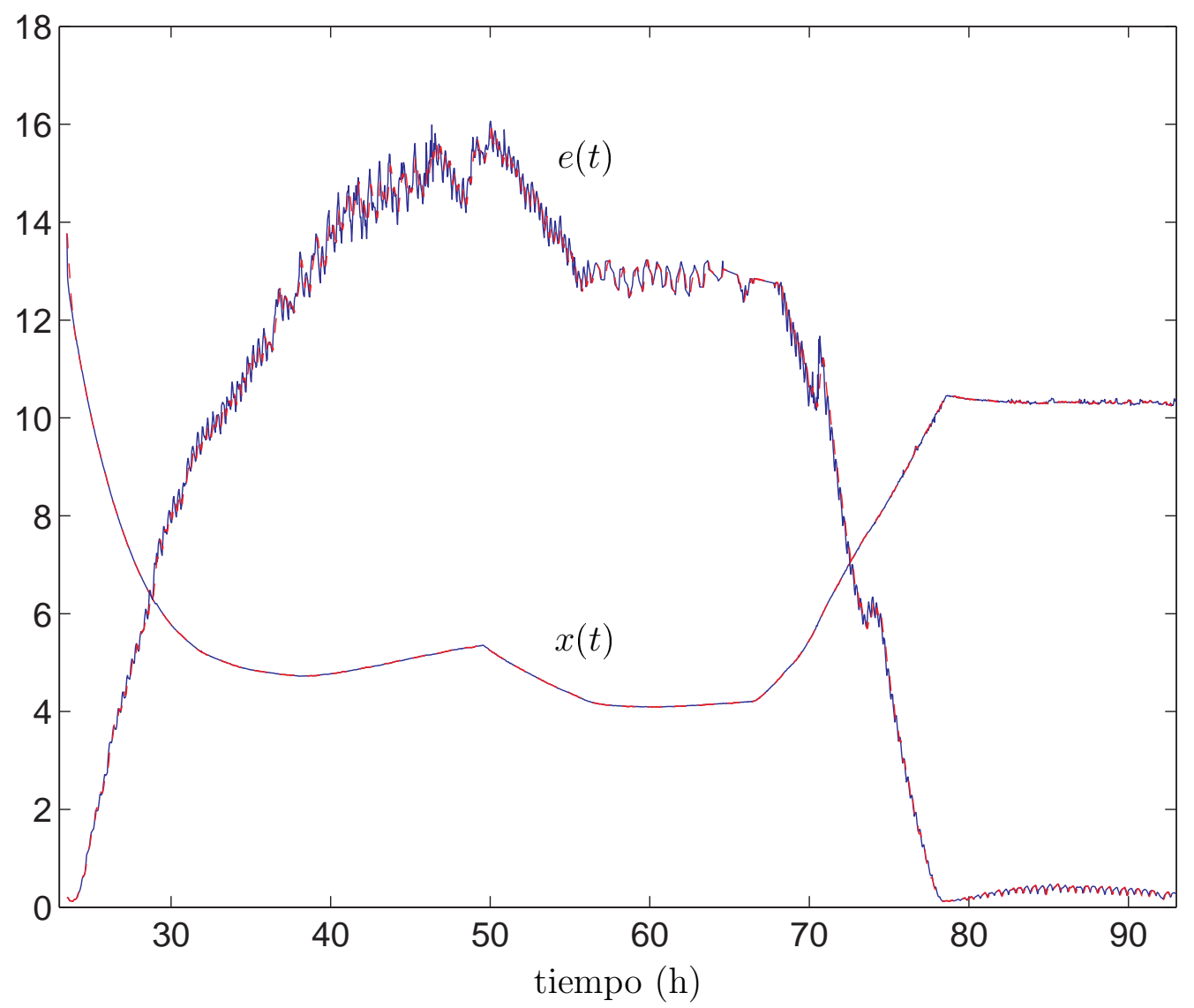

Figura 4.2: Perfil temporal de $x(t)$ (línea azul), $\widehat{x}(t)$ (línea roja punteada) y $e(t)$ (línea azul), $\widehat{e}(t)$ (línea roja punteada) en el proceso de fermentación continua (4.29).

2.1.3, la operación en estado estacionario de un cultivo continuo implica que $\mu=D$ (ec. (2.32a)). Sin embargo, en el intervalo comprendido entre las horas 67 y 79 , se aprecia que $\mu$ resultó mayor que la dilución debido al consumo de etanol. Esto ilustra cómo se puede utilizar la propuesta con fines de monitoreo del proceso, ya que no sólo permite detectar el consumo de etanol sino también se puede cuantificar la tasa de crecimiento durante este periodo de tiempo. 

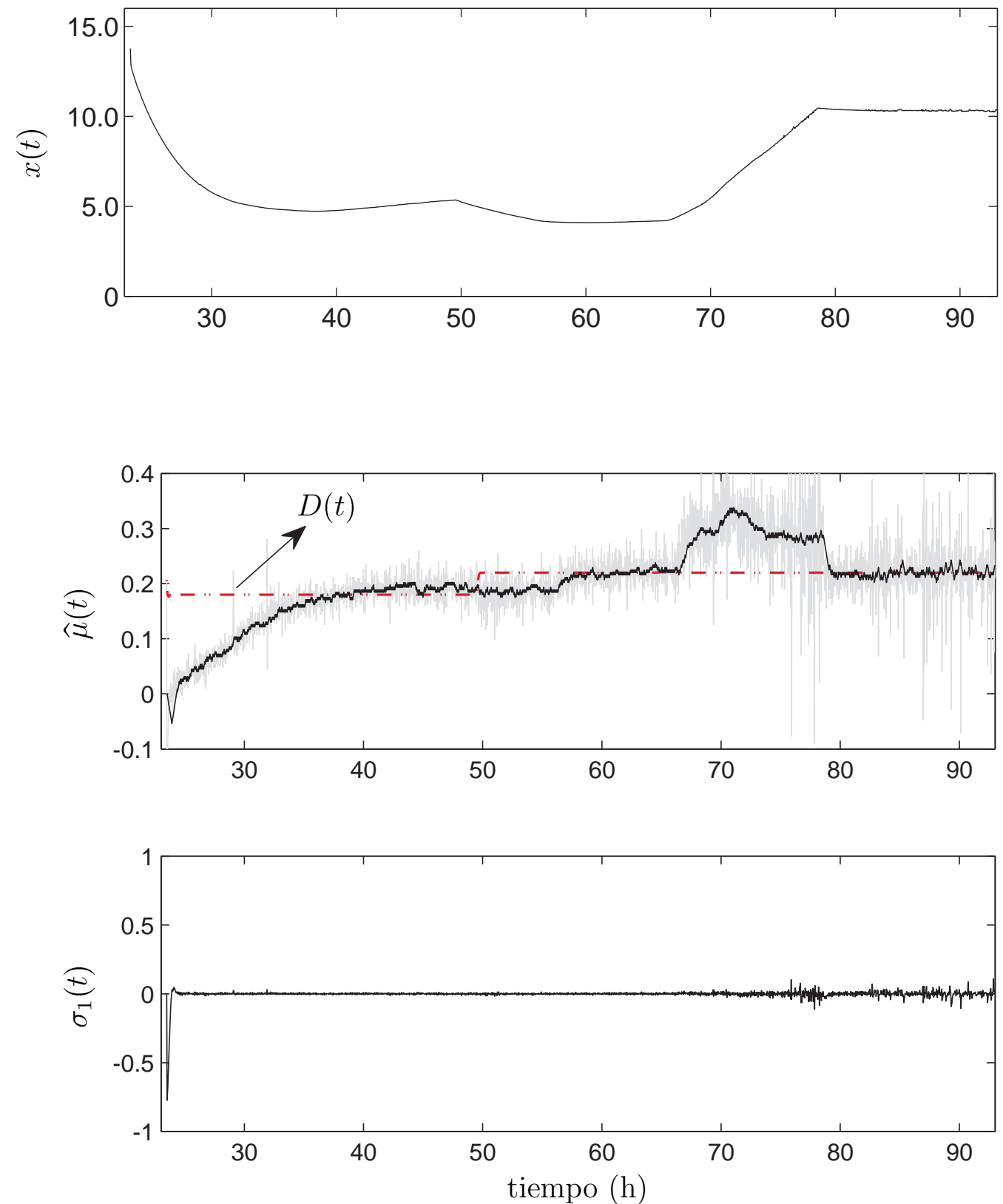

Figura 4.3: Arriba: concentración de biomasa medida. Centro: tasa específica de crecimiento estimada $\widehat{\mu}(t)$ con el observador de MD (línea negra) y ec. (4.31) (línea gris), tasa de dilución (línea roja discontinua). Abajo: coordenada $\sigma_{1}$. 

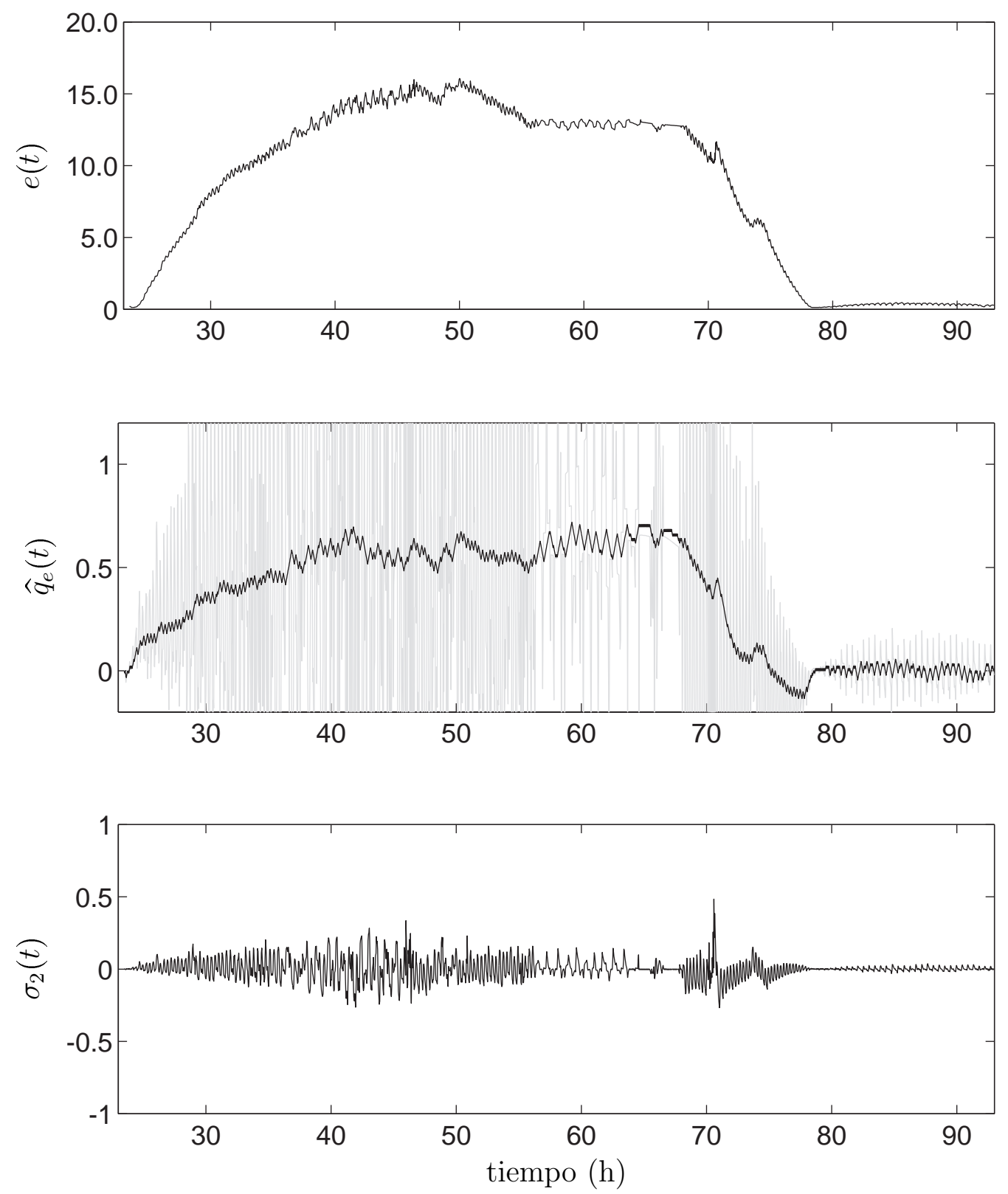

Figura 4.4: Arriba: concentración de etanol medida. Centro: estimación de la tasa específica de producción de etanol $\widehat{q}_{e}(t)$ con el observador por MD (línea negra) y ec. (4.31) (línea gris). Abajo: coordenada $\sigma_{2}$.

La estimación de $q_{e}(t)$ es una medida de la producción neta de etanol, es decir, el balance entre etanol excretado debido al crecimiento fermentativo en $s$ y etanol consumido debido al crecimiento oxidativo. La Figura 4.4 presenta $\widehat{q}_{e}(t)$ y la coordenada $\sigma_{2}$. La disminución observada en $q_{e}$ de $t \approx 67$ h ocurre en concordancia con el crecimiento observado en la Figura 4.3. 
La expresión (4.31) presenta una estimación cruda de $\alpha(t)$ obtenida invirtiendo el modelo (4.6)

$$
\widehat{\alpha}(t)=\boldsymbol{G}_{l}^{-1} \boldsymbol{K}_{l}^{-1}\left(\dot{\boldsymbol{z}}+D \boldsymbol{z}-\boldsymbol{F}_{l}+\boldsymbol{Q}_{l}\right) .
$$

Si bien esta solución es más simple que la mayoría de los observadores propuestos, el resultado es fuertemente afectado por el ruido de medición, tal como se muestra en las Figuras 4.3 y 4.4 en trazos grises. Una posible solución sería añadir un filtro, pero el retraso y la dinámica del filtro podrían tener efectos negativos en el desempeño de un sistema a lazo cerrado.

\subsection{Comparación con observadores de alta ganancia en caso de fallas típicas}

En este último caso, los resultados se compararon con un observador de alta ganancia. En particular, con el estimador de alta ganancia descripto por las siguientes expresiones [66]

$$
\begin{aligned}
\left(\begin{array}{c}
\dot{\hat{x}} \\
\dot{\hat{e}}
\end{array}\right) & =\left(\begin{array}{ll}
\hat{x} & 0 \\
0 & \hat{x}
\end{array}\right)\left(\begin{array}{c}
\hat{\mu} \\
\hat{q}_{e}
\end{array}\right)-\frac{F_{i n}}{v}\left(\begin{array}{l}
\hat{x} \\
\hat{e}
\end{array}\right)+2 \theta_{1}\left(\begin{array}{c}
x-\hat{x} \\
e-\hat{e}
\end{array}\right), \\
\left(\begin{array}{c}
\dot{\hat{\mu}} \\
\dot{\hat{q}}
\end{array}\right) & =\frac{\theta_{1}^{2}}{\widehat{x}}\left(\begin{array}{l}
x-\hat{x} \\
e-\hat{e}
\end{array}\right) .
\end{aligned}
$$

La diferencia principal entre los observadores de alta ganancia y los de modo deslizante es que en los del primer tipo existe una dinámica añadida por el observador. Este hecho es relevante en aplicaciones de lazo cerrado. Por ejemplo, si se consideran las estimaciones del observador (4.32) para realimentación, se añaden $2 l$ integradores a la dinámica de lazo cerrado. En consecuencia, la estabilidad del bucle cerrado debe ser analizada considerando que la realimentación proviene de las señales del observador. La misma observación es válida para otros algoritmos como los observadores asintóticos. Por otro lado, la convergencia en tiempo finito provista por el observador por modo deslizante hace que no haya dinámicas adicionales. Este hecho simplifica el diseño del sistema de control de lazo cerrado.

La Figura 4.5 muestra dos fallas típicas del sensor de medición de biomasa: un offset en el intervalo $(57,63)$ horas y algunos picos en $t=81$ h. Las posibles causas para este tipo de fallos incluyen descalibración del sensor, mala agitación del cultivo, burbujas en el dispositivo de medición, entre otras. Estos problemas deberían ser detectados a tiempo para tomar las acciones correctivas necesarias. Nótese en las expresiones (4.29) que un problema en la medición de $x$ afecta no sólo las estimaciones de $\mu$ sino también las de $q_{e}$.

$\mathrm{El}$ algoritmo (4.32) fue iniciado con las mismas condiciones que el observador por modo deslizante propuesto. El parámetro $\theta_{1}=4$ fue seleccionado 


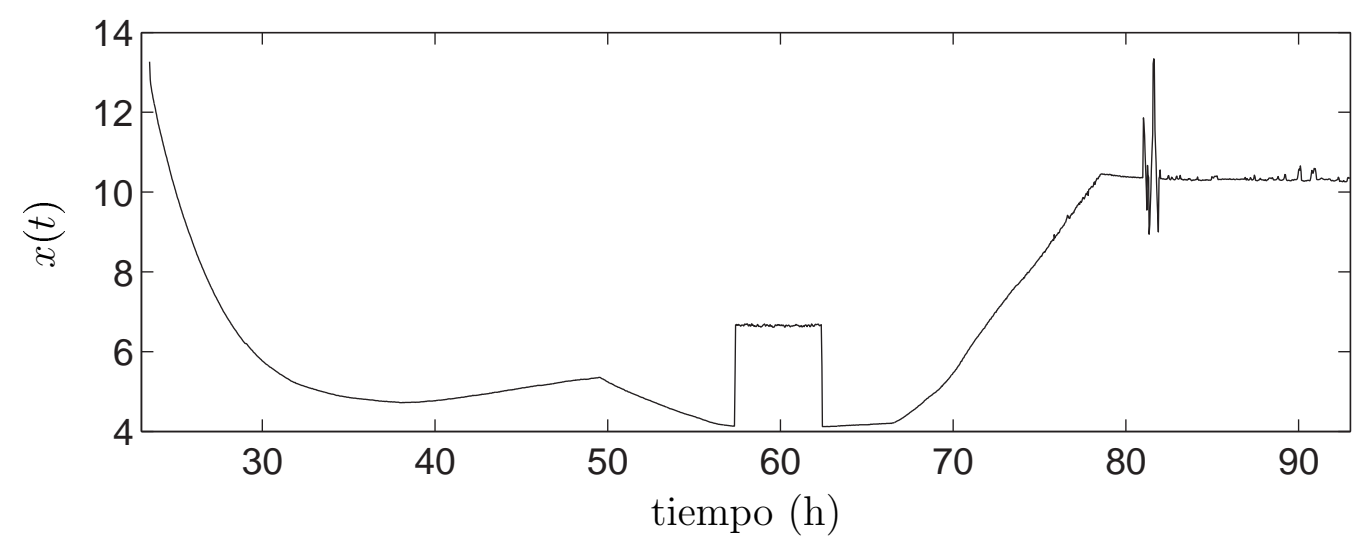

Figura 4.5: Perfil temporal de $x(t)$ con dos fallas típicas en la medición.

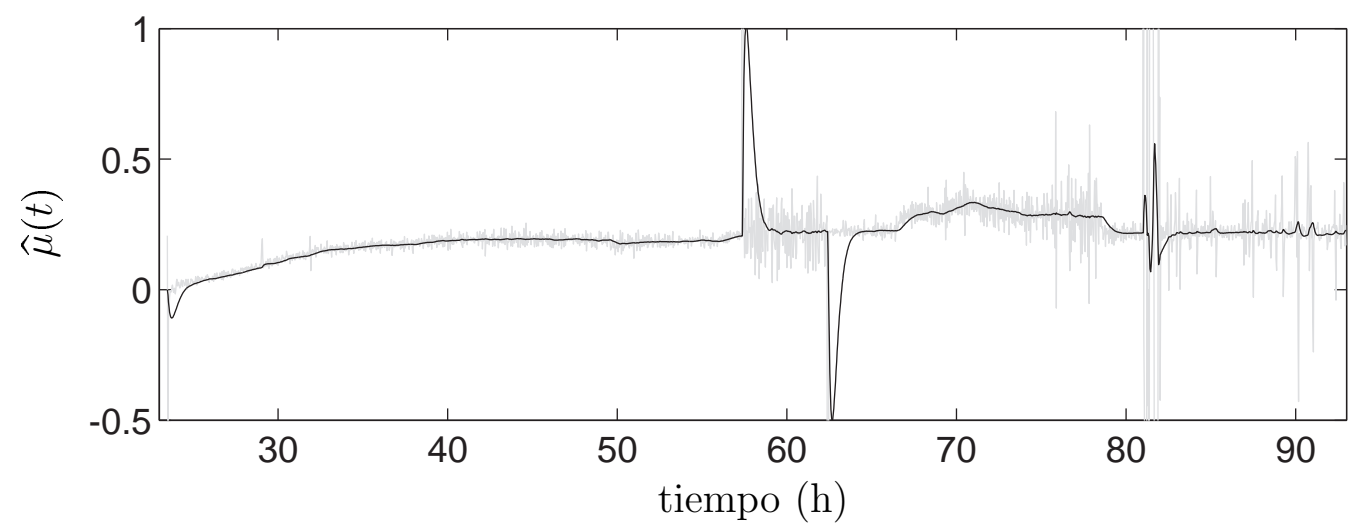

Figura 4.6: Respuesta obtenida con el observador de alta ganancia ante falla en el sensor de biomasa: algoritmo (4.32) (línea negra) vs ec. (4.31) (línea gris).

con el objetivo de tener respuestas temporales comparables con las del observador propuesto. Si bien $\theta_{1}$ puede elegirse lo suficientemente alto como para asegurar la velocidad de convergencia deseada, el ajuste de este parámetro involucra un compromiso entre velocidad de convergencia y sensibilidad al ruido de medición. Además, su simplicidad (sólo hay un parámetro para sintonizar) puede a su vez ser problemática cuando las mediciones tienen diferente nivel de ruido (como en el caso de mediciones de biomasa y etanol presentado en la Figura 4.2).

El resultado obtenido con el algoritmo de alta ganancia ante fallos del sensor de biomasa se presenta en la Figura 4.6. Dado el offset en $x$, se observa una respuesta con un gran sobrepaso en $\widehat{\mu}$. Además, los picos de $x$ generan cambios rápidos en $\widehat{\mu}$. Si bien este comportamiento de la salida exhibe la presencia de un fallo, la respuesta no es aceptable para un control de lazo cerrado. Por otro lado, el resultado de estimación de $\mu$ con el observador propuesto bajo el mismo escenario se presenta en la Figura 4.7. Como se puede observar, la coordenada $\sigma_{1}$ detecta rápidamente las fallas, lo que 

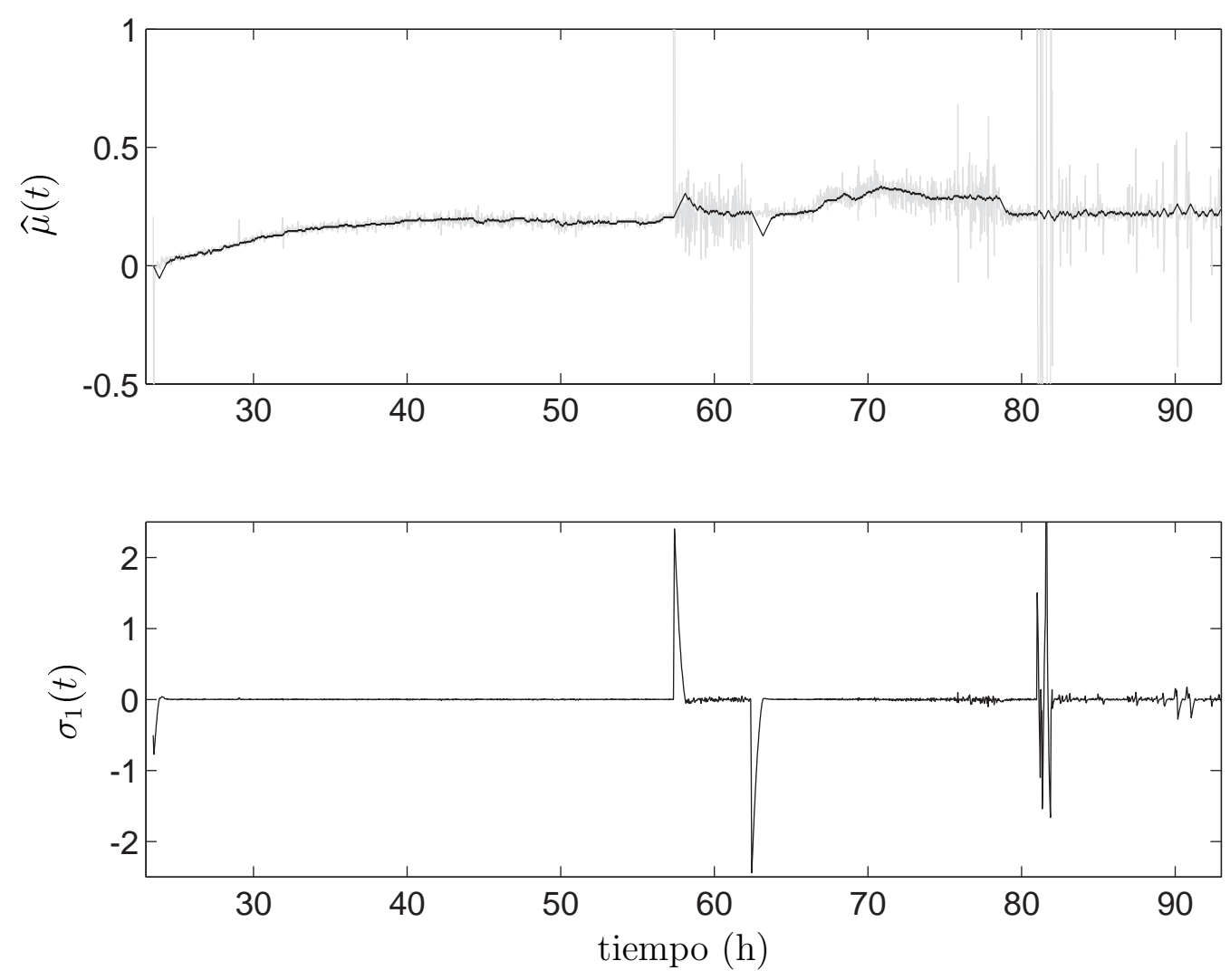

Figura 4.7: Estimación de $\mu(t)$ ante falla en el sensor de biomasa. Arriba: algoritmo propuesto (línea negra) vs expresión (4.31) (línea gris). Abajo: coordenada $\sigma_{1}(t)$.

muestra la potencialidad del observador por modo deslizante como detector de fallas. En cuanto a las variables estimadas, el error de estimación durante el offset se reduce significativamente. Esto se debe a que la derivada de cada estimación está limitada por el observador. Nótese que los picos en

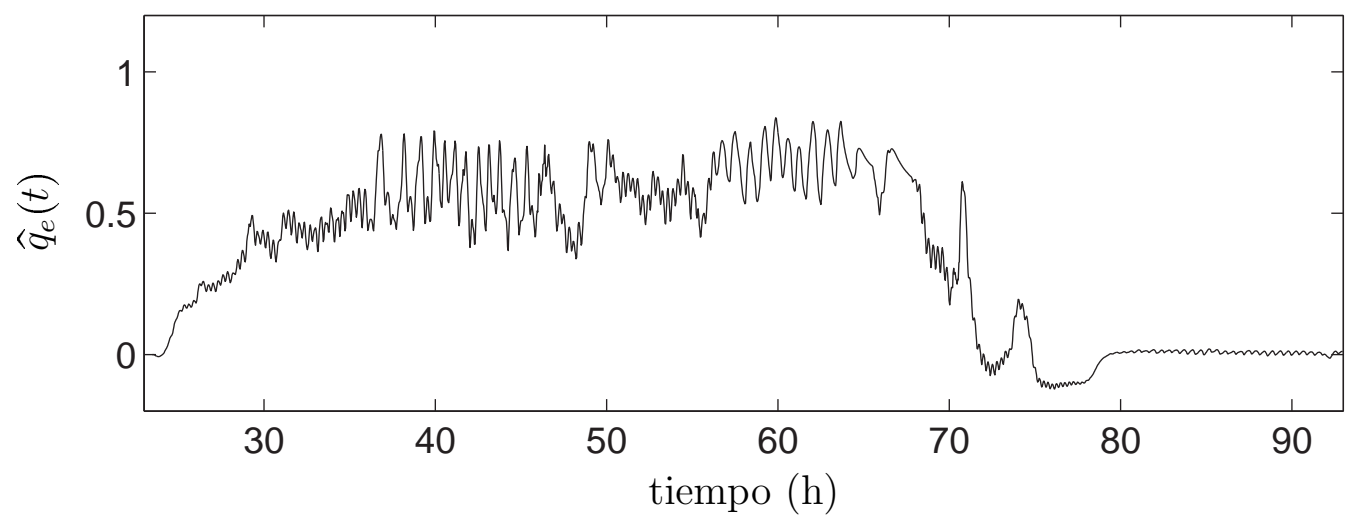

Figura 4.8: Tasa específica de formación de etanol estimada $\widehat{q}_{e}(t)$ con el observador de alta ganancia. 
$t=81 \mathrm{~h}$ son completamente rechazados por el observador y detectados en la coordenada $\sigma_{1}$. Finalmente, la estimación de $q_{e}$ obtenida se presenta en la Figura 4.8. Para las ganancias seleccionadas, el observador de alta ganancia exhibe una respuesta temporal más ruidosa que la obtenida con el observador por modo deslizante.

\subsection{Resumen del capítulo}

En este capítulo se abordó el problema de la estimación en línea de tasas específicas de producción y consumo de diferentes sustancias. Para ello se propuso un observador de modo deslizante de segundo orden, el cual es capaz de estimar múltiples tasas con convergencia en tiempo finito. Esta propiedad es especialmente importante en las aplicaciones de control porque de esta manera el observador no añade dinámica que podría dificultar el análisis y la estabilidad del sistema a lazo cerrado.

Se destaca que no es necesario asumir ningún modelo particular para las tasas a estimar. De hecho, sólo se requieren límites superiores para las derivadas temporales de las señales a estimar, las cuales se pueden determinar a partir de experiencia previa en el proceso a monitorear.

El comportamiento del observador propuesto se evaluó con datos experimentales obtenidos de una fermentación en modo continuo de la levadura S. cerevisiae. Como ejemplo de aplicación fueron estimadas la tasa de crecimiento específica y la tasa neta de producción de etanol. El algoritmo propuesto se comparó con un observador de alta ganancia durante el funcionamiento normal y ante dos fallos típicos que pueden aparecer en los sensores. En particular, el observador propuesto exhibió mejor rechazo de ruido y una mejor respuesta transitoria ante fallos de tipo offset y ante picos de ruido. 
78

CAPÍTULO 4. ESTIMACIÓN DE MÚLTIPLES TASAS... 


\section{Capítulo 5}

\section{Regulación de tasa de crecimiento preservando otros sustratos en exceso}

El modo más popular de operación de los biorreactores en producción es el modo semi-continuo, donde el biorreactor es alimentado progresivamente con medio de cultivo fresco. Este modo tiene la potencial ventaja de evitar la sobrealimentación del sustrato, que puede ser causante de inhibición del crecimiento y formación de productos no deseados [126]. Con el objetivo de mejorar la performance de estos procesos es fundamental aplicar lazos de control que aseguren tanto las condiciones de operación deseadas como la calidad del producto. Para esto, el sensorizado del biorreactor es importante ya que permite obtener datos sobre lo que ocurre en el medio de cultivo. Usualmente se tiene acceso en línea a variables fisicoquímicas como temperatura, presión, pH y concentración de oxígeno disuelto (DO). En algunos casos también se cuenta con mediciones en línea de la composición de los gases de entrada y salida, densidad óptica u otro método de medición de biomasa. En una minoría de casos se dispone de medición de la fuente de carbono en línea. Por otro lado, además de disponerse de lazos de regulación de $\mathrm{pH}$ y temperatura, las variables manipuladas suelen ser la velocidad de agitación, el flujo de aireación y el flujo de alimentación de los nutrientes. Luego, un problema importante es determinar el perfil temporal de estas variables, en particular del flujo de alimentación de nutrientes. Como se explicó en la sección 2.3, se han propuesto diversas estrategias de alimentación para cultivos semi-continuos. En todos los casos se intenta satisfacer un objetivo de control y al mismo tiempo evitar la sobrealimentación de nutrientes ya que esto puede llevar a diversos efectos indeseados.

Un objetivo de control típico, estrechamente relacionado con objetivos biotecnológicos, es la regulación del crecimiento a una tasa constante. Regular el crecimiento involucra no sólo proveer la ley de alimentación adecuada sino también mantener las condiciones ambientales apropiadas. Además, 
cuando el crecimiento se regula mediante el flujo de un sustrato limitante, debe asegurarse que los demás nutrientes se encuentren en exceso. Si bien esto puede ser garantizado incorporando al medio de cultivo una cantidad en exceso del resto de los nutrientes, algunos de estos son requeridos en gran cantidad. Esto ocurre por ejemplo con los sustratos cuyo consumo resulta asociado al crecimiento. Un caso motivador para el desarrollo de una estrategia que permita regular una variable al tiempo que se mantiene un sustrato por encima de un valor crítico ocurre en los cultivos aeróbicos. En estos, el oxígeno disuelto cumple un papel fundamental en el metabolismo celular y su valor debe ser regulado apropiadamente. Por un lado, un valor excesivo de oxígeno puede resultar tóxico para las células, mientras que por el otro, un nivel de oxígeno insuficiente afecta al crecimiento celular.

En este capítulo se presenta un algoritmo auxiliar aplicable a esquemas de alimentación típicos de los cultivos semi-continuos. En particular se desarrolla un algoritmo que monitorea el oxígeno disuelto y actúa en los casos en que esta variable decrece muy rápidamente, reduciendo el consumo de oxígeno a través de manipular las referencias del controlador de alimentación. Esto permite mantener la condición aeróbica necesaria y evitar problemas asociados a la limitación por oxígeno. Este esquema puede ser extendido con el objetivo de mantener otros sustratos por encima de valores especificados, requiriéndose para la implementación del controlador la medición o estimación de dichas sustancias.

\subsection{Regulación descentralizada en procesos aeróbicos}

\subsubsection{Modelo del cultivo aeróbico}

En los cultivos aeróbicos, resulta relevante considerar el oxígeno disuelto, dado que es utilizado por las células para oxidar la fuente de carbono. El modelo de estados que describe la dinámica en un cultivo semi-continuo aeróbico puede representarse por las expresiones:

$$
\begin{aligned}
\dot{x} & =\mu x-\frac{F_{i n}}{v} x, \\
\dot{s} & =-q_{s} x+\left(S_{i n}-s\right) \frac{F_{i n}}{v}, \\
\dot{c}_{D O} & =O T R-O U R-c_{D O} \frac{F_{i n}}{v}, \\
\dot{v} & =F_{i n},
\end{aligned}
$$

donde $x, s$ y $c_{D O}$ son las concentraciones de biomasa, sustrato y DO $(\mathrm{g} / \mathrm{L})$ respectivamente, y $v$ el volumen de cultivo.

La tasa de crecimiento $\mu(t)$ suele expresarse como el producto de diversos factores que tienen en cuenta el efecto de los diferentes parámetros 
y sustancias que afectan al crecimiento microbiano (ver expresión (2.18)). Aquí es relevante considerar el efecto de la fuente de carbono y, por tratarse de un cultivo aeróbico, de la concentración de oxígeno disuelto [127]

$$
\mu(t)=\mu(s) \mu\left(c_{D O}\right) .
$$

Dentro de la clasificación de cultivos multi-sustrato presentada en la sección 2.1.6, la expresión (5.5) corresponde al caso multiplicativo. Las tasas específicas de consumo de sustrato y oxígeno se describen considerando un término para mantenimiento [35]

$$
\begin{aligned}
q_{s} & =\frac{\mu}{y_{x / s}}+m_{s}, \\
q_{O_{2}} & =\frac{\mu}{y_{x / o}}+m_{o} .
\end{aligned}
$$

La dinámica del oxígeno disuelto está gobernada principalmente por las tasas de transferencia (OTR) y consumo de oxígeno (OUR):

$$
\begin{aligned}
& O T R=K_{L} a\left(c_{D O}^{*}-c_{D O}\right), \\
& O U R=q_{O_{2}} x .
\end{aligned}
$$

El parámetro $K_{L} a$ resulta afectado por muchos factores tales como la velocidad de agitación, el flujo de aire, la temperatura, geometría del biorreactor y las características del fluído (por ejemplo la viscosidad) [128]. En este capítulo se asume la siguiente relación no lineal entre $K_{L} a$ y la velocidad de agitación $(N)$ presentada en Chung et al. [129]:

$$
K_{L} a=k_{s t r 1} N^{k_{s t r 2}}
$$

donde $k_{s t r 1}$ y $k_{s t r 2}$ son coeficientes positivos. La expresión (5.10) puede considerarse una versión simplificada de la correlación entre $K_{L} a$ y el denominado Power Number $\left(N^{3} D^{2}\right.$, con $D$ el diámetro de las palas de mezclado), número que suele utilizarse en la literatura [128]. Cabe destacar que esta relación se asume a los efectos de realizar una simulación del proceso aeróbico y no es utilizada explícitamente en la estrategia de control propuesta. De hecho, el algoritmo que se presentará en la siguiente sección no requiere conocer un modelo de $K_{L} a$.

A los fines de ejemplificar la técnica de alimentación propuesta, se asume que la velocidad del agitador es controlada mediante un controlador Proporcional + Integral (PI). Dado un nivel de aireación, se aumenta la velocidad si el nivel de oxígeno disuelto es menor que el valor de referencia. Además, la velocidad de agitación es acotada de acuerdo a las velocidades mínima y máxima, es decir $N \in\left[N_{\min }, N_{\max }\right]$ rpm. También se supone que las variables fisicoquímicas tales como temperatura y $\mathrm{pH}$ se controlan con lazos de control externos. 


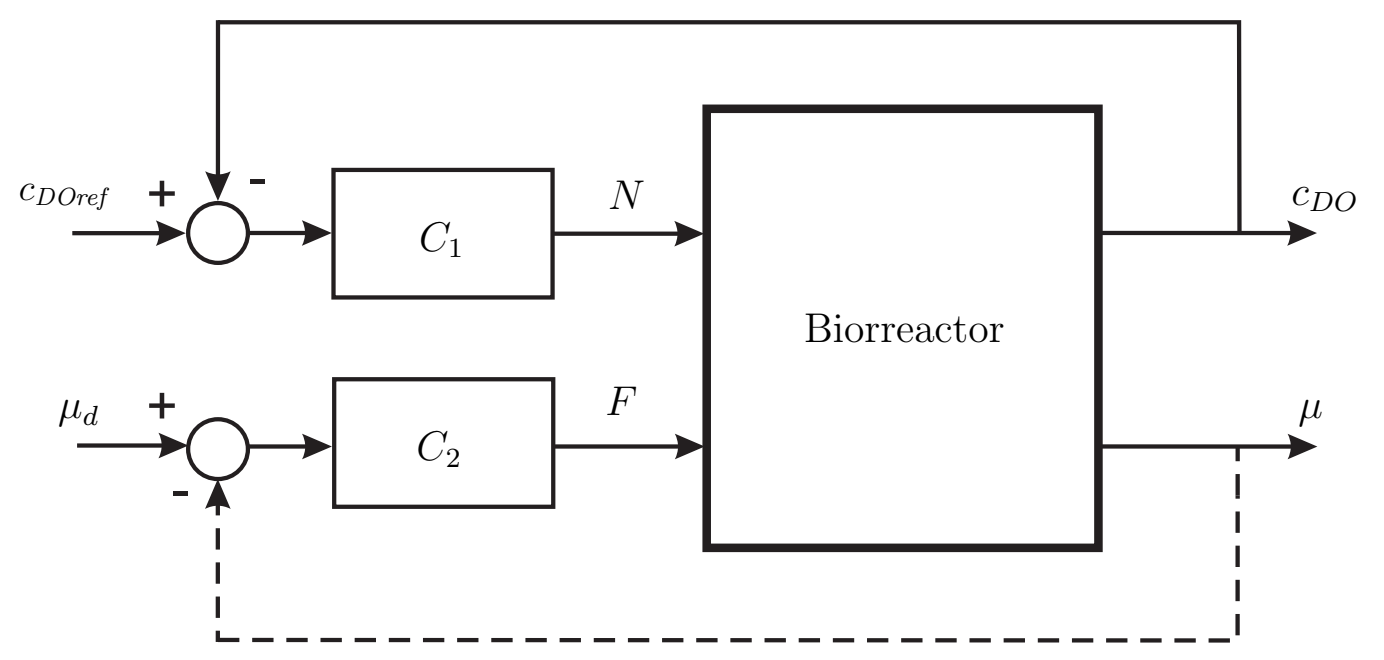

Figura 5.1: Estructura de control descentralizada para un cultivo aeróbico. control de oxígeno $\left(C_{1}\right)$, ley de alimentación de sustrato $\left(C_{2}\right)$.

\subsubsection{Problema bajo estudio}

El esquema de control considerado se presenta en la Figura 5.1. Se trata de una estructura de control descentralizado donde las salidas de interés $c_{D O}$ y $\mu$ son reguladas a partir de las entradas $N$ y $F$, respectivamente.

Cuando el objetivo de control es la regulación de $\mu$, debe proporcionarse una ley de alimentación exponencial en $F(t)$. El valor de referencia $\mu_{d}$ utilizado en el perfil de alimentación suele elegirse a partir de un compromiso entre la productividad deseada y el requerimiento de oxígeno y sus efectos negativos debido a la formación de subproductos. Dado que $\mu$ es una variable que no se puede medir directamente, y de acuerdo a lo descripto en la introducción de este capítulo, aparecen dos posibilidades para la ley de alimentación:

1) El perfil de alimentación sigue una ley exponencial precalculada, lo que lleva a definir una ley de alimentación exponencial de lazo abierto (por ejemplo: ec. (2.44)).

2) Utilizando una estimación $(\hat{\mu})$, el controlador $C_{2}$ aplica una ley de alimentación de lazo cerrado (por ejemplo: ec. (2.47)).

Por otro lado, de las expresiones (5.3), (5.7) y (5.9) puede deducirse que un aumento de $\mu$ produce un aumento en la demanda de oxígeno, el cual a su vez puede conducir a una caída abrupta de DO. Esta situación suele ser muy severa hacia el final del proceso, cuando la cantidad de biomasa es mayor. En efecto, cuando el requerimiento de oxígeno es mayor que el máximo OTR del biorreactor, el valor de DO puede disminuir a niveles muy bajos y convertirse en el sustrato limitante del crecimiento. Una forma típica 


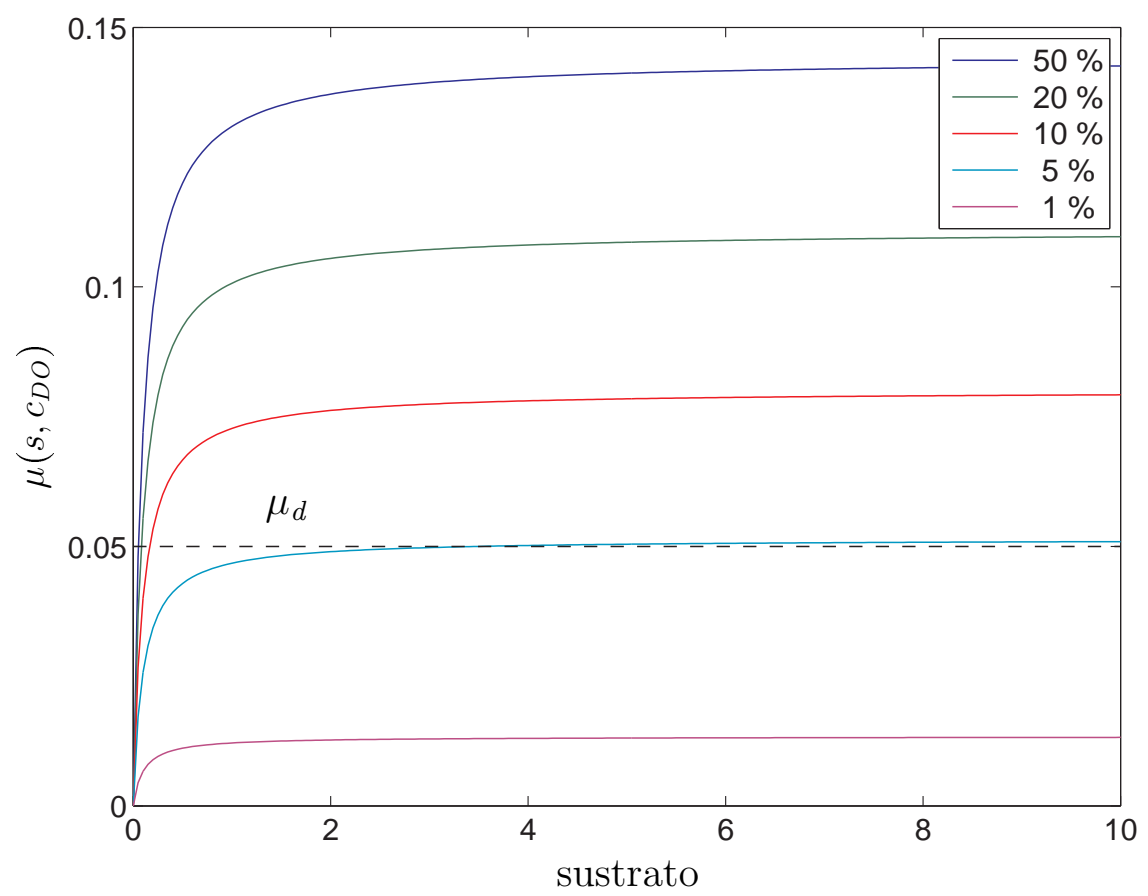

Figura 5.2: Tasa de crecimiento (5.11) en función de la concentración de sustrato y para diferentes valores de $c_{D O}$ (en porcentaje de $c_{D O}^{*}$ ).

para la expresión (5.5) en procesos aeróbicos es

$$
\mu\left(s, c_{D O}\right)=\mu_{\max } \frac{s}{s+k_{s}} \frac{c_{D O}}{c_{D O}+k_{o}} .
$$

La Figura 5.2 presenta un gráfico de la expresión (5.11) con respecto al sustrato para diferentes valores de oxígeno disuelto. También se muestra un posible valor de referencia para $\mu$. Puede verse que si la concentración de oxígeno es baja, ésta puede limitar el crecimiento y luego no es posible alcanzar el valor de $\mu$ deseado manipulando la entrada de sustrato. Para evitar esto, en la práctica se consideran valores para $c_{D O r e f}$ en el rango de [20-50]\% del valor saturación. Eso asegura que el sustrato limitante sea la fuente de carbono y por consiguiente, que se pueda regular la tasa de crecimiento mediante el flujo de alimentación del sustrato.

Usualmente, la concentración de oxígeno disuelto requerida se proporciona a través del flujo de aireación y de la velocidad del agitador [130, 131, 132]. Sin embargo, estas entradas no pueden garantizar la condición aeróbica si se alcanzan sus valores de saturación. En los casos en que el sistema de aireación alcanza su límite superior puede inyectarse oxígeno puro con el objetivo de aumentar la transferencia de oxígeno al medio líquido. Sin embargo, también se incrementan los costos operativos del proceso y aparecen turbulencias y exceso de burbujas que pueden interferir con los sensores del biorreactor. Cuando el sistema de aireación alcanza su máxima transferencia de oxígeno, pueden surgir los siguientes problemas: 
- la ley de alimentación es incapaz de regular $\mu$ al valor deseado causando respuestas no deseadas tales como acumulación de sustrato en el medio de cultivo (sobrealimentación de fuente de carbono) e inhibición.

- en condiciones anaeróbicas, algunos microorganismos (por ejemplo $E$. coli y $S$. cerevisiae) pueden modificar su metabolismo para obtener energía por una vía fermentativa. En ese caso, pueden excretarse productos no deseados que inhiben el crecimiento [133, 134]. En el caso de P. Pastoris, si bien no se la considera una levadura fermentativa, se han reportado resultados de acumulación de etanol bajo una alta velocidad de alimentación de glicerol [135]. Bajo limitación por oxígeno, el etanol puede tener un impacto negativo en la expresión de proteínas y por lo tanto el nivel de oxígeno debe mantenerse lo suficientemente alto [136]. Por otra parte, durante la fase de producción con metanol como fuente de carbono, el oxígeno es necesario dado su papel relevante en la vía de oxidación de este sustrato [137]. El valor mínimo requerido para la etapa de producción es alrededor del $20 \%$ del valor de saturación.

De esta manera parece ser clara la necesidad de evitar que el DO pueda caer por debajo de un valor mínimo. En la siguiente sección se propone la adición de un algoritmo de adaptación de la alimentación con el objetivo de garantizar que la condición aeróbica se mantenga por encima de cierto valor definido por el usuario.

\subsection{Control descentralizado con adaptación de la ley de alimentación}

En esta sección se propone un bloque de adaptación para la ley de alimentación. El mismo puede aplicarse tanto en estrategias de alimentación a lazo abierto como a lazo cerrado.

En la estructura de control presentada en la Figura 5.1, cuando el consumo de oxígeno es menor que la capacidad máxima de aireación del biorreactor, dos variables son reguladas a partir de dos entradas: el oxígeno disuelto se controla mediante la manipulación de la velocidad del agitador mientras que $\mu$ se regula con la alimentación del sustrato limitante. Debido al aumento (típicamente exponencial) de la demanda de oxígeno, el lazo de control puede alcanzar la velocidad de agitación máxima. A partir de este punto, si el consumo de oxígeno se incrementa aún más, el oxígeno disuelto decrece, pudiendo alcanzar valores extremadamente bajos. Para este caso se propone controlar $\mu$ sujeta a la restricción en la condición requerida de oxígeno disuelto, el cual no es regulado por el lazo auxiliar sino limitado con una cota inferior. De este modo, la estrategia consiste en variar el flujo 


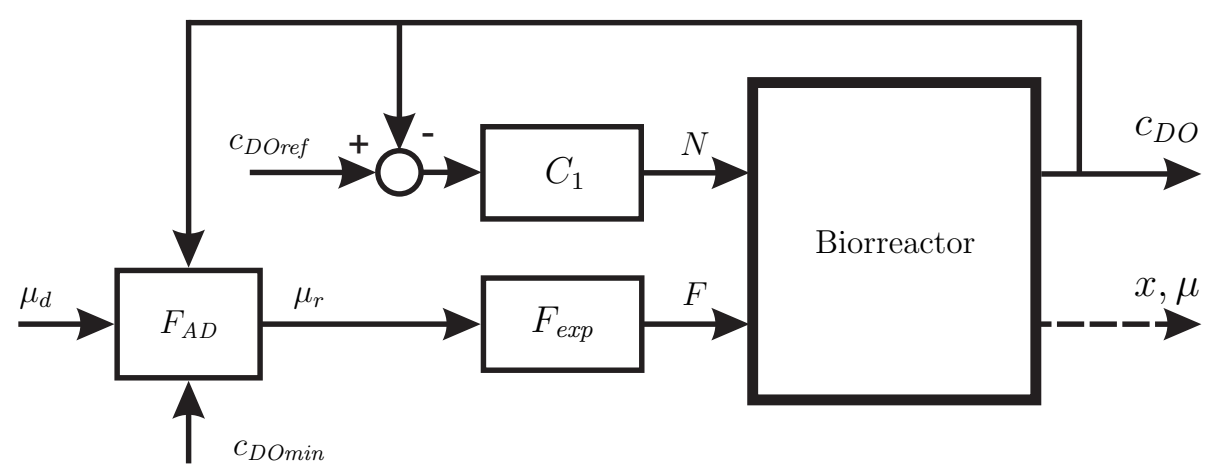

Figura 5.3: Ley de alimentación de lazo abierto con bloque de adaptación $\left(F_{A D}\right)$.

de entrada con una ley por modo deslizante para obtener un valor de $\mu$ lo más cerca posible al valor preestablecido, tal que se cumpla la restricción

$$
c_{D O} \geqslant c_{D O \min }
$$

Aquí $c_{D O m i n}$ es la mínima concentración de DO permitida en el cultivo. Este valor es un parámetro de diseño y es razonable tomarlo mayor o igual que la concentración crítica, la cual a su vez depende del microorganismo utilizado y de objetivos biotecnológicos (por ejemplo, evitar la formación de subproductos indeseados) [29].

La Figura 5.3 muestra el esquema propuesto para los casos en que la alimentación del cultivo se realiza con una ley de lazo abierto. El bloque de adaptación $\left(F_{A D}\right)$ actualiza de manera continua el parámetro $\mu_{r}$ de la ley de alimentación exponencial $F_{\text {exp }}=F_{o} e^{\mu_{r} t}$. Esto se hace considerando una función del valor de referencia $\mu_{d}$, la concentración de oxígeno disuelto $c_{D O}$ y la cota inferior deseada $c_{D O m i n}$.

Muchos bioprocesos requieren una regulación robusta del valor de $\mu$. En la Figura 5.4, la salida del bloque de adaptación $\mu_{r}$ se compara con una estimación provista por un observador de $\mu$. Es decir que, en este caso, $\mu_{r}$ actúa como el valor de referencia para el lazo de control de $\mu$. La tasa de crecimiento puede ser estimada a partir de mediciones del proceso. Por ejemplo, a partir de biomasa y volumen $[138,109]$ o a partir de la tasa volumétrica de consumo de oxígeno OUR [139, 140].

Cabe destacar que las propuestas presentadas en las Figuras 5.3 y 5.4 preservan la estructura de control descentralizada original (Figura 5.1). Por lo tanto, la adaptación de alimentación se puede aplicar a esquemas de proceso existentes sin mayores modificaciones. 


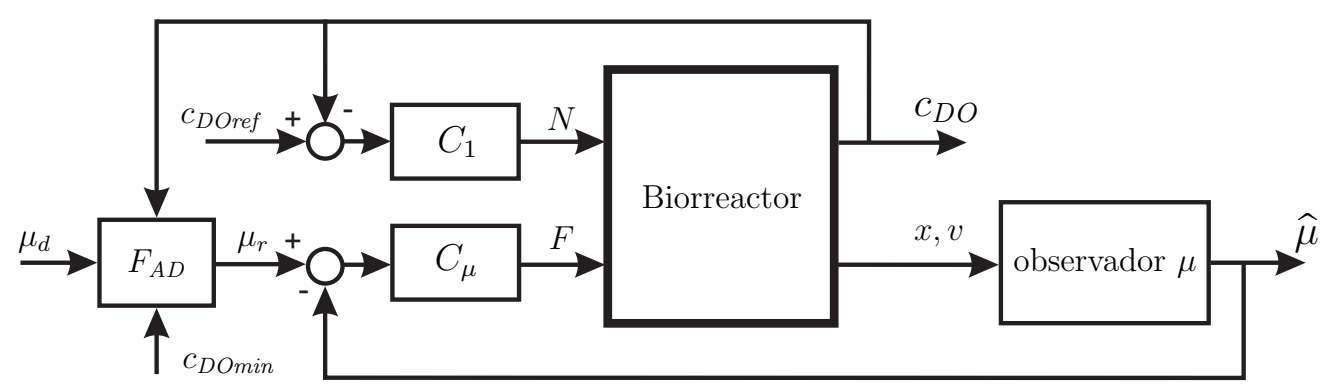

Figura 5.4: Esquema de regulación de $\mu$ en lazo cerrado con adaptación de la ley de alimentación: controlador de $\mu\left(C_{\mu}\right)$, bloque de adaptación de alim. $\left(F_{A D}\right)$.

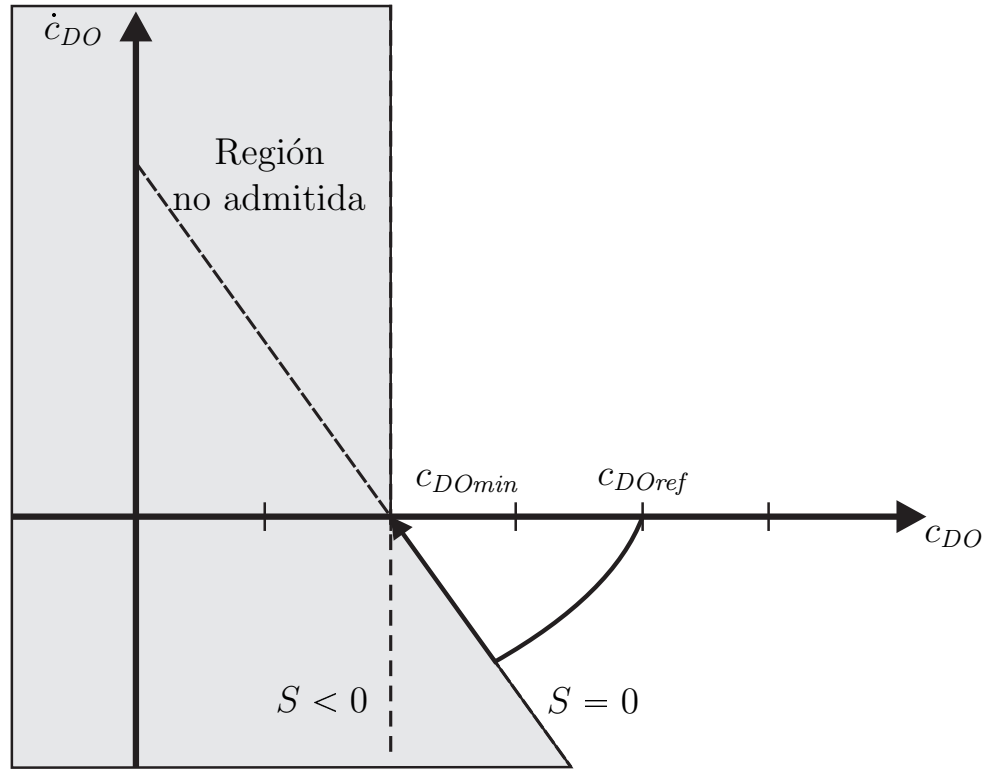

Figura 5.5: Plano de fase de oxígeno disuelto y la superficie de MD.

\subsubsection{Algoritmo de adaptación de la alimentación por modo deslizante}

En el bloque de adaptación de la alimentación, se construye la siguiente función:

$$
S\left(c_{D O}\right)=c_{D O}-c_{D O m i n}+\tau \dot{c}_{D O} .
$$

En la Figura 5.5 se representa la superficie $S\left(c_{D O}\right)=0$ en el plano de fase. Básicamente, la idea es evitar que la concentración de oxígeno disuelto decrezca más rápidamente que la dinámica descripta por $S=0$. De este modo, el algoritmo de adaptación se mantiene inactivo cuando el controlador principal es capaz de regular $c_{D O}$ cerca de $c_{D O r e f}$. Por el contrario, cuando el controlador principal no puede regular el oxígeno disuelto al valor deseado (por ejemplo, debido a la saturación de la acción o falla del agitador), el oxígeno disminuye, posiblemente alcanzando la superficie $S=0$. Si $S=0$ 


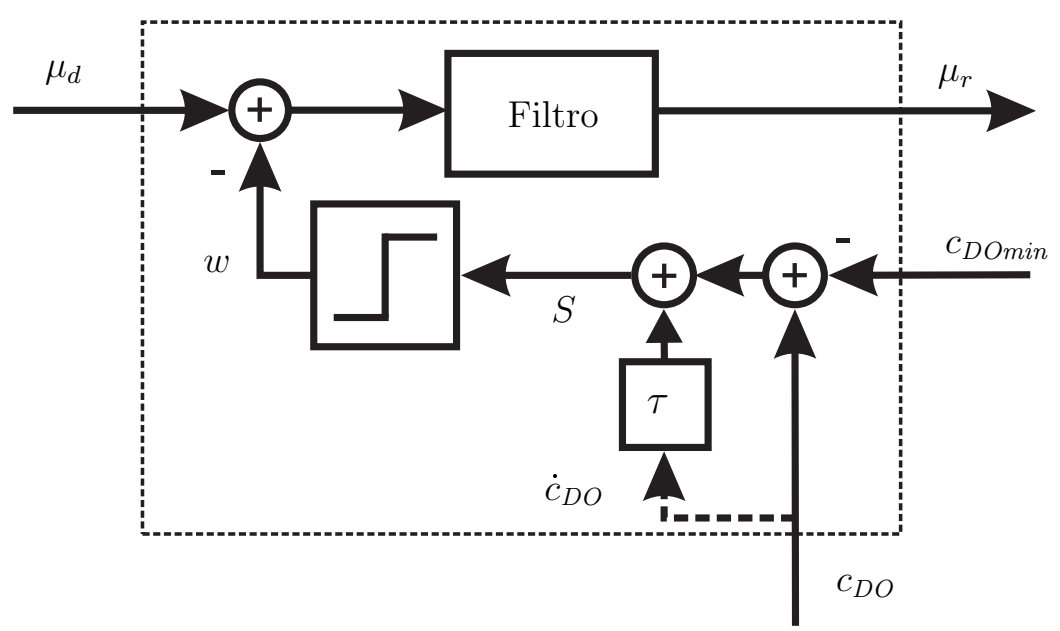

Figura 5.6: Esquema interno del bloque de adaptación $F_{A D}$.

es alcanzada, el algoritmo de adaptación se activa reduciendo la referencia de $\mu$ de manera tal que $c_{D O}$ no decrezca más rápidamente que de acuerdo con $S=0$ y evolucione hacia $c_{D O m i n}$ con la dinámica impuesta por $S=0$. Es decir, se obtiene un movimiento de deslizamiento sobre la superficie por lo que la dinámica de DO es llevada hacia el punto $\left(c_{D O}, \dot{c}_{D O}\right)=\left(c_{D O m i n}, 0\right)$.

En la Figura 5.6 se presenta un diagrama del algoritmo propuesto (bloque $F_{A D}$ en las Figuras 5.3 y 5.4 ). Con el objetivo de forzar de manera robusta la dinámica del oxígeno disuelto en $S=0$, se aplica la acción discontinua descripta por

$$
w= \begin{cases}0 & \text { si } \quad S\left(c_{D O}\right)>0 \\ w_{S M} & \text { c.c. },\end{cases}
$$

Debe remarcarse que esta acción de control se utiliza sólo cuando el DO cae por debajo de la superficie $S=0$, es decir, cuando se alcanza el valor mínimo o cuando disminuye demasiado rápido. Esta situación lleva a un cambio rápido de $w$ según el signo de la función $S$ en el entorno de $S=0$, lo que puede considerarse como un régimen transitorio de modo deslizante sobre la superficie $S=0$.

Para suavizar la señal discontinua se aplica un filtro de primer orden por lo que la dinámica de $\mu_{r}$ queda descripta por

$$
\dot{\mu}_{r}=-\alpha_{f}\left(\mu_{r}+w-\mu_{d}\right)
$$

donde $\mu_{d}>\mu_{r}$.

\subsubsection{Análisis de las condiciones de modo deslizante}

Con el objetivo de analizar las condiciones de modo deslizante, el sistema de lazo cerrado se expresa en la forma afín

$$
\dot{\boldsymbol{z}}=\boldsymbol{f}(\cdot)+\boldsymbol{g}(\boldsymbol{z}) w
$$


donde $\boldsymbol{z}$ representa el vector de estados completo.

La ley de control (5.14) conduce a un régimen deslizante [111] sobre $S\left(c_{D O}\right)=0$ si las siguientes condiciones se satisfacen localmente

$$
\dot{S}=\left\{\begin{array}{lrl}
\nabla S^{\mathrm{T}} \boldsymbol{f} & <0 & \text { si } \quad S\left(c_{D O}\right)>0 \\
\nabla S^{\mathrm{T}} \boldsymbol{f}+\nabla S^{\mathrm{T}} \boldsymbol{g} w_{S M} & >0 & \text { c.c. }
\end{array}\right.
$$

donde $\nabla S^{\mathrm{T}}$ es el gradiente de $S\left(c_{D O}\right)$ y $\nabla S^{\mathrm{T}} \boldsymbol{f}$ denota la derivada de $S$ en la dirección del campo $\boldsymbol{f}$ (derivada direccional). La primera desigualdad en (5.17) se cumple siempre que el DO decrece. A partir de la segunda desigualdad, el término $\nabla S^{\mathrm{T}} \boldsymbol{g} w_{S M}$ debe ser mayor que $\nabla S^{\mathrm{T}} \boldsymbol{f}$ para poder forzar un cambio de signo en la derivada temporal de $S$. Esto se logra seleccionando un valor de $w_{S M}$ lo suficientemente grande. Bajo esta condición, $w$ conmuta a alta frecuencia forzando que $c_{D O}$ se restrinja a $S=0$. El parámetro $\mu_{r}$ obtenido por este procedimiento es tal que la alimentación aplicada hace cumplir la condición aeróbica requerida. Bajo la operación en modo deslizante se cumple la condición de invariancia [141]:

$$
\begin{aligned}
& S\left(c_{D O}\right)=0, \\
& \dot{S}\left(c_{D O}\right)=0 .
\end{aligned}
$$

De este modo, dada la expresión (5.13), la dinámica resultante para $c_{D O}$ es

$$
\dot{c}_{D O}=\frac{c_{D O \min }-c_{D O}}{\tau} \text {. }
$$

La expresión (5.19) describe la dinámica del oxígeno disuelto cuando el sistema opera en régimen deslizante. Dado que este modo se establece con un valor de $c_{D O}$ por encima del valor mínimo, la concentración de oxígeno disuelto decrece hacia $c_{D O \min }$ con constante de tiempo $\tau$.

Ahora se considera el proceso descripto en la Figura 5.3 con la ley de alimentación (2.44):

$$
F_{\text {exp }}=\frac{\frac{\mu_{r}}{y_{x / s}}+m_{s}}{S_{\text {in }}-s_{r}} x_{0} v_{0} e^{\mu_{r} t},
$$

Como fue expuesto en el Capítulo 2, la mayor ventaja de la alimentación descripta por (5.20) es su simplicidad. Sin embargo, la cantidad de biomasa inicial $\left(x_{0} v_{0}\right)$ y ciertos parámetros del proceso deben ser conocidos.

A partir de las expresiones (5.1)-(5.4), (5.15) y (5.20), las expresiones del modelo en la forma afín (5.16) resultan

$$
\left(\begin{array}{c}
\dot{x} \\
\dot{s} \\
\dot{c}_{D O} \\
\dot{v} \\
\dot{F} \\
\dot{\mu}_{r}
\end{array}\right)=\left(\begin{array}{c}
\mu x-\frac{F}{v} x \\
-q_{s} x+\left(S_{i n}-s\right) \frac{F}{v} \\
O T R-O U R-c_{D O} \frac{F}{v} \\
F \\
-\alpha_{f} f_{5}\left(\mu_{r}-\mu_{d}\right)+g_{5} \\
-\alpha_{f}\left(\mu_{r}-\mu_{d}\right)
\end{array}\right)+\left(\begin{array}{c}
0 \\
0 \\
0 \\
0 \\
-\alpha_{f} f_{5} \\
-\alpha_{f}
\end{array}\right) w
$$


donde $w$ es la entrada (5.14) y

$$
\begin{aligned}
f_{5} & =\left[\frac{1}{y_{x / s}}+\left(\frac{\mu_{r}}{y_{x / s}}+m_{s}\right) t\right] x_{0} v_{0} e^{\mu_{r} t} \\
g_{5} & =\left(\frac{\mu_{r}}{y_{x / s}}+m_{s}\right) \mu_{r} x_{0} v_{0} e^{\mu_{r} t} .
\end{aligned}
$$

Aquí, la salida considerada es $y=c_{D O}$. Luego, la condición (5.17) resulta

$$
\dot{S}=\left\{\begin{array}{lll}
\nabla S^{\mathrm{T}} \boldsymbol{f} & <0 & \text { si } \quad S(\cdot)>0 \\
\nabla S^{\mathrm{T}} \boldsymbol{f}+\alpha_{f} \tau \frac{c_{D O}}{v} f_{5} w_{S M} & >0 & \text { c.c. }
\end{array}\right.
$$

Dado que las variables de estado son positivas y observando que $f_{5} \geqslant$ $x_{0} v_{0} / y_{x / s}$, puede verse que $\alpha_{f} \tau \frac{c_{D O}}{v} f_{5}$ es no nulo. Este resultado es, de hecho, una condición necesaria para un régimen de $\mathrm{MD}$. El análisis para la configuración con una ley de lazo cerrado puede realizarse de manera similar.

Claramente, la modificación propuesta a $\mu_{r}$ puede utilizarse fácilmente en procesos que utilicen la ley de alimentación (5.20) ya que sólo se requiere incorporar la medición de oxígeno disuelto y una estimación de su derivada temporal. Además, el bloque $F_{A D}$ no presenta mayor complejidad y puede ser implementado fácilmente en una rutina de software.

\subsection{Resultados y discusión}

En esta sección se presentan simulaciones con el objetivo de evaluar el rendimiento del algoritmo propuesto. El primer caso corresponde a un proceso con alimentación a lazo abierto (Figura 5.3). Dado que el objetivo aquí es mostrar una mejora con respecto a la dinámica del oxígeno disuelto, los parámetros de la expresión (5.20) se suponen conocidos. En el segundo caso, se considera el proceso con control de $\mu$ a lazo cerrado presentado en la Figura 5.4.

El modelo del bioproceso aeróbico (5.1)-(5.4) fue utilizado con los parámetros de una cepa de P. Pastoris presentados en Oliveira et al. [127]. La lista completa de parámetros utilizados se describe en la Tabla 5.1 (los coeficientes de mantenimiento $m_{s}$ y $m_{o}$ se asumieron despreciables). Las condiciones iniciales para la operación del cultivo semi-continuo con glicerol como fuente de carbono se presentan en la Tabla 5.2. El estudio de simulación se resolvió mediante método de Euler con un paso fijo de 0,001 h. Para considerar ruido de medición se agregó ruido aditivo y multiplicativo tanto en la medición de biomasa como en la medición de oxígeno disuelto. El tipo de señal de ruido considerada fue gaussiano con media nula filtrado (con filtro de frec. $12,5 \mathrm{rad} / \mathrm{h}$ ) y las desviaciones estándar fueron de $\sigma_{x}=0,2$ $\mathrm{g} / \mathrm{L}$ y $\sigma_{D O}=0,5 \mathrm{mg} / \mathrm{L}$, respectivamente. La dinámica del sensor de oxígeno 
disuelto fue representada con

$$
\dot{c}_{D O s}=-\frac{c_{D O s}}{\tau_{D O}}+\frac{c_{D O}}{\tau_{D O}}
$$

con $\tau_{D O}=20 \mathrm{seg}[71]$.

La derivada temporal de la señal $c_{D O}$ requerida en la función de conmutación (5.13) fue estimada con el algoritmo derivador de segundo orden descripto en la expresión (2.55)

$$
\begin{aligned}
\dot{\hat{c}}_{D O}(t) & =u_{1}+a_{1}\left|\widetilde{c}_{D O}\right|^{\frac{1}{2}} \operatorname{sign}\left(\widetilde{c}_{D O}\right), \\
\dot{u}_{1}(t) & =a_{2} \operatorname{sign}\left(\widetilde{c}_{D O}\right),
\end{aligned}
$$

donde $\widetilde{c}_{D O} \triangleq c_{D O s}-\hat{c}_{D O}$. El algoritmo (5.25) fue configurado con los parámetros $\left(a_{1}, a_{2}\right)=(8,6)$ obtenidos a partir de una relación de compromiso entre velocidad de convergencia y ruido en la estimación obtenida. Nótese que durante el régimen deslizante se tiene $\widetilde{c}_{D O} \equiv 0$. De esta manera $u_{1}$ es una estimación de la derivada temporal de la señal de oxígeno disuelto.

\subsubsection{Aplicación a leyes de alimentación de lazo abier- to}

Inicialmente, la ley de alimentación (5.20) fue aplicada sin adaptación, es decir sin modificar el parámetro $\mu_{d}$. Los resultados se presentan en línea a trazos en la Figura 5.7. Durante las primeras 25 horas, el microorganismo creció con oxígeno en exceso y el objetivo de regular $\mu \approx \mu_{d}$ fue cumplido (Figura 5.7a). Puede observarse en la Figura 5.7f que la velocidad de agitación fue incrementada cada cierto tiempo con el objetivo de mantener el nivel de oxígeno. Sin embargo al alcanzarse $N_{\text {max }}$, el oxígeno comenzó a caer por debajo de $c_{D O r e f}$ (Figura $5.7 \mathrm{~b}$ ). Como consecuencia de este exceso de consumo, $\mu$ disminuyó debido a limitación por oxígeno y el glicerol excedente comenzó a acumularse en el medio de cultivo (Figura 5.7d). Claramente, el objetivo de mantener el oxígeno disuelto por encima de un nivel mínimo no fue cumplido y esto tuvo como consecuencia la acumulación de sustrato. Los resultados con el lazo auxiliar propuesto se presentan en línea sólida. En $t \approx 26 \mathrm{~h}$ la velocidad de agitación alcanzó $N_{\max }$ y el oxígeno comenzó a decrecer debido al incremento en su demanda. Luego, el algoritmo de modo deslizante modificó la ley de alimentación de manera acorde para satisfacer el nivel aeróbico requerido (Figura 5.7e). Como puede observarse, se alcanzó satisfactoriamente el objetivo $c_{D O} \geqslant c_{D O \min }=0,2 c_{D O}^{*}$ (Figura $5.7 \mathrm{~b})$. Dado que $F_{\text {exp }}(t)$ fue reducida para ser compatible con la tasa de transferencia de oxígeno, no se observó acumulación de glicerol durante el cultivo (Figura 5.7d). 
Tabla 5.1: Valores utilizados en la simulación. Los parámetros del modelo para $P$. pastoris fueron tomados de Oliveira et al. [127].

\begin{tabular}{|c|c|c|}
\hline Parámetro & Valor & Unidad \\
\hline \multicolumn{3}{|c|}{ Microorganismo: P. Pastoris } \\
\hline$k_{o}$ & 1 & $\mathrm{mg} / \mathrm{L}$ \\
\hline$k_{s}$ & 0,1 & $\mathrm{~g} / \mathrm{L}$ \\
\hline$\mu_{\max }$ & 0,18 & $\mathrm{~h}^{-1}$ \\
\hline$y_{x / o}$ & 2,2 & $\mathrm{~g} / \mathrm{g}$ \\
\hline$y_{x / s}$ & 0,5 & $\mathrm{~g} / \mathrm{g}$ \\
\hline \multicolumn{3}{|c|}{ Parámetros del biorreactor } \\
\hline$\lambda_{s t r 1}$ & 20 & $r p m^{-\lambda_{s t r 2}} / \mathrm{h}$ \\
\hline$\lambda_{s t r 2}$ & 0,5 & - \\
\hline$N_{\min }$ & 320 & rpm \\
\hline$N_{\max }$ & 1000 & rpm \\
\hline$c_{D O}^{*}$ & 8 & $\mathrm{mg} / \mathrm{L}$ \\
\hline$k_{p}$ & 2 & rpm L/mg \\
\hline$k_{i}$ & 0,2 & $\mathrm{rpm} \mathrm{L/mg/h}$ \\
\hline$S_{i n}$ & 500 & $\mathrm{~g} / \mathrm{L}$ \\
\hline \multicolumn{3}{|c|}{ Valores de referencia } \\
\hline$\mu_{d}$ & 0,05 & $\mathrm{~h}^{-1}$ \\
\hline$c_{\text {DOref }}$ & $0,3 c_{D O}^{*}$ & $\mathrm{mg} / \mathrm{L}$ \\
\hline \multicolumn{3}{|c|}{ Controlador de $\mu$ (sección 5.3.2) } \\
\hline$k_{c}$ & 7,5 & $\mathrm{~h}$ \\
\hline \multicolumn{3}{|c|}{ Parámetros del lazo auxiliar propuest } \\
\hline$\tau$ & 0,25 & $\mathrm{~h}$ \\
\hline$\alpha_{f}$ & 1,0 & $\mathrm{rad} / \mathrm{h}$ \\
\hline$w_{S M}$ & $\mu_{d}$ & $\mathrm{~h}^{-1}$ \\
\hline$c_{D O \min }$ & $0,2 c_{D O}^{*}$ & $\mathrm{mg} / \mathrm{L}$ \\
\hline
\end{tabular}

Tabla 5.2: Condiciones iniciales para el cultivo semi-continuo de P. Pastoris.

\begin{tabular}{ll}
\hline$x_{0}=10 \mathrm{~g} / \mathrm{L}$ & $c_{D O 0}=7 \mathrm{mg} / \mathrm{L}$ \\
$s_{0}=0 \mathrm{~g} / \mathrm{L}$ & $v_{0}=15 \mathrm{~L}$ \\
\hline
\end{tabular}



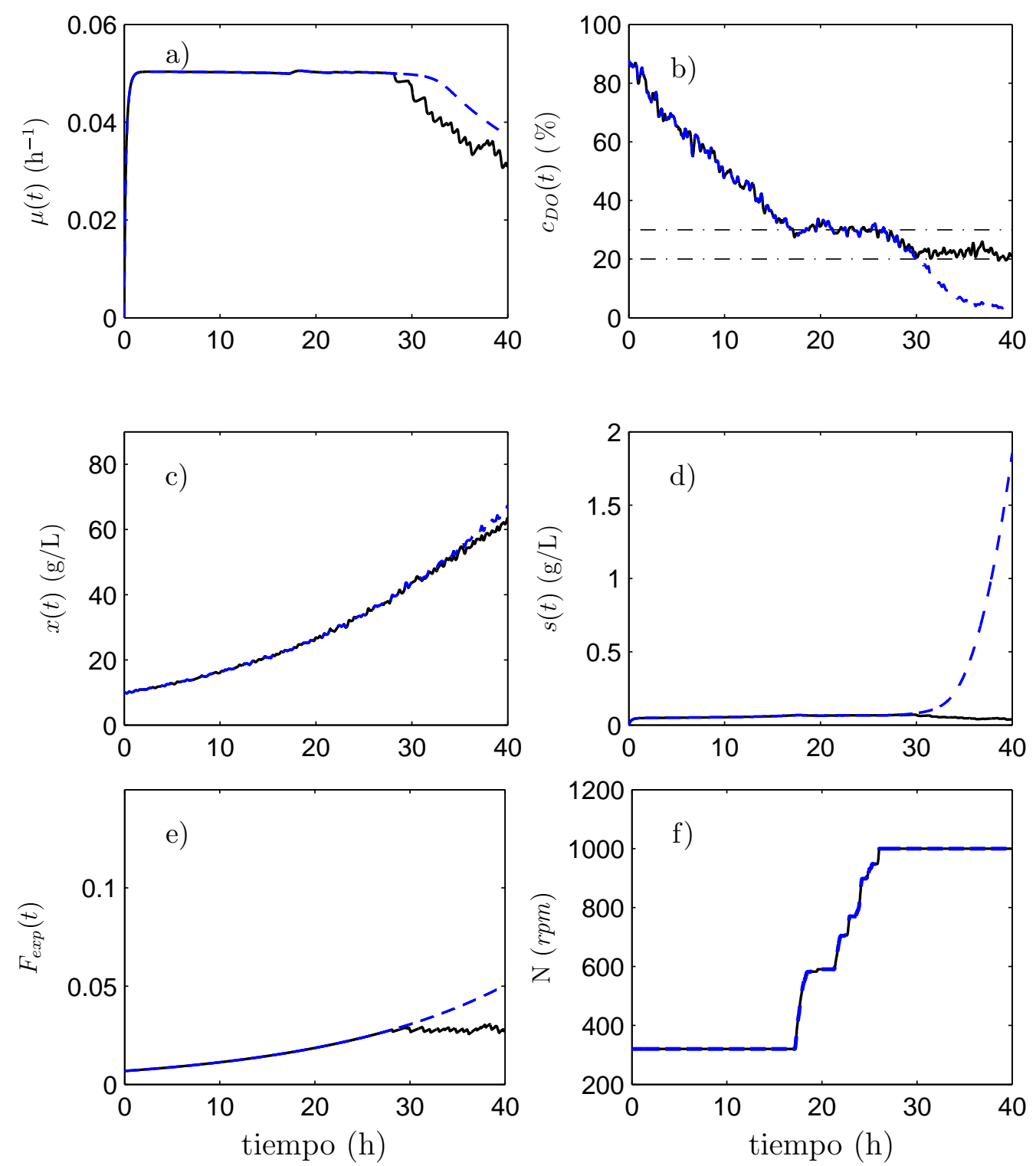

Figura 5.7: Resultados obtenidos con la ley de alimentación de lazo abierto (5.20): sin algoritmo de adaptación (línea azul a trazos) y con el algoritmo de adaptación propuesto (línea negra). 
Como puede verse, el algoritmo propuesto es una solución sencilla para garantizar el nivel aeróbico en bioprocesos semi-continuos. Proporciona una mejora a la ley de alimentación de lazo abierto, requiriendo únicamente la medición en línea de la concentración de oxígeno disuelto, la cual se encuentra disponible en la mayoría de los biorreactores actuales.

\subsubsection{Aplicación a una ley de control de lazo cerrado}

Si se dispone de mediciones de biomasa y volumen, puede implementarse una gran variedad de controladores de realimentación [34]. Por ejemplo, leyes de alimentación proporcional a la biomasa de la forma (2.47)

$$
F_{\exp C L}=\lambda x v .
$$

La medición de biomasa requerida en la ley de control anterior puede obtenerse de sensores basados en espectroscopia dieléctrica y otros métodos ópticos, los cuales han sido validados para diferentes microorganismos [138, 142]. A modo ilustrativo, se aplica la siguiente ley de realimentación

$$
\lambda=\frac{\frac{\mu_{r}}{y_{x / s}}+m_{s}}{S_{\text {in }}-s_{r}}\left(1+k_{c}\left(\mu_{r}-\widehat{\mu}\right)\right),
$$

donde $k_{c}$ es una ganancia constante para aumentar la respuesta del controlador y $\hat{\mu}$ es una estimación de $\mu$ [87].

Una reducción de $O T R$ puede causar que la concentración de oxígeno disminuya por debajo de $c_{D O m i n}$. En este ejemplo, la velocidad de agitación se redujo a $N_{\min }$ dentro del intervalo de $[22,24,5]$ h. Esta acción se realiza típicamente para reducir la formación de espuma. En la Figura 5.8 se observa que durante las primeras 22 horas, el lazo principal fue capaz de regular $\mu$ mientras que el DO se mantuvo alrededor del $30 \%$. En $t=22 \mathrm{~h}$ la velocidad de agitación se ajustó a $N_{\min }$. Sin el algoritmo de adaptación de la alimentación, el oxígeno disuelto se redujo y $\mu$ disminuyó levemente (Figura 5.8a). Cuando se restableció la velocidad de agitación, el oxígeno disuelto aumentó y $\mu$ aumentó por encima del valor de referencia. Nótese que la condición aeróbica no se cumplió. Por otro lado, con la adaptación de alimentación, cuando el oxígeno alcanzaba $c_{D O m i n}, \mu_{r}$ fue reducida (línea roja punteada en Figura 5.8a) con el objetivo de reducir la demanda de oxígeno. Puede apreciarse que la tasa de crecimiento (línea de color negro sólido) siguió de cerca su valor de referencia. En $t=24,5 \mathrm{~h}$ la velocidad de agitación se incrementó de nuevo, la concentración de oxígeno aumentó y el lazo auxiliar permitió que $\mu_{r}$ aumente. A partir de ese momento, el algoritmo de adaptación quedó inactivo porque el nivel aeróbico resultó mayor que $c_{D O m i n}$. A diferencia del resultado sin bucle auxiliar, no se observa acumulación de glicerol en ningún momento del cultivo.

La Figura 5.9 presenta los resultados ante un fallo total. Si OTR tiende a cero, no se puede garantizar un nivel mínimo de DO incluso sin crecimiento. 

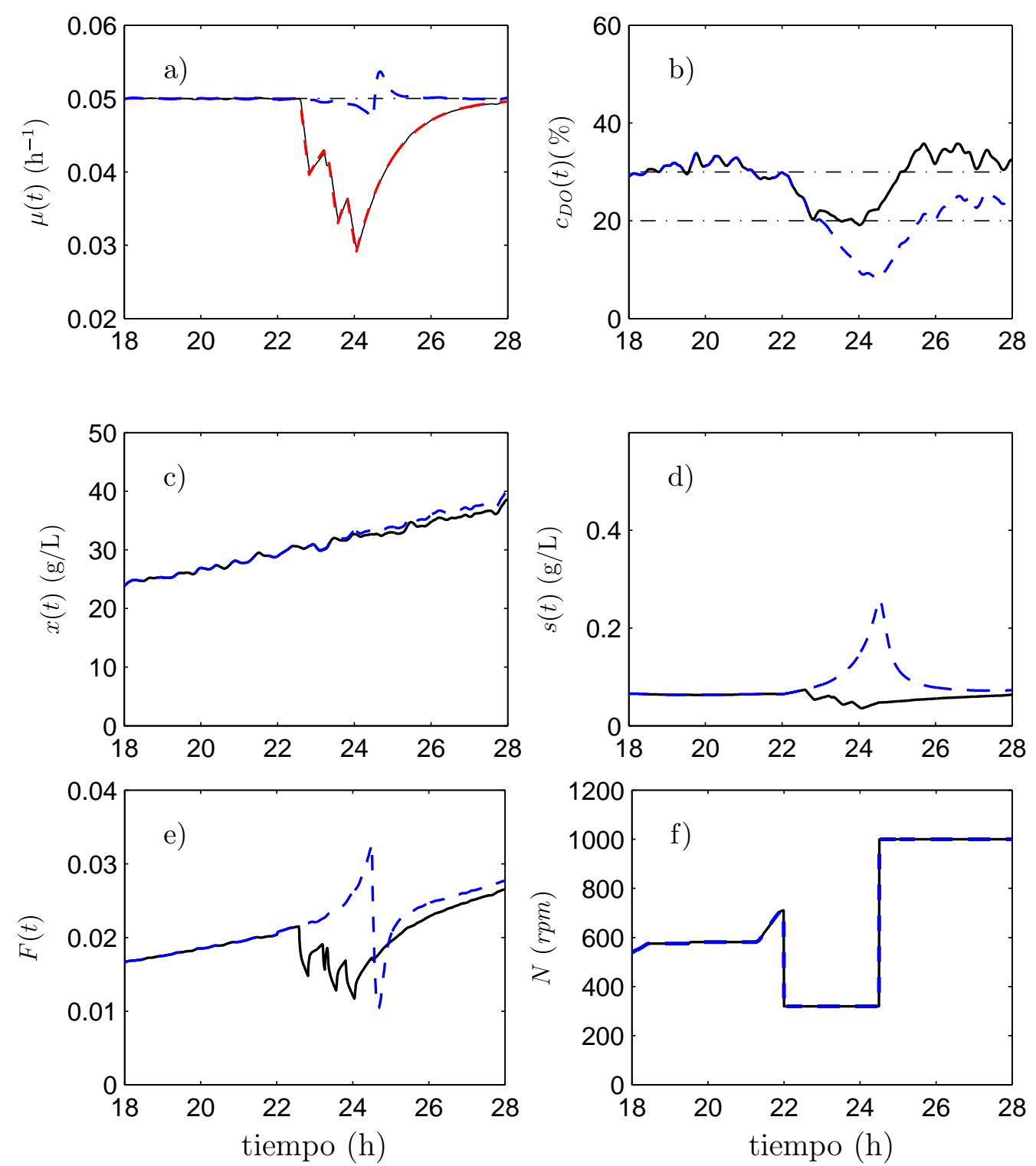

Figura 5.8: Resultados obtenidos con la ley de alimentación de lazo cerrado en caso de reducción parcial de OTR: sin algoritmo de adaptación (línea azul a trazos) y con el algoritmo propuesto (línea negra). En a) la tasa de crecimiento de referencia se observa solapada a la tasa de crecimiento del microorganismo. 

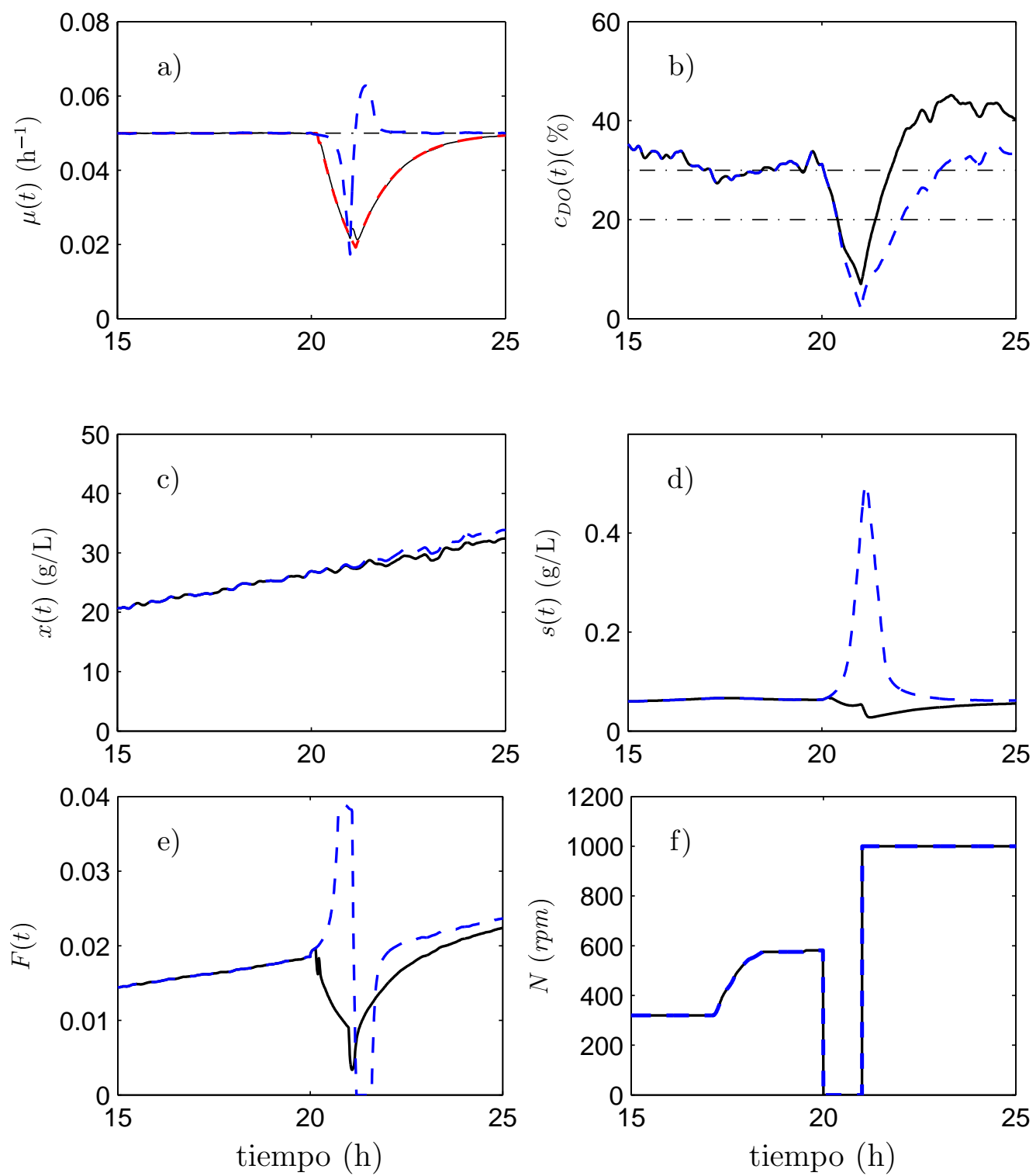

Figura 5.9: Resultados obtenidos con la ley de alimentación de lazo cerrado en caso de falla de OTR: sin algoritmo de adaptación (línea azul a trazos) y con el algoritmo propuesto (línea negra). En a) la tasa de crecimiento de referencia se muestra en línea roja a trazos. 
Sin embargo, la adaptación de la ley de alimentación sigue siendo útil para mejorar la respuesta transitoria hasta que se solucione el fallo. Una vez más, cuando el nivel de DO alcanzó un nivel limitante, la respuesta del control de $\mu$ sin adaptación de alimentación fue añadir más glicerol al cultivo. Esto ocurrió en un intento de compensar la decreciente $\mu$. Luego resultó en un exceso de glicerol en el medio de cultivo (Figura 5.9d). En el momento en el que las condiciones de transferencia de oxígeno retornan a su valor previo al fallo, el nivel de DO aumentó y, haciendo uso del glicerol en exceso, la biomasa creció más rápido que el valor de referencia. A continuación, la respuesta del controlador principal fue reducir la alimentación (Figura 5.9e) con el fin de disminuir la tasa de crecimiento. Esto muestra una respuesta no deseada tanto en $\mu(t)$ como en $s(t)$, cuando la concentración de oxígeno disuelto alcanza valores limitantes. Por el contrario, con la adaptación de alimentación activa, $\mu$ se reduce de forma controlada (Figura 5.9a) y en consecuencia el DO se mantiene por debajo de $c_{D O \min }$ en un intervalo de tiempo más corto. Si bien la restricción aeróbica no se cumple en este caso, la propuesta mantiene una baja concentración de glicerol en todo el cultivo. Esto es muy importante en cultivos semi-continuos ya que la acumulación de sustrato podría conducir no sólo a la formación de subproductos, sino también a inestabilidad (por ejemplo, en el caso de la cinética de Haldane).

\subsection{Resumen del capítulo}

En los cultivos aeróbicos, además de proveer una ley de alimentación adecuada para el sustrato que regula el crecimiento debe proveerse el oxígeno necesario para que los microorganismos utilicen los nutrientes. Si bien en muchas aplicaciones puede asumirse que el oxígeno se encuentra en exceso, el crecimiento exponencial de la biomasa produce un consumo de oxígeno exponencial. Si la capacidad de transferencia de oxígeno del biorreactor es excedida, el oxígeno disuelto puede caer a valores muy bajos y resultar limitante de la reacción de crecimiento, lo cual genera diversos problemas como exceso de sustratos, inestabilidad de la ley de alimentación y formación de productos indeseados por cambio de metabolismo. En este capítulo, se diseñó un algoritmo de adaptación de la ley de alimentación basado en técnicas de modo deslizante con el objetivo de modificar la alimentación en caso de que el oxígeno disuelto decrezca. En particular, se evita que el oxígeno decrezca más rápido que una ley pre-establecida de manera tal que la concentración de oxígeno se mantiene por encima de un valor definido por el usuario.

El diseño y el funcionamiento del sistema propuesto fue ilustrado para dos tipos de controladores relevantes: el perfil exponencial de lazo abierto y el control de $\mu$ a lazo cerrado. Se presentaron resultados ilustrativos para un cultivo semi-continuo de $P$. pastoris. Se demostró también que la acu- 
mulación de sustrato puede evitarse en la operación a alta densidad celular y en condiciones de fallas de la transferencia de oxígeno.

Es importante señalar que la propuesta no requiere mediciones adicionales, no depende del modelo y preserva la estructura descentralizada típica con la que se controlan muchos de estos procesos. De esta manera, la propuesta es aplicable a la supervisión de los algoritmos de alimentación pre-existentes sin introducir mayores cambios en los lazos de control. 


\section{Capítulo 6}

\section{Regulación de múltiples tasas de crecimiento en cultivos multi-sustrato}

La necesidad de obtener nuevos productos, reducir los costos de los procesos fermentativos, reutilizar sustancias orgánicas que surgen como desecho de ciertas industrias y buscar formas alternativas de tratar compuestos tóxicos son algunas de las motivaciones para el desarrollo de los llamados procesos multi-sustrato. En un sentido estricto todos los procesos biotecnológicos requieren múltiples sustratos ya que cualquier microorganismo necesita varios nutrientes para el crecimiento y mantenimiento de las funciones celulares. No obstante se utiliza el concepto de multi-sustrato para referirse a dos o más nutrientes que afectan notablemente la tasa de crecimiento. En los procesos semi-continuos, estos sustratos suelen ser incorporados al medio de cultivo ya sea en una única solución [53] o mediante flujos separados [55]. Como se explicó en la sección 2.1.6, los sustratos involucrados pueden cumplir la misma función en el metabolismo celular (por ejemplo fuentes de carbono) o diferentes funciones (como es el caso de una fuente de carbono, una de nitrógeno, etc.) [51]. Desde el punto de vista dinámico y según cómo sean consumidos los sustratos, se obtienen modelos de estados con estructura diferente. La principal diferencia radica en la expresión de la tasa de crecimiento (ver expresiones (2.36)-(2.39)), donde por ejemplo sustratos que son esenciales se modelizan con términos multiplicativos, mientras que caminos metabólicos que pueden ocurrir en forma paralela se representan con una tasa de crecimiento aditiva.

Este capítulo trata sobre el diseño de leyes de alimentación para un cultivo alimentado con dos sustratos homólogos, es decir dos sustratos que cumplen la misma función en el metabolismo celular. En particular se aborda el diseño de leyes de alimentación exponenciales para dos fuentes de carbono. La principal motivación para aplicar flujos exponenciales es la posibilidad de regular la tasa de crecimiento. 


\subsection{Descripción del problema}

Al igual que en los procesos alimentados con una sola fuente de carbono, ciertos objetivos biotecnológicos pueden expresarse en términos de regulación de variables y/o seguimiento de perfiles temporales. Para procesos multi-sustrato se han identificado los siguientes objetivos:

- la regulación de la tasa de crecimiento total en un valor predefinido $\mu=\mu_{\text {ref }}$, el cual es compatible con el estado metabólico deseado o bien es óptimo para el proceso de producción. Este objetivo se traduce en el seguimiento de un perfil exponencial de la forma $X^{*}(t)=x_{0} v_{0} e^{\mu_{\text {reft }}}$, de la misma forma que en los procesos alimentados con un único sustrato principal [63].

- la regulación de la tasa de crecimiento manteniendo una determinada relación de sustratos $s_{1} / s_{2}$ o de las tasas de crecimiento individuales $\mu_{1} / \mu_{2}$. Este objetivo se debe a que las propiedades de ciertos productos están estrechamente relacionadas con alguno de estos cocientes. Un ejemplo se da en procesos de producción de biopolímeros, donde la composición de los monómeros se relaciona con el cociente de las fuente de carbono [143].

Los objetivos descriptos guardan una estrecha relación entre sí y podrían resolverse manipulando adecuadamente los flujos de alimentación del biorreactor. Sin embargo, en la literatura pueden encontrarse pocos reportes donde se utilicen dos flujos de alimentación para regular la tasa de crecimiento. Entre esos aportes se encuentran leyes de alimentación exponenciales de lazo abierto (es decir leyes precalculadas) que son extensiones de las utilizadas en cultivos con un único sustrato limitante [55, 63, 144]. Como fue ilustrado en el Capítulo 2 para cultivos con un sustrato limitante, la aplicación de flujos proporcionales a la cantidad actual de biomasa, en lugar de leyes de alimentación precalculadas, tiene la potencial ventaja de evitar la sobrealimentación del cultivo al tiempo que permite regular en forma más robusta la tasa de crecimiento. En [88] se presentó una ley exponencial basada en la realimentación de la concentración de biomasa y volumen para un cultivo semi-continuo multi-sustrato, la cual se basa en conceptos de estabilidad parcial e invariancia. Recientemente, fue presentado un trabajo preliminar en el cual se extienden resultados previos con una ley que incluye correción proporcional e integral [25]. En ese trabajo las estimaciones de la tasa de crecimiento se obtienen a partir de medición de biomasa y uno de los sustratos. Si bien esto permite distinguir las tasas de crecimiento en forma individual, se requiere medir dos sustancias en el medio de cultivo. El objetivo de este capítulo es profundizar esta línea de investigación y desarrollar leyes de alimentación exponenciales que utilicen únicamente medición en línea de biomasa, al tiempo que se incorporan estimaciones de la tasa de crecimiento total. 
En particular se considera el problema de alimentar dos nutrientes en procesos con crecimiento aditivo (ec. 2.36)

$$
\mu=\mu_{1}\left(s_{1}\right)+\mu_{2}\left(s_{2}\right),
$$

donde la tasa de crecimiento total es la suma de las tasas individuales en cada sustrato. Para procesos en los que la tasa de crecimiento es de la forma (6.1), el modelo que describe la dinámica de las principales sustancias (descripto en las expresiones (2.40a)-(2.40d)) resulta en

$$
\begin{aligned}
\dot{x} & =\left(\mu_{1}+\mu_{2}\right) x-\frac{x}{v} F_{1}-\frac{x}{v} F_{2}, \\
\dot{s}_{1} & =-\frac{\mu_{1} x}{y_{1}}+\frac{\left(S_{1 i n}-s_{1}\right)}{v} F_{1}-\frac{s_{1}}{v} F_{2}, \\
\dot{s}_{2} & =-\frac{\mu_{2} x}{y_{2}}-\frac{s_{2}}{v} F_{1}+\frac{\left(S_{2 i n}-s_{2}\right)}{v} F_{2}, \\
\dot{v} & =F_{1}+F_{2},
\end{aligned}
$$

donde $x, s_{1}$ y $s_{2}$ son concentraciones de biomasa y sustratos $(\mathrm{g} / \mathrm{L}), v$ el volumen de trabajo y $F_{i}(\mathrm{~L} / \mathrm{h})$ las entradas de los sustratos $s_{i}$ en concentración $S_{(i) i n}$. Nótese que debido a que en el flujo $i$ sólo ingresa el sustrato $s_{i}$, cada una de las entradas produce dilución en la concentración del otro nutriente. Los parámetros $y_{i}$ son los rendimientos de sustrato $i$ a biomasa.

Se considera que el objetivo de la alimentación aplicada al proceso semicontinuo (6.2)-(6.5) es regular la tasa de crecimiento en el valor $\mu_{\text {ref }}$. De esta manera, la trayectoria nominal deseada es la de crecimiento exponencial, donde la cantidad de biomasa total $X(t)=x v$ evoluciona según

$$
X^{*}(t)=x_{0} v_{0} e^{\mu_{\text {reft }}} .
$$

Este objetivo puede lograrse aplicando flujos de alimentación que sean proporcionales a la cantidad de biomasa

$$
F_{i}=\lambda_{i r} x v
$$

donde $\lambda_{i r}>0$ es un coeficiente de proporcionalidad. Estos parámetros deberían seleccionarse de manera de obtener el valor deseado en cada $\mu_{i}$.

Para el caso de cinéticas aditivas, y bajo la hipótesis de que la concentración de biomasa se mide en línea, puede calcularse un control denominado invariante resolviendo el siguiente sistema de ecuaciones [88]

$$
\begin{aligned}
& \mu_{i}\left(s_{i r}\right)=\mu_{i r} \\
& \dot{s}_{i}=\left(-\frac{\mu_{i r}}{y_{i}}+\lambda_{i} S_{i(i n)}-\left(\lambda_{1}+\lambda_{2}\right) s_{i r}\right) x=0,
\end{aligned}
$$

para $i=1,2$. La ec. (6.8) permite calcular los valores de sustrato $s_{i r}$ que corresponden a los $\mu_{i r}$ deseados. La expresión (6.9), que resulta de reemplazar 
(6.7) en las expresiones (6.3) y (6.4), provee los valores $\lambda_{1 r}, \lambda_{2 r}$ que mantienen $s_{i}=s_{i r}$ para el caso de condiciones iniciales apropiadas $\left(s_{i 0}=s_{r i}\right)$, con las tasas de crecimiento en $\mu_{i}\left(s_{i r}\right)=\mu_{i r}$. Al resolver las expresiones (6.8)-(6.9) se obtienen los siguientes parámetros

$$
\begin{aligned}
& \lambda_{1 r}=\frac{\mu_{1 r} / y_{1}\left(S_{2 i n}-s_{2 r}\right)+\mu_{2 r} / y_{2} s_{1 r}}{S_{1 i n} S_{2 i n}-S_{2 i n} s_{1 r}-S_{1 i n} s_{2 r}}, \\
& \lambda_{2 r}=\frac{\mu_{2 r} / y_{2}\left(S_{1 i n}-s_{1 r}\right)+\mu_{1 r} / y_{1} s_{2 r}}{S_{1 i n} S_{2 i n}-S_{2 i n} s_{1 r}-S_{1 i n} s_{2 r}}
\end{aligned}
$$

los cuales pueden ser aplicados en el flujo de alimentación descripto por (6.7) $[88]$.

Por otro lado, si se supone crecimiento exponencial con $\mu_{i}=\mu_{i r}$ y se reemplaza (6.7) en la dinámica de la biomasa (ec. (6.2)), se tiene

$$
\dot{x}=\left(\mu_{1 r}+\mu_{2 r}\right) x-\left(\lambda_{1 r}+\lambda_{2 r}\right) x^{2} .
$$

Esta ecuación diferencial ordinaria de primer orden es de la forma $\dot{x}=$ $\mu_{r e f} x-\lambda_{r} x^{2}$ con $\mu_{r e f}=\mu_{1 r}+\mu_{2 r}, \lambda_{r}=\lambda_{1 r}+\lambda_{2 r}$. Su solución es

$$
x^{*}(t)=\frac{\mu_{r e f} / \lambda_{r}}{1+\left(\frac{\mu_{r e f}}{\lambda_{r} x_{0}}-1\right) e^{-\mu_{r e f t}}} .
$$

Dado que $X^{*}(t)=x^{*}(t) v^{*}(t)$ y utilizando la expresión (6.6) se obtiene la evolución del volumen [28]:

$$
v^{*}(t)=v_{0}+x_{0} v_{0} \frac{\lambda_{r}}{\mu_{\text {ref }}}\left(e^{\mu_{r e f} t}-1\right) .
$$

En las expresiones (6.13)-(6.14) se observa que la biomasa sigue una trayectoria acotada mientras que el volumen crece en forma exponencial. Además, para obtener $\mu_{i}=\mu_{i r}$, los sustratos deben alcanzar las concentraciones $s_{i}^{*}(t)=s_{i r}$, donde $s_{i r}$ es el valor obtenido con la expresión (6.8). Por esta razón interesa analizar la estabilidad del sistema respecto a un subconjunto de los estados, en particular los sustratos.

El enfoque que permite formalizar el análisis de estabilidad de un sistema respecto de un subconjunto de las variables de estado es el provisto por la teoría de estabilidad parcial [85], donde se considera el movimiento del sistema dinámico en un subespacio en lugar de la convergencia a un punto de equilibrio particular. En la próxima sección se presenta el análisis de estabilidad de las concentraciones de sustrato a los valores $\left(s_{1 r}, s_{2 r}\right)$.

\subsection{Regulación de tasa de crecimiento utili- zando medición de biomasa}

En caso de disponer únicamente de medición en línea de biomasa y volumen, puede aplicarse realimentación proporcional no lineal de la forma

$$
F_{i}=\lambda_{i r}(1+k e) x v
$$




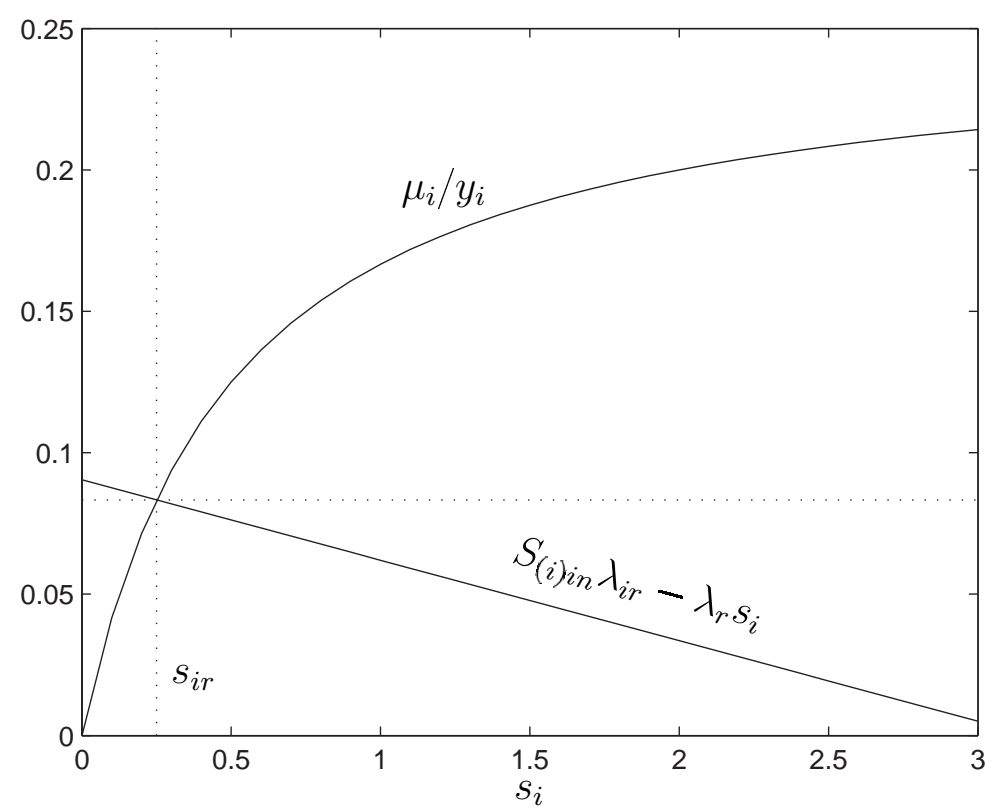

Figura 6.1: Términos que conforman $z_{i}\left(s_{i}\right)$ para cinéticas monótonas (tipo Monod).

con $e=\mu_{\text {ref }}-\mu$. La estimación de $\mu$ puede obtenerse a partir de las mediciones de biomasa y volumen. Con la expresión (6.15) se mantiene la realimentación proporcional a la biomasa y se agrega una correción sobre la ganancia invariante $\lambda_{i r}$. Nótese que con $k=0$ se recupera la expresión de flujos descripta en (6.7).

Análisis El objetivo es analizar si las trayectorias de los sustratos convergen al punto deseado $\left(s_{1 r}, s_{2 r}\right)$, que corresponde a las tasas de crecimiento $\mu_{1 r}, \mu_{2 r}$ en el caso de que cada $\mu_{i}$ es función del sustrato $i$. Esto se realiza en el contexto de estabilidad parcial antes mencionado. A partir de (6.3)-(6.4) y la ley de alimentación (6.15) se obtienen las siguientes expresiones de lazo cerrado

$$
\begin{aligned}
& \dot{s}_{1}=-x\left(z_{1}-\left(S_{1 i n} \lambda_{1 r}-\lambda_{r} s_{1}\right) k e\right), \\
& \dot{s}_{2}=-x\left(z_{2}-\left(S_{2 i n} \lambda_{2 r}-\lambda_{r} s_{2}\right) k e\right),
\end{aligned}
$$

donde $\lambda_{r}=\lambda_{1 r}+\lambda_{2 r} \mathrm{y}$

$$
z_{i}=\frac{\mu_{i}}{y_{i}}-\left(S_{(i) i n} \lambda_{i r}-\lambda_{r} s_{i}\right)
$$

Nótese que ambos sustratos son afectados por el error en la tasa de crecimiento del otro sustrato a través del término ke. Para realizar el análisis de (6.16)-(6.17) es conveniente destacar que los términos $\lambda_{i r}$ fueron calculados 
a partir de $\dot{s}_{i}=0$ en $s_{i}=s_{i r}$. Esto implica que $\mu_{i} / y_{i}$ y la recta definida por $S_{(i) i n} \lambda_{i r}-\lambda_{r} s_{i}$ se intersectan en $s_{i}=s_{i r}$ (ver Figura 6.1) y además $z_{i}$ es positivo si $s_{i}>s_{i r}$ y negativo cuando $s_{i}<s_{i r}$. Luego, para cinéticas monótonas como Monod y Tessier [28], se tiene que para todo $s_{i} \neq s_{i r}$

$$
\left(s_{i}-s_{i r}\right) z_{i}>0 \text {. }
$$

El cambio de coordenada temporal $\xi: t \rightarrow \tau$ definido por

$$
\tau=\int x(\sigma) d \sigma
$$

es una función biyectiva y diferenciable que mapea cualquier intervalo cerrado $\left[t_{a}, t_{b}\right]$ en un intervalo $\left[\tau_{a}, \tau_{b}\right]$. Además $\xi$ tiene derivada positiva dado que $d \tau / d t=x(t) \geqslant x_{0}>0$. Luego (6.20) define una parametrización regular que preserva la estabilidad [106].

Ahora, aplicando (6.20) a las expresiones (6.16)-(6.17) se obtiene

$$
\begin{aligned}
& s_{1}^{\prime}=-z_{1}+\left(S_{1 i n} \lambda_{1 r}-\lambda_{r} s_{1}\right) k e \\
& s_{2}^{\prime}=-z_{2}+\left(S_{2 i n} \lambda_{2 r}-\lambda_{r} s_{2}\right) k e
\end{aligned}
$$

donde $s_{i}^{\prime}:=d s_{i} / d \tau$. Nótese que se obtuvo un sistema que sólo depende de las variables de estado $s_{1}, s_{2}$.

En las expresiones (6.21)-(6.22) puede verse que si $k=0$, entonces $s_{i}^{\prime}=$ $-z_{i}$. Si se considera la función definida positiva

$$
V\left(s_{1}, s_{2}\right)=\frac{\left(s_{1}-s_{1 r}\right)^{2}}{2}+\frac{\left(s_{2}-s_{2 r}\right)^{2}}{2}
$$

la derivada con respecto a $\tau$ resulta

$$
V^{\prime}\left(s_{1}, s_{2}\right)=-\left[\left(s_{1}-s_{1 r}\right) z_{1}+\left(s_{2}-s_{2 r}\right) z_{2}\right]<0 .
$$

La negatividad de $V^{\prime}$ se debe a la expresión (6.19). Luego, la expresión (6.23) es una función de Lyapunov para el sistema (6.21)-(6.22) y el punto de operación deseado es asintóticamente estable. Dado que el escalado temporal (6.20) preserva la estabilidad, las trayectorias en la coordenada temporal original $\left(s_{1}(t), s_{2}(t)\right)$ también convergen a $\left(s_{1 r}, s_{2 r}\right)$. De hecho la concentración de biomasa es una función variante en el tiempo pero acotada positivamente lo que afecta la evolución temporal de las variables pero no la propiedad de estabilidad.

Cuando se considera $k>0$, el error de regulación de $\mu$ afecta la dinámica de ambos estados. Si se evalúa la derivada de la función (6.23) sobre las trayectorias (6.21)-(6.22) para el caso $k>0$ se tiene

$$
\begin{aligned}
V^{\prime}\left(s_{1}, s_{2}\right)= & -\left[z_{1}\left(s_{1}-s_{1 r}\right)+z_{2}\left(s_{2}-s_{2 r}\right)\right] \\
& +\left[\left(s_{1}-s_{r 1}\right)\left(S_{1 i n} \lambda_{1 r}-\lambda_{r} s_{1}\right)\right] k e \\
& +\left[\left(s_{2}-s_{r 2}\right)\left(S_{2 i n} \lambda_{2 r}-\lambda_{r} s_{2}\right)\right] k e .
\end{aligned}
$$




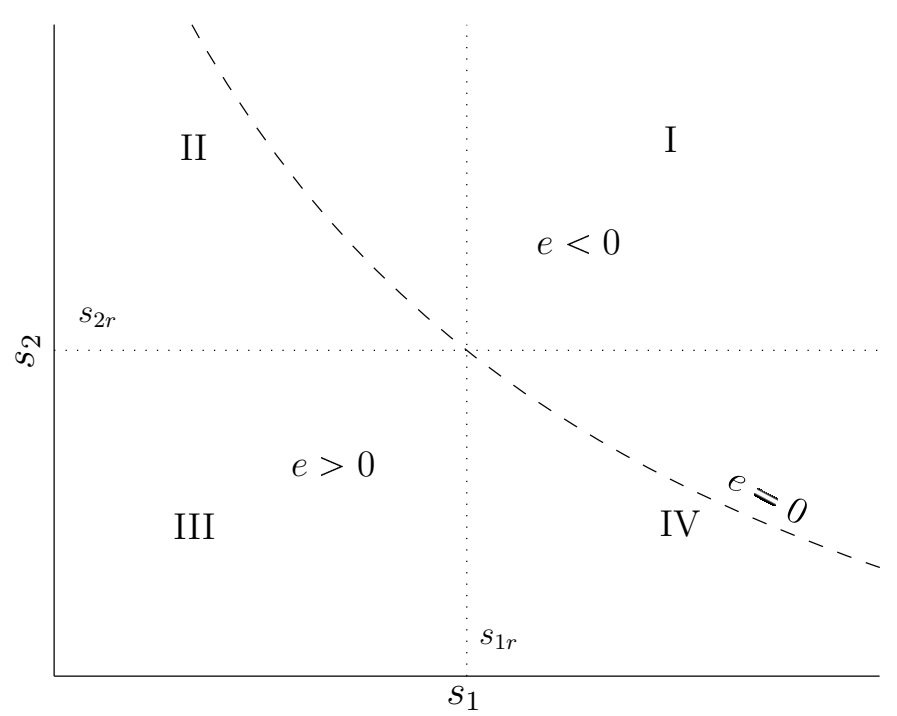

Figura 6.2: Plano $s_{1}-s_{2}$ : regiones de análisis.

Puede probarse que en los cuadrantes I y III (ver Figura 6.2) se tiene

$$
V^{\prime}\left(s_{1}, s_{2}\right)<-\left[z_{1}\left(s_{1}-s_{1 r}\right)+z_{2}\left(s_{2}-s_{2 r}\right)\right]<0,
$$

y además sobre $e=0$

$$
V^{\prime}\left(s_{1}, s_{2}\right)=-\left[z_{1}\left(s_{1}-s_{1 r}\right)+z_{2}\left(s_{2}-s_{2 r}\right)\right]<0 .
$$

Sin embargo, en los cuadrantes II y IV el segundo y tercer sumando de (6.25) tienen en general signo opuesto y el resultado de $V^{\prime}$ depende de la suma de los tres términos. Luego no puede concluirse a priori que (6.25) sea negativa en forma independiente de los parámetros del proceso.

Un análisis más detallado acerca de cómo evolucionan las trayectorias hacia el punto $\left(s_{1 r}, s_{2 r}\right)$ puede obtenerse de la Figura 6.3, donde se representan cualitativamente los signos de (6.21)-(6.22) en cada región. En esa figura puede notarse que las trayectorias evolucionan o bien hacia el punto deseado o al menos hacia los cuadrantes II y IV. Dado que las concentraciones de sustrato no pueden superar la concentración en la entrada de flujos se tiene que $0 \leqslant s_{i} \leqslant S_{(i) i n}$. Es decir que los cuadrantes definen un conjunto cerrado para la evolución de las variables $s_{i}^{\prime}$. Además, de la expresión (6.21) puede determinarse que

$$
s_{1}^{\prime}= \begin{cases}\left(S_{1 i n} \lambda_{1 r}-\lambda_{r} s_{1 r}\right) k e>0 & \text { si } s_{1}=s_{1 r}, s_{2}<s_{2 r} \\ \left(S_{1 i n} \lambda_{1 r}-\lambda_{r} s_{1 r}\right) k e<0 & \text { si } s_{1}=s_{1 r}, s_{2}>s_{2 r}\end{cases}
$$


donde se usó el hecho de que $z_{1}\left(s_{1 r}\right)=0$. De forma similar para $s_{2}$ se tiene que

$$
s_{2}^{\prime}= \begin{cases}\left(S_{2 i n} \lambda_{2 r}-\lambda_{r} s_{2 r}\right) k e>0 & \text { si } s_{1}=s_{2 r}, s_{1}<s_{1 r} \\ \left(S_{2 i n} \lambda_{2 r}-\lambda_{r} s_{2 r}\right) k e<0 & \text { si } s_{1}=s_{2 r}, s_{1}>s_{1 r},\end{cases}
$$

De esta manera, trayectorias $\left(s_{1}(\tau), s_{2}(\tau)\right)$ que ingresan o se inician en los cuadrantes II y IV permanecen dentro de esas regiones para todo tiempo futuro. Ahora, considerando la situación en el cuadrante II, las trayectorias en la región donde $e>0$ evolucionan con signo $s_{1}^{\prime}>0$ mientras que en la región donde $e<0$ las trayectorias de $s_{2}$ son decrecientes $\left(s_{2}^{\prime}<0\right)$. Nótese además que sobre la curva $e=0$ resulta $s_{2}^{\prime} / s_{1}^{\prime}=z_{2} / z_{1}<0$. Esto significa que cuando las trayectorias cortan la curva $e=0$, el vector resultante posee un ángulo $\alpha \in[-90,0]$ grados con respecto al eje horizontal. Si ese ángulo es menor al de la recta tangente a la curva de error nulo, la trayectoria ingresará en la zona de $s_{1}^{\prime}>0$ con lo que la evolución ocurre hacia $s_{1}=s_{1 r}$ mientras que si el ángulo es mayor que el de la tangente, la trayectoria ingresa en la región donde $s_{2}^{\prime}<0$. De esta manera el punto $s_{1 r}, s_{2 r}$ resulta ser un punto de operación estable dado que las trayectorias no pueden salir del cuadrante y continuamente evolucionan hacia el punto de equilibrio. El mismo análisis puede realizarse para el cuadrante IV.

El valor del parámetro $k$ puede determinarse a partir de considerar la restricción sobre los caudales: $0 \leqslant F_{i} \leqslant F_{\max }$. Suponiendo que $F_{\max }$ es lo suficientemente grande, la restricción la impone el hecho de que los flujos requeridos a las bombas deben ser no negativos. De esta manera debe satisfacerse $1+k e \geqslant 0$ donde el error $e=\mu_{\text {ref }}-\mu$ está acotado por $\mu_{\text {ref }}-\mu_{\text {max }} \leqslant e \leqslant \mu_{\text {ref }}$. Otra posibilidad es reemplazar la función lineal $k e$ con una función del error $f(e)$ que sea suave y sature en -1 evitándose así requerir valores negativos. Por ejemplo, puede considerarse la función

$$
f(e)=\tanh (k e)
$$

la cual se comporta linealmente alrededor de $e=0$ y provee una saturación suave a los valores $(-1,1)$. Cabe destacar que al aumentar la ganancia $k$, se incrementa también un camino directo para el ruido en la estimación $\hat{\mu}$ el cual afecta directamente a los flujos aplicados. De esta manera existe un compromiso entre las mejoras obtenidas al aumentar la realimentación y el efecto producido por el ruido de medición sobre los caudales $F_{i}$.

La hipótesis en la que se basa el análisis de estabilidad previo, tanto para $k=0$ como para $k>0$, es que se cumple la expresión (6.19). Esto puede no ser cierto en caso de cinéticas con inhibición como por ejemplo con el modelo de Haldane. En ese caso, y dependiendo del valor de la constante de inhibición, puede resultar que se evolucione a un punto de operación no deseado, al igual que lo que sucede en procesos monosustrato. Esta situación se puede evitar aplicando una saturación adecuada sobre $F_{i}$ de manera de evitar que los sustratos puedan evolucionar hacia valores de concentración no deseados. 

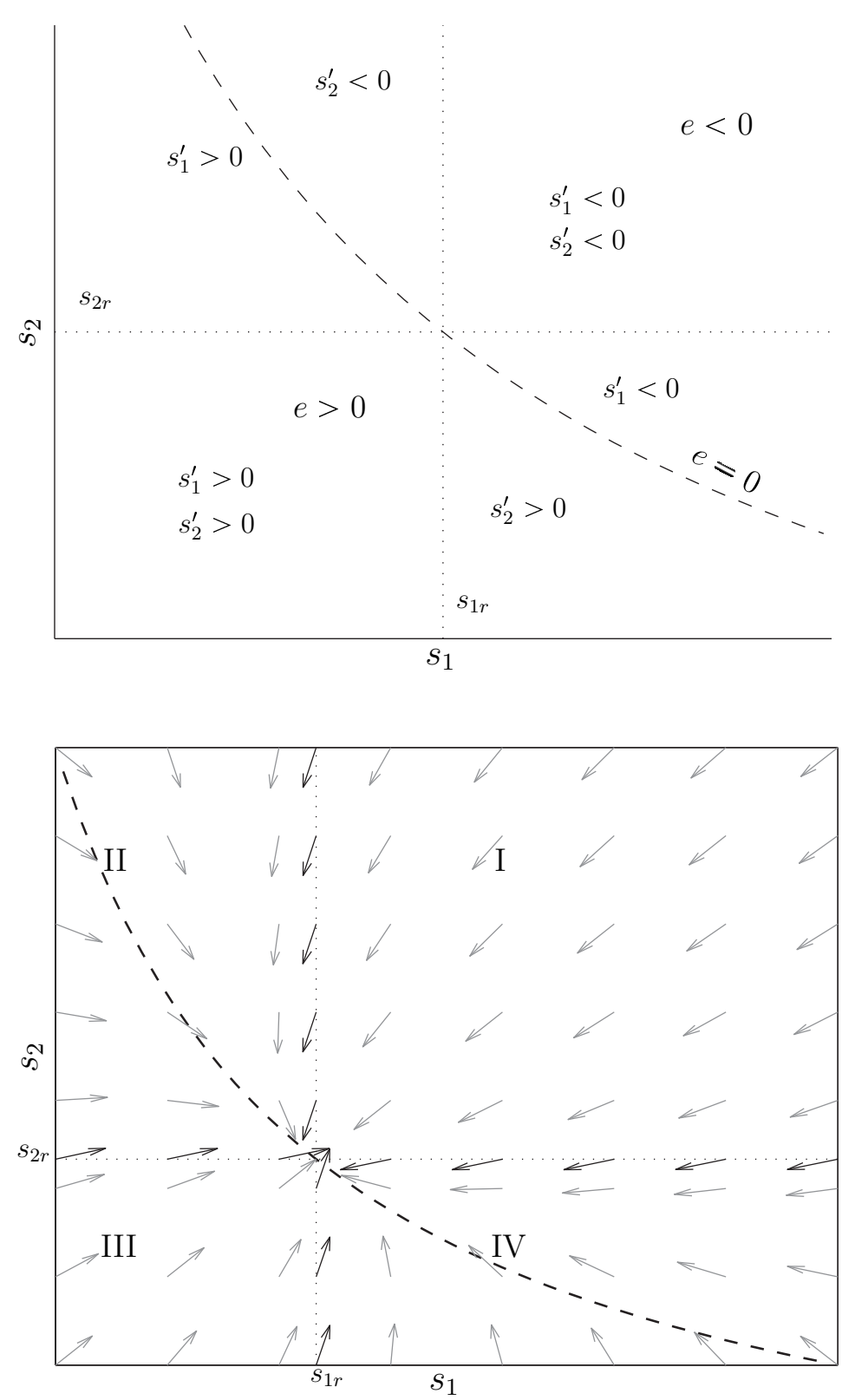

Figura 6.3: Arriba: Plano $s_{1}-s_{2}$ : análisis cualitativo de la trayectoria de los sustratos. Abajo: diagrama de campos vectoriales. 
Tabla 6.1: Valores utilizados en el proceso multi-sustrato.

\begin{tabular}{clcl}
\hline \multicolumn{4}{c}{ Parámetros del bioproceso } \\
\hline$\mu_{\max 1}$ & $0,5 \mathrm{~h}^{-1}$ & $\mu_{\max 2}$ & $0,2 \mathrm{~h}^{-1}$ \\
$k_{s 1}$ & $0,5 \mathrm{~g} / \mathrm{L}$ & $k_{s 2}$ & $0,5 \mathrm{~g} / \mathrm{L}$ \\
$y_{1}$ & $2 \mathrm{~g} / \mathrm{g}$ & $y_{2}$ & $2,1 \mathrm{~g} / \mathrm{g}$ \\
$S_{1 i n}$ & $20 \mathrm{~g} / \mathrm{L}$ & $S_{2 i n}$ & $20 \mathrm{~g} / \mathrm{L}$ \\
$x_{0}$ & $5 \mathrm{~g} / \mathrm{L}$ & $v_{0}$ & $1 \mathrm{~L}$ \\
$s_{10}$ & $0,03 \mathrm{~g} / \mathrm{L}$ & $s_{20}$ & $0,01 \mathrm{~g} / \mathrm{L}$ \\
\hline
\end{tabular}

\subsubsection{Resultados}

En esta sección se comparan las leyes de alimentación proporcional a la biomasa con y sin realimentación del error en $\mu$, las cuales están descriptas por las expresiones (6.7) y (6.15), respectivamente.

Las tasas de crecimiento individuales en el bioproceso (6.2)-(6.5) se asumen términos Monod y los parámetros utilizados junto con las condiciones iniciales se presentan en la Tabla 6.1.

El objetivo es regular la tasa de crecimiento en $\mu_{r e f}=0,25 \mathrm{~h}^{-1}$ y a modo de ejemplo se supone una relación $\mu_{r 1} / \mu_{r 2}=2$. De esto resulta que $\mu_{r 1}=0,167 \mathrm{~h}^{-1}$ y $\mu_{r 2}=0,083 \mathrm{~h}^{-1}$. Las ganancias $\lambda_{1 r}$ y $\lambda_{2 r}$ fueron calculadas con las expresiones (6.10)-(6.11). Para el parámetro $k$ se seleccionó el valor $k=10$ y la implementación se realizó utilizando la función tanh(·). La medición de biomasa se consideró con ruido gaussiano filtrado de $5 \%$ de amplitud, media nula y desviación estándar de $0,22 \mathrm{~g} / \mathrm{L}$.

La tasa de crecimiento fue estimada utilizando el observador por modo deslizante de segundo orden introducido en la sección 4.2. Para el caso de estimar una sola reacción, las expresiones del observador (4.12) resultan

$$
\begin{aligned}
\dot{\hat{x}} & =\bar{\rho} u_{1} x_{m}+2 k_{2} x_{o} \bar{\rho} u_{2},-D x_{m} \\
\dot{u}_{1} & =k_{1} \operatorname{SIGN}(\sigma) \\
u_{2} & =A B S(\sigma)^{1 / 2} \operatorname{SIGN}(\sigma) \\
\sigma & =\left(x_{o} \bar{\rho}\right)^{-1}\left(x_{m}-\hat{x}\right)
\end{aligned}
$$

donde $\bar{\rho}$ es una cota de la derivada de la función a estimar (en este caso $\mu(t)), x_{m}$ representa la concentración de biomasa medida, $D=\left(F_{1}+F_{2}\right) / v$ la dilución total y $\sigma$ es la función descripta en (4.9). Los parámetros del observador fueron seleccionados en base a la excursión de biomasa esperada. A partir del rango de excursión esperado de la variable medida, se calculó el valor $x_{o}=\left(x_{\min }+x_{\max }\right) / 2$. En este caso se seleccionó $x_{\min }=x_{0}=5 \mathrm{~g} / \mathrm{L}$ y $x_{\max }=35 \mathrm{~g} / \mathrm{L}$ los cuales se consideran valores suficientes de acuerdo a la excursión de biomasa prevista. Con estos parámetros y siguiendo el procedimiento detallado el el Capítulo 4 , se obtuvieron las ganancias $k_{1}=1,3 \mathrm{y}$ 
$k_{2}=1,35$ mientras que se seleccionó $\bar{\rho}=0,4$. Las condiciones iniciales del observador fueron $\left(\hat{x}_{0}, u_{10}\right)=\left(x_{m 0}, 0,5\right)$. Cabe destacar que en la implementación de la ley de alimentación, $\hat{\mu}$ pueden obtenerse de otros observadores con convergencia en tiempo finito (ver por ejemplo $[109,101]$ ).

Los resultados obtenidos se exhiben en las Figuras 6.4 y 6.5. La evolución de los estados se exhibe en la Figura 6.4a donde puede observarse que la variación de biomasa se encuentra en el rango asumido de $[5,35] \mathrm{g} / \mathrm{L}$. La realimentación propuesta fue activada en $t=0,25$ horas y permitió reducir el tiempo requerido para alcanzar el valor $\mu_{\text {ref }}$ tal como se aprecia en la Figura 6.4b. Nótese que esto ocurrió a expensas de un sobrepaso en el valor de referencia de $\mu_{1}$. Las acciones de control aplicadas en cada caso se presentan en la Figura 6.5, donde puede verse que la realimentación del error introdujo un aumento en el valor de $\operatorname{los} \lambda_{i}$ aplicados durante las primeras horas del cultivo. Debido a esto, el tiempo requerido para alcanzar $\mu \approx \mu_{\text {ref }}$ se redujo de 3 horas a apróximadamente la mitad de tiempo.

Los valores de $\lambda_{i r}$ fueron calculados utilizando los valores exactos del proceso. Es de esperar que ante incertidumbre en estos valores no se pueda regular $\mu$ al valor deseado y es esperable también que la realimentación propuesta reduzca el error resultante. La Figura 6.6 presenta la evolución temporal de las tasas de crecimiento ante errores del -10\%, y -20\% en $\lambda_{1 r} \mathrm{y}$ $\lambda_{2 r}$, respectivamente. Este error puede atribuirse, entre otros factores, a los rendimientos $y_{i}$ los cuales pueden cambiar durante el transcurso del cultivo. Sin realimentación de $\mu$, para el valor de referencia seleccionado $\left(\mu_{\text {ref }}=0,25\right.$ $\mathrm{h}^{-1}$ ) se obtuvo un error de regulación de $-15 \%$. Aplicando realimentación de $\mu$ (con $k=10)$ el error en $\mu$ fue $-4 \%$. Estos resultados sugieren que agregar una realimentación de $\mu$ a la expresión (6.7) permite acelerar la convergencia y reducir el error en la regulación de la tasa de crecimiento total.

\subsubsection{Extensión a un modelo con inhibición compe- titiva entre los sustratos}

En el modelo (6.1) se asume que el crecimiento en un sustrato no afecta el modo de crecimiento en el otro nutriente. Una extensión interesante consiste en considerar el efecto de inhibición cruzada que un sustrato ejerce en la tasa de crecimiento obtenida sobre el otro sustrato. Este efecto puede explicarse si se considera que los caminos metabólicos por los cuales se consumen los sustratos pueden compartir ciertas enzimas y de este modo es posible que ocurra un efecto de inhibición competitiva. Un modelo muy aceptado para describir este fenómeno es el siguiente [52]

$$
\begin{aligned}
& \mu_{1}\left(s_{1}, s_{2}\right)=\frac{\mu_{\max 1} s_{1}}{s_{1}+k_{s 1}+\Lambda_{1} s_{2}}, \\
& \mu_{2}\left(s_{1}, s_{2}\right)=\frac{\mu_{\max 2} s_{2}}{s_{2}+k_{s 2}+\Lambda_{2} s_{1}}
\end{aligned}
$$



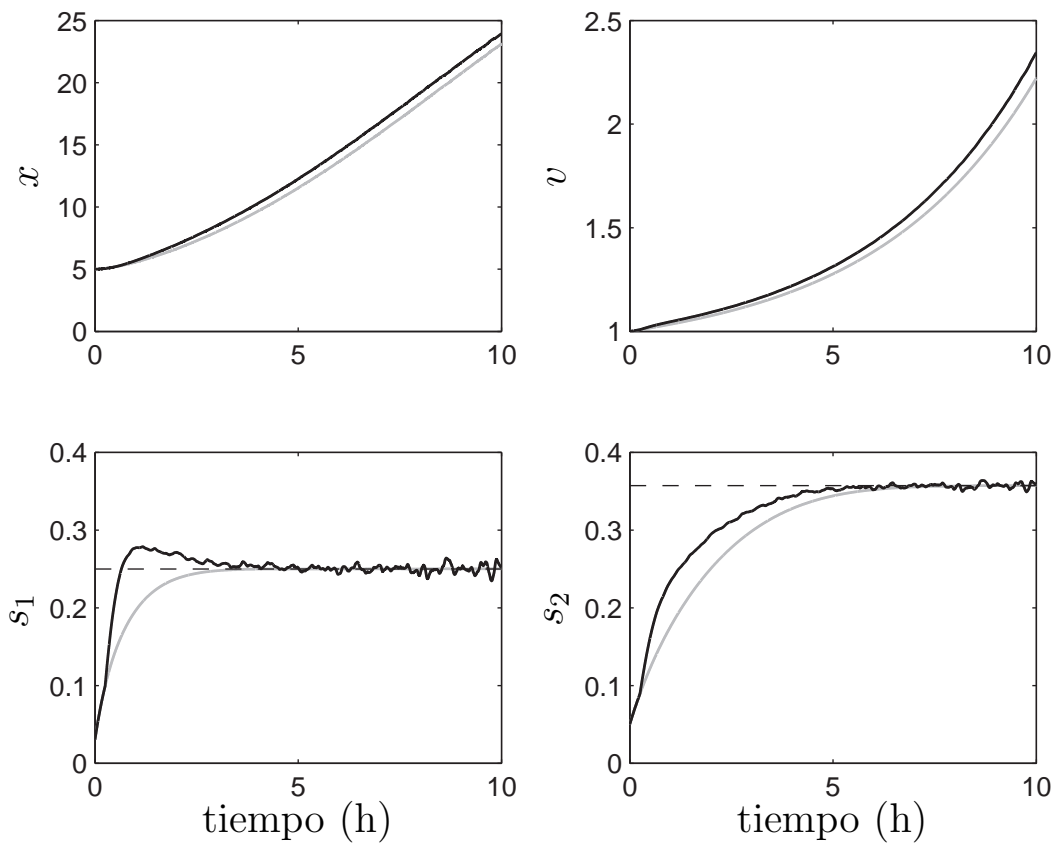

(a) Evolución de los estados del proceso.
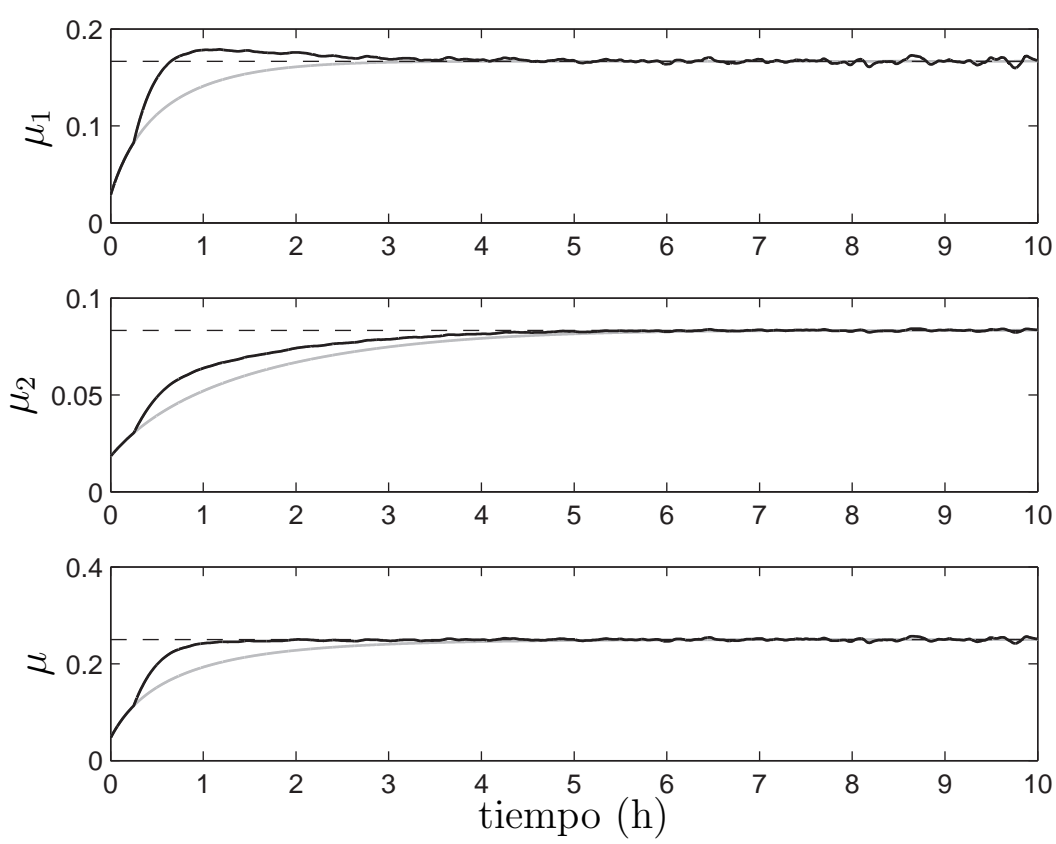

(b) Evolución de las tasas de crecimiento $\mu_{1}, \mu_{2}$ y $\mu$.

Figura 6.4: Resultados obtenidos con $k=10$ (línea negra) y lazo abierto $(k=0)$ (línea gris).

donde $\Lambda_{i}$ es un parámetro que mide el efecto competitivo sobre la tasa de crecimiento $i$. El principal efecto de $\operatorname{los} \Lambda_{i}$ es que la tasa de crecimiento $i$-ésima en la mezcla de sustratos sea menor que la que se observaría en los sustratos por separado. Si bien esto reduce el valor de las tasas individuales, 


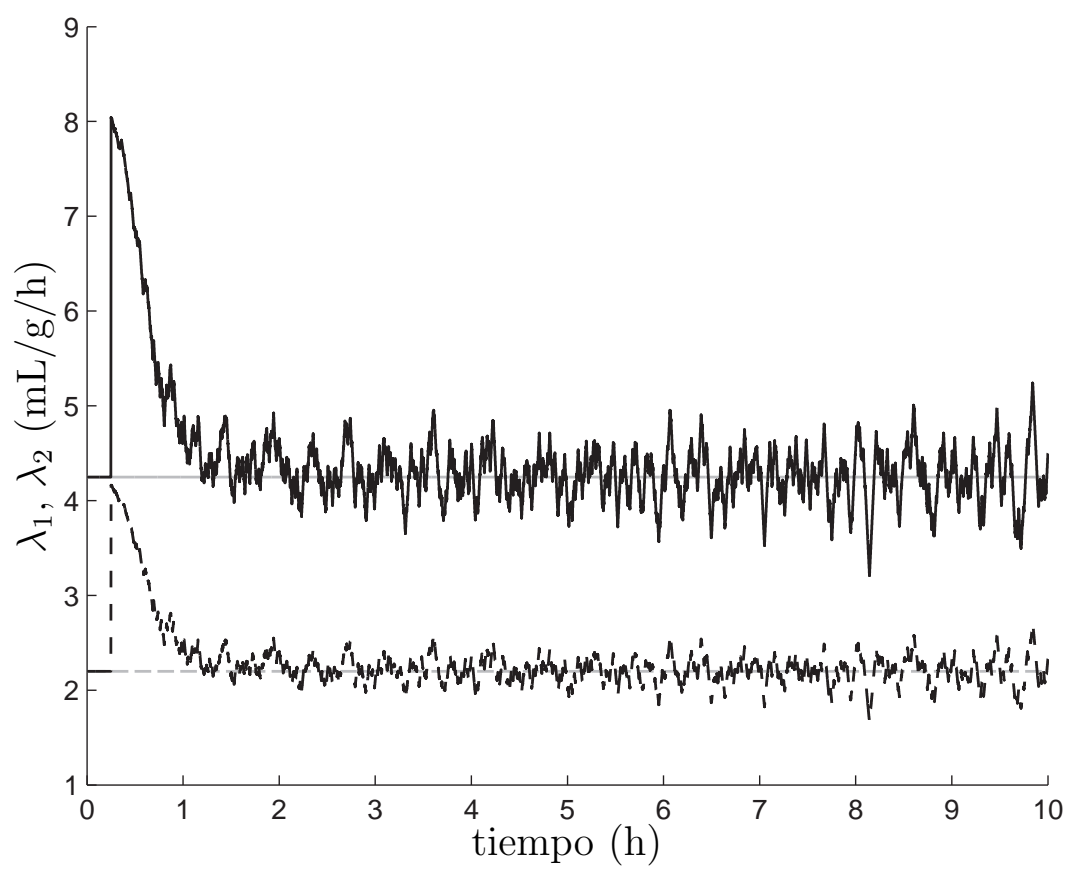

Figura 6.5: Acciones de control aplicadas en $\lambda_{1}$ (línea sólida) y $\lambda_{2}$ (línea a trazos).

la tasa de crecimiento neta es la suma de los términos individuales y de esta manera se obtiene una tasa de crecimiento mayor. El modelo (6.32) es ampliamente utilizado para representar procesos de biodegradación de sustancias tóxicas [145, 146].

Al realizar el ajuste del modelo con valores experimentales, los coeficientes $\Lambda_{1}$ y $\Lambda_{2}$ pueden ajustarse como parámetros independientes. Sin embargo, si se asume que $s_{1}$ y $s_{2}$ son perfectamente sustituibles corresponde considerar los valores particulares $\Lambda_{1}=k_{s 1} / k_{s 2}$ y $\Lambda_{2}=\Lambda_{1}^{-1}$ [52]. La Figura 6.7 presenta un ejemplo de las dos situaciones consideradas. Comparativamente, dado que la tasa de crecimiento total es menor que en el caso sin competitividad, los valores de sustrato requeridos para obtener un valor de tasa de crecimiento resultan en general mayores a los requeridos cuando no existe competitividad. Además, en la resolución de la ec. (6.8) se utiliza el hecho de que la tasa $\mu_{i}$ es función únicamente de $s_{i}$ y de esta manera el valor requerido de $s_{i}$ puede conocerse utilizando la función inversa $\mu_{i}^{-1}$. Ahora, las tasas de crecimiento dependen de los dos sustratos lo cual puede llevar a que utilizando una sola de las expresiones de $\mu_{i}$ se encuentren valores de sustratos que no sean compatibles con el valor requerido en la otra tasa de crecimiento. Por lo tanto, en este caso es conveniente seleccionar el punto de operación a partir del gráfico de la Figura 6.7. Si bien no es directo establecer un cociente de tasas, es posible obtener un punto de operación manteniendo una relación $s_{1} / s_{2}$. Cabe destacar que debido a los parámetros 

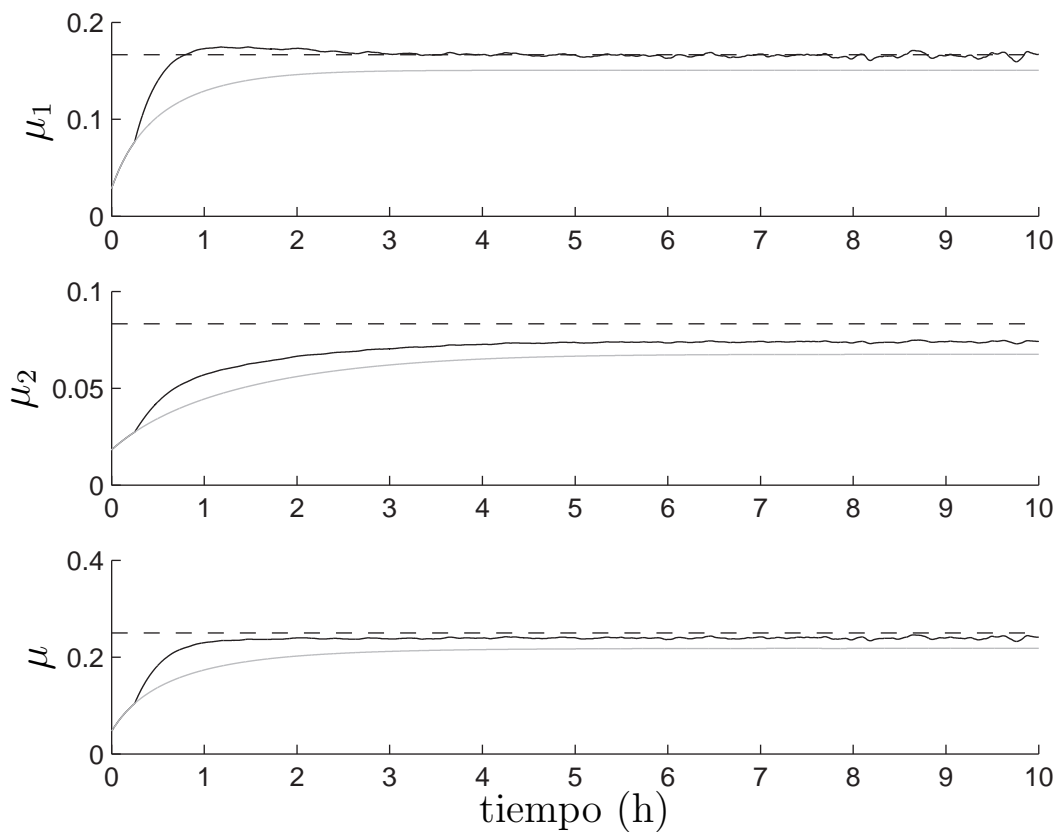

Figura 6.6: Evolución de las tasas de crecimiento $\mu_{1}, \mu_{2}$ y $\mu$ con $k=10$ (línea negra) y $k=0$ (línea gris) en el caso de incertidumbre en los parámetros $\lambda_{1 r} \mathrm{y} \lambda_{2 r}$.

considerados para el ejemplo, las curvas de nivel de la tasa de crecimiento se asemejan a rectas. Sin embargo, la expresión exacta que define las curvas de nivel es de la forma $a s_{1}^{2}+b s_{2}^{2}+c s_{1}+d s_{2}+e s_{1} s_{2}+f=0$.

La alimentación del cultivo semi-continuo cuando existe inhibición competitiva entre sustratos también puede ser resuelta aplicando flujos proporcionales a la cantidad de biomasa. En este caso, la expresión (6.19) no se cumple ya que cada $\mu_{i}$ es función de ambos sustratos. A continuación se presenta un análisis local de la situación tanto para $k=0$ como para $k>0$. Luego, se realiza un análisis global en el plano $s_{1}-s_{2}$ para el caso en que $k=0$.

\section{Análisis}

Dada la ley de alimentación $F_{i}=\lambda_{i r} x v$, la linealización de las expresiones $s_{i}^{\prime}=f_{i}=-z_{i}$ alrededor de $s_{i}=s_{i r}$ resulta en

$$
\left.\frac{\partial \boldsymbol{f}}{\partial \boldsymbol{s}}\right|_{\boldsymbol{s}=\boldsymbol{s}_{r}}=\left.\left(\begin{array}{ll}
-j_{11} & -j_{12} \\
-j_{21} & -j_{22}
\end{array}\right)\right|_{\boldsymbol{s}=\boldsymbol{s}_{r}}
$$



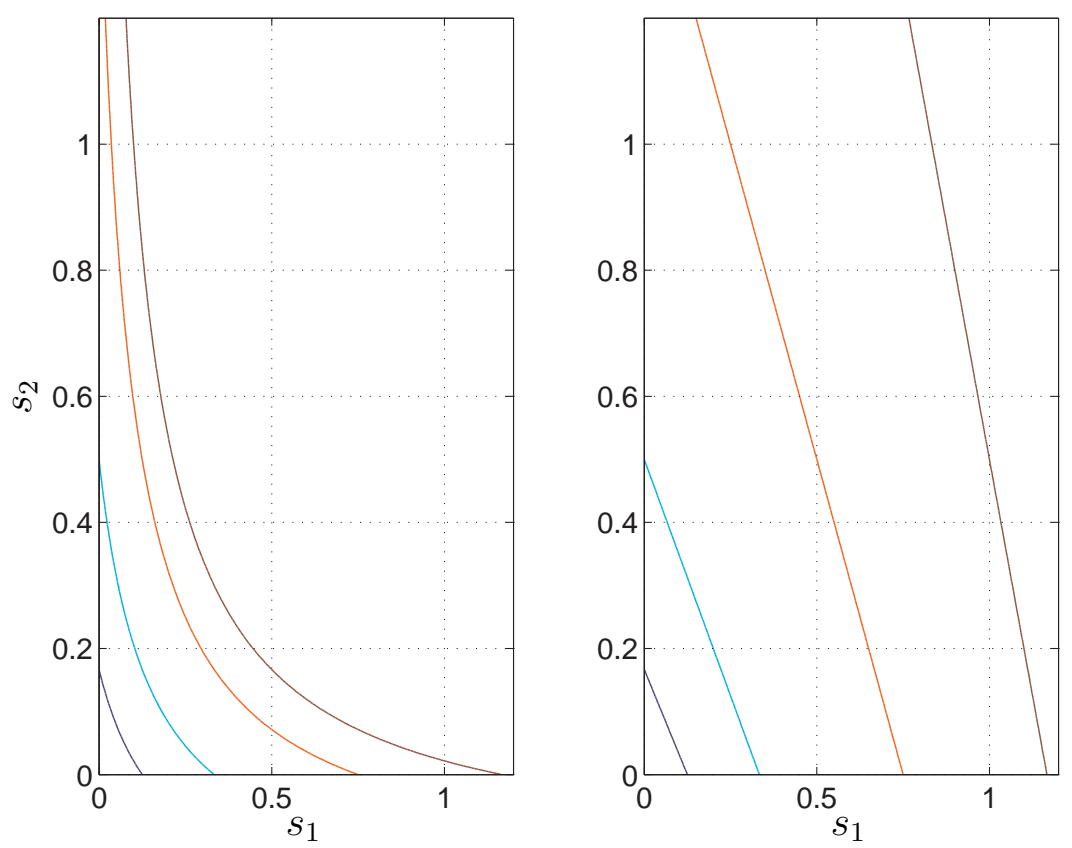

Figura 6.7: Ejemplo de curvas de nivel de la tasa de crecimiento aditiva con $\mu_{i}$ descriptos por (6.32): izq. $\Lambda_{i}=0$; der: $\Lambda_{1}=k_{s 1} / k_{s 2}, \Lambda_{2}=\Lambda_{1}^{-1}$.

$\operatorname{con} \boldsymbol{s}=\left[s_{1} s_{2}\right]^{T} \mathrm{y}$

$$
\begin{aligned}
& j_{11}=\frac{1}{y_{1}} \frac{\partial \mu_{1}}{\partial s_{1}}+\lambda_{r}, \\
& j_{12}=\frac{1}{y_{1}} \frac{\partial \mu_{1}}{\partial s_{2}}, \\
& j_{21}=\frac{1}{y_{2}} \frac{\partial \mu_{2}}{\partial s_{1}}, \\
& j_{22}=\frac{1}{y_{2}} \frac{\partial \mu_{2}}{\partial s_{2}}+\lambda_{r} .
\end{aligned}
$$

Las derivadas parciales de (6.32) involucradas en el análisis resultan

$$
\begin{aligned}
& \left.\frac{\partial \mu_{i}}{\partial s_{i}}\right|_{s=s_{r}}=\frac{\mu_{\max (i)}\left(k_{s i}+\Lambda_{i} s_{j r}\right)}{\left(s_{i r}+k_{s i}+\Lambda_{i} s_{j r}\right)^{2}}>0, \\
& \left.\frac{\partial \mu_{i}}{\partial s_{j}}\right|_{s=s_{r}}=\frac{-\mu_{\max (i)} s_{i r} \Lambda_{i}}{\left(s_{i r}+k_{s i}+\Lambda_{i} s_{j r}\right)^{2}}<0,
\end{aligned}
$$

con $i, j \in\{1,2\}, i \neq j$. Luego, en función de los parámetros del proceso y el punto de operación requerido, los autovalores de la matriz (6.33) se obtienen a partir del polinomio característico

$$
p(\xi)=\xi^{2}+a_{1} \xi+a_{2},
$$


donde los coeficientes resultan $a_{1}=j_{11}+j_{22}, a_{2}=j_{11} j_{22}-j_{12} j_{21}$. Por inspección de (6.34) y (6.35) puede determinarse que $a_{1}>0$ mientras que la positividad de $a_{2}$ puede probarse realizando el cálculo correspondiente. Luego, por el criterio de Routh, el polinomio (6.37) es estable. Este análisis permite concluir que localmente la ley de alimentación $F_{i}=\lambda_{i r} x v$ hace que $\left(s_{1 r}, s_{2 r}\right)$ sea un punto de equilibrio estable.

En caso de utilizarse la ley de alimentación (6.15) con $k>0$, los coeficientes de (6.33) resultan

$$
\begin{aligned}
& j_{11}=\frac{1}{y_{1}} \frac{\partial \mu_{1}}{\partial s_{1}}+\lambda_{r}+k \frac{\partial \mu}{\partial s_{1}}\left(S_{1 i n} \lambda_{1 r}-\lambda_{r} s_{1 r}\right), \\
& j_{12}=\frac{1}{y_{1}} \frac{\partial \mu_{1}}{\partial s_{2}}+k \frac{\partial \mu}{\partial s_{2}}\left(S_{1 i n} \lambda_{1 r}-\lambda_{r} s_{1 r}\right), \\
& j_{21}=\frac{1}{y_{2}} \frac{\partial \mu_{2}}{\partial s_{1}}+k \frac{\partial \mu}{\partial s_{1}}\left(S_{2 i n} \lambda_{2 r}-\lambda_{r} s_{2 r}\right), \\
& j_{22}=\frac{1}{y_{2}} \frac{\partial \mu_{2}}{\partial s_{2}}+\lambda_{r}+k \frac{\partial \mu}{\partial s_{2}}\left(S_{2 i n} \lambda_{2 r}-\lambda_{r} s_{2 r}\right) .
\end{aligned}
$$

Nótese que en $\frac{\partial \mu}{\partial s_{i}}=\frac{\partial \mu_{1}}{\partial s_{i}}+\frac{\partial \mu_{2}}{\partial s_{i}}$ (evaluado en $s=\left(s_{1 r}, s_{2 r}\right)$ ) uno de los sumandos es positivo y el otro negativo (ver (6.35)-(6.36)). Luego, si uno de los términos mencionados fuese negativo en un punto de operación seleccionado, no podría concluirse que los $a_{i}$ resulten positivos para cualquier valor de $k$. De todas maneras, y aun en esa situación, dado un punto de operación es factible encontrar valores de $k>0$ tal que, localmente, $\left(s_{1 r}, s_{2 r}\right)$ sea un punto de equilibrio estable.

Los resultados previos tienen validez local alrededor del punto de operación. Para el caso en que $k=0$, se tiene la dinámica $s_{i}^{\prime}=-z_{i}$ y puede estudiarse la situación en el plano de estados en forma global. De hecho, puede calcularse fácilmente que los valores de sustrato para los cuales se tiene $s_{i}^{\prime}=0$ están dados por

$$
s_{j}=\frac{1}{\Lambda_{i}}\left(\frac{\mu_{\max i} s_{i}}{y_{i}\left(S_{(i) i n} \lambda_{i r}-\lambda_{r} s_{i}\right)}-s_{i}-k_{s i}\right) .
$$

En la Figura 6.8 se representa la situación en el plano $s_{1}-s_{2}$ para el punto de operación $s_{1 r}=0,2 \mathrm{~g} / \mathrm{L}, s_{2 r}=0,13 \mathrm{~g} / \mathrm{L}$ y se identifica el signo de $s_{i}^{\prime}$ en cada región del plano de estados. Las líneas a trazos representan los conjuntos definidos por (6.39). También se ilustran las trayectorias obtenidas desde diferentes condiciones iniciales de sustrato. A diferencia del caso sin inhibición competitiva, los términos $z_{i}$ no se anulan en $s_{i}=s_{i r}$ sino que lo hacen en las variedades de dimensión 1 definidas por la expresión (6.39). Luego puede verse que las dos concentraciones se incrementan simultáneamente sólo en una región del cuadrante III (donde se tiene $s_{i}<s_{i r}$ ) mientras que en el resto de los cuadrantes, cada $s_{i}^{\prime}$ tiene el signo adecuado para converger al punto de operación $\left(s_{1 r}, s_{2 r}\right)$. También puede apreciarse el comportamiento 


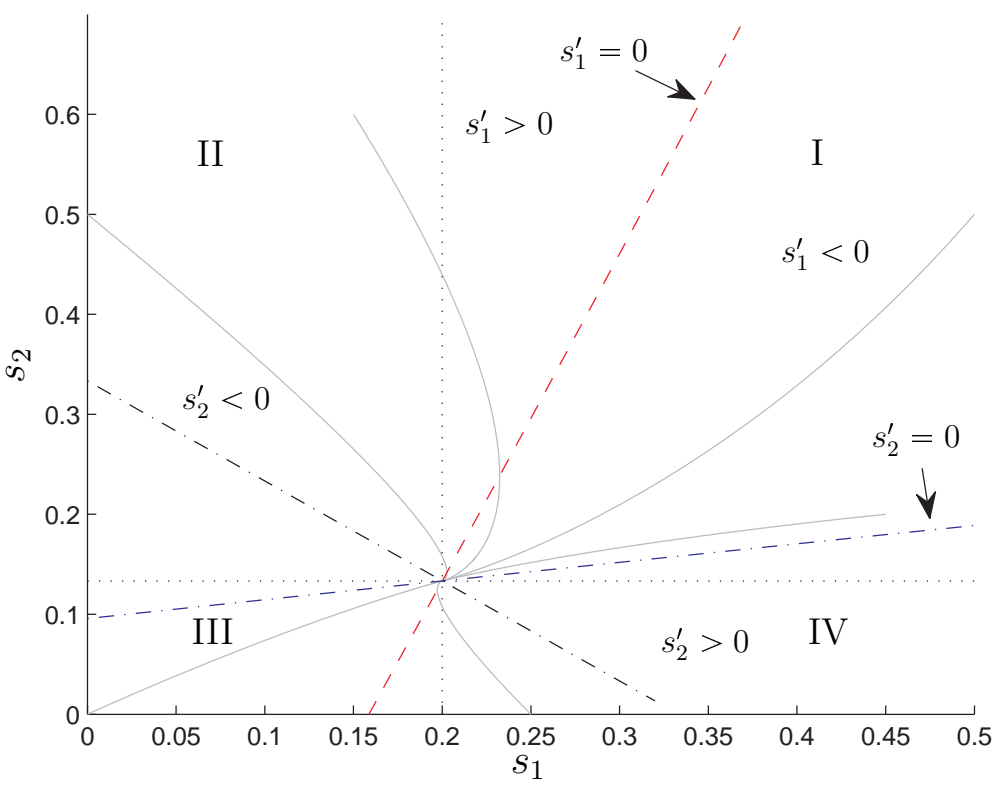

Figura 6.8: Plano $s_{1}-s_{2}$ : regiones de análisis con la ley de alimentación (6.7) (ver parámetros en la Tabla 6.2).

estable en el entorno del punto deseado, el cual había sido adelantado en el análisis de la matriz (6.33). De esta manera, el problema de alimentar dos sustratos en procesos donde existen inhibición competitiva puede ser resuelto con una ley proporcional a la biomasa.

En caso de considerar los flujos definidos en la expresión (6.15), no es posible encontrar una expresión analítica que vincule las concentraciones de sustrato que anulan cada $s_{i}^{\prime}$ de forma explícita y los resultados demostrados son en este caso locales.

\section{Resultados}

La Figura 6.9 presenta trayectorias en el plano $s_{1}-s_{2}$ para el punto de operación antes mencionado y ganancia $k=10$. Los parámetros utilizados en este ejemplo se presentan en la Tabla 6.2. En la Figura 6.10a se exhibe la respuesta temporal de las tasas de crecimiento obtenidas en ambos casos. Nuevamente, la realimentación aumenta los flujos aplicados durante las primeras horas del proceso con el objetivo de alcanzar más rápidamente el valor de $\mu$ deseado (ver Figura 6.10b). 
Tabla 6.2: Valores utilizados en el proceso con inhibición competitiva.

\begin{tabular}{clcl}
\hline \multicolumn{4}{c}{ Parámetros del bioproceso } \\
\hline$\mu_{\max 1}$ & $0,5 \mathrm{~h}^{-1}$ & $\mu_{\max 2}$ & $0,5 \mathrm{~h}^{-1}$ \\
$k_{s 1}$ & $0,5 \mathrm{~g} / \mathrm{L}$ & $k_{s 2}$ & $0,5 \mathrm{~g} / \mathrm{L}$ \\
$\Lambda_{1}$ & $k_{s 1} / k_{s 2}$ & $\Lambda_{2}$ & $k_{s 2} / k_{s 1}$ \\
$y_{1}$ & $2,1 \mathrm{~g} / \mathrm{g}$ & $y_{2}$ & $2 \mathrm{~g} / \mathrm{g}$ \\
$S_{1 i n}$ & $20 \mathrm{~g} / \mathrm{L}$ & $S_{2 i n}$ & $20 \mathrm{~g} / \mathrm{L}$ \\
$x_{0}$ & $5 \mathrm{~g} / \mathrm{L}$ & $v_{0}$ & $1 \mathrm{~L}$ \\
\hline
\end{tabular}

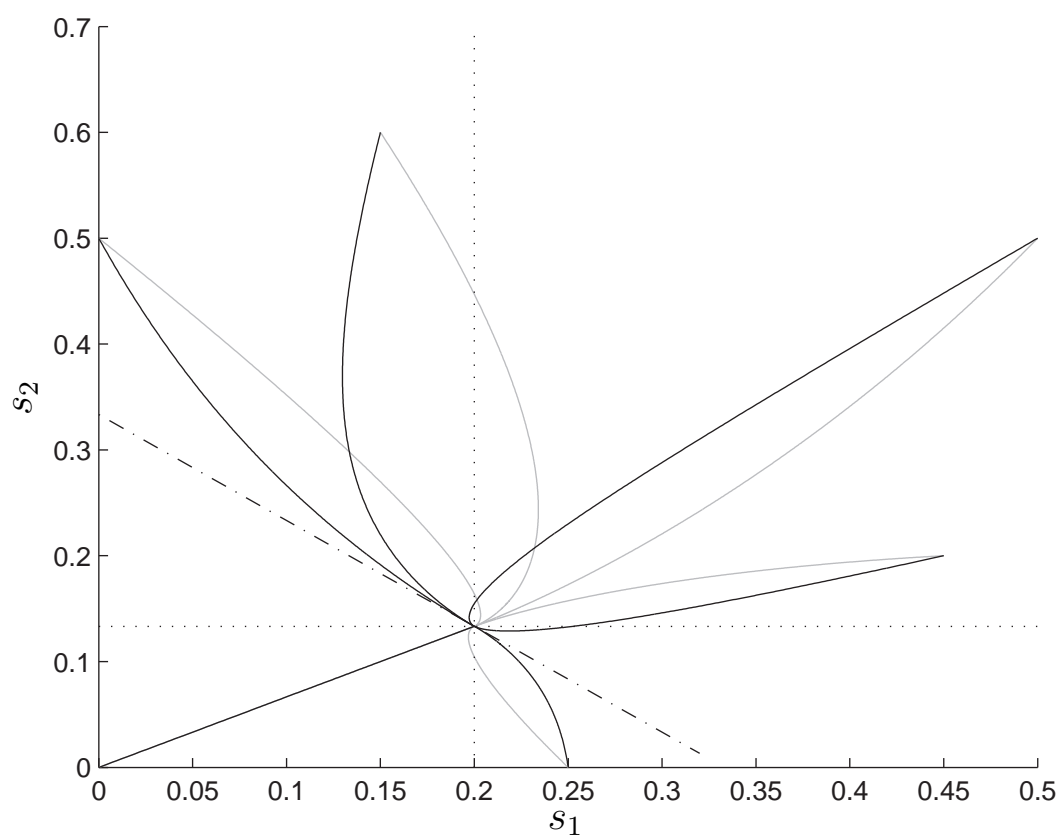

Figura 6.9: Plano $s_{1}-s_{2}$ : comparación entre la ley de alimentación (6.7) (línea gris) y la ec. (6.15) con $k=10$ (línea negra). 

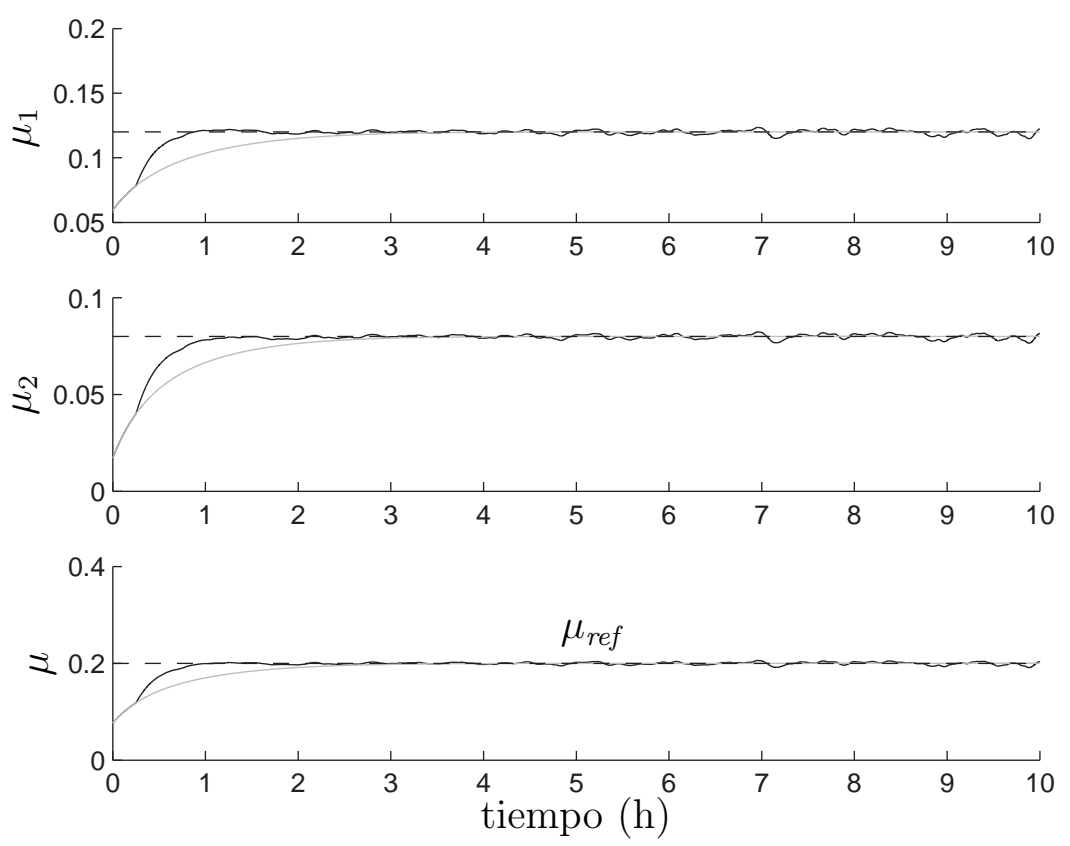

(a) Tasas de crecimiento $\mu_{1}, \mu_{2} \mathrm{y} \mu$.

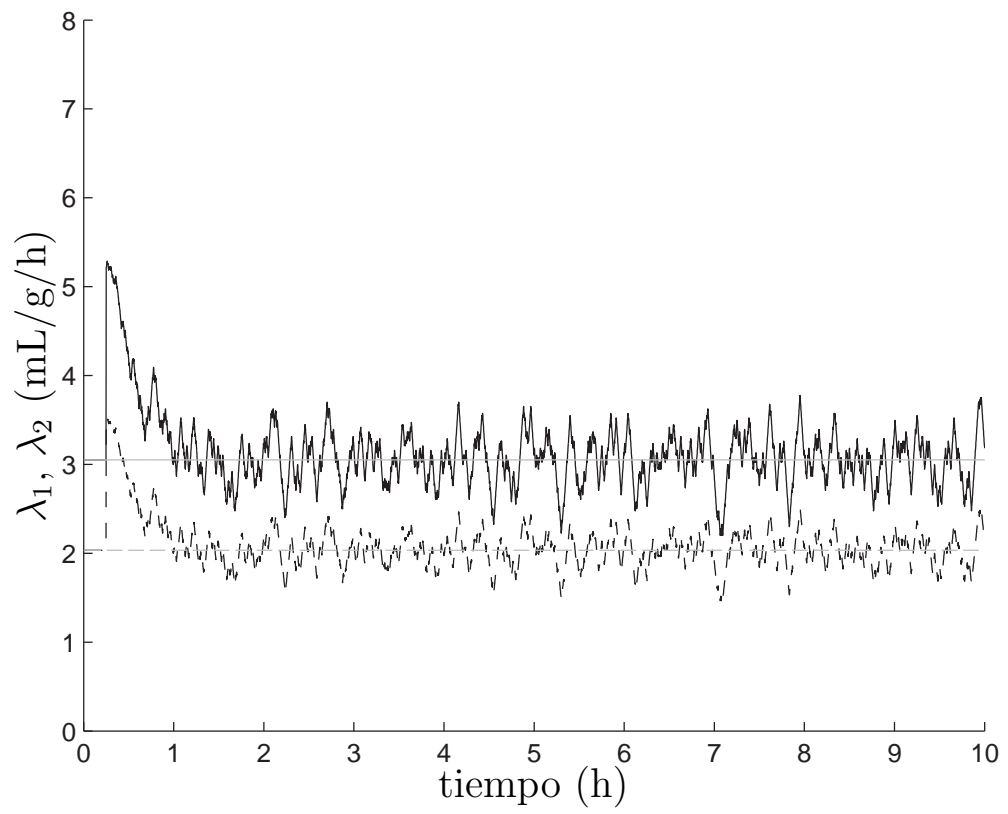

(b) Ganancias aplicadas en $\lambda_{i}$.

Figura 6.10: Evolución temporal de las variables con $k=10$ (línea negra), $k=0$ (línea gris) y tasas de crecimiento descriptas por (6.32) 


\subsection{Resumen del capítulo}

En este capítulo se propusieron leyes de alimentación exponencial para cultivos semi-continuos multi-sustrato. En particular se consideraron cultivos con cinética de crecimiento aditiva. Se estudiaron leyes de alimentación exponencial por ser las más apropiadas para regular la tasa de crecimiento en un valor constante. Se propuso incorporar, en una ley de alimentación proporcional a la biomasa, una estimación del error de tasa de crecimiento. Esta modificación permite acelerar la convergencia y reducir los errores producidos debido a la incertidumbre en los parámetros del modelo. El principal argumento para incorporar una estimación de $\mu$ en la ley de alimentación es que en la actualidad se dispone de diversos algoritmos robustos de estimación de tasas de crecimiento. Además, la utilización de observadores con convergencia en tiempo finito no afecta el análisis de estabilidad una vez superado el modo de alcance. La demostración de estabilidad para la ley de flujo propuesta involucró un análisis no lineal de las trayectorias de los sustratos, basándose en el concepto de estabilidad parcial, es decir estabilidad respecto a un subconjunto de los estados. Dado que en algunos casos la tasa de crecimiento neta es menor a la suma de las tasas individuales en cada uno de los nutrientes, también se consideró el posible efecto de competitividad de los sustratos por una enzima intermedia. Los resultados de simulación sugieren que las leyes de alimentación son también aplicables a este caso. Se concluyó que los flujos $F_{i}=\lambda_{i r} x v$ hacen que el punto de operación sea localmente asintóticamente estable. También es factible encontrar valores de $k>0$ tales que el punto de operación se mantenga localmente asintóticamente estable con la mejora en la velocidad de convergencia.

Como trabajo futuro puede considerarse extender los resultados obtenidos a cinéticas con inhibición (modelos tipo Haldane), los cuales representan la otra gran familia de cinéticas de crecimiento. Una idea es extender las leyes de alimentación aplicadas en procesos mono-sustrato Haldane con una cota superior apropiada de manera de obtener convergencia al punto de operación deseado. 


\section{Capítulo 7}

\section{Conclusiones}

En este trabajo de Tesis se trataron problemas de estimación y control en procesos biotecnológicos desde el punto de vista de sistemas dinámicos no lineales. Se hizo uso de técnicas de modo deslizante para resolver una serie de problemas de observación de variables no medibles. Los observadores presentados abordaron los problemas de estimación de biomasa y tasa de crecimiento en cultivos a partir de la medición del producto, como así también la estimación de un conjunto de tasas de reacción, a partir de un conjunto de mediciones del proceso. Como ejemplos de aplicación se presentaron resultados de estimación de concentración de biomasa y tasa de crecimiento de una bacteria fotosintética en cultivo por lote, y de las tasas de crecimiento y de formación de etanol de una levadura en modo de cultivo continuo. También se abordaron problemas de regulación de variables incluyendo restricciones en el estado con sentido biológico. Este fue el caso del problema de regulación de dos variables (tasa de crecimiento y oxígeno disuelto) en el contexto de cultivos multi-sustrato. Con el objetivo de evitar los problemas asociados a la falta de oxígeno, se propuso un algoritmo auxiliar que realiza la adaptación de un parámetro o referencia del controlador de alimentación en un valor tan próximo al deseado como sea posible pero compatible con el valor de oxígeno disuelto crítico del cultivo. En el último capítulo se estudiaron leyes de alimentación exponencial con el objetivo de regular el crecimiento en un proceso multi-sustrato con cinética aditiva. Se propusieron leyes de alimentación basadas en la medición de biomasa que incluyen un término de realimentación del error de regulación de $\mu$.

Una conclusión general es que la utilización de técnicas conmutadas, en particular modos deslizantes, permite resolver de manera robusta diferentes problemas con alto grado de incertidumbre. En esta Tesis, esto se corroboró respecto al modelo de $\mu$ tanto en el diseño de observadores como en el algoritmo de adaptación para cultivos aeróbicos, el cual sólo requiere medición en línea del oxígeno disuelto.

Además, de los desarrollos presentados pueden extraerse las siguientes conclusiones: 
- Se demostró la factibilidad de estimar variables importantes como la concentración de biomasa y su tasa de crecimiento en procesos de producción con cinética tipo Luedeking y Piret, el cual es uno de los modelos más importantes para representar la dinámica de la formación de productos. Los observadores presentados en el Capítulo 3 tienen como principal ventaja la robustez con respecto al modelo de $\mu$ y presentan además dinámica reducida en el error de estimación. También se concluyó que en caso de un proceso semi-continuo o continuo, el término de dilución ayuda a acelerar la convergencia del error de estimación. De esta manera, los observadores resultan aplicables a los otros modos de operación.

Los algoritmos fueron aplicados a un proceso de producción de hidrógeno con bacterias fotosintéticas demostrando la potencial aplicación de monitoreo para estos procesos los cuales, actualmente, se encuentran en fase de investigación y desarrollo.

- La estimación de múltiples tasas de consumo y producción de sustancias puede ser realizada con un observador de modo deslizante de segundo orden. En comparación con otras estrategias, como los observadores de alta ganancia, se obtuvo en general mejor desempeño. En particular el observador propuesto no agrega dinámica adicional dado que permite obtener convergencia en tiempo finito. Esta característica es relevante a la hora de incorporar las estimaciones en sistemas de lazo cerrado. El observador presentado sólo requiere conocer una cota de la tasa de cambio máxima de las variables a estimar. Esto no representa un mayor problema dado que en general se conoce cierta información del proceso a monitorear.

- Los problemas de interacción de lazos de control en procesos aeróbicos producidos por falta de oxígeno pueden ser evitados manejando apropiadamente las leyes de alimentación de sustratos. El algoritmo presentado en el Capítulo 5 puede aplicarse en los lazos de alimentación típicamente utilizados en los procesos semi-continuos sin introducir mayores modificaciones. De hecho, se aplicó en los casos de lazo abierto con flujo exponencial precalculado y lazo cerrado con flujo proporcional a la biomasa manipulando las referencias únicamente en los momentos necesarios y sin agregar mediciones adicionales. Su estructura en forma de bloque auxiliar brinda una clara ventaja de implementación y el hecho de que sólo se activa en los períodos de tiempo requeridos hace que el algoritmo no interfiera en la operación normal del proceso. La propuesta también demostró utilidad en caso de una reducción parcial de la transferencia de oxígeno, evitando transitorios indeseados y la acumulación de sustratos en el medio de cultivo. 
- Un desafío importante en los procesos alimentados con dos sustratos es el de definir un perfil de alimentación adecuado. En el Capítulo 6 se presentaron leyes basadas en realimentación de biomasa y una estimación de la tasa de crecimiento con el objetivo de regular el crecimiento en cada sustrato. Cuando sólo se dispone de medición de la concentración de biomasa, si bien no se puede garantizar que las tasas individuales alcancen un determinado valor, es posible alcanzar la tasa de crecimiento neta deseada incorporando un término de corrección adecuado. En la propuesta realizada, la incorporación de una realimentación de $\mu$ adicional permite aumentar la velocidad de convergencia respecto a leyes de alimentación exponenciales anteriores. También se analizó el caso en el que existe inhibición competitiva entre los sustratos, donde se concluyó que es factible aplicar las leyes de alimentación proporcionales a la biomasa en este tipo de procesos.

A partir de estas apreciaciones, se consideran los siguientes trabajos futuros:

- Diseño de observadores para procesos con cinética Luedeking y Piret agregando robustez respecto a los parámetros del modelo. En los observadores presentados en el Capítulo 3, la única variable medida es la concentración de producto. Puede explorarse la idea de incorporar información de mediciones esporádicas obtenidas durante el transcurso del cultivo, por ejemplo mediciones de biomasa obtenidas fuera de línea.

- En el observador por modo deslizante de segundo orden presentado en el Capítulo 4, es interesante estudiar el efecto introducido por errores en el modelizado de la matriz $\boldsymbol{K}_{l}$ y cómo puede mejorarse la estimación de las tasas específicas ante esos errores. Recientemente, se han publicado estrategias que utilizan información obtenida en sucesivos cultivos para mejorar la estimación que se tiene de esta matriz. También es relevante estudiar la relación entre los parámetros del observador y su desempeño en casos de ruido e incertidumbre de los parámetros.

- El observador de múltiples tasas de reacción puede ser utilizado para control del proceso. Una posible tarea es la de estudiar valores de referencia para esas tasas, y luego diseñar controladores que aprovechen las estimaciones obtenidas.

- En el Capítulo 5 se abordó el problema de evitar la insuficiencia de un sustrato esencial para el crecimiento celular. En otros casos, la ausencia o exceso de otras sustancias, como pueden ser los subproductos del metabolismo, podrían tener un efecto inhibitorio en el crecimiento. Esto a su vez generaría problemas en la regulación de la fase exponencial. Una posible extensión consiste en aplicar lazos auxiliares por 
modo deslizante con cotas inferiores y superiores sobre la concentración de esas sustancias. De esta manera, sería posible garantizar que el efecto inhibitorio sea eliminado o al menos sustancialmente reducido.

- Extensión de las leyes de alimentación multi-sustrato presentadas en el Capítulo 6 a casos con cinética de crecimiento multiplicativa y mejorada. En el desarrollo se consideraron modelos dinámicos con tasa de crecimiento de la forma $\mu=\mu_{1}+\mu_{2}$. Dado que los procesos multisustrato son de creciente interés industrial, puede considerarse realizar la extensión al caso multiplicativo (para dos sustratos esenciales) y al caso en el que existen dos caminos metabólicos (crecimiento aumentado en presencia de un segundo sustrato). 


\section{Apéndice A}

\section{Análisis de una condición de observabilidad no lineal}

\section{A.1. Definiciones}

Considérese un sistema no lineal de la forma

$$
\begin{aligned}
\dot{\boldsymbol{z}} & =\boldsymbol{f}(\boldsymbol{z}), \\
y & =h(\boldsymbol{z}),
\end{aligned}
$$

donde $\boldsymbol{z}^{T} \in R^{n}$ es el vector de estados, $\boldsymbol{z}_{0}=\boldsymbol{z}(0)$ la condición inicial e $y \in R$ la salida disponible. El campo vectorial $\boldsymbol{f}(\cdot)$ se asume suave en un abierto de $R^{n}$.

Se denota $y(0: T)$ a la trayectoria de salida obtenida en el intervalo de tiempo $[0, T]$, esto es el mapa $t \rightarrow y(t)$ en $0 \leqslant t \leqslant T$. El sistema (A.1a)(A.1b) es observable en el intervalo $[0, T]$ si el mapa desde el estado inicial $\left(\boldsymbol{z}_{0}\right)$ a la trayectoria $y(0, T)$ es uno a uno. El sistema es localmente observable en $[0, T]$ si este mapa es uno a uno localmente. El sistema es localmente observable en tiempo corto (del inglés short time locally observable) si el mapa es uno a uno localmente para todo $T>0$ [147]. Corresponde aclarar que el hecho de que el mapa sea uno a uno localmente significa que para cada $\boldsymbol{z}_{0}$ existe un entorno $U\left(\boldsymbol{z}_{0}\right)$ tal que si $\boldsymbol{z}_{1} \in U\left(\boldsymbol{z}_{0}\right)$, entonces la salida obtenida desde $\boldsymbol{z}_{0}$ y $\boldsymbol{z}_{1}$ son diferentes. Esta propiedad de observabilidad puede ser estudiada utilizando un enfoque geométrico. El concepto fundamental es el de codistribución de observabilidad [148]. Para describir este concepto se utilizará la siguiente notación. La derivada Lie de una función $h$ en la dirección del campo $\boldsymbol{f}$ se define como

$$
L_{f} h=<d h, \boldsymbol{f}>
$$

En esta expresión, $d h$ es el diferencial (gradiente) de la función $h$, es decir el vector fila de $(1 \times n) d h=\left[\frac{\partial h}{\partial z_{1}}, \ldots, \frac{\partial h}{\partial z_{n}}\right]$ mientras que $<\cdot, \cdot>$ representa 
el producto interno. Así

$$
<d h, \boldsymbol{f}>=\sum_{i=1}^{n} \frac{\partial h}{\partial z_{i}} f_{i} .
$$

El cálculo de derivadas de orden superior puede hacerse iterativamente mediante la expresión $L_{f}^{j} h=<d L_{f}^{j-1} h, \boldsymbol{f}>\operatorname{con} L_{f}^{0} h=h[119]$.

Definición A.1 (Condición de rango de observabilidad) El sistema no lineal (A.1a)-(A.1b) satisface la condición de rango de observabilidad si el conjunto

$$
\left\{d h, d L_{f} h, \ldots, d L_{f}^{k} h\right\}
$$

contiene $n$ covectores linealmente independientes para algún $k \geqslant 0$.

El conjunto de covectores (A.4) está formado por elementos de la denominada codistribución de observabilidad la cual, en cada valor del estado, genera el espacio

$$
\operatorname{span}\left\{d L_{f}^{j} h(\boldsymbol{z}), j \geqslant 0\right\}
$$

Nótese que si el conjunto (A.4) tiene $n$ covectores linealmente independientes, el espacio generado en (A.5) es de dimensión $n$. De hecho, esos covectores linealmente independientes forman una base para la codistribución. Además, el espacio generado en (A.5) puede entenderse como la generalización a sistemas no lineales del espacio generado por la matriz de observabilidad de Kalman. La principal diferencia con los sistemas lineales radica en que cuando los campos $\boldsymbol{f}$ y $\boldsymbol{h}$ son lineales, la dimensión del espacio (A.5) queda determinada con derivadas Lie de hasta orden $k=n-1$ (esto es debido al teorema de Cayley-Hamilton). Por el contrario, en sistemas no lineales puede requerirse tomar derivadas de orden superior. Finalmente, cabe destacar que los conceptos ilustrados se pueden extender a más de una salida. En particular, si se tienen $l$ salidas, $d L_{f} \boldsymbol{h}$ representa los $l$ diferenciales correspondientes a las derivadas de las $l$ salidas en la dirección del campo $\boldsymbol{f}$.

Teorema A.2 Suponiendo que el sistema (A.1a)-(A.1b) satisface la condición de rango de observabilidad A.1, entonces el sistema es localmente observable en tiempo corto.

La demostración de este teorema puede verse en [149]. El resultado se basa en probar condiciones para que exista un mapa inyectivo local entre el estado y la salida. 


\section{A.2. Análisis aplicado al proceso con pro- ducción asociada}

Un proceso por lotes con formación de producto corresponde a un modelo no lineal de la forma (A.1), donde el vector de estado $\boldsymbol{z}^{T}=\left(\begin{array}{lll}x & s & p\end{array}\right)$ de dimensión $n=3$ denota las concentraciones de biomasa, sustrato y producto, respectivamente y la salida disponible es $y(t)=p(t)$.

Para el cálculo de los covectores del conjunto (A.4) se asume que la tasa de crecimiento es función del sustrato limitante. Es decir:

$$
\frac{\partial \mu}{\partial x}=\frac{\partial \mu}{\partial p}=0
$$

Esta hipótesis no es restrictiva ya que incluye a todos los modelos donde se representa $\mu$ como función de $s$. En particular se incluyen los modelos de Monod y Haldane, los cuales son ampliamente utilizados para describir el crecimiento de diversos microorganismos en diversos sustratos. En caso de considerar un modelo que dependa de otra variable, como puede ser la biomasa (modelo de Contois, ec. (2.17)), debe tenerse en cuenta la derivada parcial correspondiente para el cálculo de los covectores.

Considerando $y(t)=p$ y la expresión (A.6), se tienen las siguientes expresiones para los covectores y derivadas Lie involucradas en el análisis:

$$
\begin{aligned}
& d p=\left[\begin{array}{lll}
0 & 0 & 1
\end{array}\right], \\
& L_{f} p=(\alpha \mu+\beta) x, \\
& d L_{f} p=\left[\begin{array}{lll}
\alpha \mu+\beta & \alpha x \frac{\partial \mu}{\partial s} & 0
\end{array}\right], \\
& L_{f}^{2} p=(\alpha \mu+\beta) \mu x-\frac{\alpha \mu x^{2}}{y_{x / s}} \frac{\partial \mu}{\partial s}, \\
& d L_{f}^{2} p=\left[\begin{array}{lll}
h_{31}(\boldsymbol{z}) & h_{32}(\boldsymbol{z}) & 0
\end{array}\right],
\end{aligned}
$$

con

$$
\begin{aligned}
& h_{31}(\boldsymbol{z})=(\alpha \mu+\beta) \mu-\frac{2 \alpha \mu x}{y_{x / s}} \frac{\partial \mu}{\partial s} \\
& h_{32}(\boldsymbol{z})=2 \alpha \mu x \frac{\partial \mu}{\partial s}+\beta x \frac{\partial \mu}{\partial s}-\frac{\alpha x^{2}}{y_{x / s}}\left(\left(\frac{\partial \mu}{\partial s}\right)^{2}+\mu \frac{\partial^{2} \mu}{\partial s^{2}}\right) .
\end{aligned}
$$

Luego, los primeros elementos del conjunto (A.4) ordenados en forma matricial resultan

$$
\left(\begin{array}{c}
d p \\
d L_{f} p \\
d L_{f}^{2} p \\
\vdots
\end{array}\right)=\left(\begin{array}{ccc}
0 & 0 & 1 \\
\alpha \mu+\beta & \alpha x \frac{\partial \mu}{\partial s} & 0 \\
h_{31}(\boldsymbol{z}) & h_{32}(\boldsymbol{z}) & 0 \\
\vdots & \vdots & \vdots
\end{array}\right) .
$$


La condición de menor orden para obtener rango completo en (A.10) es que las tres primeras filas sean linealmente independientes. Esto es completar el rango utilizando derivadas Lie de hasta orden $k=n-1$. En (A.10) se observa que esta condición ocurre cuando el menor inferior izquierdo es no singular. Calculando el determinante correspondiente se obtiene la siguiente expresión

$$
\left(\alpha^{2} \mu^{2}+2 \alpha \beta \mu+\beta^{2}\right) \frac{\partial \mu}{\partial s}+(\alpha \mu-\beta) \frac{\alpha x}{y_{x / s}}\left(\frac{\partial \mu}{\partial s}\right)^{2}-(\alpha \mu+\beta) \frac{\alpha \mu x}{y_{x / s}} \frac{\partial^{2} \mu}{\partial s^{2}} \neq 0 .
$$

Para analizar esta expresión puede considerarse que en caso de cinéticas crecientes (por ejemplo: Monod, Tessier, entre otras), la primera derivada es positiva y la segunda negativa. De esta manera, el primer y tercer sumando resultan positivos. También se observa que el segundo término es negativo cuando $\mu(s)<\beta / \alpha$. Por esta razón, la desigualdad (A.11) no puede garantizarse a priori sobre todo el plano $(x, s)$. No obstante el resultado puede ser evaluado en la región del espacio de estados de interés.

El hecho de que las derivadas parciales de la tasa de crecimiento tengan signo definido puede utilizarse para analizar por regiones casos más complejos. En la siguiente sección se presentan condiciones suficientes para satisfacer rango completo en la codistribución de observabilidad para cultivos semi-continuos multi-sustrato.

\section{A.3. Condiciones de observabilidad de culti- vos semi-continuos multi-sustrato}

Los siguientes resultados de observabilidad de estados, en el sentido de la definición introducida en la sección A.1, fueron obtenidos para cultivos multi-sustrato con tasa de crecimiento aditiva. Estos resultados son de utilidad para establecer relaciones entre los parámetros del proceso y la condición de rango de observabilidad. Las expresiones obtenidas involucran a las tasas de crecimiento individuales y sus derivadas parciales. Si bien se obtienen expresiones algebraicas, muchas de estas pueden ser evaluadas fácilmente para modelos de tasa de crecimiento típicos como Monod y Haldane.

Nuevamente se considera el proceso estudiado en el Capítulo 6

$$
\begin{aligned}
\dot{x} & =\mu x-x D_{1}-x D_{2}, \\
\dot{s}_{1} & =-\sigma_{1} x+\left(S_{1 i n}-s_{1}\right) D_{1}-s_{1} D_{2}, \\
\dot{s}_{2} & =-\sigma_{2} x-s_{2} D_{1}+\left(S_{2 i n}-s_{2}\right) D_{2},
\end{aligned}
$$


con entradas $D_{i}=F_{i} / v$ y cinética de crecimiento descripta por

$$
\begin{aligned}
\mu\left(s_{1}, s_{2}\right) & =\mu_{1}\left(s_{1}\right)+\mu_{2}\left(s_{2}\right), \\
\sigma_{i}\left(s_{1}, s_{2}\right) & =\frac{\mu_{i}}{y_{i}},
\end{aligned}
$$

y se analiza el rango de la codistribución de observabilidad (A.5). En este caso, el modelo (A.12) puede escribirse como un sistema no lineal afín en el control

$$
\dot{\boldsymbol{z}}=\boldsymbol{f}(\boldsymbol{z})+\sum_{i=1}^{m} \boldsymbol{g}_{i}(\boldsymbol{z}) D_{i},
$$

donde $\boldsymbol{z}^{T}=\left(\begin{array}{lll}x & s_{1} & s_{2}\end{array}\right)$. Puede probarse que la codistribución de observabilidad para el sistema (A.14) queda descripta por

$$
\mathcal{H}=\operatorname{span}\left\{d L_{g_{j k}} \ldots L_{g_{j 1}} h_{i} \mid 1 \leqslant i \leqslant l, 0 \leqslant j_{t} \leqslant m\right\},
$$

donde $\boldsymbol{g}_{0}=\boldsymbol{f}, h_{i}$ es la salida $i$-ésima, $l$ el número de salidas y $m$ el número de entradas [150].

A continuación se presentan resultados obtenidos para tres posibles salidas.

Resultado A.3 Dado el proceso (A.12)-(A.13) con medición de biomasa y un sustrato, una condición suficiente de observabilidad local para el sustrato no medido es

$$
\frac{\partial \mu_{2}}{\partial s_{2}} \neq 0
$$

o, si la expresión (A.16) no se cumple,

$$
\frac{\partial^{2} \mu_{2}}{\partial s_{2}^{2}}\left(S_{2 i n}-s_{2}\right) \neq 0 .
$$

Dem. Para el proceso (A.12)-(A.13) con las salidas $\boldsymbol{y}=\left(x, s_{1}\right)$ se puede construir la siguiente matriz

$$
\begin{aligned}
\mathcal{O}(\boldsymbol{z}) & =\operatorname{span}\left(\begin{array}{c}
d x \\
d s_{1} \\
d L_{f} x
\end{array}\right) \\
& =\operatorname{span}\left(\begin{array}{ccc}
1 & 0 & 0 \\
0 & 1 & 0 \\
\mu & \frac{\partial \mu_{1}}{\partial s_{1}} x & \frac{\partial \mu_{2}}{\partial s_{2}} x
\end{array}\right) .
\end{aligned}
$$

Nótese que las filas de esta matriz son elementos de la codistribución (A.15). Además, puede verse fácilmente que (A.18) tiene rango completo cuando

$$
\frac{\partial \mu_{2}}{\partial s_{2}} x \neq 0
$$


Luego, si para un dado valor del estado la matriz $\mathcal{O}\left(\boldsymbol{z}_{\mathbf{0}}\right)$ tiene rango completo, entonces $\operatorname{dim} \mathcal{H}\left(\boldsymbol{z}_{\mathbf{0}}\right)=3$. Por lo tanto, el proceso resulta localmente observable si la ec. (A.19) se cumple. Dado que se asume que la concentración de biomasa es positiva, la ec. (A.19) implica el resultado (A.16). La demostración del resultado (A.17) sigue el mismo argumento con $d L_{g 2} L_{f} x$ como última fila de (A.18). La expresión de este diferencial puede encontrarse al final de esta sección.

Los resultados anteriores pueden ser interpretados para diferentes modelos de crecimiento. En particular, cuando $\mu_{2}$ es un término Monod

$$
\mu_{2}=\mu_{\max } \frac{s_{2}}{s_{2}+k_{s 2}}
$$

la interpretación física de la expresión (A.16) es que $s_{2}$ es localmente observable si su concentración no se encuentra en exceso. El resultado descripto en (A.16) es una condición suficiente. Para el caso en que la derivada parcial de la tasa de crecimiento con respecto al sustrato no medido es cero, puede considerarse la expresión (A.17). Tal es el caso del modelo de Haldane en el punto donde la tasa de crecimiento es máxima. Nótese que en este último caso el resultado es dependiente de una de las entradas.

Resultado A.4 Dado el bioproceso (A.12)-(A.13) con medición de un sustrato, una condición suficiente para observabilidad local de las concentraciones no medidas es

$$
\frac{\mu_{1} x}{y_{1}} \frac{\partial \mu_{2}}{\partial s_{2}} \neq 0
$$

o, si $\partial \mu_{2} / \partial s_{2}$ se anula,

$$
\frac{\mu_{1} x}{y_{1}} \frac{\mu_{2}}{y_{2}} \frac{\partial^{2} \mu_{2}}{\partial s_{2}^{2}} \neq 0
$$

Dem. Se considera el modelo (A.12) con el vector de salida $\boldsymbol{y}=s_{1}$. Utilizando el diferencial de la salida disponible y dos derivadas Lie en la dirección de $\boldsymbol{f}$ se obtiene la siguiente matriz

$$
\begin{aligned}
\mathcal{O}(\boldsymbol{z}) & =\operatorname{span}\left(\begin{array}{c}
d s_{1} \\
d L_{f} s_{1} \\
d L_{f}^{2} s_{1}
\end{array}\right) \\
& =\operatorname{span}\left(\begin{array}{ccc}
0 & 1 & 0 \\
-\frac{\mu_{1}}{y_{1}} & -\frac{x}{y_{1}} \frac{\partial \mu_{1}}{\partial s_{1}} & 0 \\
a_{31} & a_{32} & -\frac{\mu_{1} x}{y_{1}} \frac{\partial \mu_{2}}{\partial s_{2}}
\end{array}\right) .
\end{aligned}
$$

En la tercer columna de (A.23) se ve fácilmente que la matriz tiene rango completo cuando se cumple la ec. (A.21). Luego, en esos puntos, la condición de rango se cumple y los estados no medidos son localmente observables. La ec. (A.22) se obtiene con el mismo análisis pero empleando $d L_{f}^{3} s_{1}$ como última fila de (A.23). 
El resultado (A.21) se traduce en consumo del sustrato medido (es decir $\left.\mu_{1} x / y_{1}>0\right) \mathrm{y}$, al igual que en la ec. (A.16), se requiere sensibilidad de $\mu$ con respecto al sustrato no medido. De acuerdo con el modelo (A.12), si el sustrato medido es consumido, la biomasa aparece en la derivada de $s_{1}$. A su vez, si se alcanza una estimación de la concentración de microorganismo, se tiene información acerca de $s_{2}$ en la dinámica de biomasa (ver (A.12a)).

En cuanto al modelo de $\mu_{2}$, si se trata de un término Monod la condición de observabilidad puede analizarse con ec. (A.21) de donde se concluye nuevamente que $s_{2}$ no debe estar en exceso para que se cumpla la condición. Si $\mu_{2}$ es un término Haldane, la condición de observabilidad para todo $s_{2} \neq$ $s_{2}^{*}$ se verifica con la ec. (A.21) mientras que para el valor de sustrato al cual la tasa de crecimiento es máxima, $s_{2}=s_{2}^{*}$, se satisface la condición (A.22).

Resultado A.5 Dado el bioproceso (A.12)-(A.13) con medición de biomasa, una condición suficiente para observabilidad local de los sustratos es que

$$
\frac{\partial \mu_{i}}{\partial s_{i}} \frac{\partial^{2} \mu_{j}}{\partial s_{j}^{2}}\left(S_{(j) i n}-s_{j}\right)+\frac{\partial \mu_{j}}{\partial s_{j}} \frac{\partial^{2} \mu_{i}}{\partial s_{i}^{2}} s_{i} \neq 0,
$$

para $i, j \in\{1,2\} i \neq j$ o, si las derivadas parciales $\partial \mu_{i} / \partial s_{i}$ se anulan,

$$
\frac{\partial^{2} \mu_{1}}{\partial s_{1}^{2}} \frac{\partial^{2} \mu_{2}}{\partial s_{2}^{2}} s_{1} s_{2} \neq 0
$$

Dem. En este caso, para la salida $\boldsymbol{y}=x$ se consideran dos derivadas Lie de elementos del espacio $H$

$$
\begin{aligned}
\mathcal{O}(\boldsymbol{z}) & =\operatorname{span}\left(\begin{array}{c}
d x \\
d L_{f} x \\
d L_{g j} L_{f} x
\end{array}\right) \\
& =\operatorname{span}\left(\begin{array}{ccc}
1 & 0 & 0 \\
\mu & \frac{\partial \mu_{1}}{\partial s_{1}} x & \frac{\partial \mu_{2}}{\partial s_{2}} x \\
a_{31} & a_{32} & a_{33}
\end{array}\right),
\end{aligned}
$$

donde $a_{3 k}$ es la k-ésima componente de $d L_{g j} L_{f} x$. La matriz (A.26) tiene rango completo cuando la submatriz

$$
\left(\begin{array}{cc}
\frac{\partial \mu_{1}}{\partial s_{1}} x & \frac{\partial \mu_{2}}{\partial s_{2}} x \\
a_{32} & a_{33}
\end{array}\right)
$$

es no singular. Si la matriz $\mathcal{O}\left(\boldsymbol{z}_{\mathbf{0}}\right)$ tiene rango completo, entonces $\operatorname{dim} \mathcal{H}\left(\boldsymbol{z}_{\mathbf{0}}\right)=$ 3. De (A.27) la condición a analizar resulta $\frac{\partial \mu_{1}}{\partial s_{1}} a_{33}-\frac{\partial \mu_{2}}{\partial s_{2}} a_{32} \neq 0$. La expresión (A.24) se obtiene de evaluar esta condición. El resultado (A.25) se determina con el mismo procedimiento pero utilizando $d L_{g 1} L_{f} x$ y $d L_{g 2} L_{f} x$ como las dos últimas filas de (A.26). 
La condición de observabilidad local de los sustratos fue analizada para combinaciones de modelos Monod y Haldane haciendo uso del Resultado A.5. En este caso los resultados presentados son dependientes de los vectores de entrada. Nótese también que los dos términos de (A.24) consisten en productos de la primer y segunda derivada de $\mu_{i}$. En la Figura A.1a se aprecia que para el modelo de Monod $\frac{\partial \mu_{i}}{\partial s_{i}}>0$ y $\frac{\partial^{2} \mu_{i}}{\partial s_{i}^{2}}<0$. Por lo tanto, si se consideran términos Monod para $\mu_{1}$ y $\mu_{2}$, la expresión (A.24) es negativa para todo $\left(s_{1}, s_{2}\right)$ en la región de interés. Luego los sustratos resultan localmente observables. Si un término corresponde al modelo de Haldane, el argumento previo es válido en los intervalos $\left(0, s_{i}^{*}\right]$ y $\left[s_{i p}, S_{(i) i n}\right)$, donde $s_{i p}$ es el valor de sustrato para el cual la segunda derivada cambia de valores negativos a positivos. El modelo de Haldane y las derivadas involucradas en el análisis se presentan en la Figura A.1b. Puede verse que en el intervalo $\left(s_{i}^{*}, s_{i p}\right)$, la primera y segunda derivadas de la expresión de Haldane son negativas. Luego, analizando el signo de cada término que compone (A.24) se ve que la condición puede anularse para ciertos valores del estado. Por lo tanto, la condición (A.24) debe evaluarse numéricamente en esta región. Si $\mu_{1}$ y $\mu_{2}$ son términos Haldane, el análisis previo puede extenderse y la región donde se requiere evaluación numérica resulta:

$$
\begin{aligned}
& R_{1}=\left\{s_{1} \notin\left(s_{1}^{*}, s_{1 p}\right), s_{2}^{*}<s_{2}<s_{2 p}\right\}, \\
& R_{2}=\left\{s_{2} \notin\left(s_{2}^{*}, s_{2 p}\right), s_{1}^{*}<s_{1}<s_{1 p}\right\} .
\end{aligned}
$$

La Figura A.2 presenta la evaluación numérica de la expresión (A.24) para el caso de dos modelos Haldane. Los parámetros utilizados son $k_{s i}=0,5$ $\mathrm{g} / \mathrm{L}, k_{I i}=2,0 \mathrm{~g} / \mathrm{L} \mathrm{y} \mu_{o}=1 \mathrm{~h}^{-1}$ [151]. A izquierda se presenta la evaluación de (A.24) para $(i, j)=(2,1)$ mientras que en la derecha se observan los puntos en los cuales las dos expresiones definidas por (A.24) se anulan. Como puede verse, las condiciones se cumplen en todo $s_{1}, s_{2}$ fuera de $R_{1} \mathrm{y}$ $R_{2}$. De esta manera, la condición debe evaluarse solamente en $R_{1}$ y $R_{2}$. En particular, la condición no se cumple sobre dos curvas. Sin embargo, ambas condiciones fallan simultáneamente en los puntos $\left(s_{1}^{*}, s_{2}^{*}\right)=(1,1) \mathrm{g} / \mathrm{L} \mathrm{y}$ $\left(s_{1 p}, s_{2 p}\right)=(2,2) \mathrm{g} / \mathrm{L}$. Dado que en $\left(s_{1}^{*}, s_{2}^{*}\right)$ se cumple la expresión (A.25), la condición de rango queda probada para todo $\left(s_{1}, s_{2}\right)$ excepto en el valor de sustrato al cual ambas derivadas segundas de $\mu_{i}$ se anulan.

Cabe destacar que el análisis realizado para términos Monod se puede extender a otras expresiones monótonas. La incorporación de términos de competitividad (ec. (6.32)) o de inhibición con el aumento de la concentración de biomasa (Modelo de Contois) puede ser tratado con la misma metodología. 
$\mathrm{A}$

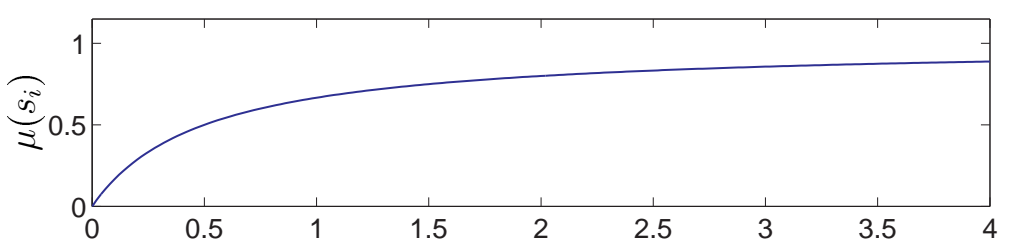

$\mathrm{B}$

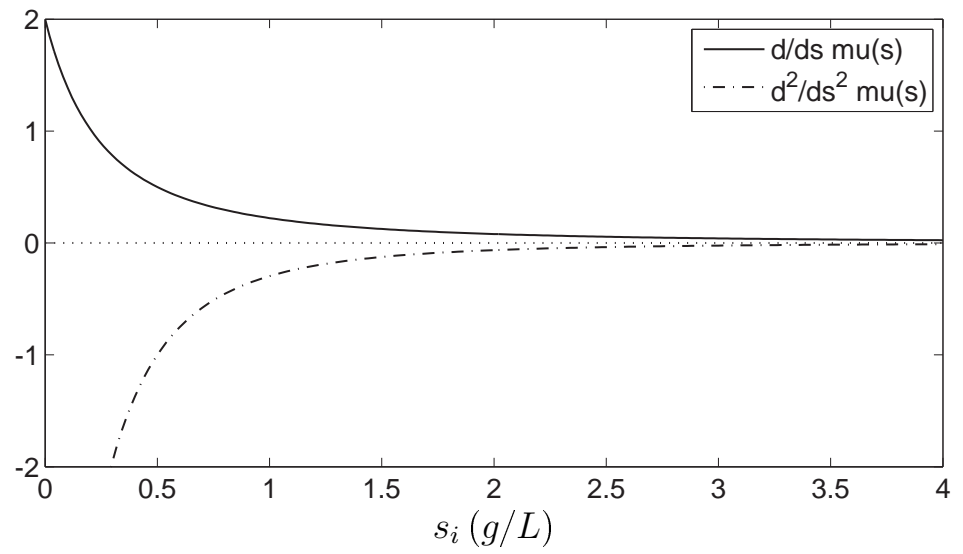

(a) Arriba: Modelo Monod (ec. (A.20)). Abajo: primera y segunda derivada de la expresión (A.20) con respecto a $s$.

A

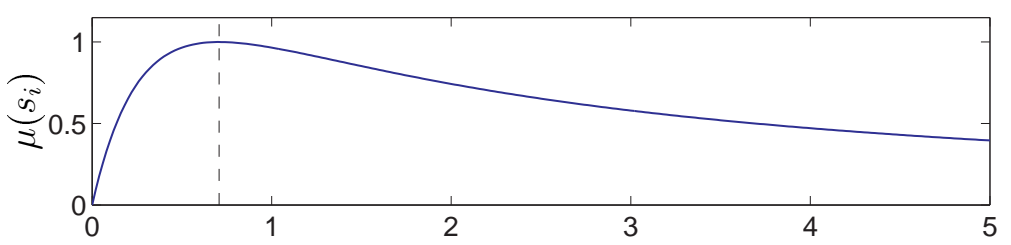

B

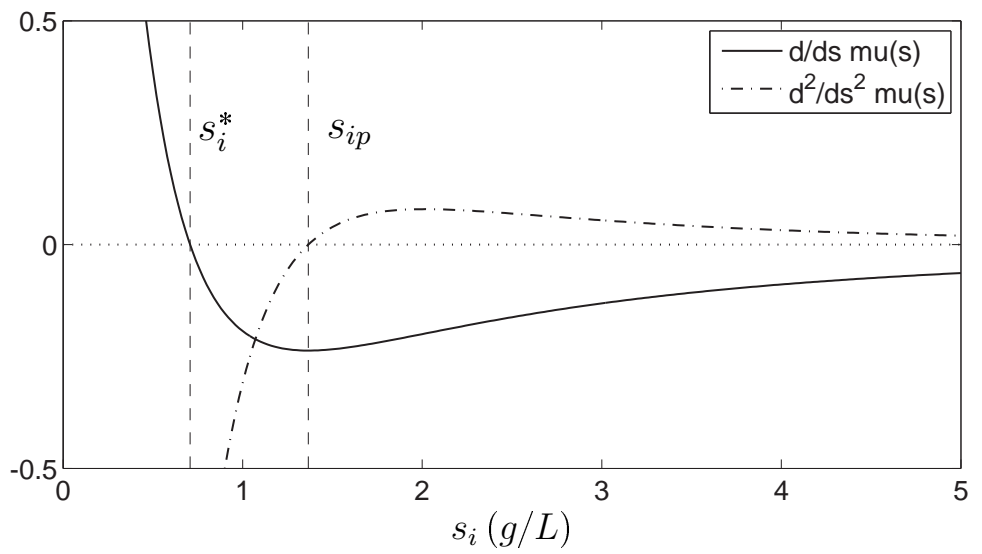

(b) Arriba: Modelo Haldane (ec. (2.12)). Abajo: primera y segunda derivada de la expresión (2.12) con respecto a $s$.

Figura A.1: Tasas de crecimiento y sus derivadas parciales involucradas en el análisis. 

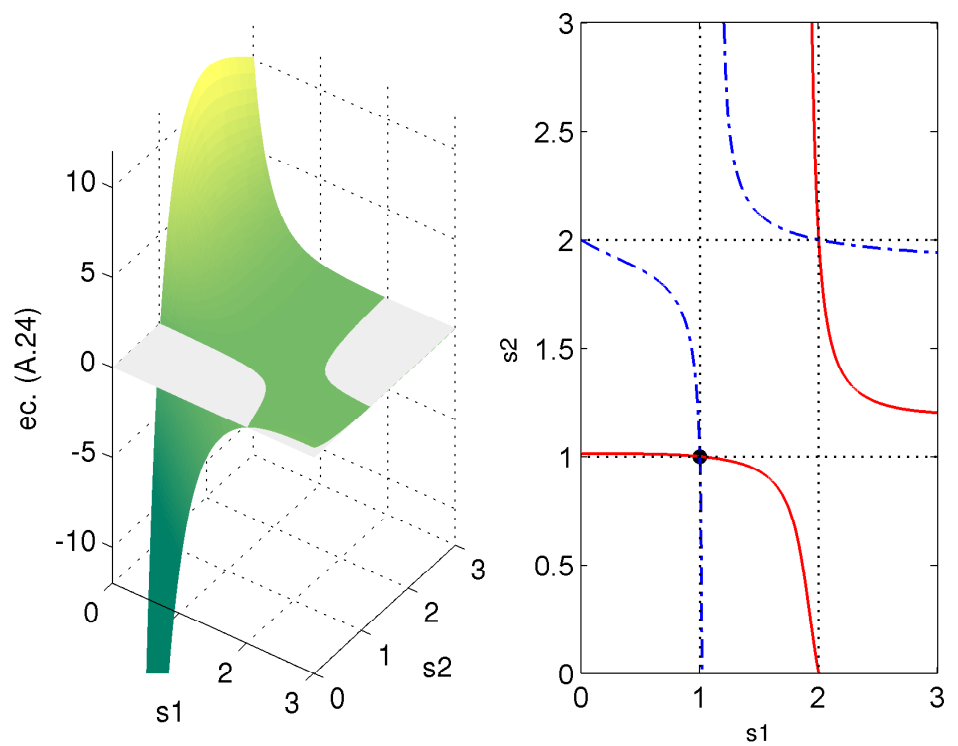

Figura A.2: Evaluación numérica del Resultado A.5 para el caso HaldaneHaldane. Izq: condición (A.24) con $(i, j)=(2,1)$. Der: puntos en los cuales las condiciones (A.24) se anulan para $(i, j)=(2,1)$ (línea roja), $(i, j)=$ $(1,2)$ (línea azul a trazos).

\section{Derivadas Lie y diferenciales de las salidas}

Salida: biomasa

$$
\begin{gathered}
L_{f} x=\mu x \\
d L_{f} x=\left(\mu \frac{\partial \mu_{1}}{\partial s_{1}} x \frac{\partial \mu_{2}}{\partial s_{2}} x\right) \\
L_{g i} L_{f} x=-\mu x+x \frac{\partial \mu_{i}}{\partial s_{i}}\left(S_{(i) i n}-s_{i}\right)-x \frac{\partial \mu_{j}}{\partial s_{j}} s_{j}
\end{gathered}
$$

para $i, j \in\{1,2\} i \neq j$.

$$
d L_{g 1} L_{f} x=\left(\begin{array}{c}
-\mu+\frac{\partial \mu_{1}}{\partial s_{1}}\left(S_{1 i n}-s_{1}\right)-s_{2} \frac{\partial \mu_{2}}{\partial s_{2}} \\
-2 x \frac{\partial \mu_{1}}{\partial s_{1}}+x \frac{\partial^{2} \mu_{1}}{\partial s_{1}^{2}}\left(S_{1 i n}-s_{1}\right) \\
-2 x \frac{\partial \mu_{2}}{\partial s_{2}}-x \frac{\partial^{2} \mu_{2}}{\partial s_{2}^{2}} s_{2}
\end{array}\right)^{T}
$$




$$
d L_{g 2} L_{f} x=\left(\begin{array}{c}
-\mu+\frac{\partial \mu_{2}}{\partial s_{2}}\left(S_{2 i n}-s_{2}\right)-s_{1} \frac{\partial \mu_{1}}{\partial s_{1}} \\
-2 x \frac{\partial \mu_{1}}{\partial s_{1}}-x \frac{\partial^{2} \mu_{1}}{\partial s_{1}^{2}} s_{1} \\
-2 x \frac{\partial \mu_{2}}{\partial s_{2}}+x \frac{\partial^{2} \mu_{2}}{\partial s_{2}^{2}}\left(S_{2 i n}-s_{2}\right)
\end{array}\right)^{T}
$$

Salida: sustrato 1

$$
\begin{aligned}
& L_{f} s_{1}=-\frac{\mu_{1}}{y_{1}} x \\
& d L_{f} s_{1}=\left(\begin{array}{lll}
-\frac{\mu_{1}}{y_{1}} & -\frac{x}{y_{1}} \frac{\partial \mu_{1}}{\partial s_{1}} & 0
\end{array}\right) \\
& L_{f}^{2} s_{1}=-\frac{\mu_{1}^{2} x}{y_{1}}-\frac{\mu_{1} x}{y_{1}} \mu_{2}+\left(\frac{x}{y_{1}}\right)^{2} \mu_{1} \frac{\partial \mu_{1}}{\partial s_{1}} \\
& d L_{f}^{2} s_{1}=\left(\frac{\partial}{\partial x}\left(L_{f}^{2} s_{1}\right) \quad \frac{\partial}{\partial s_{1}}\left(L_{f}^{2} s_{1}\right)-\frac{\mu_{1} x}{y_{1}} \frac{\partial \mu_{2}}{\partial s_{2}}\right)
\end{aligned}
$$




\section{Apéndice B}

\section{Regulación de tasa de crecimiento utilizando medición de biomasa y un sustrato}

Si se dispone de medición de biomasa y uno de los sustratos (o cualquier otra variable que permita distinguir una de las tasas de crecimiento en forma individual), es posible realimentar una estimación de $\mu_{1}$ y $\mu_{2}$. Luego, pueden aplicarse leyes exponenciales individuales. En [25] se propuso utilizar flujos de la forma $F_{i}=\lambda_{i} x v$ donde $\operatorname{los} \lambda_{i}$ incluyen un término proporcional e integral. En el caso en que sólo se considera acción proporcional no lineal se tiene

$$
\lambda_{i}=\lambda_{i r}\left(1+f\left(e_{i}\right)\right),
$$

con $e_{i}=\mu_{r i}-\hat{\mu}_{i}$ y $f\left(e_{i}\right)=\tanh \left(e_{i}\right)$. Luego, si se miden biomasa y un sustrato, puede aplicarse el observador de múltiples tasas presentado en el Capítulo 4 sobre el subsistema

$$
\dot{\boldsymbol{z}}=\left(\begin{array}{cc}
1 & 0 \\
0 & -1 / y_{1}
\end{array}\right)\left(\begin{array}{cc}
x & 0 \\
0 & x
\end{array}\right)\left(\begin{array}{c}
\mu \\
\mu_{1}
\end{array}\right)-\left(D_{1}+D_{2}\right) \boldsymbol{z}+\left(\begin{array}{c}
0 \\
D_{1} s_{1 \text { in }}
\end{array}\right),
$$

donde $\boldsymbol{z}=\left[x, s_{1}\right]^{T}, \boldsymbol{\alpha}_{l}=\left[\mu, \mu_{1}\right]^{T}$ y $D_{i}=F_{i} / v$. Nótese que en este caso $\boldsymbol{G}_{l}=x \boldsymbol{I}_{2} \mathrm{y}$

$$
\boldsymbol{K}_{l}=\left(\begin{array}{cc}
1 & 0 \\
0 & -1 / y_{1}
\end{array}\right)
$$

con lo cual se requiere conocer el rendimiento $y_{1}$. De esta manera se obtienen estimaciones de $\widehat{\mu}_{1} \mathrm{y} \hat{\mu}$, las cuales se utilizan en la implementación de (B.1).

A diferencia de la propuesta del Capítulo 6, en la expresión (B.1) se utiliza información de las tasas de crecimiento individuales, lo que permite una regulación más precisa en caso de incertidumbre en los parámetros del modelo. No obstante la implementación de esta mejora requiere mediciones adicionales, las cuales no siempre se encuentran disponibles. 
136 APÉNDICE B. REGULACIÓN DE TASA DE CRECIMIENTO ... 


\section{Bibliografía}

[1] W. Leuchtenberger, K. Huthmacher, and K. Drauz, "Biotechnological production of amino acids and derivatives: current status and prospects," $A p$ plied Microbiology and Biotechnology, vol. 69, no. 1, pp. 1-8, 2005.

[2] B. Max, J. M. Salgado, N. Rodríguez, S. Cortés, and J. M. Attilio Converti; Domínguez, "Biotechnological production of citric acid," Brazilian Journal of Microbiology, vol. 41, no. 4, pp. 862 - 875, 2010.

[3] S. Alonso, M. Herrero, M. Rendueles, and M. Díaz, "Physiological heterogeneity in Lactobacillus casei fermentations on residual yoghurt whey," Process Biochemistry, vol. 49, no. 5, pp. 732 - 739, 2014.

[4] C. S. López-Garzón and A. J. Straathof, "Recovery of carboxylic acids produced by fermentation," Biotechnology Advances, vol. 32, no. 5, pp. 873 $-904,2014$.

[5] L. C. Domingues, J. C. Teodoro, C. O. Hokka, A. C. Badino, and M. L. G. Araujo, "Optimisation of the glycerol-to-ornithine molar ratio in the feed medium for the continuous production of clavulanic acid by Streptomyces clavuligerus," Biochemical Engineering Journal, vol. 53, no. 1, pp. 7 - 11, 2010.

[6] J. Anné, B. Maldonado, J. V. Impe, L. V. Mellaert, and K. Bernaerts, "Recombinant protein production and streptomycetes," Journal of Biotechnology, vol. 158, no. 4, pp. 159 - 167, 2012.

[7] S. Y. Lee, H. U. Kim, J. H. Park, J. M. Park, and T. Y. Kim, "Metabolic engineering of microorganisms: general strategies and drug production," Drug Discovery Today, vol. 14, pp. 78 - 88, 2009.

[8] I. Schmidt, H. Schewe, S. Gassel, C. Jin, J. Buckingham, M. Hümbelin, G. Sandmann, and J. Schrader, "Biotechnological production of astaxanthin with Phaffia rhodozyma/Xanthophyllomyces dendrorhous," Applied Microbiology and Biotechnology, vol. 89, no. 3, pp. 555-571, 2011.

[9] J. Costa, M. De Morais, and M. Andrade, Microalgal engineering: The metabolic products and the bioprocess, pp. 141-170. Nova Science Publishers, Inc., 2013.

[10] B. Andualema and A. Gessesse, "Microbial lipases and their industrial applications: Review," Biotechnology, vol. 11, pp. 100-118, 2013. 
[11] T. Abuhamed, E. Bayraktar, T. Mehmetoğlu, and Ülkü Mehmetoğlu, "Kinetics model for growth of Pseudomonas putida F1 during benzene, toluene and phenol biodegradation," Process Biochemistry, vol. 39, no. 8, pp. 983 $-988,2004$.

[12] P. Christen, S. Davidson, Y. Combet-Blanc, and R. Auria, "Phenol biodegradation by the thermoacidophilic archaeon Sulfolobus solfataricus $98 / 2$ in a fed-batch bioreactor," Biodegradation, vol. 22, no. 3, pp. 475-484, 2011.

[13] D. Das and T. N. Veziroglu, "Hydrogen production by biological processes: a survey of literature," International Journal of Hydrogen Energy, vol. 26, no. 1 , pp. $13-28,2001$.

[14] S. Yadav, G. Rawat, P. Tripathi, and R. Saxena, "A novel approach for biobutanol production by Clostridium acetobutylicum using glycerol: A low cost substrate," Renewable Energy, vol. 71, no. 0, pp. 37 - 42, 2014.

[15] G. Chen, G. Zhang, S. Park, and S. Lee, "Industrial scale production of poly(3-hydroxybutyrate-co-3-hydroxyhexanoate)," Applied Microbiology and Biotechnology, vol. 57, no. 1-2, pp. 50-55, 2001.

[16] Food and Drug Administration (FDA), "Guidance for industry: PAT - a framework for innovative pharmaceutical development, manufacturing and quality assurance," 2004.

[17] J. Lee, S. Y. Lee, S. Park, and A. P. Middelberg, "Control of fed-batch fermentations," Biotechnology Advances, vol. 17, no. 1, pp. 29 - 48, 1999.

[18] S. Nuñez, F. Garelli, and H. De Battista, "Sliding mode observer for biomass estimation in a biohydrogen production process," International Journal of Hydrogen Energy, vol. 37, no. 13, pp. 10089 - 10094, 2012.

[19] S. Nuñez, H. De Battista, F. Garelli, A. Vignoni, and J. Picó, "Second-order sliding mode observer for multiple kinetic rates estimation in bioprocesses," Control Engineering Practice, vol. 21, no. 9, pp. 1259 - 1265, 2013.

[20] S. Nuñez, F. Garelli, and H. De Battista, "Decentralized control with minimum dissolved oxygen guaranties in aerobic fed-batch cultivations," Industrial \& Engineering Chemistry Research, vol. 52, no. 50, pp. 18014-18021, 2013.

[21] S. Nuñez, F. Garelli, and H. De Battista, "Second-order sliding mode observer for biomass concentration and growth rate estimation in batch photobioreactors," International Journal of Hydrogen Energy, vol. 39, no. 16, pp. $8772-8779,2014$.

[22] S. Nuñez, H. De Battista, F. Garelli, and J. Picó, "Sufficient conditions for state observability in multi-substrate bioprocesses with additive growth dynamics," Latin America Transactions, IEEE, vol. 12, no. 5, pp. $928-$ 934, 2014. 
[23] S. Nuñez, H. De Battista, and F. Garelli, "Control y acondicionamiento de la tasa de crecimiento específico en bioprocesos aeróbicos," in Anales de la XIV Reunión de Trabajo en Procesamiento de la Información y Control (RPIC 2011), 2011.

[24] S. Nuñez, H. De Battista, A. Vignoni, and F. Garelli, "Observador de segundo orden para velocidades específicas en bioprocesos," in Anales del $23^{\circ}$ Congreso Argentino de Control Automático (AADECA 2012), 2012.

[25] A. Vignoni, S. Nuñez, H. De Battista, J. Picó, E. Picó-Marco, and F. Garelli, "Specific kinetic rates regulation in multi-substrate fermentation processes," in Proceedings of the 12th IFAC Symposium on Computer Applications in Biotechnology, pp. 42 - 47, 2013.

[26] S. Nuñez, H. De Battista, F. Garelli, and J. Picó, "Sufficient conditions for state observability in multi-substrate bioprocesses with additive growth dynamics," in Anales del Congreso Bienal de IEEE Argentina (ARGENCON 2014), 2014.

[27] S. Nuñez, F. Garelli, H. De Battista, and J. Picó, "Diseño de control no lineal para regulación de tasa de crecimiento en cultivos multi-sustrato," in Actas de las XXXV Jornadas de Automática, España, 2014.

[28] J. Nielsen, J. Villadsen, and G. Lidén, Bioreaction Engineering Principles. Kluwer Academic / Plenum Publishers, 2003.

[29] R. Ertola, O. Yantorno, and C. Mignone, Microbiologia Industrial. OEA, 2000 .

[30] J. Monod, "The growth of bacterial cultures," Annual Review of Microbiology, vol. 3, pp. 371-394, 1949.

[31] T. Paalme, K. Tiisma, A. Kahru, K. Vanatalu, and R. Vilu, "Glucoselimited fed-batch cultivation of Escherichia coli with computer-controlled fixed growth rate," Biotechnology and Bioengineering, vol. 35, no. 3, pp. 312 $-319,1990$.

[32] O. Levenspiel, "The monod equation: A revisit and a generalization to product inhibition situations," Biotechnology and Bioengineering, vol. 22, no. 8, pp. $1671-1687,1980$.

[33] L. Krzystek, S. Ledakowicz, H.-J. Kahle, and K. Kaczorek, "Degradation of household biowaste in reactors," Journal of Biotechnology, vol. 92, no. 2, pp. $103-112,2001$.

[34] G. Bastin and D. Dochain, On-line Estimation and Adaptive Control of Bioreactors. Elsevier, 1990.

[35] S. J. Pirt, "The maintenance energy of bacteria in growing cultures," Proc. R. Soc. of London. Series B, vol. 163, no. 991, pp. 224 - 231, 1965. 
[36] M. Shuler and F. Karg1, Bioprocess engineering: basic concepts. Prentice Hall, 1992.

[37] J. Baranyi and T. A. Roberts, "A dynamic approach to predicting bacterial growth in food," International Journal of Food Microbiology, vol. 23, no. 34, pp. $277-294,1994$.

[38] K. Yamuna Rani and V. S. Ramachandra Rao, "Control of fermenters - a review," Bioprocess Engineering, vol. 21, no. 1, pp. 77-88, 1999.

[39] S. Erm, K. Adamberg, and R. Vilu, "Multiplying steady-state culture in multi-reactor system," Bioprocess and Biosystems Engineering, p. in press, 2014.

[40] M. Gu, M. Park, and D.-I. Kim, "Growth rate control in fed-batch cultures of recombinant Saccharomyces cerevisiae producing hepatitis B surface antigen (HBsAg)," Applied Microbiology and Biotechnology, vol. 35, no. 1, pp. 46-50, 1991.

[41] D. B. Seifert and J. A. Phillips, "The production of monoclonal antibody in growth-arrested hybridomas cultivated in suspension and immobilized modes," Biotechnology Progress, vol. 15, no. 4, pp. 655-666, 1999.

[42] M. Ogaki, K. Sonomoto, H. Nakajima, and A. Tanaka, "Continuous production of oxytetracycline by immobilized growing Streptomyces rimosus cells," Applied Microbiology and Biotechnology, vol. 24, no. 1, pp. 6-11, 1986 .

[43] J. Li, J. Jaitzig, F. Hillig, R. Süssmuth, and P. Neubauer, "Enhanced production of the nonribosomal peptide antibiotic valinomycin in Escherichia coli through small-scale high cell density fed-batch cultivation," Applied Microbiology and Biotechnology, vol. 98, no. 2, pp. 591-601, 2014.

[44] R. Luedeking and E. L. Piret, "A kinetic study of the lactic acid fermentation. Batch process at controlled pH. reprinted from journal of Biochemical and Microbiological Technology Engineering Vol. I, No. 4. Pages 393-412 (1959)," Biotechnology and Bioengineering, vol. 67, no. 6, pp. $636-644$, 2000 .

[45] M. Elibol and D. Ozer, "Influence of oxygen transfer on lipase production by Rhizopus arrhizus," Process Biochemistry, vol. 36, no. 4, pp. 325 - 329, 2000 .

[46] J.-Z. Liu, L.-P. Weng, Q.-L. Zhang, H. Xu, and L.-N. Ji, "A mathematical model for gluconic acid fermentation by Aspergillus niger," Biochemical Engineering Journal, vol. 14, no. 2, pp. 137 - 141, 2003.

[47] H. Song, S. H. Jang, J. M. Park, and S. Y. Lee, "Modeling of batch fermentation kinetics for succinic acid production by Mannheimia succiniciproducens," Biochemical Engineering Journal, vol. 40, no. 1, pp. 107 - 115, 2008. 
[48] Y. Mu, G. Wang, and H.-Q. Yu, "Kinetic modeling of batch hydrogen production process by mixed anaerobic cultures," Bioresource Technology, vol. 97 , no. 11, pp. $1302-1307,2006$.

[49] V. Gadhamshetty, A. Sukumaran, N. Nirmalakhandan, and M. T. Myint, "Photofermentation of malate for biohydrogen production- a modeling approach," International Journal of Hydrogen Energy, vol. 33, no. 9, pp. 2138 - 2146, 2008.

[50] J. E. Bailey and D. F. Ollis, Biochemical Engineering Fundamentals (2nd edition). McGraw-Hill, 1986.

[51] M. Zinn, B. Witholt, and T. Egli, "Dual nutrient limited growth: models, experimental observations, and applications," Journal of Biotechnology, vol. 113 , no. 1 - 3, pp. 263 - 279, 2004.

[52] H. Yoon, G. Klinzing, and H. W. Blanch, "Competition for mixed substrates by microbial populations," Biotechnology and Bioengineering, vol. 19, no. 8, pp. $1193-1210,1977$.

[53] M. C. d'Anjou and A. J. Daugulis, "Mixed-feed exponential feeding for fedbatch culture of recombinant methylotrophic yeast," Biotechnology Letters, vol. 22 , no. 5 , pp. 341-346, 2000.

[54] D. Das, A. Basu, A. Nigam, P. S. Phale, and P. P. Wangikar, "Dynamics of rate limiting enzymes involved in the sequential substrate uptake by Pseudomonas putida CSV86: Modeling and experimental validation," Process Biochemistry, vol. 46, no. 3, pp. $701-708,2011$.

[55] H. Moon, S. Kim, J. Lee, S. Rhee, E. Choi, H. Kang, I. Kim, and S. Hong, "Independent exponential feeding of glycerol and methanol for fed-batch culture of recombinant Hansenula polymorpha DL-1," Applied Biochemistry and Biotechnology, vol. 111, no. 2, pp. 65-79, 2003.

[56] L.-M. Whang, C.-J. Hsiao, and S.-S. Cheng, "A dual-substrate steady-state model for biological hydrogen production in an anaerobic hydrogen fermentation process," Biotechnology and Bioengineering, vol. 95, no. 3, pp. 492500, 2006.

[57] H. Beyenal, S. N. Chen, and Z. Lewandowski, "The double substrate growth kinetics of Pseudomonas aeruginosa," Enzyme and Microbial Technology, vol. 32, no. 1, pp. $92-98,2003$.

[58] C. Tanase, A. A. Chirvase, C. Unguruneau, M. Caramihai, and O. Muntean, "Study of double-substrate limited growth of Pseudomonas aeruginosa in aerobic bioprocess," Revue Roumaine de Chimie, vol. 56, no. 12, pp. 1147$1153,2011$.

[59] S. Şeker, H. Beyenal, B. Salih, and A. Tanyolaç, "Multi-substrate growth kinetics of Pseudomonas putida for phenol removal," Applied Microbiology and Biotechnology, vol. 47, no. 5, pp. 610-614, 1997. 
[60] I. V. Špoljarić, M. Lopar, M. Koller, A. Muhr, A. Salerno, A. Reiterer, K. Malli, H. Angerer, K. Strohmeier, S. Schober, M. Mittelbach, and P. Horvat, "Mathematical modeling of poly[(R)-3-hydroxyalkanoate] synthesis by Cupriavidus necator DSM 545 on substrates stemming from biodiesel production," Bioresource Technology, vol. 133, no. 0, pp. 482 - 494, 2013.

[61] S. Alagesan, S. B. Gaudana, S. Krishnakumar, and P. P. Wangikar, "Model based optimization of high cell density cultivation of nitrogen-fixing cyanobacteria," Bioresource Technology, vol. 148, no. 0, pp. 228 - 233, 2013.

[62] B. Sonnleitner and O. Käppeli, "Growth of Saccharomyces cerevisiae is controlled by its limited respiratory capacity: Formulation and verification of a hypothesis," Biotechnology and Bioengineering, vol. 28, no. 6, pp. 927 $-937,1986$.

[63] B.-Y. Chen, J.-W. You, and J.-S. Chang, "Optimal exponential feeding strategy for dual-substrate biostimulation of phenol degradation using $\mathrm{Cu}$ priavidus taiwanensis," Journal of Hazardous Materials, vol. 168, no. 1, pp. $507-514,2009$.

[64] Y. J. Kwon and C. R. Engler, "Kinetic models for growth and product formation on multiple substrates," Biotechnology and Bioprocess Engineering, vol. 10, no. 6, pp. 587-592, 2005.

[65] R. Neeleman, M. Joerink, C. Beuvery, and T. Boxtel, "Dual-substrate utilization by Bordetella pertussis," Applied Microbiology and Biotechnology, vol. 57, no. 4, pp. 489-493, 2001.

[66] M. Farza, K. Busawon, and H. Hammouri, "Simple nonlinear observers for on-line estimation of kinetic rates in bioreactors," Automatica, vol. 34, no. 3, pp. $301-318,1998$.

[67] M. Perrier, S. Feyo de Azevedo, E. Ferreira, and D. Dochain, "Tuning of observer-based estimators: theory and application to the on-line estimation of kinetic parameters," Control Engineering Practice, vol. 8, no. 4, pp. 377 $-388,2000$.

[68] A. M. Jobé, C. Herwig, M. Surzyn, B. Walker, I. Marison, and U. von Stockar, "Generally applicable fed-batch culture concept based on the detection of metabolic state by on-line balancing," Biotechnology and Bioengineering, vol. 82 , no. 6 , pp. $627-639,2003$.

[69] M. Schuler and I. Marison, "Real-time monitoring and control of microbial bioprocesses with focus on the specific growth rate: current state and perspectives," Applied Microbiology and Biotechnology, vol. 94, no. 6, pp. 1469$1482,2012$.

[70] H. Ren and J. Yuan, "Model-based specific growth rate control for Pichia pastoris to improve recombinant protein production," Journal of Chemical Technology and Biotechnology, vol. 80, no. 11, pp. 1268 - 1272, 2005. 
[71] Z. Soons, J. Voogt, G. van Straten, and A. van Boxtel, "Constant specific growth rate in fed-batch cultivation of Bordetella pertussis using adaptive control," Journal of Biotechnology, vol. 125, no. 2, pp. 252 - 268, 2006.

[72] M. Aehle, K. Bork, S. Schaepe, A. Kuprijanov, R. Horstkorte, R. Simutis, and A. Lübbert, "Increasing batch-to-batch reproducibility of cho-cell cultures using a model predictive control approach," Cytotechnology, vol. 64, no. 6, pp. 623-634, 2012.

[73] T. Suzuki, T. Yamane, and S. Shimizu, "Phenomenological background and some preliminary trials of automated substrate supply in pH-Stat modal fed-batch culture using a setpoint of high limit," Journal of Fermentation and Bioengineering, vol. 69, no. 5, pp. 292 - 297, 1990.

[74] J. Cutayar and D. Poillon, "High cell density culture of E. coli in a fed-batch system with dissolved oxygen as substrate feed indicator," Biotechnology Letters, vol. 11, no. 3, pp. 155-160, 1989.

[75] K. Konstantinov, M. Kishimoto, T. Seki, and T. Yoshida, "A balanced DOstat and its application to the control of acetic acid excretion by recombinant Escherichia coli," Biotechnology and Bioengineering, vol. 36, no. 7, pp. $750-758,1990$.

[76] Y. S. Park, K. Kai, S. Iijima, and T. Kobayashi, "Enhanced $\beta$-galactosidase production by high cell-density culture of recombinant Bacillus subtilis with glucose concentration control," Biotechnology and Bioengineering, vol. 40, no. 6, pp. 686 - 696, 1992.

[77] R. Biener, A. Steinkämper, and J. Hofmann, "Calorimetric control for high cell density cultivation of a recombinant Escherichia coli strain," Journal of Biotechnology, vol. 146, no. 1-2, pp. 45 - 53, 2010.

[78] M. Dabros, M. Schuler, and I. Marison, "Simple control of specific growth rate in biotechnological fed-batch processes based on enhanced online measurements of biomass," Bioprocess and Biosystems Engineering, vol. 33, no. 9 , pp. $1109-1118,2010$.

[79] E. Picó-Marco, J. L. Navarro, and J. M. Bruno-Barcena, "A closed loop exponential feeding law: Invariance and global stability analysis," Journal of Process Control, vol. 16, no. 4, pp. 395 - 402, 2006.

[80] V. Nyttle and M. Chidambaram, "Fuzzy logic control of a fed-batch fermentor," Bioprocess Engineering, vol. 9, no. 2-3, pp. 115-118, 1993.

[81] L. Johansson, A. Lindskog, G. Silfversparre, C. Cimander, K. F. Nielsen, and G. Lidén, "Shikimic acid production by a modified strain of E. coli (W3110.shik1) under phosphate-limited and carbon-limited conditions," Biotechnology and Bioengineering, vol. 92, no. 5, pp. 541-552, 2005.

[82] L. Yee and H. W. Blanch, "Recombinant trypsin production in high cell density fed-batch cultures in Escherichia coli," Biotechnology and Bioengineering, vol. 41, no. 8, pp. 781 - 790, 1993. 
[83] D. Riesenberg and R. Guthke, "High-cell-density cultivation of microorganisms," Applied Microbiology and Biotechnology, vol. 51, pp. 422 - 430, 1999.

[84] T. Yamane, W. Hibino, K. Ishihara, Y. Kadotani, and M. Kominami, "Fedbatch culture automated by uses of continuously measured cell concentration and culture volume," Biotechnology and Bioengineering, vol. 39, no. 5, pp. 550-555, 1992.

[85] V. Chellaboina and M. Haddad, "A unification between partial stability and stability theory for time-varying systems," Control Systems, IEEE, vol. 22, no. 6, pp. 66-75, 2002.

[86] H. De Battista, J. Picó, and E. Picó-Marco, "Globally stabilizing control of fed-batch processes with Haldane kinetics using growth rate estimation feedback," Journal of Process Control, vol. 16, no. 8, pp. 865 - 875, 2006.

[87] H. De Battista, J. Picó, and E. Picó-Marco, "Nonlinear PI control of fedbatch processes for growth rate regulation," Journal of Process Control, vol. 22, no. 4, pp. $789-797,2012$.

[88] E. Picó-Marco and J. L. Navarro, "A closed-loop exponential feeding law for multi-substrate fermentation processes," in Proceedings of the 17th IFAC World Congress, pp. 9685-9689, 2008.

[89] S. Aborhey and D. Williamson, "State and parameter estimation of microbial growth processes," Automatica, vol. 14, no. 5, pp. 493 - 498, 1978.

[90] V. Vojinović, J. Cabral, and L. Fonseca, "Real-time bioprocess monitoring: Part I: In situ sensors," Sensors and Actuators B: Chemical, vol. 114, no. 2, pp. 1083 - 1091, 2006.

[91] R. Luttmann, D. G. Bracewell, G. Cornelissen, K. V. Gernaey, J. Glassey, V. C. Hass, C. Kaiser, C. Preusse, G. Striedner, and C.-F. Mandenius, "Soft sensors in bioprocessing: A status report and recommendations," Biotechnology Journal, vol. 7, no. 8, pp. 1040 - 1048, 2012.

[92] G. Bastin and D. Dochain, "On-line estimation of microbial specific growth rates," Automatica, vol. 22, no. 6, pp. $705-709,1986$.

[93] Y. Pomerleau and M. Perrier, "Estimation of multiple specific growth rates in bioprocesses," AIChE Journal, vol. 36, no. 2, pp. 207 - 215, 1990.

[94] H. Shimizu, T. Takamatsu, S. Shioya, and K.-I. Suga, "An algorithmic approach to constructing the on-line estimation system for the specific growth rate," Biotechnology and Bioengineering, vol. 33, no. 3, pp. 354-364, 1989.

[95] J.-P. Gauthier, H. Hammouri, and S. Othman, "A simple observer for nonlinear systems applications to bioreactors," Automatic Control, IEEE Transactions on, vol. 37, no. 6, pp. 875-880, 1992. 
[96] R. Martinez-Guerra, R. Garrido, and A. Osorio-Miron, "Parametric and state estimation by means of high-gain nonlinear observers: application to a bioreactor," Proceedings of the American Control Conference, vol. 5, pp. $3807-3808,2001$.

[97] J. Picó, H. De Battista, and F. Garelli, "Smooth sliding-mode observers for specific growth rate and substrate from biomass measurement," Journal of Process Control, vol. 19, no. 8, pp. 1314 - 1323, 2009.

[98] A. F. N. A. Rahman, S. K. Spurgeon, and X.-G. Yan, "A sliding mode observer for estimating substrate consumption rate in a fermentation process," in 11th International Workshop on Variable Structure Systems, 2010.

[99] J. A. Moreno and M. Osorio, "A Lyapunov approach to second-order sliding mode controllers and observers," in Decision and Control (CDC), 2008. 47th IEEE Conference on, pp. 2856 -2861, Dec. 2008.

[100] H. De Battista, J. Picó, F. Garelli, and A. Vignoni, "Specific growth rate estimation in (fed-)batch bioreactors using second-order sliding observers," Journal of Process Control, vol. 21, no. 7, pp. 1049 - 1055, 2011.

[101] A. Vargas, J. Moreno, and A. Vande Wouwer, "A weighted variable gain super-twisting observer for the estimation of kinetic rates in biological systems," Journal of Process Control, vol. 24, no. 6, pp. 957 - 965, 2014.

[102] C. Karakuzu, M. Türker, and S. Öztürk, "Modelling, on-line state estimation and fuzzy control of production scale fed-batch baker's yeast fermentation," Control Engineering Practice, vol. 14, no. 8, pp. 959 - 974, 2006.

[103] V. Utkin, J. Guldner, and J. Shi, Sliding Mode Control in Electromechanical Systems. London: Taylor \& Francis, 1st ed., 1999.

[104] A. Levant, "Robust exact differentiation via sliding mode technique," Automatica, vol. 34, no. 3, pp. 379 - 384, 1998.

[105] A. Poznyak, A. Polyakov, and V. Strygin, "Analysis of finite-time convergence by the method of Lyapunov functions in systems with second-order sliding modes," Journal of Applied Mathematics and Mechanics, vol. 75, no. 3, pp. 289 - 303, 2011.

[106] J. Picó, E. Picó-Marco, A. Vignoni, and H. De Battista, "Stability preserving maps for finite-time convergence: Super-twisting sliding-mode algorithm," Automatica, vol. 49, no. 2, pp. $534-539,2013$.

[107] D. Carp, M. Barbu, and S. Caraman, "Robust state observers for biological wastewater treatment processes with activated sludge," in System Theory, Control and Computing (ICSTCC), 2012 16th Int Conference on, pp. 1-8, 2012.

[108] K. Veluvolu, Y. Soh, and W. Cao, "Discrete-time sliding mode observer design for a class of uncertain nonlinear systems with application to bioprocess," in Control, Automation, Robotics and Vision Conference, 2004. ICARCV 2004 8th, vol. 2, pp. 855-860, 2004. 
[109] H. De Battista, J. Picó, F. Garelli, and J. L. Navarro, "Reaction rate reconstruction from biomass concentration measurement in bioreactors using modified second-order sliding mode algorithms," Bioprocess and Biosystems Engineering, vol. 35, pp. 1615-1625, 2012.

[110] A. Vargas, A. Vande Wouwer, and J. A. Moreno, "Virtual output estimation in a bioreactor using a generalized super-twisting," in Preprints of the 12th IFAC Symposium on Computer Applications in Biotechnology, pp. 314 319, 2013.

[111] C. Edwards and S. Spurgeon, Sliding Mode Control: Theory and Applications. Taylor \& Francis, 1998.

[112] H. Saadaoui, N. Manamanni, M. Djemaï, J. Barbot, and T. Floquet, "Exact differentiation and sliding mode observers for switched Lagrangian systems," Nonlinear Analysis: Theory, Methods \& Applications, vol. 65, no. 5, pp. 1050 - 1069, 2006.

[113] J. A. Moreno, Sliding Modes after the first Decade of the 21st Century, ch. Lyapunov Approach for Analysis and Design of Second Order Sliding Mode Algorithms, pp. 113 - 149. Springer, 2012.

[114] M. Redwood, M. Paterson-Beedle, and L. Macaskie, "Integrating dark and light bio-hydrogen production strategies: towards the hydrogen economy," Reviews in Environmental Science and Biotechnology, vol. 8, no. 2, pp. 149$185,2009$.

[115] Y.-Z. Wang, Q. Liao, X. Zhu, J. Li, and D.-J. Lee, "Effect of culture conditions on the kinetics of hydrogen production by photosynthetic bacteria in batch culture," International Journal of Hydrogen Energy, vol. 36, no. 21, pp. $14004-14013,2011$.

[116] C.-A. Aceves-Lara, E. Latrille, and J.-P. Steyer, "Optimal control of hydrogen production in a continuous anaerobic fermentation bioreactor," International Journal of Hydrogen Energy, vol. 35, no. 19, pp. 10710 - 10718, 2010 .

[117] J. Obeid, J.-M. Flaus, O. Adrot, J.-P. Magnin, and J. C. Willison, "State estimation of a batch hydrogen production process using the photosynthetic bacteria Rhodobacter capsulatus," International Journal of Hydrogen Energy, vol. 35, no. 19, pp. 10719 - 10724, 2010.

[118] J. Obeid, J.-P. Magnin, J.-M. Flaus, O. Adrot, J. C. Willison, and R. Zlatev, "Modelling of hydrogen production in batch cultures of the photosynthetic bacterium Rhodobacter capsulatus," International Journal of Hydrogen Energy, vol. 34, no. 1, pp. 180 - 185, 2009.

[119] A. Isidori, Nonlinear Control Systems. Springer, 1995.

[120] O. Bernard and G. Bastin, "On the estimation of the pseudo-stoichiometric matrix for macroscopic mass balance modelling of biotechnological processes," Mathematical Biosciences, vol. 193, no. 1, pp. 51 - 77, 2005. 
[121] S. Boyd, L. El Ghaoui, E. Feron, and V. Balakrishnan, Linear Matrix Inequalities in System and Control Theory, vol. 15 of Studies in Applied Mathematics. Society for Industrial and Applied Mathematics (SIAM), 1994.

[122] J. Löfberg, "Automatic robust convex programming," Optimization methods and software, vol. 27, no. 1, pp. 115 - 129, 2012.

[123] J. Navarro, J. Picó, J. Bruno, E. Picó-Marco, and S. Valles, "On-line method and equipment for detecting, determining the evolution and quantifying a microbial biomass and other substances that absorb light along the spectrum during the development of biotechnological processes. Patent ES20010001757, EP20020751179," 2001.

[124] Y. Shtessel, J. Moreno, F. Plestan, L. Fridman, and A. Poznyak, "Supertwisting adaptive sliding mode control: A Lyapunov design," in Decision and Control (CDC), 2010 49th IEEE Conference on, pp. 5109 - 5113, 2010.

[125] C. Evangelista, P. Puleston, F. Valenciaga, and L. Fridman, "LyapunovDesigned Super-Twisting Sliding Mode Control for Wind Energy Conversion Optimization," Industrial Electronics, IEEE Transactions on, vol. 60, no. 2 , pp. $538-545,2013$.

[126] A. S. Soni and R. S. Parker, "Closed-loop control of fed-batch bioreactors: A shrinking-horizon approach," Industrial \& Engineering Chemistry Research, vol. 43, no. 13, pp. 3381 - 3393, 2004.

[127] R. Oliveira, J. J. Clemente, A. E. Cunha, and M. J. T. Carrondo, "Adaptive dissolved oxygen control through the glycerol feeding in a recombinant $P i$ chia pastoris cultivation in conditions of oxygen transfer limitation," Journal of Biotechnology, vol. 116, no. 1, pp. 35 - 50, 2005.

[128] B. Özbek and S. Gayik, "The studies on the oxygen mass transfer coefficient in a bioreactor," Process Biochemistry, vol. 36, no. 8-9, pp. 729 - 741, 2001.

[129] Y. Chung, I. Chien, and D. Chang, "Multiple-model control strategy for a fed-batch high cell-density culture processing," Journal of Process Control, vol. 16 , no. 1 , pp. $9-26,2006$.

[130] J. Gomes and A. S. Menawat, "Precise control of dissolved oxygen in bioreactors - a model-based geometric algorithm," Chemical Engineering Science, vol. 55, no. 1, pp. $67-78,2000$.

[131] H.-G. Han and J.-F. Qiao, "Adaptive dissolved oxygen control based on dynamic structure neural network," Applied Soft Computing, vol. 11, no. 4, pp. $3812-3820,2011$.

[132] S. C. Lee, Y. B. Hwang, H. N. Chang, and Y. K. Chang, "Adaptive control of dissolved oxygen concentration in a bioreactor," Biotechnology and Bioengineering, vol. 37, no. 7, pp. 597-607, 1991. 
[133] S. Ertunc, B. Akay, H. Boyacioglu, and H. Hapoglu, "Self-tuning control of dissolved oxygen concentration in a batch bioreactor," Food and Bioproducts Processing, vol. 87, no. 1, pp. 46 - 55, 2009.

[134] D. J. Korz, U. Rinas, K. Hellmuth, E. A. Sanders, and W. D. Deckwer, "Simple fed-batch technique for high cell density cultivation of Escherichia coli," Journal of Biotechnology, vol. 39, no. 1, pp. 59-65, 1995.

[135] M. Inan and M. M. Meagher, "The effect of ethanol and acetate on protein expression in Pichia pastoris," Journal of Bioscience and Bioengineering, vol. 92, pp. 337-341, 2001.

[136] G. Potvin, A. Ahmad, and Z. Zhang, "Bioprocess engineering aspects of heterologous protein production in Pichia pastoris: A review," Biochemical Engineering Journal, vol. 64, no. 0, pp. 91 - 105, 2012.

[137] H.-K. Lim, S.-J. Choi, K.-Y. Kim, and K.-H. Jung, "Dissolved-oxygen-stat controlling two variables for methanol induction of rGuamerin in Pichia pastoris and its application to repeated fed-batch," Applied Microbiology and Biotechnology, vol. 62, no. 4, pp. 342-348, 2003.

[138] J. E. Claes and J. F. Van Impe, "On-line estimation of the specific growth rate based on viable biomass measurements: experimental validation," Bioprocess Engineering, vol. 21, no. 5, pp. 389-395, 1999.

[139] R. Neeleman, Biomass performance: monitoring and control in biopharmaceutical production. PhD thesis, Wageningen University, The Netherlands, 2002. ISBN 90-5808-733-6.

[140] S. S. Mohseni, V. Babaeipour, and A. R. Vali, "Design of sliding mode controller for the optimal control of fed-batch cultivation of recombinant E. coli," Chemical Engineering Science, vol. 64, no. 21, pp. 4433 - 4441, 2009 .

[141] V. Utkin, J. Guldner, and J. Shi, Sliding Mode Control in Electromechanical Systems. London: Taylor \& Francis, 1st ed., 1999.

[142] K. Kiviharju, K. Salonen, U. Moilanen, and T. Eerikäinen, "Biomass measurement online: the performance of in situ measurements and software sensors," Journal of Industrial Microbiology \& Biotechnology, vol. 35, no. 7, pp. 657-665, 2008.

[143] J. Xu, B. Guo, Z. Zhang, Q. Wu, Q. Zhou, J. Chen, G. Chen, and G. Li, "A mathematical model for regulating monomer composition of the microbially synthesized polyhydroxyalkanoate copolymers," Biotechnology and Bioengineering, vol. 90, no. 7, pp. 821-829, 2005.

[144] H. Huang, D. Ridgway, T. Gu, and M. Moo-Young, "Enhanced amylase production by Bacillus subtilis using a dual exponential feeding strategy," Bioprocess and Biosystems Engineering, vol. 27, no. 1, pp. 63-69, 2004. 
[145] C. D. Knightes and C. A. Peters, "Multisubstrate biodegradation kinetics for binary and complex mixtures of polycyclic aromatic hydrocarbons," Environmental Toxicology and Chemistry, vol. 25, no. 7, pp. 1746 - 1756, 2006.

[146] I. Durruty, E. Okada, J. F. González, and S. E. Murialdo, "Multisubstrate monod kinetic model for simultaneous degradation of chlorophenol mixtures," Biotechnology and Bioprocess Engineering, vol. 16, no. 5, pp. 908 915, 2011.

[147] A. J. Krener and K. Ide, "Measures of unobservability," in Decision and Control, 2009. Proceedings of the 48th IEEE Conference on, pp. 6401-6406, Dec 2009.

[148] R. Hermann and A. J. Krener, "Nonlinear controllability and observability," Automatic Control, IEEE Transactions on, vol. 22, no. 5, pp. 728-740, 1977.

[149] A. J. Krener, "Observability of vortex flows," in Decision and Control, 2008. CDC 2008. 47th IEEE Conference on, pp. 3884-3889, Dec 2008.

[150] E. D. Sontag, Mathematical Control Theory: Deterministic Finite Dimensional Systems (Second Edition). No. 6 in Textbooks in Applied Mathematics, Springer, 1998.

[151] D.-M. Chang, "The snowball effect in fed-batch bioreactions," Biotechnology Progress, vol. 19, no. 3, pp. 1064-1070, 2003. 